Photodissociation and Photoionization of organosulfur Radicals

by

Hsu, Chia-Wei

PHD Thesis submitted to Iowa State University

Ames Laboratory, U.S. DOE

Iowa State University

Ames, Iowa 50011

Date Transmitted: May 27, 1994

PREPARED FOR THE U.S. DEPARTMENT OF ENERGY

UNDER CONTRACT NO. W-7405-ENg-82. 


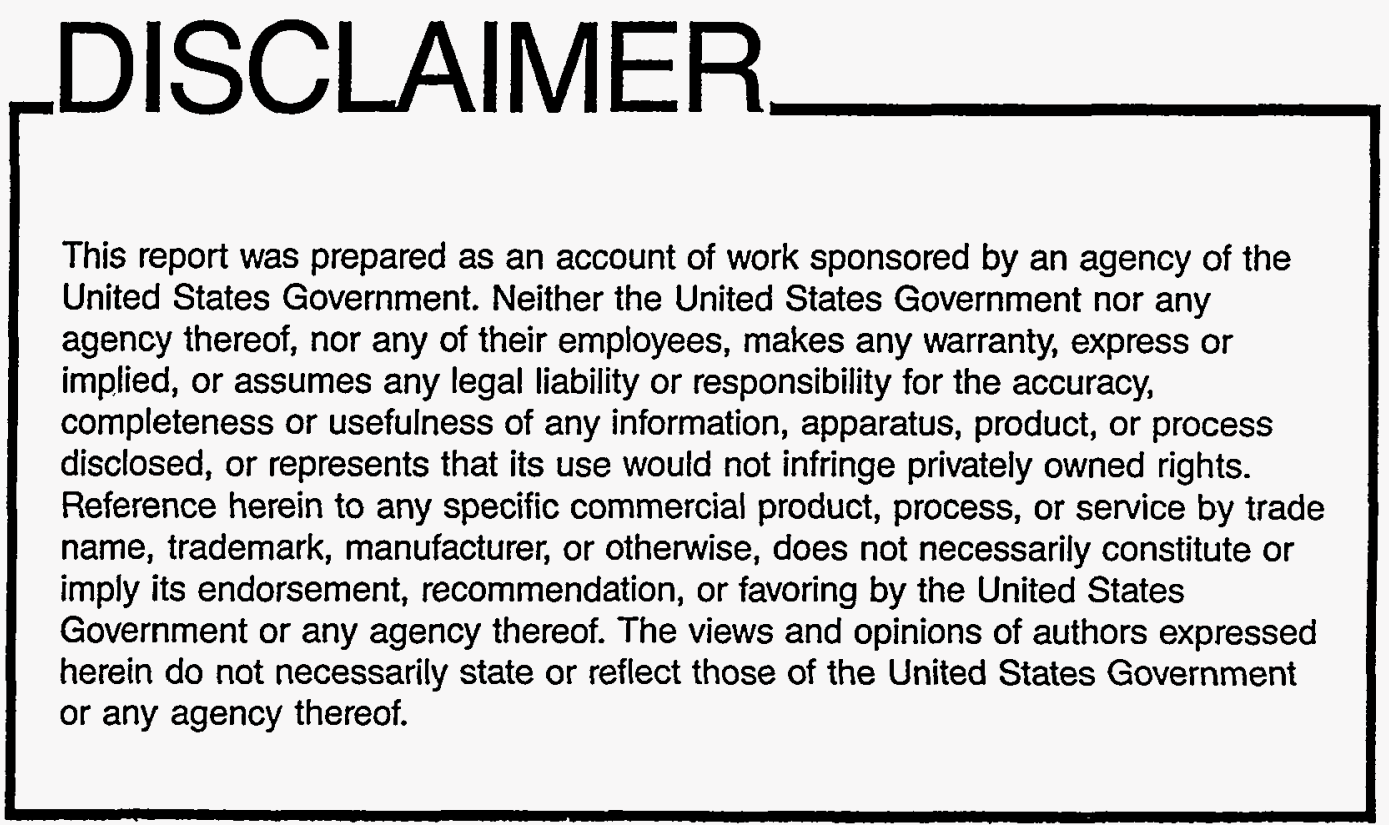




\section{DISCLAIMER}

Portions of this document may be illegible in electronic image products. Images are produced from the best available original document. 


\title{
Photodissociation and photoionization of organosulfur radicals
}

\author{
Chia-Wei Hsu \\ Major Professor: Cheuk-Yiu Ng \\ Iowa State University
}

The dynamics of $S\left(\mathrm{P}_{2,1,0},{ }^{1} \mathrm{D}_{2}\right)$ production from the $193 \mathrm{~nm}$ photodissociation of $\mathrm{CH}_{3} \mathrm{SCH}_{3}, \mathrm{H}_{2} \mathrm{~S}$ and $\mathrm{CH}_{3} \mathrm{SH}$ have been studied using $2+1$ resonance-enhanced multiphoton ionization (REMPI) techniques. The $193 \mathrm{~nm}$ photodissociation cross sections for the formation of $\mathrm{S}$ from $\mathrm{CH}_{3} \mathrm{~S}$ and $\mathrm{HS}$ initially prepared in the photodissociation of $\mathrm{CH}_{3} \mathrm{SCH}_{3}$ and $\mathrm{H}_{2} \mathrm{~S}$ are estimated to be $1 \times 10^{-18}$ and $1.1 \times 10^{-18} \mathrm{~cm}^{2}$, respectively. The dominant product from $\mathrm{CH}_{3} \mathrm{~S}$ is $\mathrm{S}\left({ }^{1} \mathrm{D}\right)$, while that from $\mathrm{SH}$ is $\mathrm{S}\left({ }^{3} \mathrm{P}\right)$. Possible potential energy surfaces involved in the $193 \mathrm{~nm}$ photodissociation of $\mathrm{CH}_{3} \mathrm{~S}(\tilde{X})$ and $\mathrm{SH}(X)$ have been also examined theoretically. Threshold photoelectron (PE) spectra for $\mathrm{SH}$ and $\mathrm{CH}_{3} \mathrm{~S}$ formed in the ultraviolet photodissociation of $\mathrm{H}_{2} \mathrm{~S}$ and $\mathrm{CH}_{3} \mathrm{SH}$, respectively, have been measured using the nonresonant two-photon pulsed field ionization (N2P-PFI) technique. The rotationally resolved N2P-PFI-PE spectrum obtained for SH indicates that photoionization dynamics favors the rotational angular momentum change $\Delta N<0$ with the $\Delta N$ value up to -3 , an observation similar to that found in the PFI-PE spectra of OH (OD) and NO. The ionization energies for $\mathrm{SH}\left(X^{2} \Pi_{3 / 2}\right)$ and $\mathrm{CH}_{3} \mathrm{~S}\left(\tilde{X}^{2} E_{3 / 2}\right)$ are determined to be $84,057.5 \pm 3$ $\mathrm{cm}^{-1}(10.4219 \pm 0.0004 \mathrm{eV})$ and $74,726 \pm 8 \mathrm{~cm}^{-1}(9.2649 \pm 0.0010 \mathrm{eV})$, respectively. The spin-orbit splittings for $\mathrm{SH}\left(X^{2} \Pi_{3 / 2, l / 2}\right)$ and $\mathrm{CH}_{3} \mathrm{~S}\left(\tilde{X}^{2} E_{3 / 2, I / 2}\right)$ are found to be $377 \pm 2$ and 
$257 \pm 5 \mathrm{~cm}^{-1}$, respectively, in agreement with previous measurements. The C-S stretching frequency for $\mathrm{CH}_{3} \mathrm{~S}^{+}\left(\widetilde{\mathrm{X}}^{3} A_{2}\right)$ is $733 \pm 5 \mathrm{~cm}^{-1}$. This study illustrates that the PFI-PE detection method can be a sensitive probe for the nascent internal energy distribution of photoproducts. 
Photodissociation and photoionization of organosulfur radicals

by

\author{
Chia-Wei Hsu
}

\author{
A Thesis submitted to the \\ Graduate Faculty in Partial Fulfillment of the \\ Requirements for the Degree of \\ DOCTOR OF PHILOSOPHY
}

\title{
Department: Chemistry \\ Major: Physical Chemistry
}

Approved:

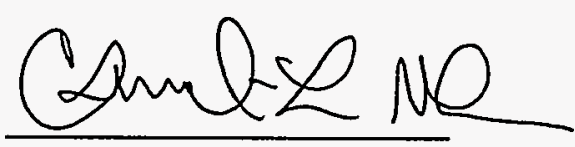

In Charge of Major Work
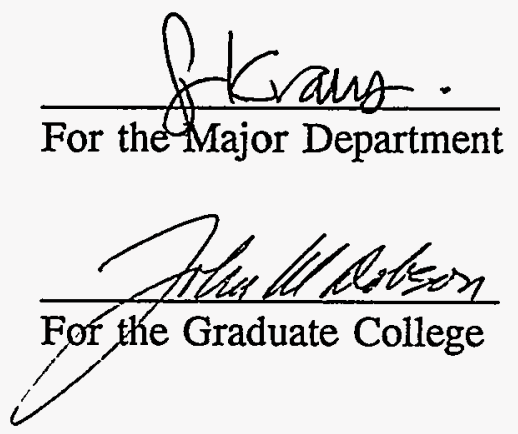

Iowa State University

Ames,Iowa 
TABLE OF CONTENTS

page

ACKNOWLEDGEMENTS

$\mathrm{V}$

GENERAL INTRODUCTION

PAPER 1. A STUDY OF THE $S\left(\mathrm{P}_{2,1,0}, ; \mathrm{D}_{2}\right)$ PRODUCTION IN THE $193 \mathrm{~nm}$ PHOTODISSOCIATION OF $\mathrm{CH}_{3} \mathrm{~S}(\tilde{\mathrm{X}})$

ABSTRACT

4

INTRODUCTION

5

EXPERIMENTAL

8

$A B$ INITIO CALCULATION

RESULTS AND DISCUSSION

CONCLUSION

ACKNOWLEDGEMENT

REFERENCES

PAPER 2. A STUDY OF THE $S\left(\mathrm{P}_{2,1,0} ; \mathrm{D}_{2}\right)$ PRODUCTION IN THE $193 \mathrm{~nm}$ PHOTODISSOCIATION OF HS AND $\mathrm{H}_{2} \mathrm{~S}$

ABSTRACT

INTRODUCTION

EXPERIMENTAL

RESULTS

DISCUSSION

CONCLUSION 
REFERENCES

PAPER 3. A STUDY OF THE $S\left(\mathrm{P}_{2,1,0} ;{ }^{1} \mathrm{D}_{2} ;{ }^{1} \mathrm{~S}_{0}\right)$ PRODUCTION IN THE $193 \mathrm{~nm}$ PHOTODISSOCIATION OF $\mathrm{CH}_{3} \mathrm{SH}$

ABSTRACT

69

INTRODUCTION

70

EXPERIMENTAL 74

RESULTS AND DISCUSSION 78

CONCLUSION 87

REFERENCES

88

PAPER 4. ROTATIONALLY RESOLVED NONRESONANT TWO-PHOTON IONIZATION OF SH

ABSTRACT

91

INTRODUCTION

92

EXPERIMENTAL

96

RESULTS AND DISCUSSION

103

CONCLUSION

122

REFERENCES

123

PAPER 5. NONRESONANT TWO-PHOTON PULSED FIELD IONIZATION OF $\mathrm{CH}_{3} \mathrm{~S}$ FORMED IN PHOTODISSOCIATION OF $\mathrm{CH}_{3} \mathrm{SH}$ AND $\mathrm{CH}_{3} \mathrm{SSCH}_{3}$ 128

ABSTRACT 129

INTRODUCTION 130

EXPERIMENTAL

RESULTS 
$\begin{array}{ll}\text { DISCUSSION } & 141\end{array}$

$\begin{array}{lr}\text { CONCLUSION } & 158\end{array}$

$\begin{array}{ll}\text { ACKNOWLEDGEMENT } & 159\end{array}$

$\begin{array}{ll}\text { REFERENCES } & 160\end{array}$

$\begin{array}{ll}\text { GENERAL CONCLUSION } & 164\end{array}$

$\begin{array}{ll}\text { REFERENCES } & 166\end{array}$

$\begin{array}{ll}\text { APPENDIX. COMPUTER PROGRAMS } & 168\end{array}$ 


\section{ACKNOWLEDGEMENTS}

Many people have helped me during my Ph.D. studies at Iowa State University. In these past five years, a great deal of assistance from many people has led to my success in graduate school. At this time, I would like to express my cordial appreciation to them.

First, I deeply thank Dr. Ng for his support, understanding, assistance and encouragement in my research. To be frank, I received a lot pressure from Dr. Ng ever since I joined his group. The most frequent words he said to me were " Are you doing O.K? ". Whenever I heard these words I felt I needed to accomplish something before I met him the next time. It was this motivation that really inspired me and had a tremendous impact on my life. His past guidance will continue to benefit me for the rest of my life.

I would also like to thank Chung-Lin Liao for his assistance in my academic studies. He also taught me how to do the experiments from the very beginning. He is very thorough and knowledgeable, and always comes up with ingenious ideas to solve experimental difficulties. I improved my skill and knowledge in science through work and discussion with him. I acknowledge Jerry Flesch for helping me to safely pass some very difficult times during my work in Ames Lab. He also took care of every detailed work in our lab. Without him, my work would surely have been delayed. I acknowledge ChuXiong Liao for helping me in fixing the apparatus. He patiently explained problems to me whenever I came to ask him for help. I also thank Eldon Ness, Terry Soseman, and Dick Egger in the chemistry machine shop for their invaluable service. They were always helpful and friendly and did an excellent job in the construction of my apparatus. I 
especially thank Eldon for his understanding and suggestions as well as for rapidly completing my job whenever it was urgent.

Finally, I deeply thank my family for their support and understanding. My wife, I-Quei Wang, has given me a lot of support and encouragement. She took care of the family very well so that I could concentrate on my work. She always encouraged me to do my best whenever I encountered difficulties. Her support for my study keeps me striving for success.

This work was performed at Ames Laboratory under contract no. W-7405-eng-82 with the U.S. Department of Energy. The United States government has assigned the DOE Report number 1709 to this thesis. 


\section{GENERAL INTRODUCTION}

\section{Explanation of the Thesis Format}

The thesis is composed of five papers prepared in a format ready for publication. The tables, figures, and references mentioned in each paper pertain only to that paper. The specific experimental conditions used in each study are described in each paper. The references quoted in the general introduction and general conclusion are listed after the general conclusion. The appendix contains the computer programs used for the simulation of the experimental data.

\section{Background}

Sulfur, which occurs naturally in crude oil and coal in the range from $0.2 \%$ to $10 \%$, is an important species contributing to air pollution in the atmosphere. The modelings of the combustion and oxidation of sulfur compounds represent important steps for the control of both the production and the elimination of sulfur-containing pollutants ${ }^{1}$. The studies of the photodissociation and photoionization of $\mathrm{H}_{2} \mathrm{~S}$ and organosulfides like $\mathrm{CH}_{3} \mathrm{SH}$ and $\mathrm{CH}_{3} \mathrm{SSCH}_{3}$, etc., have been major subjects in our group ${ }^{2-6}$. They have provided valuable information on the energetics and photochemical processes of these molecules. However, the study of the intermediate reactive radicals, such as $\mathrm{SH}$ and $\mathrm{CH}_{3} \mathrm{~S}$, remains an open area in research, mainly due to their instability. In a continuing effort to study organosulfur compounds, I focused my attention primarily on the studies of these two radicals.

The first three papers of the thesis contain the photodissociation studies of $\mathrm{CH}_{3} \mathrm{~S}$, 
SH , $\mathrm{CH}_{3} \mathrm{SH}$, and $\mathrm{H}_{2} \mathrm{~S}$. Basically, these experiments directly measure the nascent electronic state distributions of $\left.\mathrm{S}^{3} \mathrm{P}_{2,1,0} ;{ }^{1} \mathrm{D}_{2}\right)$ atoms formed in the $193 \mathrm{~nm}$ photodissociation of $\mathrm{CH}_{3} \mathrm{SCH}_{3}, \mathrm{H}_{2} \mathrm{~S}$, and $\mathrm{CH}_{3} \mathrm{SH}$ using $2+1$ resonance-enhanced multiphoton ionization (REMPI) detection schemes ${ }^{7-9}$. Using the rate equation scheme, we have estimated the 193 nm photodissociation cross section of the nascent radicals $\mathrm{CH}_{3} \mathrm{~S}$ and $\mathrm{SH}$ initially formed in the photodissociation of $\mathrm{CH}_{3} \mathrm{SCH}_{3}, \mathrm{H}_{2} \mathrm{~S}$, and $\mathrm{CH}_{3} \mathrm{SH}$. To our knowledge, this is the first report on the absolute photodissociation cross sections at $193 \mathrm{~nm}$ for these radicals. The dominant product from $\mathrm{CH}_{3} \mathrm{~S}$ is $\mathrm{S}\left({ }^{1} \mathrm{D}\right)$, while that from $\mathrm{SH}$ is $\mathrm{S}\left({ }^{3} \mathrm{P}\right)$.

The fourth and fifth papers focus on the photoionization studies of $\mathrm{SH}$ and $\mathrm{CH}_{3} \mathrm{~S}$. The experiments use pulsed field ionization $(\mathrm{PFI})^{10}$, which is a version of the zero-kineticenergy (ZEKE) ${ }^{11,12}$ photoelectron (PE) technique. The ZEKE/PFI detection scheme relies on delayed PFI of long-lived high-n-Rydberg states populated by laser excitation at a few wavenumbers below the ionization threshold. In the experiments, a one-color three-photon process is involved. That is, the $\mathrm{SH}\left[\mathrm{CH}_{3} \mathrm{~S}\right]$ radical is first prepared from $\mathrm{H}_{2} \mathrm{~S}\left[\mathrm{CH}_{3} \mathrm{SH}\right]$ by the absorption of a signal photon. The subsequent ionization of $\mathrm{SH}\left[\mathrm{CH}_{3} \mathrm{~S}\right]$ is accomplished by the nonresonant two-photon (N2P) excitation of $\mathrm{SH}\left[\mathrm{CH}_{3} \mathrm{~S}\right]$ to the high-nRydberg state $\mathrm{SH}^{*}(\mathrm{n})\left[\mathrm{CH}_{3} \mathrm{~S}^{*}(\mathrm{n})\right]$ followed by PFI of $\mathrm{SH}^{*}(\mathrm{n})\left[\mathrm{CH}_{3} \mathrm{~S}^{*}(\mathrm{n})\right]$. This is the first report on rotationally resolved PE spectrum of SH and vibrationally resolved PE spectrum of $\mathrm{CH}_{3} \mathrm{~S}^{13-15}$. 
PAPER 1.

A STUDY OF THE $S\left({ }^{3} P_{2,1,0} ;{ }^{1} D_{2}\right)$ PRODUCTION IN THE 193 nm PHOTODISSOCIATION OF $\mathrm{CH}_{3} \mathrm{~S}(\tilde{\mathrm{X}})$ 


\begin{abstract}
The dynamics of $S\left({ }^{3} \mathrm{P}_{2,1,0} ;{ }^{1} \mathrm{D}_{2}\right)$ production from the $193 \mathrm{~nm}$ photodissociation of $\mathrm{CH}_{3} \mathrm{SCH}_{3}$ has been studied using $2+1$ REMPI techniques. The $193 \mathrm{~nm}$ photodissociation cross section for the formation of $\mathrm{S}$ from $\mathrm{CH}_{3} \mathrm{~S}$ initially prepared in the photodissociation of $\mathrm{CH}_{3} \mathrm{SCH}_{3}$ is estimated to be $1 \times 10^{-18} \mathrm{~cm}^{2}$. The branching ratio for $\mathrm{S}\left({ }^{3} \mathrm{P}\right) / \mathrm{S}\left({ }^{1} \mathrm{D}\right)$ is found to be $0.15 / 0.85$. The fine-structure distribution observed for product $S\left({ }^{3} P_{2,1,0}\right)$ is nearly statistical. Possible potential energy surfaces involved in the $193 \mathrm{~nm}$ photodissociation of $\mathrm{CH}_{3} \mathrm{~S}(\tilde{\mathrm{X}})$ have been examined theoretically along the $\mathrm{CH}_{3}-\mathrm{S}$ dissociation coordinate in $\mathrm{C}_{3 \mathrm{v}}$ symmetry. These calculations suggest that predissociation of $\mathrm{CH}_{3} \mathrm{~S}\left(\tilde{\mathrm{C}}^{2} \mathrm{~A}_{2}\right)$ via the repulsive $\mathrm{CH}_{3} \mathrm{~S}\left(\tilde{\mathrm{E}}^{2} \mathrm{E}\right)$ surface is most likely responsible for the efficient production of $\mathrm{S}\left({ }^{1} \mathrm{D}\right)$. For vibrationally excited $\mathrm{CH}_{3} \mathrm{~S}(\tilde{\mathrm{X}})$, a viable mechanism for the dominant production of $\mathrm{S}\left({ }^{1} \mathrm{D}\right)$ may involve direct dissociation via the $\mathrm{CH}_{3} \mathrm{~S}\left(\tilde{\mathrm{E}}^{2} \mathrm{E}\right)$ state formed in the $193 \mathrm{~nm}$ photoexcitation.
\end{abstract}




\section{INTRODUCTION}

Unlike unimolecular dissociation on the ground electronic potential energy surface, molecular dissociation in excited electronic states often involves predissociation due to nonadiabatic interactions with other electronic states. Translational energy distributions, internal state distributions, and final product branching ratios can be critically sensitive to the predissociating excited potential energy surfaces. In the past decade, tremendous progress has been made in understanding the photodissociation dynamics of triatomic molecules. ${ }^{1-3}$ However, the photodissociation study of radicals, especially polyatomic radicals, has remained essentially an unexplored research area. Detailed state-to-state photodissociation cross sections for radicals in the ultraviolet (UV) and vacuum ultraviolet (VUV) provide challenges not only for dynamical calculations, but also for ab initio quantum chemical studies.

Recent photofragmentation studies on a series of organosulfur compounds ${ }^{4-8}$ performed in our laboratory have yielded valuable information on the energetics and the photodissociation dynamics of these molecules. Based on the kinetic energy distributions observed for $\mathrm{S},{ }^{5,6}$ the photodissociation studies of $\mathrm{CH}_{3} \mathrm{SSCH}_{3}$ and $\mathrm{CH}_{3} \mathrm{SCH}_{3}$ suggest that the $\mathrm{CH}_{3} \mathrm{~S}$ photofragment can further dissociate by the absorption of a second $193 \mathrm{~nm}$ photon to produce $S$ predominantly in the ${ }^{1} \mathrm{D}$ state. In order to examine this suggestion, we have measured directly the nascent electronic state distributions of $S\left({ }^{3} \mathrm{P}_{2,1,0} ;{ }^{1} \mathrm{D}_{2}\right)$ atoms formed in the $193 \mathrm{~nm}$ photodissociation of $\mathrm{CH}_{3} \mathrm{SCH}_{3}$ [processes (1) and (2)] using $2+1$ resonance-enhanced multiphoton ionization (REMPI) detection schemes. ${ }^{9,10}$ 


$$
\begin{aligned}
& \mathrm{CH}_{3} \mathrm{SCH}_{3}+\mathrm{h} \nu(193 \mathrm{~nm}) \rightarrow \mathrm{CH}_{3} \mathrm{~S}(\tilde{\mathrm{X}})+\mathrm{CH}_{3} \\
& \mathrm{CH}_{3} \mathrm{~S}(\tilde{\mathrm{X}})+\mathrm{h} \nu(193 \mathrm{~nm}) \rightarrow \mathrm{CH}_{3}+\mathrm{S}\left({ }^{3} \mathrm{P}_{2,1,0} ;{ }^{1} \mathrm{D}_{2}\right)
\end{aligned}
$$

The previous $193 \mathrm{~nm}$ laser photofragmentation time-of-flight (TOF) studies ${ }^{5,6}$ indicate that $\mathrm{S}\left({ }^{3} \mathrm{P}_{\mathrm{J}},{ }^{1} \mathrm{D}_{2}\right)$ atoms are produced from $\mathrm{CH}_{3} \mathrm{SCH}_{3}$ via processes (1) and (2).

Many kinetic $\mathrm{c}^{11-14}$ and spectroscopic ${ }^{15-21}$ investigations have been made involving $\mathrm{CH}_{3} \mathrm{~S}$ radicals produced by excimer laser photodissociation of $\mathrm{CH}_{3} \mathrm{SCH}_{3}$ and $\mathrm{CH}_{3} \mathrm{SSCH}_{3}$. Also, the energetics and geometries of $\mathrm{CH}_{3} \mathrm{~S}$ in the ground and excited electronic states have been the subject of many ab initio calculations. ${ }^{22-28}$

The measurements of absolute UV and VUV photodissociation cross sections of organosulfur radicals are relevant to the modeling of atmospheric sulfur chemistry. To our knowledge, absolute UV and VUV photodissociation cross sections for organosulfur radicals have not been reported. By using $2+1$ REMPI detection schemes to monitor the formation of $S\left({ }^{3} \mathrm{P}_{2,1,0} ;{ }^{1} \mathrm{D}_{2}\right)$, and by calibrating the $\mathrm{S}^{+}$intensities due to $S\left({ }^{3} \mathrm{P}_{2,1,0} ;{ }^{1} \mathrm{D}_{2}\right)$ from process (2) to those from process (3), we have obtained an estimate of the absolute photodissociation cross section for the formation of $S\left({ }^{3} \mathrm{P}_{2,1,0} ;{ }^{1} \mathrm{D}_{2}\right)$ from the $193 \mathrm{~nm}$ photodissociation of $\mathrm{CH}_{3} \mathrm{~S}(\tilde{\mathrm{X}})$.

$$
\mathrm{CS}_{2}+\mathrm{h} \nu(193 \mathrm{~nm}) \rightarrow \mathrm{CS}(v)+\mathrm{S}\left({ }^{3} \mathrm{P}_{2,1,0} ;{ }^{1} \mathrm{D}_{2}\right)
$$

The absolute cross sections for process (3) are known. ${ }^{29}$ The branching ratio for $\mathrm{S}\left({ }^{3} \mathrm{P}\right) / \mathrm{S}\left({ }^{1} \mathrm{D}\right)(=2.78)$ and the fine-structure distribution of $S\left({ }^{3} \mathrm{P}_{2,1,0}\right)$ resulting from the 
193nm photodissociation of $\mathrm{CS}_{2}$ have also been measured previously by the VUV laserinduced fluorescence ${ }^{30}$ and time-of-flight (TOF) mass spectrometric ${ }^{31}$ methods.

In order to rationalize the experimental observations, we have examined the $a b$ initio multi-configuration-self-consistence-field (MCSCF) potential energy surfaces of $\mathrm{CH}_{3} \mathrm{~S}$ along the $\mathrm{CH}_{3}-\mathrm{S}$ dissociation coordinate. In addition, the geometrical parameters for the $\mathrm{CH}_{3} \mathrm{~S}(\tilde{\mathrm{X}}, \tilde{\mathrm{A}})$ have been optimized by MCSCF calculations. 


\section{EXPERIMENTAL}

The experiment basically involves the delayed $2+1$ REMPI detection of $\mathrm{S}\left({ }^{3} \mathrm{P}_{2,1,0} ;{ }^{1} \mathrm{D}_{2}\right)$ produced by processes (1) and (2). The schematic diagram of the experimental setup is shown in Fig. 1. A home-built TOF mass spectrometer of the twostage Wiley-McLaren design ${ }^{32}$ is used to detect $\mathrm{S}^{+}$ions [see Fig. 2]. A pulsed beam of neat $\mathrm{CH}_{3} \mathrm{SCH}_{3}$ is produced by supersonic expansion through a commercial pulsed valve (General Valve No. 9, nozzle diameter $=0.5 \mathrm{~mm}$, temperature $\approx 298 \mathrm{~K}$, stagnation pressure $\leq 150$ Torr). The molecular beam is skimmed $(7 \mathrm{~cm}$ from the nozzle) by a conical skimmer ( $1 \mathrm{~mm}$ dia.) and intersects with both the dissociation and ionization lasers $8.3 \mathrm{~cm}$ downstream from the skimmer. The molecular beam source chamber is pumped by a liquid-nitrogen trapped 6 in. diffusion pump (pumping speed $\approx 2,000 \ell / \mathrm{s}$ ), while the photodissociation and detection chamber is evacuated by a $50 \mathrm{l} / \mathrm{s}$ turbomolecular pump. For a pulsed valve repetition rate of $17 \mathrm{~Hz}$, the beam source and photodissociation chambers are maintained at pressures of $\approx 1 \times 10^{-4}$ and $2 \times 10^{-6}$ Torr, respectively. The ArF photodissociation laser (Questek 2460) is operated in the constant pulse energy mode. The laser beam is attenuated by layers of stainless steel wire mesh and is spatially filtered by two irises before being focused by a ( $200 \mathrm{~mm} \mathrm{f.1.)}$ fused-silica lens to a spot of $\approx 2 \times 2$ $\mathrm{mm}^{2}$. in the intersection region. The laser energies used are in the range of 160 to 1000 $\mu \mathrm{J} /$ pulse.

The ionization of $S\left({ }^{3} \mathrm{P}_{2,1,0} ;{ }^{1} \mathrm{D}_{2}\right)$ is accomplished with an excimer laser (Lambda Physik EMG 201 MSC) pumped dye laser (FL 3002) system. Rhodamine 6G and Kiton 
Figure 1. Schematic diagram of the experimental setup. 


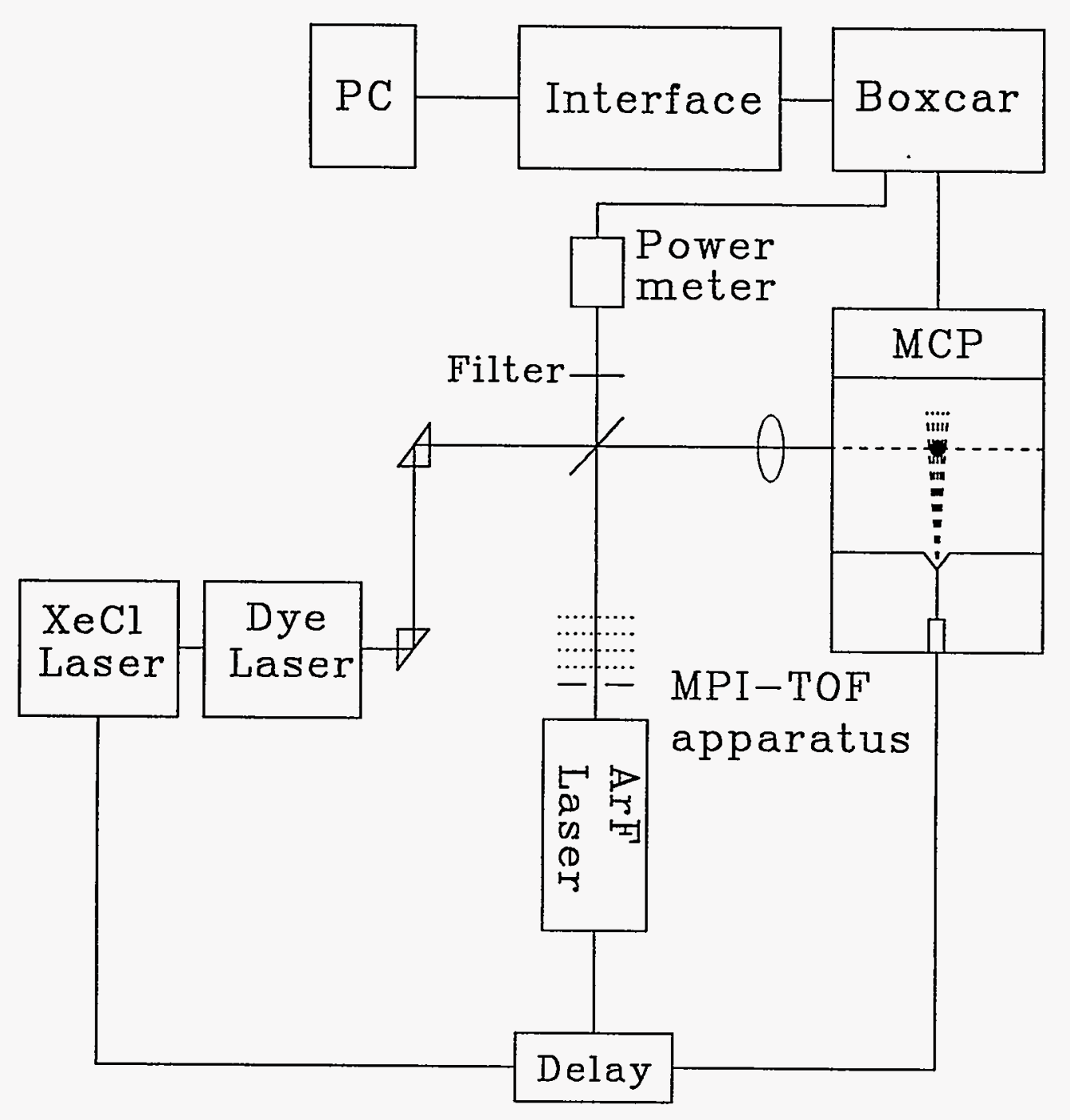


Figure 2. Cross section view of the TOF mass spectrometer. (1)photodissociation photoionization chamber; (2) photodissociation and photoionization region;

(3) beam source chamber; (4) pulsed valve; (5) skimmer; (6) TOF tube; and (7) microchannel plate detector. 


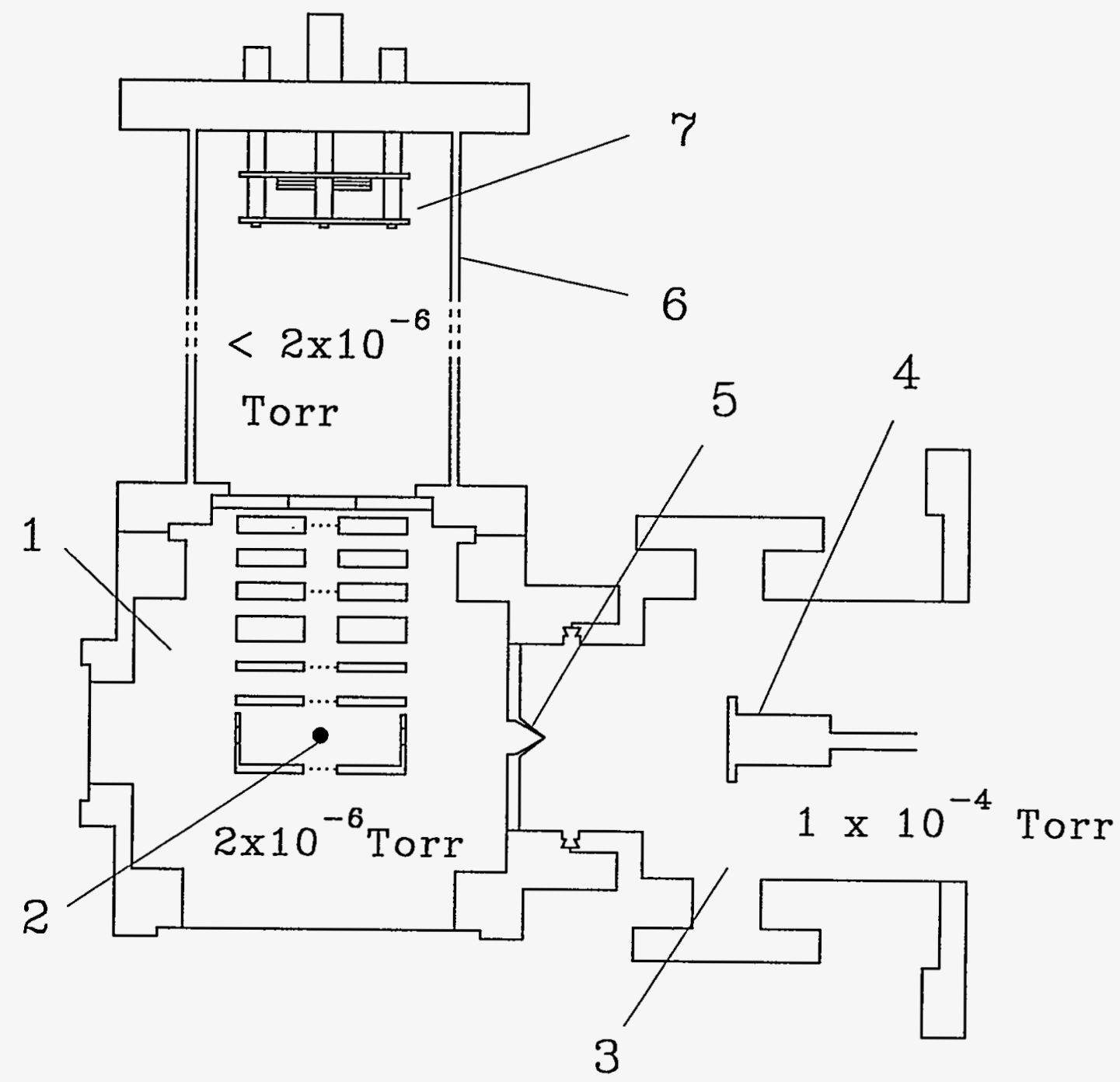


Red are used to produce the fundamental in the $570-630 \mathrm{~nm}$ region. The UV second harmonic is generated using a temperature stabilized angle-tuned BBO crystal (FL-37-1). The pulse energy, typically $200 \mu \mathrm{J} /$ pulse, is monitored with a pyroelectric detector (Molectron J3-05). The dye laser beam propagates coaxially with the ArF laser beam into the reaction chamber and intersects with the molecular beam at $90^{\circ}$.

The firing of the dissociation excimer laser is delayed by $570 \mu \mathrm{s}$ with respect to the triggering pulse for opening the pulsed valve. We find that the $\mathrm{S}^{+}$intensity remains nearly constant when the delay between the photodissociation and ionization lasers is varied in the range of 30-100 ns. Therefore, a delay of $50 \mathrm{~ns}$ between the two lasers is set for all the experiments. The firing sequence of the pulsed valve and the two lasers is controlled by two digital delay units (Stanford Research, Model DG 535). The ion signal from the microchannel plate (MCP) and the excimer laser signal from the pyroelectric detector are fed into two identical boxcar integrators (Stanford Research, SR-250), which are interfaced to an IBM AT computer.

The liquid $\mathrm{CS}_{2}$ and $\mathrm{CH}_{3} \mathrm{SCH}_{3}$ samples (99\% purity) were obtained from Aldrich. The liquid $\mathrm{CH}_{3} \mathrm{SCH}_{3}$ sample was degassed by a series of freeze-and-thaw-cycles before use in the experiment.

\section{A. Detection of $S\left({ }^{3} P_{2,1,0}\right)$ and $S\left({ }^{1} D_{2}\right)$}

Probing of the $S\left(3^{3} \mathrm{P}_{\mathrm{J}}\right)$ and $S\left(3^{1} \mathrm{D}_{2}\right)$ atomic states is accomplished by 2-photon absorption, $\mathrm{S}\left(3^{3} \mathrm{P}_{\mathrm{J}}\right) \rightarrow \mathrm{S}\left(4^{3} \mathrm{P}_{\mathrm{J}}\right)$ and $\mathrm{S}\left(3^{1} \mathrm{D}_{2}\right) \rightarrow \mathrm{S}\left(4^{1} \mathrm{~F}_{3}\right)$, followed by absorption of a third photon to produce $\mathrm{S}^{+}$in the ${ }^{4} \mathrm{~S}^{\circ}$ and ${ }^{2} \mathrm{D}^{\circ}$ states, respectively (Fig. 3). These schemes have been used previously for the detection of $S\left({ }^{3} \mathrm{P}_{2,1,0} ;{ }^{1} \mathrm{D}_{2}\right)$ formed in the photodissociation of 
Figure 3. $2+1$ REMPI detection schemes for $S\left({ }^{3} \mathrm{P}_{2,1,0}\right)$ and $S\left({ }^{1} D_{2}\right)$. 


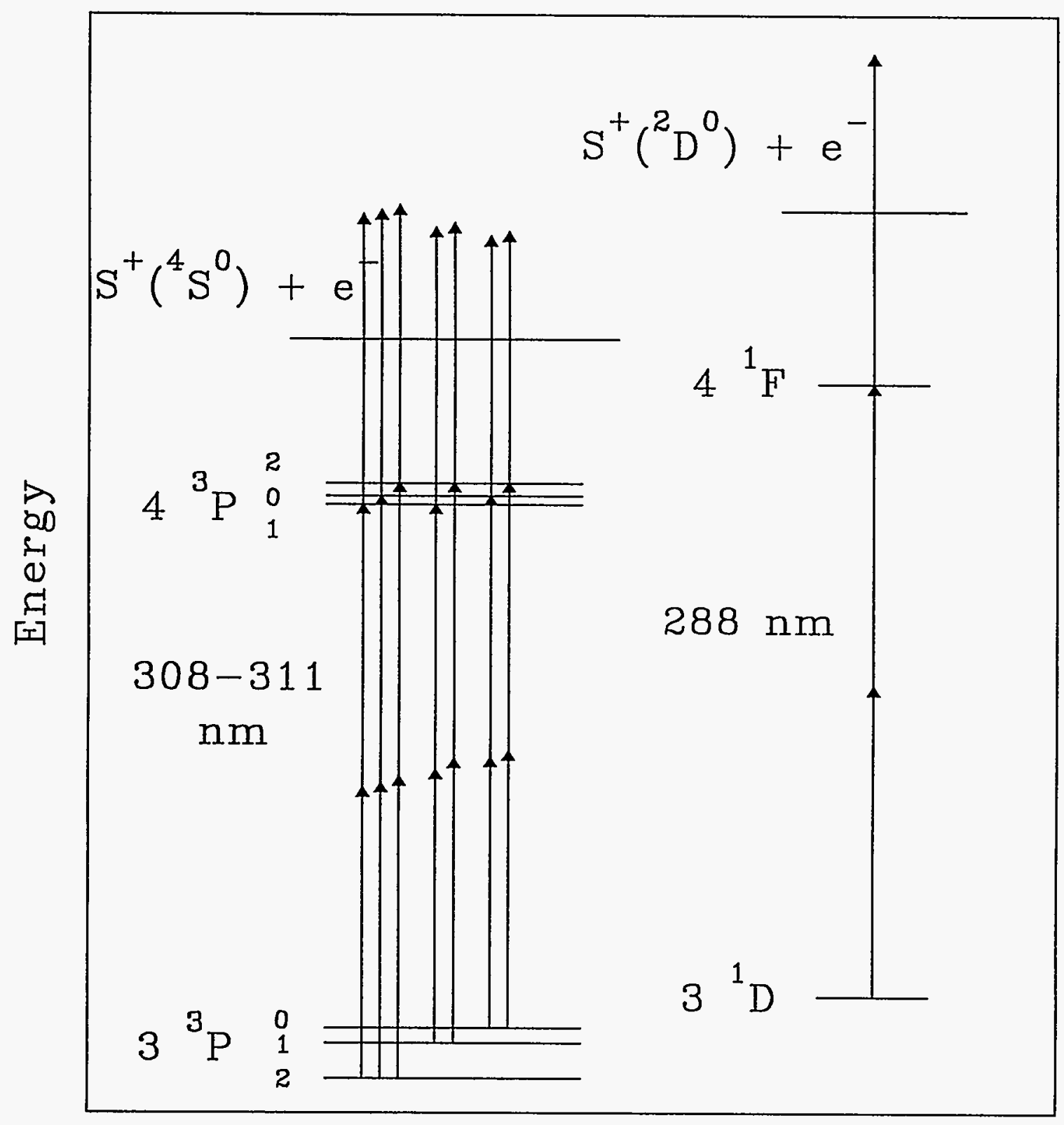


sulfur-containing molecules. ${ }^{10,11}$ The ionization peaks corresponding to the detection of $\mathrm{S}\left({ }^{3} \mathrm{P}_{2,1,0}\right)$ and $\mathrm{S}\left({ }^{1} \mathrm{D}_{2}\right)$ appear in the wavelength region of $308-311 \mathrm{~nm}$ and at $288.19 \mathrm{~nm}$, respectively.

Ideally, the $\mathrm{S}^{+}$signal formed in the $2+1$ REMPI of $S\left({ }^{3} \mathrm{P}_{2} ;{ }^{1} \mathrm{D}_{2}\right)$ should have an $\mathrm{E}^{\mathrm{n}}$ dependence with $n=3$, where $E$ is the ionization dye laser power. For $S\left({ }^{3} P_{2}\right)$ and $S\left({ }^{1} D_{2}\right)$ formed by the $193 \mathrm{~nm}$ photodissociation of $\mathrm{CS}_{2}$ in a dissociation excimer laser power range of $0.18-1.2 \mathrm{~mJ}$, we observe that $\mathrm{n}=2.3-2.4$ in an $\mathrm{E}$ range of $0.01-0.40 \mathrm{~mJ}$. This compares with $\mathrm{n}=2.7-3.0$ observed for the $\mathrm{S}^{+}$signal produced from $\mathrm{CH}_{3} \mathrm{SCH}_{3}$ in an $\mathrm{E}$ range of $0.03-0.40 \mathrm{~mJ}$ and a dissociation excimer laser power range of $0.54-5.7 \mathrm{~mJ}$. The higher power dependence observed for $\mathrm{S}^{+}$from $\mathrm{CH}_{3} \mathrm{SCH}_{3}$ is interpreted that $\mathrm{S}$ atoms are also produced from the dissociation of $\mathrm{CH}_{3} \mathrm{~S}$ by the dye laser. The ionization of these $\mathrm{S}$ atoms by the dye laser contributes to the observed $\mathrm{S}^{+}$signal from processes (1) and (2). Using the observed ionization laser power dependence of $\mathrm{S}^{+}$from $\mathrm{CS}_{2}$ as a normalization factor, we have subtracted the background $\mathrm{S}^{+}$signal attributed to dye laser photodissociation of $\mathrm{CH}_{3} \mathrm{~S}$.

The fine-structure distribution of $\mathrm{S}\left(3^{3} \mathrm{P}_{2,1,0}\right)$ is measured by summation over the peak intensities corresponding to transitions to the upper $\mathrm{S}\left(4^{3} \mathrm{P}_{2,1,0}\right)$ fine-structure levels. ${ }^{33}$ Figure 4 shows a typical spectrum for the ionization of $S\left(3^{3} \mathrm{P}_{2,1,0}\right)$ formed by process (3). The fine-structure distribution has been determined to be ${ }^{3} \mathrm{P}_{2}:{ }^{3} \mathrm{P}_{1}:{ }^{3} \mathrm{P}_{0}=0.71 \pm 0.02$ : $0.20 \pm 0.02: 0.09 \pm 0.04$, in excellent agreement with the result obtained by Waller and Hepburn $^{30}$ using the VUV laser-induced fluorescence technique. 
Figure 4. Typical $2+1$ REMPI spectrum for $S\left({ }^{3} \mathrm{P}_{2,1,0}\right)$ formed in the $193 \mathrm{~nm}$ photodissociation of $\mathrm{CS}_{2}$. 


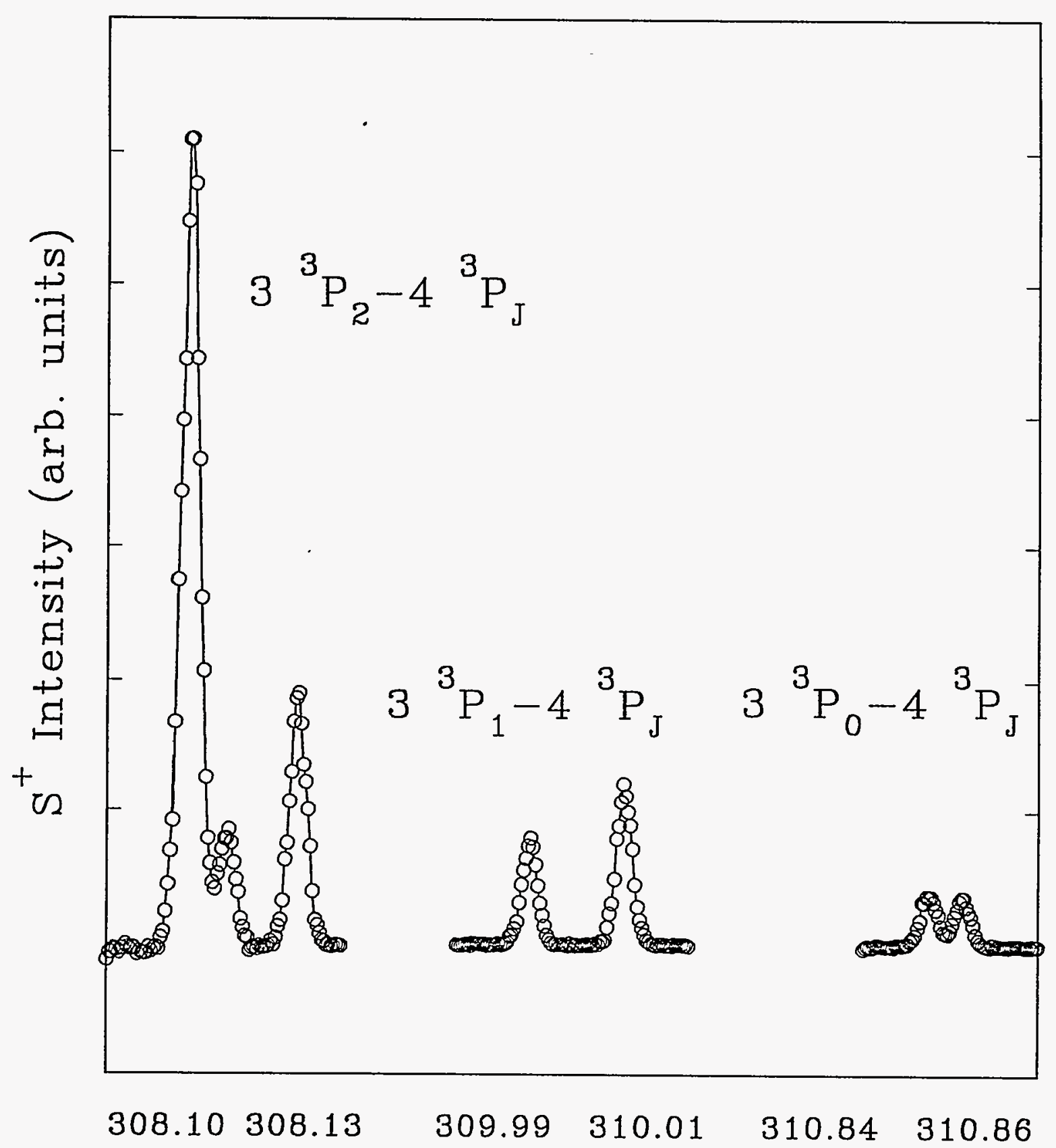


B. $S\left({ }^{3} \mathbf{P}\right) / S\left({ }^{1} \mathrm{D}\right)$ branching ratio and absolute cross section for process (2)

The rate equations applicable to processes (1) and (2) are:

$$
\begin{aligned}
& \mathrm{d}\left[\mathrm{CH}_{3} \mathrm{SCH}_{3}\right] / \mathrm{dt}=-\mathrm{I}_{1}\left[\mathrm{CH}_{3} \mathrm{SCH}_{3}\right], \\
& \mathrm{d}\left[\mathrm{CH}_{3} \mathrm{~S}\right] / \mathrm{dt}=\mathrm{I} \sigma_{1}\left[\mathrm{CH}_{3} \mathrm{SCH}_{3}\right]-\mathrm{I}_{2}\left[\mathrm{CH}_{3} \mathrm{~S}\right], \\
& \mathrm{d}[\mathrm{S}] / \mathrm{dt}=\mathrm{I} \sigma_{2}\left[\mathrm{CH}_{3} \mathrm{~S}\right] .
\end{aligned}
$$

Here, $I$ is the ArF laser photon intensity [\# of photons $/\left(\mathrm{cm}^{2} \cdot \sec \right)$ ] and $\sigma_{1}$ and $\sigma_{2}$ represent the absolute cross sections for processes (1) and (2), respectively. The number densities for $\mathrm{CH}_{3} \mathrm{SCH}_{3}\left(\left[\mathrm{CH}_{3} \mathrm{SCH}_{3}\right]\right), \mathrm{CH}_{3} \mathrm{~S}\left(\left[\mathrm{CH}_{3} \mathrm{~S}\right]\right)$, and $\mathrm{S}([\mathrm{S}])$ due to one laser pulse are related to $\sigma_{1}, \sigma_{2}$, the laser flux $(\mathrm{F})$, and the initial number density of $\mathrm{CH}_{3} \mathrm{SCH}_{3}\left(\left[\mathrm{CH}_{3} \mathrm{SCH}_{3}\right]_{0}\right)$ by the relations:

$$
\begin{aligned}
& {\left[\mathrm{CH}_{3} \mathrm{SCH}_{3}\right]=\left[\mathrm{CH}_{3} \mathrm{SCH}_{3}\right]_{0} \exp \left(-\sigma_{1} \mathrm{~F}\right)} \\
& {\left[\mathrm{CH}_{3} \mathrm{~S}\right]=\left[\mathrm{CH}_{3} \mathrm{SCH}_{3}\right]_{0}\left[\sigma_{1} /\left(\sigma_{2}-\sigma_{1}\right)\right]\left[\exp \left(-\sigma_{1} \mathrm{~F}\right)-\exp \left(-\sigma_{2} \mathrm{~F}\right)\right]} \\
& {[\mathrm{S}]=\left[\mathrm{CH}_{3} \mathrm{SCH}_{3}\right]_{0}\left[\sigma_{1} \sigma_{2} /\left(\sigma_{2}-\sigma_{1}\right)\right]\left[-\left(1 / \sigma_{1}\right) \exp \left(-\sigma_{1} \mathrm{~F}\right)+\left(1 / \sigma_{2}\right) \exp \left(-\sigma_{2} \mathrm{~F}\right)+1 / \sigma_{1}-1 / \sigma_{2}\right]}
\end{aligned}
$$

The laser flux F (\# of photons $/ \mathrm{cm}^{2}$ ) is the intensity integrated over the laser pulse width. The $\mathrm{S}^{+}$signal resulting from the $2+1$ REMPI is directly proportional to the number density of $S$. Since $\sigma_{1}$ is known to be $1 \times 10^{-17} \mathrm{~cm}^{2},{ }^{34}$ the $S\left({ }^{3} \mathrm{P}\right) / \mathrm{S}\left({ }^{1} \mathrm{D}\right)$ branching ratio and the value for $\sigma_{2}$ can be determined by calibrating the $S^{+}$signals due to the formation of $\mathrm{S}\left(\mathrm{P}_{2,1,0} ;{ }^{1} \mathrm{D}_{2}\right)$ from $\mathrm{CH}_{3} \mathrm{SCH}_{3}$ to those from $\mathrm{CS}_{2}$. 
In principle, the best method for calibrating the $\mathrm{S}^{+}$signal of $\mathrm{S}\left({ }^{3} \mathrm{P}_{2,1,0} ;{ }^{1} \mathrm{D}_{2}\right)$ from the photodissociation of $\mathrm{CH}_{3} \mathrm{SCH}_{3}$ to that from process (3) is to measure the $\mathrm{S}^{+}$signal due to $\mathrm{CS}_{2}$ formed in the pulsed beam using the same expansion conditions as that used for the production of the $\mathrm{CH}_{3} \mathrm{SCH}_{3}$ beam. However, the $\mathrm{S}^{+}$signal from $\mathrm{CS}_{2}$ observed in such an experiment saturates the microchannel plate detector. The $\mathrm{S}^{+}$signal from $\mathrm{CS}_{2}$ is much higher than that from $\mathrm{CH}_{3} \mathrm{SCH}_{3}$ because process (3) is proportional to the dissociation excimer laser power, whereas the formation of $S$ from processes (1) and (2) is proportional to the second power of the dissociation excimer laser power. For this reason, a slight contamination of the nozzle by $\mathrm{CS}_{2}$ can affect significantly the measurement of the relative signals for $S\left({ }^{3} P_{2,1,0}\right)$ and $S\left({ }^{1} D_{2}\right)$. We find that the most reliable measurement of the $S^{+}$ signal from $\mathrm{CS}_{2}$ is obtained in a calibration experiment under gas cell conditions. This is achieved by leaking $\mathrm{CS}_{2}$ through a leak valve into the photodissociation (and photoionization) chamber to a pressure of $2 \times 10^{-6}$ Torr. The $\mathrm{CS}_{2}$ calibration experiment can be performed immediately after the measurement of the $\mathrm{S}^{+}$from $\mathrm{CH}_{3} \mathrm{SCH}_{3}$ with all the other experimental conditions unchanged.

The number density of $\mathrm{CH}_{3} \mathrm{SCH}_{3}$ in the photodissociation region is needed to estimate the absolute cross section for process (2). The number density of $\mathrm{CH}_{3} \mathrm{SCH}_{3}$ at the photodissociation region is calculated by using a standard molecular beam flow formula ${ }^{35}$ based on the known nozzle diameter and distance between the nozzle and the photodissociation region. The temporal profile for the pulsed beam is sufficiently broad that its intensity is essentially flat in the central portion used in this experiment.

In the estimation of the dissociation excimer laser flux, we assume that the mildly 
focused laser beam has a Gaussian beam profile. ${ }^{36}$ The photodissociation laser spot size has also been checked by examining the burn spots on thermal papers at various distances from the focusing lens. The variation of the laser beam spot size with distance from the focusing lens is consistent with that predicted by the Gaussian beam profile. In the photodissociation region the ionization laser beam spot is smaller than the photodissociation laser beam spot.

The volumes of product $S$ atoms sampled by the ionization detector in the pulsed beam mode and in the gas cell mode are different. The determination of the intersection volume of the ionization laser beam and the $\mathrm{CH}_{3} \mathrm{SCH}_{3}$ beam, as well as that of the ionization laser beam and the $\mathrm{CS}_{2}$ molecules in the gas cell, is necessary for the calibration. Here, the ionization dye laser beam profile is again assumed to conform with the Gaussian profile. The size of the $\mathrm{CH}_{3} \mathrm{SCH}_{3}$ beam is determined by the skimmer opening and the nozzle-skimmer distance. 


\section{AB INITIO CALCULATION}

All calculations on the electronic structures of $\mathrm{CH}_{3} \mathrm{~S}$ are performed using of the GAMESS program. ${ }^{37}$ The calculations are based on the MCSCF and the first order configuration interaction (FOCI) methods. The standard $6-31 \mathrm{G}^{* *}$ basis set is used. In order to properly describe the excited states of $\mathrm{CH}_{3} \mathrm{~S}$, we have extended the basis set to include the Rydberg functions with $\alpha_{4 \mathrm{~s}}=0.023, \alpha_{4 \mathrm{p}}=0.020$ and $\alpha_{3 \mathrm{~d}}=0.015$ for the sulfur atom and $\alpha_{3 s}=\alpha_{3 \mathrm{p}}=0.040$ for the carbon atom.

The electronic configuration for the $\mathrm{CH}_{3} \mathrm{~S}\left(\tilde{\mathrm{X}}^{2} \mathrm{E}\right)$ ground state in $\mathrm{C}_{3 \mathrm{v}}$ symmetry is

$$
1 a_{1}^{2} 2 a_{1}^{2} 3 a_{1}^{2} 4 a_{1}^{2} 1 e^{4} 5 a_{1}^{2} 2 e^{4} 6 a_{1}^{2} 7 a_{1}^{2} 3 e^{3} 8 a_{1}{ }^{0}
$$

The $1 a_{1}, 2 a_{1}, 3 a_{1}, 4 a_{1}$, and 1e orbitals are the core orbitals corresponding to the $1 s, 2 s$, and $2 p$ orbitals of the sulfur atom and the $1 \mathrm{~s}$ orbital of the carbon atom. The $5 a_{1}$ and $2 \mathrm{e}$ orbitals are $\mathrm{C}-\mathrm{H}$ bonding orbitals associated with the methyl group. The $6 \mathrm{a}_{1}$ and $3 \mathrm{e}$ orbitals correspond essentially to the $3 s$ and $\left(3 p_{x}, 3 p_{y}\right)$ orbitals of sulfur, respectively. The $7 \mathrm{a}_{1}$ orbital is the C-S bonding orbital, while the $8 \mathrm{a}_{1}$ orbital is the C-S anti-bonding orbital. In the calculation of the potential energy curves along the $\mathrm{CH}_{3}-\mathrm{S}$ dissociation coordinate, we restrict $\mathrm{CH}_{3} \mathrm{~S}$ to $\mathrm{C}_{3 \mathrm{v}}$ symmetry and we freeze the core and the $5 \mathrm{a}_{1}$ and $2 \mathrm{e} \mathrm{C}-\mathrm{H}$ bonding orbitals. The active space includes the $6 a_{1}, 7 a_{1}, 8 a_{1}$, and $3 e$ orbitals and the number of active electrons is seven. In the calculation of the excited states, we use the state-averaged MCSCF with equal weights for the three lowest states. The FOCI calculations are carried 
out using the molecular orbitals obtained in the MCSCF calculations. The potential energy curves for $\mathrm{CH}_{3} \mathrm{~S}$ thus calculated are depicted in Fig. 5. The figure only includes the doublet excited states, which may be populated by spin-allowed transitions from the ground $\mathrm{CH}_{3} \mathrm{~S}\left(\tilde{\mathrm{X}}^{2} \mathrm{E}\right)$ state.

The $\mathrm{CH}_{3} \mathrm{~S}\left(\tilde{\mathrm{X}}^{2} \mathrm{E}\right)$ state is subjected to the Jahn-Teller distortion, and the actual structure for $\mathrm{CH}_{3} \mathrm{~S}(\tilde{\mathrm{X}})$ is expected to have a $\mathrm{C}_{\mathrm{s}}$ symmetry. The previous studies, however, indicate that the Jahn-Teller stabilization is small ${ }^{22}$ and is substantially smaller than the spin-orbit splitting $\left(259 \mathrm{~cm}^{-1}\right)^{20}$ for $\mathrm{CH}_{3} \mathrm{~S}\left(\tilde{\mathrm{X}}^{2} \mathrm{E}_{3 / 2,1 / 2}\right)$. In a lower $\mathrm{C}_{\mathrm{s}}$ symmetry, $\mathrm{a}_{1}$ transforms as $\mathrm{a}^{\prime}$ and the e-orbitals are split into orbitals transformed as $\mathrm{a}^{\prime}$ and $\mathrm{a}^{\prime \prime}$. The $\mathrm{CH}_{3} \mathrm{~S}\left(\tilde{\mathrm{X}}^{2} \mathrm{~A}^{\prime}\right)$ ground state has the electronic configuration,

$$
1 a^{\prime 2} 2 a^{\prime 2} 3 a^{\prime 2} 4 a^{\prime} 5 a^{\prime 2} 1 a^{\prime 2} 6 a^{\prime 2} 7 a^{\prime 2} 2 a^{\prime 2} 8 a^{\prime 2} 9 a^{\prime 2} 3 a^{\prime \prime 2} 10 a^{\prime 1} 11 a^{\prime 0} \ldots
$$

We have also optimized the ground $\mathrm{CH}_{3} \mathrm{~S}\left(\tilde{\mathrm{X}}^{2} \mathrm{~A}^{\prime},{ }^{2} \mathrm{~A}^{\prime \prime}\right)$ state and the first excited $\mathrm{CH}_{3} \mathrm{~S}\left(\tilde{\mathrm{A}}^{2} \mathrm{~A}_{2}\right)$ state using the MCSCF method. 
Figure 5. $A b$ Initio potential energy curves for $\mathrm{CH}_{3} \mathrm{~S}$ in $\mathrm{C}_{3 \mathrm{v}}$ symmetry plotted as a function of the $\mathrm{CH}_{3}-\mathrm{S}$ distance (see text). 


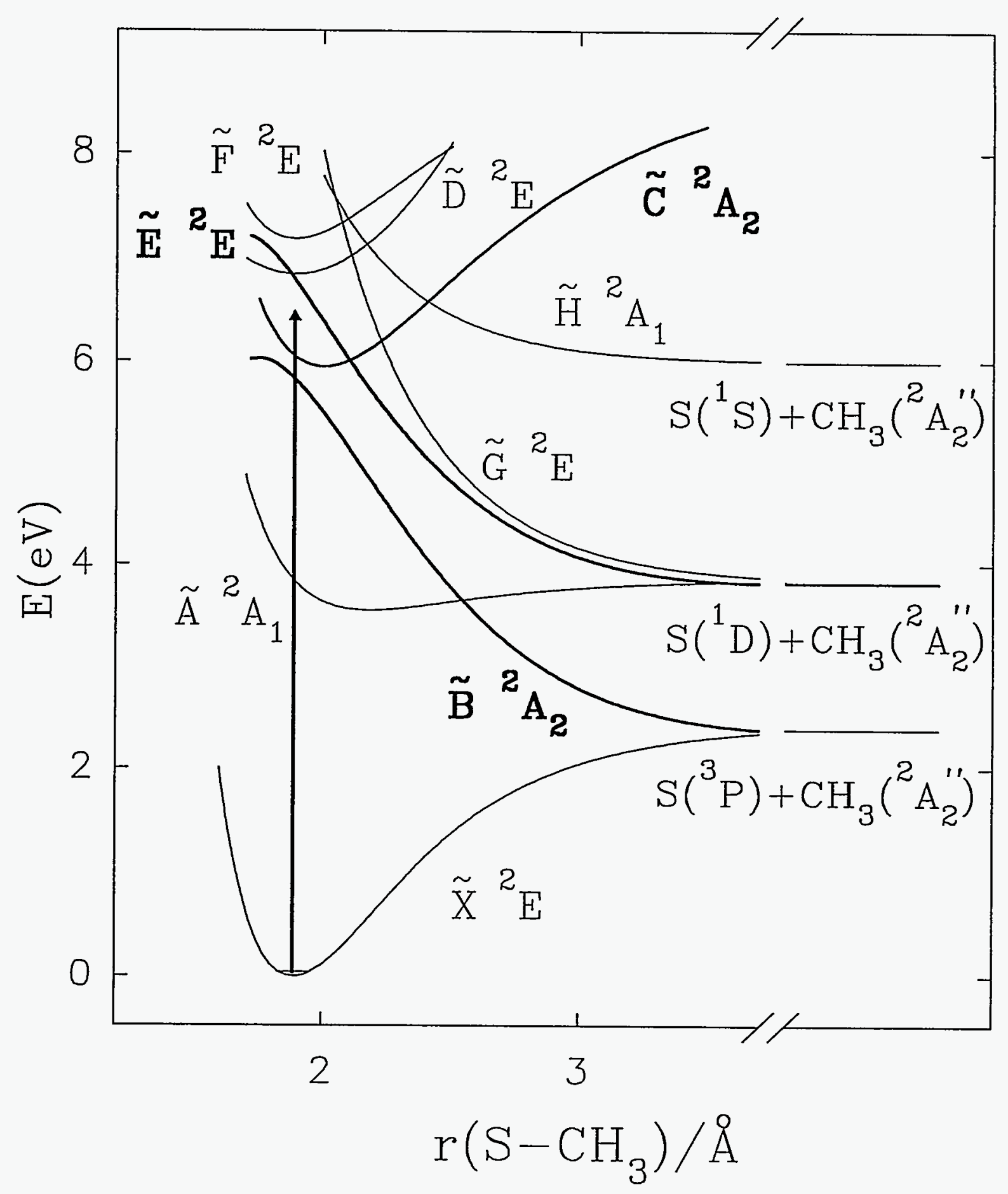




\section{RESULTS AND DISCUSSION}

\section{A. Comparison of theoretical and experimental geometrical parameters for $\mathrm{CH}_{3} \mathrm{~S}(\tilde{\mathbf{X}}, \tilde{\mathrm{A}})$}

Using the standard Gaussian program, the geometry of $\mathrm{CH}_{3} \mathrm{~S}(\tilde{\mathrm{X}})$ was examined by Janousek and Brauman in a restricted $\mathrm{C}_{3 \mathrm{v}}$ symmetry at the STO-3G and 4-31G levels. ${ }^{22}$ Most recently, the structure of $\mathrm{CH}_{3} \mathrm{~S}$ in the ground $\tilde{\mathrm{X}}^{2} \mathrm{~A}^{\prime}$ state has been optimized using the density function (DF) method ${ }^{27}$ and using the Gaussian program at the HF/6-31G ${ }^{*}{ }^{26}$ MP2/6-31G ${ }^{*}{ }^{23}$ and the MP2/6-31G ${ }^{* 28}$ levels. All these higher level $a b$ initio calculations predict that $\mathrm{CH}_{3} \mathrm{~S}$ in the ground state has a $\mathrm{C}_{s}$ symmetry with the distance of one of the $\mathrm{C}-\mathrm{H}$ bonds $[\mathrm{r}(\mathrm{C}-\mathrm{H}(1))]$ slightly longer than those for the other two $\mathrm{C}-\mathrm{H}$ bonds $[\mathrm{r}(\mathrm{C}-$ $\mathrm{H}(2))=r(\mathrm{C}-\mathrm{H}(3))]$. In Table I, the geometrical parameters for $\left.\mathrm{CH}_{3} \mathrm{~S}_{\mathrm{X}^{2}} \mathrm{~A}^{\prime}\right)$ predicted by the previous calculations are compared to those obtained here. The $\theta$ values shown in the table are the bond angles. The MCSCF parameters of this work are in fair agreement with those obtained from the MP2/6-31G ${ }^{*}$ and MP2/6-31G** calculations.

Despite many previous experimental studies, detailed structural information for $\mathrm{CH}_{3} \mathrm{~S}$ is still lacking. In a recent high resolution laser-induced fluorescence study of jet cooled $\mathrm{CH}_{3} \mathrm{~S}$, Hsu et al. ${ }^{17}$ have analyzed the rotationally resolved spectra obtained in their experiment by considering a $\mathrm{C}_{3 v}$ symmetry for $\mathrm{CH}_{3} \mathrm{~S}$. By assuming a distance of $1.10 \AA$ for $\mathrm{r}(\mathrm{C}-\mathrm{H}(1))[=\mathrm{r}(\mathrm{C}-\mathrm{H}(2))=\mathrm{r}(\mathrm{C}-\mathrm{H}(3))]$, they have obtained estimates of $1.767 \AA$ and $115.8^{\circ}$ for $\mathrm{r}(\mathrm{C}-\mathrm{S})$ and $\theta(\mathrm{S}-\mathrm{C}-\mathrm{H}(1))[=\theta(\mathrm{S}-\mathrm{C}-\mathrm{H}(2))=\theta(\mathrm{S}-\mathrm{C}-\mathrm{H}(3))]$, respectively. The $\theta(\mathrm{S}-$ $\mathrm{C}-\mathrm{H})$ value thus deduced from the experiment is greater than the theoretical predictions $\mathrm{s}^{23,26-}$ 
Table I. Optimized geometrical parameters for $\mathrm{CH}_{3} \mathrm{~S}$ in the $\left.\mathrm{X}^{2} \mathrm{~A}^{\prime},{ }^{2} \mathrm{~A}^{\prime \prime}, \mathrm{A}^{2} \mathrm{~A}^{\prime}\right)$ states.

\begin{tabular}{|c|c|c|c|c|c|}
\hline Methods & $\begin{array}{l}\mathrm{r}(\mathrm{C}-\mathrm{S}) \\
(\AA)\end{array}$ & $\begin{array}{l}r(\mathrm{C}-\mathrm{H}(1)) \\
(\AA)\end{array}$ & $\begin{array}{l}\mathrm{r}(\mathrm{C}-\mathrm{H}(2)) \\
(\AA)\end{array}$ & $\begin{array}{l}\theta(\mathrm{S}-\mathrm{C}-\mathrm{H}(1)) \\
\text { (degree) }\end{array}$ & $\begin{array}{l}\theta(\mathrm{S}-\mathrm{CH}(2)) \\
\text { (degree) }\end{array}$ \\
\hline \multicolumn{6}{|l|}{$\mathrm{CH}_{3} \mathrm{~S}\left(\tilde{\mathrm{X}}^{2} \mathrm{~A}^{\prime}\right)$} \\
\hline $\mathrm{UHF} / 4-31 \mathrm{G}^{\mathrm{a}}$ & 1.76 & 1.10 & 1.10 & 110.9 & 110.9 \\
\hline $\mathrm{MP} 2 / 6-31 \mathrm{G}^{* \mathrm{~b}}$ & 1.799 & 1.095 & 1.090 & 107.0 & 111.7 \\
\hline $\mathrm{MP} 2 / 6-31 \mathrm{G}^{* *} \mathrm{c}$ & 1.797 & 1.090 & 1.085 & 106.9 & 111.7 \\
\hline $\mathrm{DF}^{\mathrm{d}}$ & 1.762 & 1.116 & 1.107 & 106.0 & 113.0 \\
\hline $\mathrm{MCSCF}^{\mathrm{e}}$ & 1.808 & 1.084 & 1.081 & 107.0 & 110.5 \\
\hline $\operatorname{Expt}^{f}$ & 1.767 & 1.10 & 1.10 & 115.8 & 115.8 \\
\hline \multicolumn{6}{|l|}{$\mathrm{CH}_{3} \mathrm{~S}\left({ }^{2} \mathrm{~A}^{\prime \prime}\right)$} \\
\hline $\mathrm{MCSCF}^{\mathrm{c}}$ & 1.808 & 1.080 & 1.083 & 111.3 & 108.3 \\
\hline \multicolumn{6}{|l|}{$\mathrm{CH}_{3} \mathrm{~S}\left(\tilde{\mathrm{A}}^{2} \mathrm{~A}^{\prime}\right)$} \\
\hline $\mathrm{MCSCF}^{\mathrm{c}}$ & 2.191 & 1.073 & 1.073 & 99.1 & 99.3 \\
\hline $\operatorname{Expt}^{\mathrm{f}}$ & 2.057 & 1.100 & 1.100 & 111.7 & 111.7 \\
\hline
\end{tabular}
a) Reference 22 .
b) Reference 23 .
c) Reference 28 .
d) Reference 27.
e) This work.
f) Reference 17. In the derivation of $\mathrm{r}(\mathrm{C}-\mathrm{S})$ from experimental data, $\mathrm{CH}_{3} \mathrm{~S}$ is assumed to have a $\mathrm{C}_{3 \mathrm{v}}$ symmetry and $\mathrm{r}(\mathrm{C}-\mathrm{H}(1))[=\mathrm{r}(\mathrm{C}-\mathrm{H}(2))=\mathrm{r}(\mathrm{C}-\mathrm{H}(3))]$ is assumed to have a value of $1.10 \AA$.


${ }^{28}$ by $\approx 6^{\circ}$. The geometrical parameters for the first excited $\mathrm{CH}_{3} \mathrm{~S}\left(\tilde{\mathrm{A}}^{2} \mathrm{~A}_{1}\right)$ state have also been derived using similar procedures. These values are also included in Table I.

As a result of Jahn-Teller distortion, the $\mathrm{CH}_{3} \mathrm{~S}\left(\mathrm{C}_{3 v} ; \tilde{\mathrm{X}}^{2} \mathrm{E}\right)$ state is split into the ${ }^{2} \mathrm{~A}^{\prime}$ and ${ }^{2} \mathrm{~A}$ " states. The geometrical parameters predicted by the MCSCF calculation for the ${ }^{2} \mathrm{~A}^{\prime \prime}$ state are also listed in Table I. We find that the ${ }^{2} \mathrm{~A}$ " state is higher than the ${ }^{2} \mathrm{~A}^{\prime}$ state by only $9 \mathrm{~cm}^{-1}$. Therefore, these two states essentially remain degenerate. The JahnTeller barrier between these states is $<50 \mathrm{~cm}^{-1}$. These theoretical results are consistent with previous calculations. ${ }^{22,25}$

The geometrical parameters predicted by the MCSCF calculation for the first excited $\mathrm{CH}_{3} \mathrm{~S}(\tilde{\mathrm{A}})$ correspond to a structure deviating only slightly from a $\mathrm{C}_{3 \mathrm{v}}$ symmetry. Because of this, we have labelled the first excited state for $\mathrm{CH}_{3} \mathrm{~S}$ as $\tilde{A}^{2} \mathrm{~A}_{1}$. Since the $\tilde{\mathrm{A}}^{2} \mathrm{~A}_{1}$ state corresponds to the excitation of an electron from the C-S bonding $7 a_{1}$ orbital to the non-bonding 3e orbital, the C-S bond in $\mathrm{CH}_{3} \mathrm{~S}\left(\tilde{\mathrm{A}}^{2} \mathrm{~A}_{1}\right)$ is expected to be substantially weaker than that in $\mathrm{CH}_{3} \mathrm{~S}(\tilde{\mathrm{X}})$. The geometrical parameters for $\mathrm{CH}_{3} \mathrm{~S}\left(\tilde{\mathrm{A}}^{2} \mathrm{~A}_{1}\right)$ obtained in the experiment of Hsu et al. ${ }^{17}$ and in the MCSCF calculation are in qualitative agreement. The experimental and theoretical values for $\mathrm{r}(\mathrm{C}-\mathrm{S})$ in $\mathrm{CH}_{3} \mathrm{~S}\left(\tilde{\mathrm{A}}^{2} \mathrm{~A}_{1}\right)$ are $>2 \AA$, significantly longer than $\mathrm{r}(\mathrm{C}-\mathrm{S})$ in the ground state. As a result of this, the structure of the methyl group in this state comes close to that of the methyl radical. This is manifested by the observation that the bond angle $\theta(\mathrm{S}-\mathrm{C}-\mathrm{H})$ in $\mathrm{CH}_{3} \mathrm{~S}\left(\tilde{\mathrm{A}}^{2} \mathrm{~A}_{1}\right)$ is smaller than that in $\mathrm{CH}_{3} \mathrm{~S}(\tilde{\mathrm{X}})$. We note that the theoretical value for $\mathrm{r}(\mathrm{C}-\mathrm{S})$ is greater than the experimental estimate by $\approx 0.13 \AA$, while the theoretical bond angle $\theta(\mathrm{S}-\mathrm{C}-\mathrm{H})$ is smaller than deduced from the experiment by more than $11^{\circ}$. 
Based on the MCSCF total energies of the optimized $\mathrm{CH}_{3} \mathrm{~S}(\tilde{\mathrm{X}}, \tilde{\mathrm{A}})$ states, the energy difference between the potential wells of the $\mathrm{CH}_{3} \mathrm{~S}(\tilde{\mathrm{X}})$ and $\mathrm{CH}_{3} \mathrm{~S}(\tilde{\mathrm{A}})$ states is $3.34 \mathrm{eV}$, a value in good agreement with the transition energy of $3.29 \mathrm{eV}$ for $\tilde{\mathrm{X}}^{2} \mathrm{E}_{3 / 2} \rightarrow \tilde{\mathrm{A}}^{2} \mathrm{~A}_{1}$ obtained in a recent laser-induced fluorescence experiment. ${ }^{20}$ The MCSCF calculation predicts that the well depth for $\mathrm{CH}_{3} \mathrm{~S}(\tilde{\mathrm{A}})$ with respect to $\mathrm{CH}_{3}\left(\tilde{\mathrm{X}}^{2} \mathrm{~A}_{2}{ }^{\prime \prime}\right)+\mathrm{S}\left({ }^{1} \mathrm{D}\right)$ is $0.31 \mathrm{eV}$.

\section{B. Potential energy curves for $\mathrm{CH}_{3} \mathrm{~S}$ calculated along the $\mathrm{CH}_{3}-\mathrm{S}$ dissociation coordinate}

The vertical arrow in Fig. 5 corresponds to the excitation energy of $6.41 \mathrm{eV}$ in the absorption of a $193 \mathrm{~nm}$ photon by $\mathrm{CH}_{3} \mathrm{~S}\left(\tilde{\mathrm{X}}^{2} \mathrm{E}\right)$ in its ground vibrational state. Table II summarizes some properties of selected excited states for $\mathrm{CH}_{3} \mathrm{~S}\left(\tilde{\mathrm{A}}^{2} \mathrm{~A}_{1}, \tilde{\mathrm{B}}^{2} \mathrm{~A}_{2}, \tilde{\mathrm{C}}^{2} \mathrm{~A}_{2}, \tilde{\mathrm{D}}^{2} \mathrm{E}\right.$, $\left.\tilde{\mathrm{E}}^{2} \mathrm{E}, \tilde{\mathrm{F}}^{2} \mathrm{E}\right)$, which may be involved in the $193 \mathrm{~nm}$ photodissociation of $\mathrm{CH}_{3} \mathrm{~S}(\tilde{\mathrm{X}})$. Considering the internal excitation of $\mathrm{CH}_{3} \mathrm{~S}$ initially formed by process (1), ${ }^{6}$ the excitation to the $\tilde{\mathrm{F}}^{2} \mathrm{E}$ state, which has a vertical transition energy $\left(\mathrm{T}_{\mathrm{e}}\right)$ of $7.16 \mathrm{eV}$, is possible. Note that the potential energy curves plotted as a function of $r(C-S)$ in Fig. 5 are calculated assuming a $\mathrm{C}_{3 \mathrm{v}}$ symmetry for $\mathrm{CH}_{3} \mathrm{~S}$. It is expected that the $\mathrm{T}_{\mathrm{e}}$ values corresponding to optimized $\mathrm{CH}_{3} \mathrm{~S}$ structures may be slightly different from those given in the table. The $\tilde{\mathrm{C}}$ and $\tilde{\mathrm{D}}$ states are Rydberg in nature and the $\tilde{\mathrm{B}}$ and $\tilde{\mathrm{E}}$ states are repulsive. Mouflih et al. ${ }^{25}$ report the energies for $\mathrm{CH}_{3} \mathrm{~S}$ in the excited $\tilde{\mathrm{A}}, \tilde{\mathrm{B}}$, and $\tilde{\mathrm{D}}$ states to be $4.02,5.70$, and $6.45 \mathrm{eV}$, respectively, relative to the ground $\mathrm{CH}_{3} \mathrm{~S}$ state. Their SCF molecular orbital calculations used a moderately large basis set, and configuration interaction calculations were included for all the electronic states. Their predictions are in reasonable accord with the corresponding $T_{c}$ values obtained here. The $\tilde{G}$ (repulsive) and $\tilde{H}$ (repulsive) states, 
Table II. Predicted spectroscopic properties for selected excited states which may be involved in the $193 \mathrm{~nm}$ photodissociation of $\mathrm{CH}_{3} \mathrm{~S}$.

\begin{tabular}{llll}
\hline \hline Excited state & $\begin{array}{c}\text { Vertical transition } \\
\text { energy (eV) } \\
\text { (From } \tilde{\mathrm{X}}^{2} \mathrm{E} \text { state) }\end{array}$ & $\begin{array}{l}\text { Oscillator strength } \\
\text { (From } \tilde{\mathrm{X}}^{2} \mathrm{E} \text { state) }\end{array}$ & $\begin{array}{l}\text { Adiabatic product } \\
\mathrm{C}\left({ }^{3} \mathrm{P},{ }^{1} \mathrm{D}\right) \text { states }\end{array}$ \\
\hline$\left.\tilde{\mathrm{A}}_{3 \mathrm{v}} \mathrm{A}_{1}\right)$ & 3.72 & 0.0035 & $\mathrm{~S}\left({ }^{1} \mathrm{D}\right)$ \\
$\tilde{\mathrm{B}}^{2} \mathrm{~A}_{2}$ & 5.82 & 0.0073 & $\mathrm{~S}\left({ }^{3} \mathrm{P}\right)$ \\
$\tilde{\mathrm{C}}^{2} \mathrm{~A}_{2}$ & 6.17 & 0.0408 & $\ldots$ \\
$\tilde{\mathrm{D}}^{2} \mathrm{E}$ & 6.81 & 0.0014 & $\ldots$ \\
$\tilde{\mathrm{E}}^{2} \mathrm{E}$ & 6.86 & 0.0006 & $\mathrm{~S}\left({ }^{1} \mathrm{D}\right)$ \\
$\tilde{\mathrm{F}}^{2} \mathrm{E}$ & 7.12 & $\ldots$ & $\ldots$ \\
\hline \hline
\end{tabular}


which have theoretical $T_{c}$ values greater than $8.0 \mathrm{eV}$, may not be directly populated in the 193nm excitation of $\mathrm{CH}_{3} \mathrm{~S}(\tilde{\mathrm{X}})$.

The radiative lifetimes measured for the $\nu_{3}=0,1$, and 2 vibrational states of $\mathrm{CH}_{3} \mathrm{~S}\left(\tilde{\mathrm{A}}^{2} \mathrm{~A}_{1}\right)$ indicate that the $\nu_{3}=1$ and 2 states of $\mathrm{CH}_{3} \mathrm{~S}\left(\tilde{\mathrm{A}}^{2} \mathrm{~A}_{1}\right)$ are predissociative. ${ }^{17-19}$ This observation is consistent with the crossing of the $\tilde{\mathrm{A}}^{2} \mathrm{~A}_{1}$ and $\tilde{\mathrm{B}}^{2} \mathrm{~A}_{2}$ states as shown in Fig. 5. The crossing occurs at $746 \mathrm{~cm}^{-1}$ above the potential well of the $\mathrm{CH}_{3} \mathrm{~S}\left(\tilde{\mathrm{A}}^{2} \mathrm{~A}_{1}\right)$ state. Since the $\nu_{3}$ spacing for the $\mathrm{CH}_{3} \mathrm{~S}\left(\tilde{\mathrm{A}}^{2} \mathrm{~A}_{1}\right)$ state is measured to be $401 \pm 2 \mathrm{~cm}^{-1}$, we expect that $\nu_{3}=0$ is stable, whereas $\nu_{3}>0$ states are predissociative, a prediction consistent with the experimental observation. Predissociation of $\mathrm{CH}_{3} \mathrm{~S}\left(\tilde{\mathrm{A}}^{2} \mathrm{~A}_{1}\right)$ via $\mathrm{CH}_{3} \mathrm{~S}\left(\tilde{\mathrm{B}}^{2} \mathrm{~A}_{2}\right)$, due to nonadiabatic interactions, should lead to the formation of $\mathrm{CH}_{3}\left(\tilde{\mathrm{X}}^{2} \mathrm{~A}_{2}{ }^{\prime \prime}\right)+\mathrm{S}\left({ }^{3} \mathrm{P}\right)$.

\section{Fine-structure distribution of $S\left({ }^{3} \mathrm{P}_{2,1,0}\right)$ and $S\left({ }^{3} \mathrm{P}\right) / \mathrm{S}\left({ }^{1} \mathrm{D}\right)$ branching ratio}

The fine-structure distribution of $S\left({ }^{3} \mathrm{P}_{\mathrm{J}}\right)$ produced in the $193 \mathrm{~nm}$ photodissociation of $\mathrm{CH}_{3} \mathrm{~S}$ [process (2)] is determined to be ${ }^{3} \mathrm{P}_{2}:{ }^{3} \mathrm{P}_{1}:{ }^{3} \mathrm{P}_{0}=0.59 \pm 0.02: 0.32 \pm 0.02$ : $0.09 \pm 0.04$, which is close to the statistical distribution of $5 / 9: 3 / 9: 1 / 9$.

The $\mathrm{S}^{+}$intensities observed in the $2+1$ REMPI of $S\left({ }^{3} \mathrm{P}_{2}\right)$ and $S\left({ }^{1} \mathrm{D}_{2}\right)$ are plotted as a function of the 193nm photodissociation laser photon flux in Figs. $6(\mathrm{a})$ and $6(\mathrm{~b})$, respectively. The similarity of the photon flux dependencies for $\mathrm{S}^{+}$due to $S\left({ }^{3} \mathrm{P}_{2}\right)$ and $S\left({ }^{1} D_{2}\right)$ is consistent with the conclusion that both $\left.S^{3} P_{2}\right)$ and $S\left({ }^{1} D_{2}\right)$ originate from $\mathrm{CH}_{3} S$ formed in process (1). Based on the fine-structure distribution and the overall $S\left({ }^{3} \mathrm{P}\right) / \mathrm{S}\left({ }^{1} \mathrm{D}\right)$ ratio known for process $(3),{ }^{30,31}$ the $S\left({ }^{3} \mathrm{P}\right) / \mathrm{S}\left({ }^{1} \mathrm{D}\right)$ ratio for process (2) is determined to be $0.15 / 0.85$. According to six independent measurements, the fraction of $S\left({ }^{1} D_{2}\right)$ formed in the $193 \mathrm{~nm}$ photodissociation of $\mathrm{CH}_{3} \mathrm{~S}$ is found to be $0.85 \pm 0.05$. This finding is in accord 
Figure 6. Photodissociation laser flux (\# photons $/ \mathrm{cm}^{2}$ ) dependence of $\mathrm{S}^{+}$signal due to the ionization of (a) $S\left({ }^{3} \mathrm{P}_{2}\right)$ and (b) $S\left({ }^{1} \mathrm{D}_{2}\right)$ formed by processes (1) and (2). (o) experimental data; $(\bullet)$ best fit using Eq. (9). 


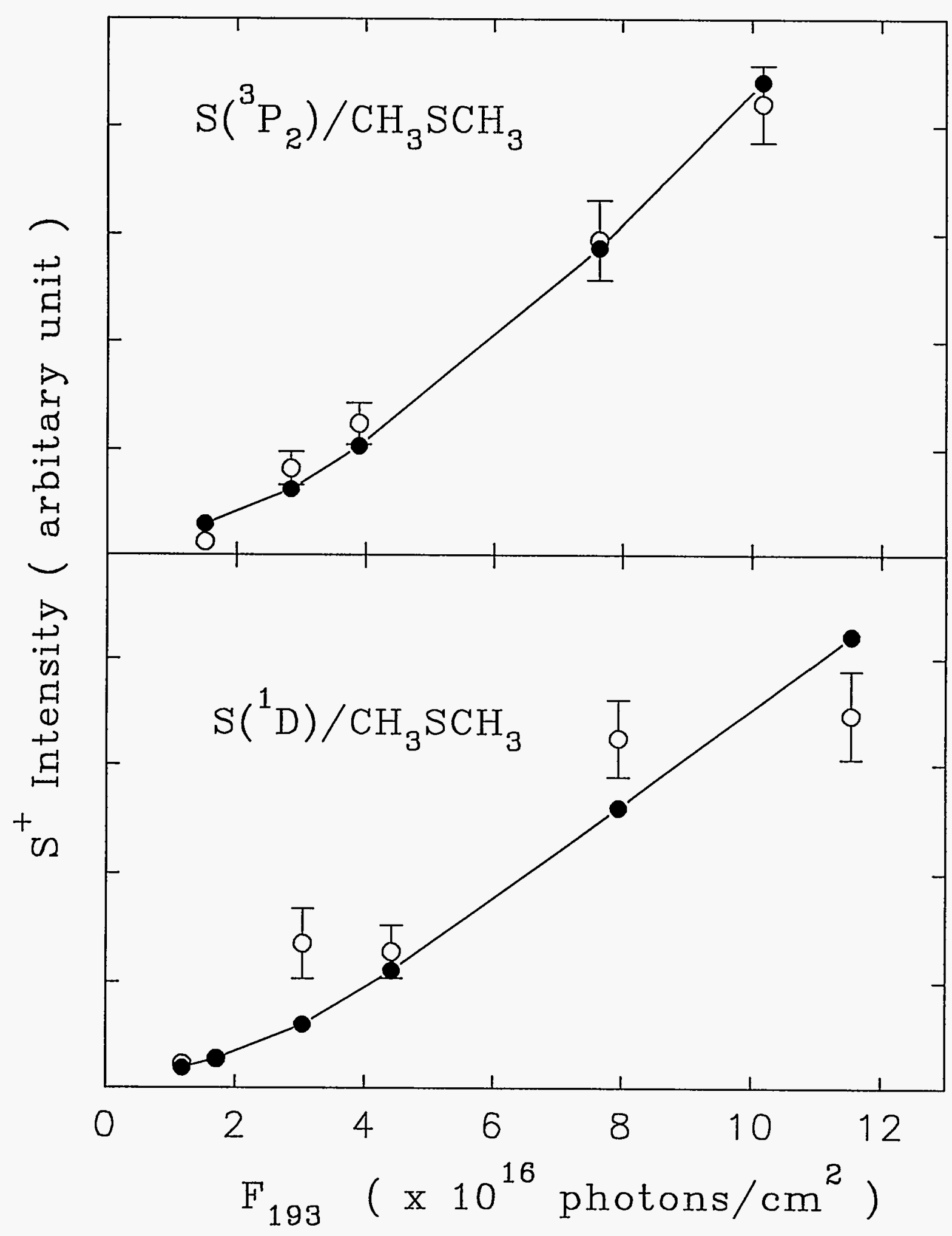


with the suggestion of the TOF experiment that $S$ atoms formed in process (2) are predominantly in the ${ }^{1} \mathrm{D}$ state. ${ }^{5,6}$

The theoretical photodissociation study of Freed and co-workers ${ }^{38}$ shows that photodissociation may proceed in two limiting cases, depending on the relative kinetic energy of the dissociation process. At low recoil energy, the fine-structure distribution is governed by the adiabatic potential surfaces. In this limit, symmetry correlation determines the fine-structure distribution. At the high energy limit a frame transformation would result in a statistical fine-structure distribution. The potential curves shown in Fig. 5 suggest that the formation of $\left.\mathrm{S}^{\beta} \mathrm{P}_{\mathrm{J}}\right)$ proceeds most likely via the repulsive $\mathrm{CH}_{3} \mathrm{~S}\left(\tilde{\mathrm{B}}^{2} \mathrm{~A}_{2}\right)$ state and that the dissociation is a case of the high energy regime.

As shown in Table II, the transition $\mathrm{CH}_{3} \mathrm{~S}\left(\tilde{\mathrm{X}}^{2} \mathrm{E}\right) \rightarrow \mathrm{CH}_{3} \mathrm{~S}\left(\tilde{\mathrm{C}}^{2} \mathrm{~A}_{2}\right)$ has by far the highest oscillator strength. This, together with the good match of the $T_{e}$ value and the photon energy, the absorption of a $193 \mathrm{~nm}$ photon by $\mathrm{CH}_{3} \mathrm{~S}\left(\tilde{\mathrm{X}}^{2} \mathrm{E}\right)$ is expected to produce $\mathrm{CH}_{3} \mathrm{~S}\left(\tilde{\mathrm{C}}^{2} \mathrm{~A}_{2}\right)$. We note that $\mathrm{CH}_{3} \mathrm{~S}\left(\tilde{\mathrm{C}}^{2} \mathrm{~A}_{2}\right)$ is crossed by the repulsive $\mathrm{CH}_{3} \mathrm{~S}\left(\tilde{\mathrm{E}}^{2} \mathrm{E}\right)$ state and that an avoided crossing exists between the $\tilde{\mathrm{B}}$ and $\tilde{\mathrm{C}}$ states. Due to nonadiabatic couplings, $\mathrm{CH}_{3} \mathrm{~S}\left(\tilde{\mathrm{C}}^{2} \mathrm{~A}_{2}\right)$ may predissociate via the $\mathrm{CH}_{3} \mathrm{~S}\left(\tilde{\mathrm{E}}^{2} \mathrm{E}\right)$ state and lead to product $\mathrm{S}\left({ }^{1} \mathrm{D}_{2}\right)+$ $\mathrm{CH}_{3}\left(\tilde{\mathrm{X}}^{2} \mathrm{~A}^{\prime \prime}\right)$, while predissociation via the $\mathrm{CH}_{3} \mathrm{~S}\left(\tilde{\mathrm{B}}^{2} \mathrm{~A}_{2}\right)$ state yields $\mathrm{S}\left({ }^{3} \mathrm{P}_{\mathrm{J}}\right)+\mathrm{CH}_{3}\left(\tilde{\mathrm{X}}^{2} \mathrm{~A}^{\prime \prime}\right)$. The dominant formation of $S\left({ }^{1} \mathrm{D}_{2}\right)$ by process (2) may be attributed to more favorable couplings of the $\mathrm{CH}_{3} \mathrm{~S}(\tilde{\mathrm{E}})$ and $\mathrm{CH}_{3} \mathrm{~S}(\tilde{\mathrm{C}})$ states. The previous $193 \mathrm{~nm}$ laser photofragmentation TOF experiment indicates that the $\mathrm{CH}_{3} \mathrm{~S}(\tilde{\mathrm{X}})+\mathrm{CH}_{3}$ produced by process (1) may be excited internally by $1.3 \mathrm{eV}$. Assuming that the internal energies are partitioned according to the internal degrees of freedom of the photofragments, $\mathrm{CH}_{3} \mathrm{~S}$ may 
be internally excited by $\approx 0.7 \mathrm{Ev}$, and the direct $193 \mathrm{~nm}$ excitation to $\mathrm{CH}_{3} \mathrm{~S}(\tilde{\mathrm{E}})$ from $\mathrm{CH}_{3} \mathrm{~S}(\tilde{\mathrm{X}})$ formed in process (1) is possible. The direct formation of $\mathrm{CH}_{3} \mathrm{~S}(\tilde{\mathrm{E}})$ should favor the $\mathrm{S}\left({ }^{1} \mathrm{D}_{2}\right)+\mathrm{CH}_{3}\left(\tilde{\mathrm{X}}^{2} \mathrm{~A}^{\prime \prime}\right)$ dissociation channel, a conclusion in accord with the experimental observation. We note that the inclusion of the interactions with potential curves of other multiplicities adds to the complexity of the photodissociation mechanism of this system.

We have also searched for the production of $S\left({ }^{1} S\right)$ from the $193 \mathrm{~nm}$ photolysis of $\mathrm{CH}_{3} \mathrm{SCH}_{3}$. Within the sensitivity of our experiment, $\mathrm{S}^{+}$resulting from REMPI of $\mathrm{S}\left({ }^{1} \mathrm{~S}\right)$ was not observed.

\section{Absolute cross section for process (2)}

Following the procedures described in the experimental section, we have obtained an estimate of $1 \times 10^{-18} \mathrm{~cm}^{2}$ for $\sigma_{2}$. The open circles shown in Figs. $6(\mathrm{a})$ and $6(\mathrm{~b})$ are the experimental $\mathrm{S}^{+}$intensities from $\mathrm{CH}_{3} \mathrm{SCH}_{3}$ measured at specific ionization laser flux and the solid dots represent the best fits obtained using Eq. (9) and the cross sections for the formation of $S\left({ }^{3} \mathrm{P}_{2}\right)$ and $S\left({ }^{\prime} D_{2}\right)$ by process (2). Due to the uncertainties involved in the calibration of the $\mathrm{S}^{+}$signals from $\mathrm{CS}_{2}$ and $\mathrm{CH}_{3} \mathrm{SCH}_{3}$ as described above, we consider that the absolute value for $\sigma_{2}$ is a rough estimate. Furthermore, the absolute photodissociation cross section determined here for $\mathrm{CH}_{3} \mathrm{~S}(\tilde{\mathrm{X}})$ is characteristic of the $\mathrm{CH}_{3} \mathrm{~S}(\tilde{\mathrm{X}})$ radicals prepared by process (1), which contains significant internal excitations. The photodissociation cross section for $\mathrm{CH}_{3} \mathrm{~S}(\tilde{\mathrm{X}})$ may depend on its internal excitations. Nevertheless, we find that the $S\left({ }^{3} \mathrm{P}\right) / S\left({ }^{1} \mathrm{D}\right)$ branching ratios and absolute cross sections observed in the $193 \mathrm{~nm}$ photodissociation of $\mathrm{CH}_{3} \mathrm{~S}(\tilde{\mathrm{X}})$ prepared by the photolysis of 
$\mathrm{CH}_{3} \mathrm{SSCH}_{3}$ and $\mathrm{CH}_{3} \mathrm{SH}^{39}$ are consistent with those determined in this experiment. It will be interesting to examine the $S\left({ }^{3} \mathrm{P}\right) / \mathrm{S}\left({ }^{1} \mathrm{D}\right)$ branching ratio due to the photodissociation of supersonically cooled $\mathrm{CH}_{3} \mathrm{~S}^{40}$

According to energetic considerations, the $193 \mathrm{~nm}$ photodissociation of $\mathrm{CH}_{3} \mathrm{~S}$ may lead to many exothermic channels other than process (2), for example

$$
\begin{aligned}
\mathrm{CH}_{3} \mathrm{~S}(\tilde{\mathrm{X}})+\mathrm{h} \nu(193 \mathrm{~nm}) & \rightarrow \mathrm{CH}_{2} \mathrm{~S}\left(\tilde{\mathrm{X}}^{1} \mathrm{~A}_{1}, \tilde{\mathrm{a}}^{3} \mathrm{~A}_{2}, \tilde{\mathrm{A}}^{1} \mathrm{~A}_{2}\right)+\mathrm{H}(\mathrm{S}) \\
& \rightarrow \mathrm{CHS}(\tilde{\mathrm{X}})+\mathrm{H}_{2} .
\end{aligned}
$$

For process (10), the exothermicities are $-100,-59$, and $-53 \mathrm{kcal} / \mathrm{mol}$ for the formation of $\mathrm{CH}_{2} \mathrm{~S}$ in the $\tilde{\mathrm{X}}^{1} \mathrm{~A}_{1}, \tilde{\mathrm{a}}^{3} \mathrm{~A}_{2}$, and $\tilde{\mathrm{A}}^{1} \mathrm{~A}_{2}$ states, ${ }^{41,42}$ respectively. The exothermicity for process (11) is $\approx-104 \mathrm{kcal} / \mathrm{mol}^{42}$ Although the good fits to the experimental data observed in Figs. 6(a) and 6(b) using Eq. (9) can be taken as evidence that process (2) is the major channel for the $193 \mathrm{~nm}$ photodissociation of $\mathrm{CH}_{3} \mathrm{~S}(\tilde{\mathrm{X}})$, we cannot, however, eliminate other channels such as processes (10) and (11). 


\section{CONCLUSION}

The distribution of $S\left({ }^{3} \mathrm{P}_{2,1,0},{ }^{1} \mathrm{D}_{2}\right)$ resulting from the $193 \mathrm{~nm}$ photodissociation of $\mathrm{CH}_{3} \mathrm{~S}(\tilde{\mathrm{X}})$ prepared by process (1) has been determined by using $2+1$ REMPI detection schemes and by calibrating the $S\left(\mathrm{P}_{2,1,0} ;{ }^{1} \mathrm{D}_{2}\right)$ formation from process (3). The finestructure distribution of product $S\left({ }^{3} \mathrm{P}_{2,1,0}\right)$ is found to be nearly statistical, while the $\mathrm{S}\left({ }^{3} \mathrm{P}\right)$ : $S\left({ }^{1} \mathrm{D}\right)$ branching ratio is determined to be $0.15: 0.85$. Based on the potential energy curves calculated along the $\mathrm{CH}_{3}-\mathrm{S}$ dissociation coordinate using the MCSCF and FOCI methods, we have rationalized the observed branching ratio for product $S$ atoms. The MCSCF calculation shows that the curve crossing between $\mathrm{CH}_{3} \mathrm{~S}(\tilde{\mathrm{A}})$ and $\mathrm{CH}_{3} \mathrm{~S}(\tilde{\mathrm{B}})$ provides an efficient predissociation pathway for $\mathrm{CH}_{3} \mathrm{~S}(\tilde{\mathrm{A}})$ to form $\mathrm{CH}_{3}(\tilde{\mathrm{X}})+\mathrm{S}\left({ }^{3} \mathrm{P}\right)$.

The geometries for $\mathrm{CH}_{3} \mathrm{~S}(\tilde{\mathrm{X}}, \tilde{\mathrm{A}})$ have been optimized using the MCSCF method. The geometrical parameters thus obtained are compared with those determined in previous calculations and experimental results.

The calibration of the $\mathrm{S}^{+}$signals from $\mathrm{CH}_{3} \mathrm{SCH}_{3}$ to that from $\mathrm{CS}_{2}$ makes possible the estimation of the absolute $193 \mathrm{~nm}$ photodissociation cross section of $\mathrm{CH}_{3} \mathrm{~S}(\tilde{\mathrm{X}})$. 


\section{ACKNOWLEDGEMENT}

The authors thank Drs. M. W. Schmidt and T. S. Elbert for making available to us the GAMESS program, which is used for performing all the calculations presented in this article. Funds in the form of a Research Opportunity Award from NSF, which provided partial support for P.J.H.T. during his stay in Ames, are gratefully acknowledged. 


\section{REFERENCES}

(1) See extensive references cited in Dynamics of Molecular Photofragmentation, Faraday Discussions of Chem. Soc., No. 82, 1986.

(2) M. N. R. Ashfold and J. E. Baggott, eds., Molecular Photodissociation Dynamics, Royal Society of Chemistry 1987.

(3) J. W. Hepburn in, Vacuum Ultraviolet Photoionization and Photodissociation of Molecules and Clusters, edited by C. Y. Ng (World Scientific, Singapore, 1991), p. 435.

(4) W. B. Tzeng, H.-M. Yin, W.-Y. Leung, J.-Y. Luo, S. Nourbakhsh, G. D. Flesch, and C. Y. Ng, J. Chem. Phys. $\underline{88}, 1658$ (1986).

(5) S. Nourbakhsh, C.-L. Liao, and C. Y. Ng, J. Chem. Phys. 92, 6587 (1989).

(6) S. Nourbakhsh, K. Norwood, H.-M. Yin, C.-L. Liao, and C. Y. Ng, J. Chem. Phys. 95, 5014 (1991).

(7) S. Nourbakhsh, K. Norwood, H.-M. Yin, C.-L. Liao, and C. Y. Ng, J. Chem. Phys. 95, 946, (1991).

(8) S. Nourbakhsh, H.-M. Yin, C.-L. Liao, and C. Y. Ng, Chem. Phys. Lett. 183, 348 (1991).

(9) P. Brewer, N. van Veen, and R. Bersohn, Chem. Phys. Lett. 91, 126 (1982).

(10) G. Black and L. E. Jusinski, J. Chem. Phys. $\underline{82}, 789$ (1985).

(11) G. Black and L. E. Jusinski, J. Chem. Soc. Faraday Trans. 2 82, 2143 (1986).

(12) R. J. Balla, H. H. Nelson, and J. R. McDonald, Chem. Phys. 109, 101 (1986). 
(13) R. J. Balla, B. R. Weiner, and H. H. Nelson, J. Am. Chem. Soc. 109, 4804 (1987).

(14) G. S. Tyndall and A. R. Ravishankara, J. Phys. Chem. 93, 2426, 4707 (1989).

(15) K. Ohbayashi, H. Akimoto, and I. Tanaka, Chem. Phys. Lett. 52, 47 (1977).

(16) M. Suzuki, G. Inoue, and H. Akimoto, J. Chem. Phys. $\underline{81}, 5405$ (1984).

(17) Y.-C. Hsu, X. Liu, and T. A. Miller, J. Chem. Phys. 90, 6852 (1989).

(18) G. Black and L. E. Jusinski, J. Chem. Phys. 모, 5379 (1986).

(19) Y.-Y. Lee, S.-Y. Chiang, and Y. P. Lee, J. Chem. Phys. 93, 4487 (1990).

(20) S.-Y. Chiang and Y.-P. Lee, J. Chem. Phys. 95, 66 (1991).

(21) S. Nourbakhsh, K. Norwood, G.-Z. He, and C. Y. Ng, J. Am. Chem. Soc. 113 , 6311 (1991).

(22) B. K. Janousek and J. I. Brauman, J. Chem. Phys. 22, 694 (1980).

(23) R. H. Nobes and L. Radom, Chem. Phys. Lett. 189, 554 (1992).

(24) K. K. Baldridge, M. S. Gordon, and D. E. Johnson, J. Chem. Phys. 91, 4145 (1987).

(25) B. Mouflih, C. Larrieu, and M. Chaillet, Chem. Phys. 119, 221 (1988).

(26) J. Fossey and J. Sorba, J. Mol. Struct. (Theochem), 186, 305 (1989).

(27) R. Fournier and A. E. DePristo, J. Chem. Phys. 96, 1183 (1992).

(28) C. Y. Ng, S.-W. Chiu, and W.-K. Li, J. Chem. Research, accepted.

(29) V. R. McCrary, R. Lu, D. Zakheim, J. A. Russell, J. B. Halpern, and W. M. Jackson, J. Chem. Phys. $\underline{83}, 3481$ (1985); J. W. Rabalais, J. M. McDonald, V. Scherr, and S. P. McGlynn, Chem. Rev. 71, 73 (1971). 
(30) I. M. Waller and W. J. Hepburn, J. Chem. Phys. $\underline{87}, 3261$ (1987).

(31) W.-B. Tzeng, H.-M. Yin, W.-Y. Leung, J.-Y. Luo, S. Nourbakhsh, G. D. Flesch, and C. Y. Ng, J. Chem. Phys. $\underline{88}, 1658$ (1988).

(32) W. C. Wiley and I. H. McLaren, Rev. Sci. Instr. 26, 1150 (1955).

(33) D. J. Bamford, M. J. Dyer, and W. K. Bishel, Phys. Rev. A, ㅌ6, 3497 (1987).

(34) J. G. Calvert and J. N. Pitts, Jr., Photochemistry (Wiley, New York, 1966).

(35) H. Beijerinck and N. Verster, Physica 111C, 327 (1981).

(36) A. Yariv, Quantum Electronics (Wiley, New York, 1975).

(37) M. W. Schmidt, K. K. Baldridge, J. A. Boatz, J. H. Jensen, S. Koseki, M. S. Gordon, K. A. Nguyen, T. L. Windus, T. S. Elbert, QCPE Bulletin, 10, 52 (1990).

(38) S. J. Singer, K. F. Freed, and Y. B. band, J. Chem. Phys. 모, 6060 (1983).

(39) C.-W. Hsu, C.-L. Liao, and C. Y. Ng, SPIE Conference Proceedings, Optical Methods for Time- and State-Resolved Selective Chemistry, edited by C. Y. Ng, Vol. 1638 (1992), in press.

(40) S. Nourbakhsh, K. Norwood, G.-Z. He, and C. Y. Ng, J. am. chem. Soc. $\underline{113}$, $6311(1991)$.

(41) R. H. Judge, D. C. Moule, and G. W. King, J. Mol. Spectrosc. 81 , 37 (1980).

(42) S. G. Lias, J. E. Bartmess, J. F. Liebman, J. L. Holmes, R. D. Levin, and W, G. Mallard, J. Phys. Chem. Ref. Data, 17, Suppl. 1 No. 1, 65 (1988). 
PAPER 2.

A STUDY OF THE $S\left({ }^{3} \mathrm{P}_{2,1,0} ;{ }^{1} \mathrm{D}_{2}\right)$ PRODUCTION IN THE $193 \mathrm{~nm}$ PHOTODISSOCIATION OF HS and $\mathrm{H}_{2} \mathrm{~S}$ 


\begin{abstract}
The dynamics of the photodissociation processes, HS $+h \nu(193 \mathrm{~nm}) \rightarrow \mathrm{H}\left({ }^{2} \mathrm{~S}\right)+$ $\mathrm{S}\left({ }^{3} \mathrm{P}_{\mathrm{J}},{ }^{1} \mathrm{D}_{2}\right)$ [process $\left.(\mathrm{A})\right]$ and $\mathrm{H}_{2} \mathrm{~S}+\mathrm{h} \nu(193 \mathrm{~nm}) \rightarrow \mathrm{H}_{2}(\mathrm{X})+\mathrm{S}\left({ }^{3} \mathrm{P}_{\mathrm{J}},{ }^{1} \mathrm{D}_{2}\right)$ [process (B)] have been studied using $2+1$ resonance-enhanced-multiphoton-ionization techniques. By using the rate equation model and by calibrating the $S\left({ }^{\beta} \mathrm{P}_{\mathrm{J}}, \mathrm{D}_{2}\right)$ formation from processes $(\mathrm{A})$ and (B) with that from the $193 \mathrm{~nm}$ photodissociation of $\mathrm{CS}_{2}$, we have determined the $\mathrm{S}\left({ }^{3} \mathrm{P}\right)$ : $S\left({ }^{1} D\right)$ branching ratios, the fine-structure distributions of $S\left({ }^{3} \mathrm{P}_{2,1,0}\right)$, and the absolute cross sections for processes $(A)$ and $(B)$. The branching ratio $S\left({ }^{3} \mathrm{P}\right): S\left({ }^{1} \mathrm{D}\right)=0.87: 0.13$ observed for process (A) supports the direct photodissociation mechanism for HS at 193nm via the excited repulsive $\operatorname{HS}\left({ }^{2} \Sigma,{ }^{2} \Delta\right)$ potential energy surfaces. The fine-structure distribution $S\left({ }^{\beta} \mathrm{P}_{2}\right): S\left({ }^{\beta} \mathrm{P}_{1}\right): S\left({ }^{\beta} \mathrm{P}_{0}\right)=0.68: 0.24: 0.08$ for process $(\mathrm{A})$ is colder than the statistical distribution. The absolute cross section for process (A) is estimated to be $1.1 \times 10^{-18} \mathrm{~cm}^{2}$. Process $(\mathrm{B})$, which is estimated to have an absolute cross section of $0.3 \times 10^{-}$ ${ }^{18} \mathrm{~cm}^{2}$, is minor compared to the formation $\mathrm{HS}+\mathrm{H}$ in the $193 \mathrm{~nm}$ photodissociation of $\mathrm{H}_{2} \mathrm{~S}$.
\end{abstract}




\section{INTRODUCTION}

The ultraviolet and vacuum ultraviolet (VUV) photodissociation of $\mathrm{H}_{2} \mathrm{~S}$ has received considerable experimenta $1^{1-12}$ and theoretica ${ }^{13-18}$ attention. Most of the experimental studies ${ }^{1-5,7,8}$ have focused on the photodissociation process,

$$
\mathrm{H}_{2} \mathrm{~S}+\mathrm{h} \nu(193 \mathrm{~nm}) \rightarrow \mathrm{HS}(\mathrm{X}, \mathrm{v})+\mathrm{H} .
$$

Because of the rapid dissociation of vibrationally excited HS radicals in the $\mathrm{A}^{2} \Sigma^{+}$state, the determination of the $\mathrm{HS}(\mathrm{X})$ vibrational distribution has not been made by the laser-induced fluorescence method. ${ }^{1}$ Previous laser photofragmentation time-of-flight (TOF) mass spectrometric ${ }^{2,45}$ and Doppler spectroscopic ${ }^{3}$ experiments indicate that HS(X) formed by process (1) is vibrationally excited up to $v=6$ with the HS vibrational distribution peaked strongly at $v=0$. Recently, Continetti et al..$^{5}$ have observed the $193 \mathrm{~nm}$ photodissociation of $\mathrm{HS}(\mathrm{X}, \mathrm{v})$ [process (2)] formed in process (1) at high photodissociation laser powers.

$$
H S(X, v)+h \nu(193 n m) \rightarrow H\left({ }^{2} S\right)+S\left({ }^{3} P,{ }^{1} D\right)
$$

By measuring the TOF distribution for $\mathrm{H}$ from process (2), they estimate that the branching ratio $S\left({ }^{3} \mathrm{P}\right): \mathrm{S}\left({ }^{1} \mathrm{D}\right)$ for process $(2)$ is $3: 1$. Referring to the ab initio calculation ${ }^{17}$, they suggest that $S\left({ }^{3} \mathrm{P}\right)$ and $S\left({ }^{1} \mathrm{D}\right)$ are produced by direct dissociation following the $193 \mathrm{~nm}$ photoexcitation of HS from the ground $X^{2} \Pi$ state to the excited ${ }^{2} \Sigma$ 
and ${ }^{2} \Delta$ repulsive states, respectively. The $193 \mathrm{~nm}$ photodissociation of $\mathrm{HS}$ to form $\mathrm{S}+$ $\mathrm{H}$ has also been reported in the recent photodissociation TOF mass spectrometric study of $\mathrm{CH}_{3} \mathrm{SH} .{ }^{19}$

As suggested by Roberge and Salahub, ${ }^{18}$ the photodissociation process

$$
\mathrm{H}_{2} \mathrm{~S}+\mathrm{h} \nu(193 \mathrm{~nm}) \rightarrow \mathrm{H}_{2}+\mathrm{S}\left({ }^{3} \mathrm{P}_{\mathrm{J}} ; \mathrm{D}_{2}\right)
$$

is a feasible channel which may be induced by the $2 b_{1} \rightarrow 6 a_{1}$ excitation of $\mathrm{H}_{2} \mathrm{~S}$. Below $2000 \AA, \mathrm{S}$ atoms have been observed in the flash photolysis of $\mathrm{H}_{2} \mathrm{~S}^{20}$ Recent multiphoton ionization studies ${ }^{10,11}$ show that $\mathrm{H}_{2} \mathrm{~S}$ dissociates to form $\mathrm{H}_{2}+\mathrm{S}\left({ }^{3} \mathrm{P},{ }^{1} \mathrm{D},{ }^{1} \mathrm{~S}\right)$ by two-photon absorption in the wavelength range of $285-297 \mathrm{~nm}$. However, process (3) has not been identified in previous photodissociation experiments. Thus, it may be concluded that the $\mathrm{H}_{2}+\mathrm{S}$ channel is of minor significance in the $193 \mathrm{~nm}$ photodissociation of $\mathrm{H}_{2} \mathrm{~S}$.

Using the $2+1$ resonance-enhanced-multiphoton-ionization (REMPI) scheme to detect $S\left({ }^{3} \mathrm{P}_{\mathrm{J}}, \mathrm{D}_{2}\right),{ }^{21}$ we have recently examined the $193 \mathrm{~nm}$ photodissociation of the $\mathrm{CH}_{3} \mathrm{~S}$ radical. ${ }^{22,23}$ By using the $\mathrm{S}^{+}$intensity from the $193 \mathrm{~nm}$ photodissociation of $\mathrm{CS}_{2}$ to calibrate the $\mathrm{S}^{+}$intensity from $\mathrm{CH}_{3} \mathrm{~S}$, we have estimated the absolute photodissociation cross section for $\mathrm{CH}_{3} \mathrm{~S}$ at $193 \mathrm{~nm}$. The absorption cross section for $\mathrm{CS}_{2}$ at $193 \mathrm{~nm}$ is known. ${ }^{24}$ The branching ratio $S\left({ }^{3} \mathrm{P}\right): S\left({ }^{1} D\right)$ and the fine-structure distribution $S\left({ }^{3} \mathrm{P}_{2}\right): S\left({ }^{3} \mathrm{P}_{1}\right): S\left({ }^{3} \mathrm{P}_{0}\right)$ resulting from the $193 \mathrm{~nm}$ photodissociation of $\mathrm{CS}_{2}$ have been determined previously in VUV laser-induced fluorescence ${ }^{25}$ and TOF mass spectrometric ${ }^{26}$ experiments. Here, we report the application of the $2+1$ REMPI scheme for detecting $S\left({ }^{3} \mathrm{P}_{2,1,0} ;{ }^{1} \mathrm{D}_{2}\right)$ formed by 
processes (2) and (3). By careful analysis of the $193 \mathrm{~nm}$ photodissociation laser power dependencies for the $S\left({ }^{3} \mathrm{P}_{2},{ }^{1} \mathrm{D}_{2}\right)$ formation from the $193 \mathrm{~nm}$ photolysis of $\mathrm{H}_{2} \mathrm{~S}$, we have determined the branching ratio $\mathrm{S}\left({ }^{3} \mathrm{P}\right): \mathrm{S}\left({ }^{1} \mathrm{D}\right)$ and the fine-structure distribution $\mathrm{S}\left({ }^{3} \mathrm{P}_{2}\right)$ : $\mathrm{S}\left({ }^{3} \mathrm{P}_{1}\right): \mathrm{S}\left({ }^{3} \mathrm{P}_{0}\right)$ for process (2) as well as those for process (3). 


\section{EXPERIMENTAL}

The schematic diagram of the experimental setup is shown in Fig. 1. A home-built TOF mass spectrometer of the two-stage Wiley-McLaren design (not shown here) is used to detect $\mathrm{S}^{+}$ions. The details of the experimental procedures have been described previously. ${ }^{22}$ Briefly, a pulsed molecular beam of neat $\mathrm{H}_{2} \mathrm{~S}$ is produced by supersonic expansion through a pulsed valve (nozzle diameter $=0.5 \mathrm{~mm}$, temperature $\approx 298 \mathrm{~K}$, stagnation pressure $\approx 125$ Torr). The molecular beam is skimmed by a conical skimmer and intersects with both the dissociation and ionization lasers $15.3 \mathrm{~cm}$ downstream from the pulsed nozzle. The molecular beam source chamber and the dissociation chambers are pumped by a $2000 \mathrm{\ell} / \mathrm{s}$ diffusion pump and a $50 \mathrm{\ell} / \mathrm{s}$ turbomolecular pump, respectively. For a pulsed valve repetition rate of $17 \mathrm{~Hz}$, the beam source and photodissociation chambers are maintained at pressures of $\approx 1 \times 10^{-4}$ and $2 \times 10^{-6}$ Torr, respectively.

The ArF photodissociation laser (Questek 2460) is operated in the constant pulse energy mode. The laser beam is attenuated by layers of stainless steel wire mesh and is spatially filtered by two irises before being focused by a fused-silica lens (200 mm f.1.) to an $\approx 2 \times 2 \mathrm{~mm}^{2}$ spot in the intersection region. The ArF laser energies used are in the range of 160 to $1000 \mu \mathrm{J} /$ pulse.

The ionization of $S\left({ }^{3} \mathrm{P}_{2,1,0} ;{ }^{1} \mathrm{D}_{2}\right)$ is accomplished with an excimer laser (Lambda Physik EMG 201 MSC) pumped dye laser (FL 3002) system. The pulse energy, typically $200 \mu \mathrm{J} / \mathrm{pulse}$, is monitored with a pyroelectric detector (Molectron J3-05). The dye laser beam propagates coaxially with the ArF laser beam into the reaction chamber and 
Figure 1. Schematic diagram of the experimental setup. 


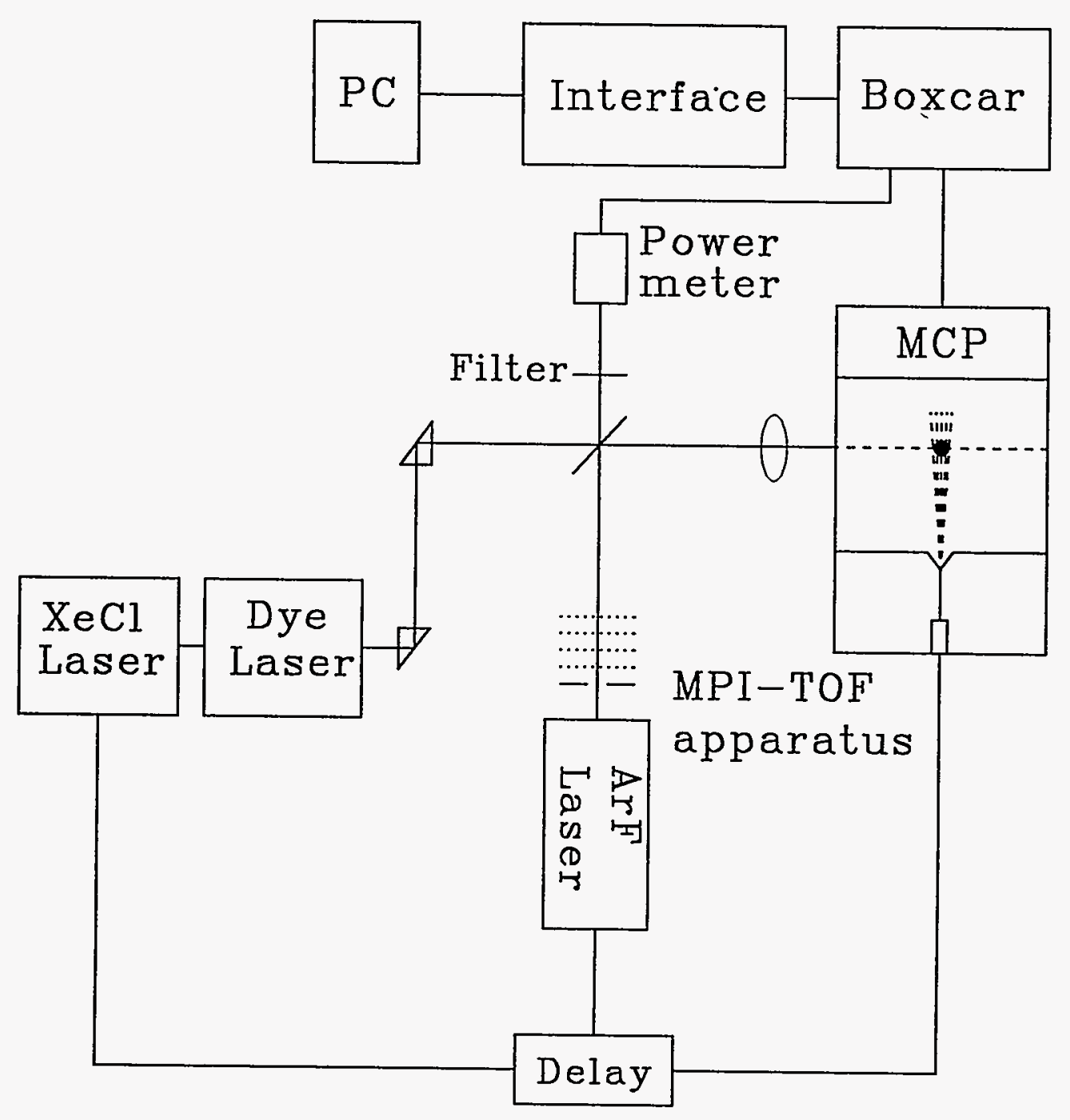


intersects with the molecular beam at $90^{\circ}$.

The firing of the dissociation excimer laser is delayed by $630 \mu \mathrm{s}$ with respect to the triggering pulse for opening the pulsed valve. The $\mathrm{S}^{+}$intensity remains nearly constant when the delay between the photodissociation and ionization lasers is varied in the range of 30-100 ns. Therefore, a delay of $50 \mathrm{~ns}$ between the two lasers is set for all the experiments. The firing sequence of the pulsed valve and the two lasers is controlled by two digital delay units (Stanford Research, Model DG 535). The ion signal from the microchannel plate (MCP) and the dye laser signal from the pyroelectric detector are fed into two identical boxcar integrators (Stanford Research, SR-250), which are interfaced to an IBM AT computer.

The $\mathrm{CS}_{2}$ sample (99\% purity) was obtained from Aldrich and the $\mathrm{H}_{2} \mathrm{~S}(\geq 99.6 \%$ purity) was obtained from Matheson.

\section{A. Detection of $S\left({ }^{3} P_{2,1,0}\right)$ and $S\left({ }^{1} D_{2}\right)$}

Probing of the $S\left(3^{3} \mathrm{P}_{\mathrm{J}}\right)$ and $\mathrm{S}\left(3^{1} \mathrm{D}_{2}\right)$ atomic states is accomplished by 2-photon absorption, $\mathrm{S}\left(3^{3} \mathrm{P}_{\mathrm{J}}\right) \rightarrow \mathrm{S}\left(4^{3} \mathrm{P}_{\mathrm{J}}\right)$ and $\mathrm{S}\left(3^{1} \mathrm{D}_{2}\right) \rightarrow \mathrm{S}\left(4^{1} \mathrm{~F}_{3}\right)$, followed by absorption of a third photon to produce $\mathrm{S}^{+}$in the ${ }^{4} \mathrm{~S}^{\circ}$ and ${ }^{2} \mathrm{D}^{\circ}$ states, respectively. The ionization peaks corresponding to the detection of $S\left({ }^{3} \mathrm{P}_{2,1,0}\right)$ and $S\left({ }^{1} \mathrm{D}_{2}\right)$ appear in the wavelength region of $308-311 \mathrm{~nm}$ and at $288.19 \mathrm{~nm}$, respectively.

The fine-structure distribution of $S\left(3^{3} \mathrm{P}_{2,1,0}\right)$ is measured by summation over the peak intensities corresponding to transitions to the upper $\mathrm{S}\left(4^{3} \mathrm{P}_{2,1,0}\right)$ fine-structure levels. ${ }^{27}$ The fine-structure distribution for $\left.\mathrm{S}^{3} \mathrm{P}_{2,1,0}\right)$ from the $193 \mathrm{~nm}$ photodissociation of $\mathrm{CS}_{2}$ determined here using the $2+1$ REMPI detection schemes is in excellent agreement with 
that obtained using the VUV laser-induced fluorescence technique. ${ }^{25}$

B. $S\left({ }^{3} \mathrm{P}\right) / \mathrm{S}\left({ }^{\mathrm{d} D}\right)$ branching ratio and absolute cross section for processes $(1)-(3)$

The rate equations applicable to processes (1), (2), and (3) are:

$$
\begin{aligned}
& \mathrm{d}\left[\mathrm{H}_{2} \mathrm{~S}\right] / \mathrm{dt}=-\mathrm{I}\left(\sigma_{1}+\sigma_{3}\right)\left[\mathrm{H}_{2} \mathrm{~S}\right] \\
& \mathrm{d}[\mathrm{HS}] / \mathrm{dt}=\mathrm{I} \sigma_{1}\left[\mathrm{H}_{2} \mathrm{~S}\right]-\mathrm{I} \sigma_{2}[\mathrm{HS}] \\
& \mathrm{d}[\mathrm{S}(2)] / \mathrm{dt}=\mathrm{I} \sigma_{2}[\mathrm{HS}] \\
& \mathrm{d}[\mathrm{S}(3)] / \mathrm{dt}=\mathrm{I} \sigma_{3}\left[\mathrm{H}_{2} \mathrm{~S}\right]
\end{aligned}
$$

Here, I is the ArF laser photon intensity [\# of photons $/\left(\mathrm{cm}^{2} \cdot \mathrm{sec}\right)$ ] and $\sigma_{1}, \sigma_{2}$, and $\sigma_{3}$ represent the absolute cross sections for processes (1), (2) and (3), respectively. For each laser pulse, the number densities for $\mathrm{H}_{2} \mathrm{~S}\left(\left[\mathrm{H}_{2} \mathrm{~S}\right]\right), \mathrm{HS}$ ([HS]), and $\mathrm{S}$ from process (2) ([S(2)]) and process (3) [S(3)] are related to $\sigma_{1}, \sigma_{2}, \sigma_{3}, \sigma_{\mathrm{t}}\left(=\sigma_{1}+\sigma_{3}\right)$, the laser flux (F) (\# of photons $/ \mathrm{cm}^{2}$ ), and the initial number density of $\mathrm{H}_{2} \mathrm{~S}\left(\left[\mathrm{H}_{2} \mathrm{~S}\right]_{0}\right)$ by the relations:

$$
\begin{aligned}
& {\left[\mathrm{H}_{2} \mathrm{~S}\right]=\left[\mathrm{H}_{2} \mathrm{~S}\right]_{0} \exp \left[-\left(\sigma_{t}\right) \mathrm{F}\right]} \\
& {[\mathrm{HS}]=\left[\mathrm{H}_{2} \mathrm{~S}\right]_{0}\left[\sigma_{1} /\left(\sigma_{\mathrm{t}}-\sigma_{2}\right)\right]\left[\exp \left(-\sigma_{2} \mathrm{~F}\right)-\exp \left(-\sigma_{\mathrm{t}} \mathrm{F}\right)\right],} \\
& {[\mathrm{S}(2)]=\left[\mathrm{H}_{2} \mathrm{~S}\right]_{0}\left[\sigma_{1} \sigma_{2} /\left(\sigma_{\mathrm{t}}-\sigma_{2}\right)\right]\left[-\left(1 / \sigma_{2}\right) \exp \left(-\sigma_{2} \mathrm{~F}\right)+\left(1 / \sigma_{t}\right) \exp \left(-\sigma_{\mathrm{t}} \mathrm{F}\right)+1 / \sigma_{2}-1 / \sigma_{\mathrm{J}}\right]} \\
& {[\mathrm{S}(3)]=\left[\mathrm{H}_{2} \mathrm{~S}\right]_{0}\left(\sigma_{3} / \sigma_{\imath}\right)\left[1-\exp \left(-\sigma_{\mathrm{t}} \mathrm{F}\right)\right] .}
\end{aligned}
$$

The $\mathrm{S}^{+}$signal resulting from the $2+1$ REMPI is directly proportional to the number density of $S$, and $\sigma_{1}$ is known to be $6.8 \times 10^{-18} \mathrm{~cm}^{2} .^{6,20}$ In order to determine the $S\left({ }^{3} \mathrm{P}\right) / \mathrm{S}\left({ }^{1} \mathrm{D}\right)$ 
branching ratio and the values for $\sigma_{2}$ and $\sigma_{3}$, the $\mathrm{CS}_{2}$ calibration experiment is performed immediately after the measurement of the $\mathrm{S}^{+}$from $\mathrm{H}_{2} \mathrm{~S}$.

In the estimation of the dissociation excimer laser flux, we assume that the mildly focused laser beam has a Gaussian beam profile. ${ }^{28}$ The photodissociation laser spot size has also been checked by examining the burn spots on thermal paper at various distances from the focusing lens. The variation of the laser beam spot size with distance from the focusing lens is consistent with that predicted by the Gaussian beam profile. In the photodissociation region the ionization laser beam spot is smaller than the photodissociation laser beam spot. 


\section{RESULTS}

The $\mathrm{S}^{+}$intensities (open circles) resulting from the REMPI of $S\left(\mathrm{P}_{2}\right)$ and $S\left({ }^{1} \mathrm{D}\right)$ formed by processes (1)-(3) are plotted as a function of the ArF photodissociation laser flux in Figs. 2(a) and 2(b), respectively. The slope for the $\mathrm{S}^{+}$intensity curve for $\left.\mathrm{S}^{3} \mathrm{P}_{2}\right)$ increases as $F$ is increased, while the $S^{+}$intensity curve for $S\left({ }^{1} D_{2}\right)$ shows a nearly linear dependency on $F$. The fraction of $S\left({ }^{3} \mathrm{P}\right)$ is found to increase from 0.6 to 0.8 as $F$ is increased in the range of $0.5-40 \times 10^{16}$ photons $/ \mathrm{cm}^{2}$. The different laser flux dependencies observed for $S\left({ }^{3} \mathrm{P}\right)$ and $\mathrm{S}\left({ }^{1} \mathrm{D}\right)$ indicate that $\mathrm{S}\left({ }^{3} \mathrm{P},{ }^{1} \mathrm{D}\right)$ atoms are produced by more than one process, and that the $S\left({ }^{3} \mathrm{P}\right): \mathrm{S}\left({ }^{1} \mathrm{D}\right)$ branching ratios due to these processes are different. We note that in the photodissociation experiment of $\mathrm{CH}_{3} \mathrm{~S}$, where $S\left({ }^{3} \mathrm{P}\right)$ and $\mathrm{S}\left({ }^{1} \mathrm{D}\right)$ are formed from $\mathrm{CH}_{3} \mathrm{~S}$, the $\mathrm{F}$ dependencies for $\mathrm{S}^{+}$due to $\mathrm{S}\left({ }^{3} \mathrm{P}_{2}\right)$ and $\mathrm{S}\left({ }^{1} \mathrm{D}_{2}\right)$ are found to be the same. ${ }^{21,22}$

The cross sections and the $S\left({ }^{3} P_{2}\right): S\left({ }^{1} D_{2}\right)$ branching ratios for processes (2) and (3) can be determined uniquely because process (3), which is linearly dependent on the photodissociation laser power, dominates at low $\mathrm{F}$ values, while process (2), which is proportional to the square of the photodissoication laser power, is expected to dominate at high $\mathrm{F}$ values. The simulations for the $\mathrm{S}^{+}$intensities due to ionization of $\left.\mathrm{S}^{3} \mathrm{P}_{2}\right)$ and $S\left({ }^{1} D_{2}\right)$ formed in processes (2) and (3) using Eqs. (10) and (11) are shown in Figs. 2(a) and $2(b)[\Delta$ for process (2) and $\nabla$ for process (3)]. The solid circles represent the sums of the contributions due to processes (2) and (3). The cross section values corresponding to the best fit are: $\sigma_{1}=6.5 \times 10^{-18} \mathrm{~cm}^{2}, \sigma_{2}=1.1 \times 10^{-18} \mathrm{~cm}^{2}$, and $\sigma_{3}=0.3 \times 10^{-18} \mathrm{~cm}^{2}$. The 
Figure 2. Photodissociation laser flux (\# photons $/ \mathrm{cm}^{2}$ ) dependence of $\mathrm{S}^{+}$signal due to the ionization of (a) $S\left({ }^{3} \mathrm{P}_{2}\right)$ and (b) $S\left({ }^{1} \mathrm{D}_{2}\right)$ formed by processes (2) $(\Delta)$ and $(3)(\nabla) .(O)$ experimental data; $(\bullet)$ best fits using Eqs. (11) and (12). 


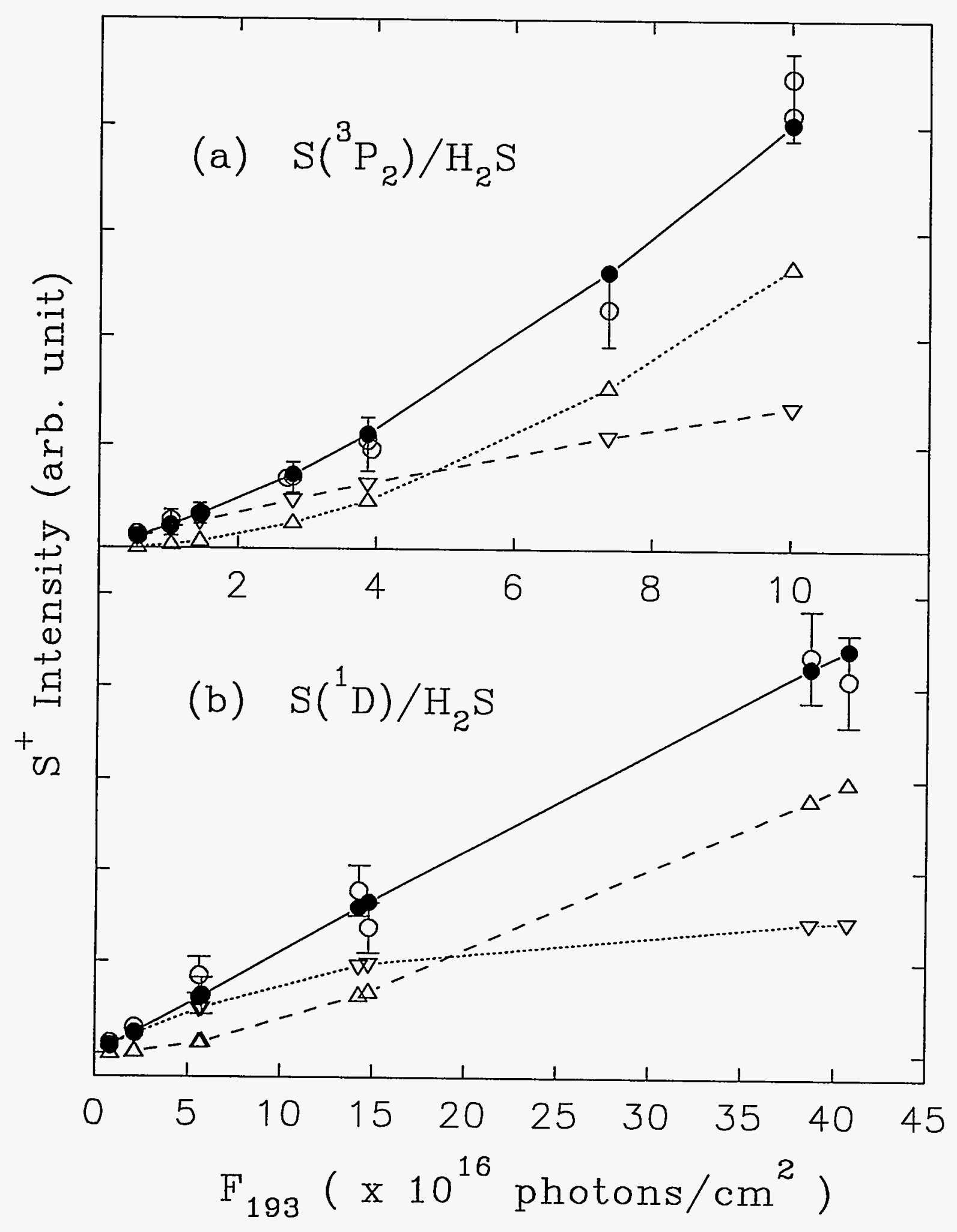


absorption cross section for $\mathrm{H}_{2} \mathrm{~S}\left(6.8 \times 10^{-18} \mathrm{~cm}^{2}\right)^{6,20}$ is assumed to be $\sigma_{\mathrm{t}}=\sigma_{1}+\sigma_{3}$. This assumption is supported by the VUV photoabsorption and fluorescence experiment. ${ }^{6}$ The $S\left({ }^{3} \mathrm{P}\right): S\left({ }^{1} \mathrm{D}\right)$ branching ratios for processes $(2)$ and $(3)$ are determined to be $0.87: 0.13$ and $0.6: 0.4$, respectively.

The determination of the $S(P): S\left({ }^{1} D\right)$ branching ratio from the $S\left({ }^{3} \mathrm{P}_{2}\right): S\left({ }^{1} D\right)$ ratio requires the values for the fine-structure distribution $S\left({ }^{3} \mathrm{P}_{2}\right): \mathrm{S}\left({ }^{3} \mathrm{P}_{1}\right): \mathrm{S}\left({ }^{3} \mathrm{P}_{0}\right)$. The finestructure distribution measured at $\mathrm{F}=10 \times 10^{16}$ photons $/ \mathrm{cm}^{2}$ is $\mathrm{S}\left({ }^{3} \mathrm{P}_{2}\right): \mathrm{S}\left({ }^{3} \mathrm{P}_{1}\right): \mathrm{S}\left({ }^{3} \mathrm{P}_{0}\right)=$ $0.68 \pm 0.03: 0.24 \pm 0.03: 0.08 \pm 0.03$. However, since the $S^{+}$signal due to $S\left({ }^{3} P_{0}\right)$ is small, the population of $S\left({ }^{3} \mathrm{P}_{0}\right)$ relative to $S\left({ }^{3} \mathrm{P}_{2}\right)$ cannot be determined accurately at low $\mathrm{F}$ values. Based on this observation, we assume that the fine-structure distributions for both processes (2) and (3) are equal to that measured at $\mathrm{F}=10 \times 10^{16}$ photons $/ \mathrm{cm}^{2}$. Because the populations of $S\left({ }^{3} P_{2,1}\right)$ are overwhelmingly greater than that of $S\left({ }^{3} P_{0}\right)$, the finestructure distribution used has a very minor effect on the values reported here for the $S\left({ }^{3} \mathrm{P}\right): S\left({ }^{1} \mathrm{D}\right)$ branching ratios of $S\left({ }^{3} \mathrm{P},{ }^{1} \mathrm{D}\right)$ formed in processes (2) and (3). 


\section{DISCUSSION}

In order to gain some insight about the photodissociation process of HS, we show in Fig. 3 the $a b$ initio potential energy curves calculated by Bruna and Hirsch ${ }^{17}$ as a function of the H-S distance $[r(\mathrm{H}-\mathrm{S})]$ in atomic units $\left(\mathrm{Bohr}\right.$ radius $\left.=\mathrm{a}_{\mathrm{o}}\right)$. The $\operatorname{HS}\left({ }^{2} \Sigma\right)$ and HS $\left({ }^{2} \Delta\right)$ potential curves are repulsive and correlate asymptotically with the formation of $\mathrm{S}\left({ }^{3} \mathrm{P}\right)+\mathrm{H}\left({ }^{2} \mathrm{~S}\right)$ and $\mathrm{S}\left({ }^{1} \mathrm{D}\right)+\mathrm{H}\left({ }^{2} \mathrm{~S}\right)$, respectively. The ab initio calculation of Bruna and Hirsch does not report the oscillator strengths for transitions from the ground $\operatorname{HS}\left(X^{2} \Pi\right)$ state to the $\operatorname{HS}\left(\mathrm{A}^{2} \Sigma^{+},{ }^{2} \Sigma^{-},{ }^{2} \Delta\right)$ states. In order to obtain estimates for these oscillator strengths, we have performed MCSCF calculations on HS using the GAMESS program. ${ }^{28}$ In this calculation, the standard 6-31G** basis set with extended Rydberg functions is used to properly describe the excited states of HS. The MCSCF calculations predict that the vertical transition energies for $\operatorname{HS}(\mathrm{X})$ to $\operatorname{HS}(\mathrm{A}), \operatorname{HS}\left({ }^{2}{ }^{-}\right)$, and $H S\left({ }^{2} \Delta\right)$ are 4.17, 5.99, and $7.05 \mathrm{eV}$, in good agreement with the values of $4.05,6.19$, and $7.05 \mathrm{eV}$, respectively, obtained by Bruna and Hirsch. The corresponding oscillator strengths for these transitions are predicted by the MCSCF calculations to be $0.0025,0.0496$, and 0.0167 .

The branching ratio $S\left({ }^{3} \mathrm{P}\right): S\left({ }^{1} \mathrm{D}\right)=0.87: 0.13$ determined here for process (2) is in qualitative agreement with the value of $3: 1$ deduced from the H-atom TOF mass spectrometric study. ${ }^{5}$ If the $193 \mathrm{~nm}$ photodissociation of $\mathrm{HS}(\mathrm{X}, \mathrm{v})$ is direct via the repulsive $\mathrm{HS}\left({ }^{2}{ }^{-2}, \Delta\right)$ states, as suggested in Ref. $5,^{5}$ the branching ratio $\mathrm{S}\left({ }^{3} \mathrm{P}\right): \mathrm{S}\left({ }^{1} \mathrm{D}\right)$ for process

(2) should reflect the relative vibrational population of $\mathrm{HS}\left(\mathrm{X}^{2} \mathrm{I}\right)$ initially formed by process

(1). The literature values for the relative vibrational populations for $\operatorname{HS}(\mathrm{X}, \mathrm{v})$ formed in 
Figure 3. Ab initio potential energy curves for HS plotted as a function of the H-S bond distance $[r(H-S)]$ in atomic units (Bohr radius $=a_{0}$ ). Taken from Ref. 17. 


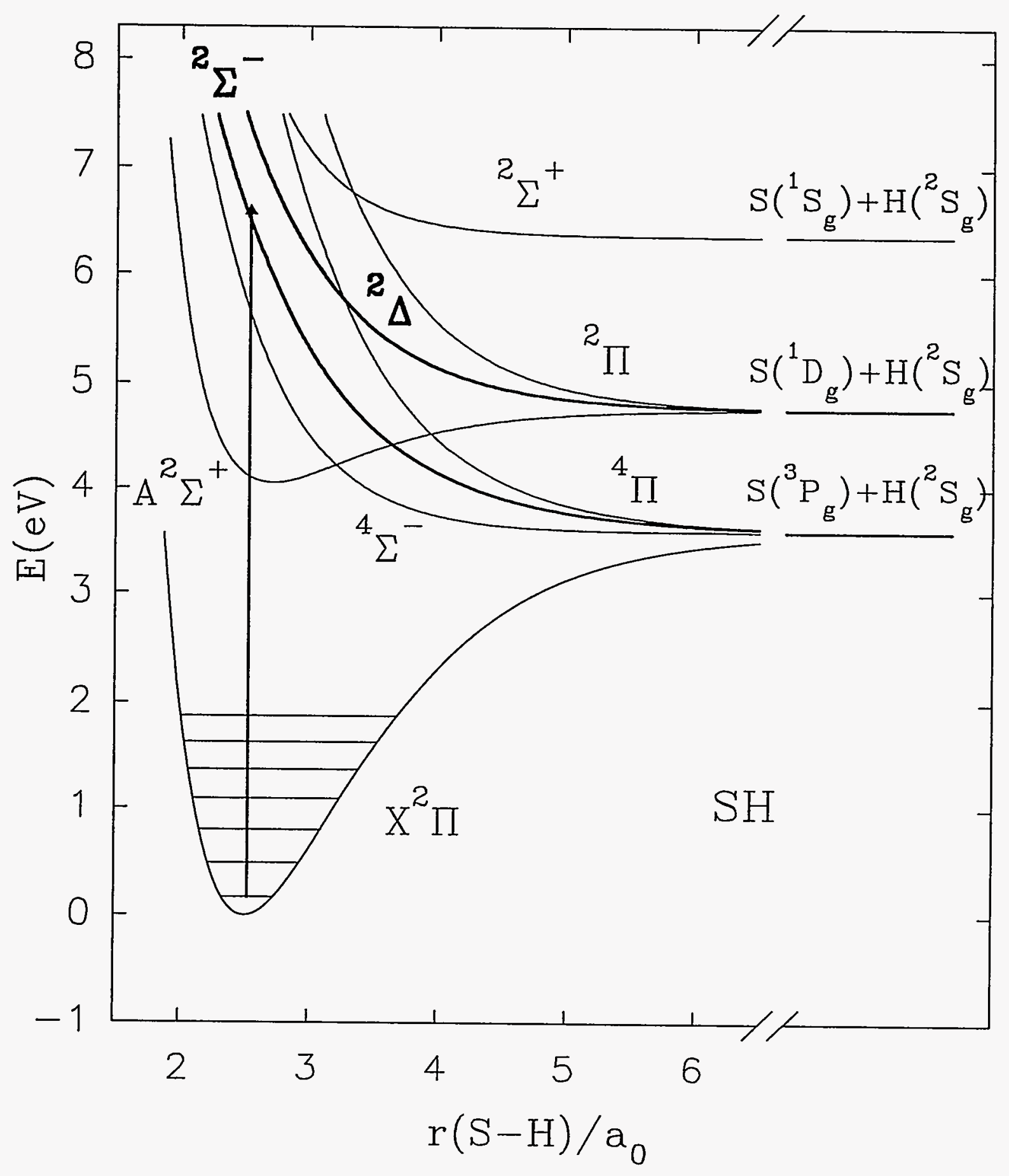


process (1) have been examined and compared by Continetti et al. ${ }^{5}$ They find that the HTOF mass spectrometric results ${ }^{2,5}$ agree within experimental uncertainties. Since the HTOF $^{4}$ and the velocity-aligned Doppler shift ${ }^{3}$ experiments are possibly complicated by a slow $\mathrm{H}$ signal, we quote here the relative populations, $(\mathrm{v}=0):(\mathrm{v}=1):(\mathrm{v}=2):(\mathrm{v}=3)$ : $(v=4):(v=5):(v=6)=0.728: 0.056: 0.051: 0.037: 0.040: 0.018: 0.001$ determined by the H-TOF mass spectrometric experiment of Continetti et al. ${ }^{5}$ According to the potential energy surfaces shown in Fig. $3, \operatorname{HS}(\mathrm{X}, \mathrm{v}=0)$ can only be excited to $\operatorname{HS}^{2}{ }^{2} \Sigma$ ) by the absorption of a 193nm photon, the dissociation of which leads to the formation of $S\left({ }^{3} \mathrm{P}\right)$. The $193 \mathrm{~nm}$ photoexcitation of $H S(X, v \geq 1)$ can populate both the $H S\left({ }^{2}\right)$ and HS $\left({ }^{2} \Delta\right)$ states. However, because of the favorable oscillator strength for the $\operatorname{HS}(X) \rightarrow$ HS $\left({ }^{2} \Sigma\right)$ transition, the population of $\operatorname{HS}\left({ }^{2} \Sigma^{-}\right)$from $\mathrm{HS}(\mathrm{X}, \mathrm{v} \geq 1)$ by $193 \mathrm{~nm}$ photoexcitation should also be significant, favoring the formation of $\mathrm{S}\left({ }^{3} \mathrm{P}\right)$. Therefore, the high $\mathrm{S}\left({ }^{3} \mathrm{P}\right) / \mathrm{S}\left({ }^{1} \mathrm{D}\right)$ ratio observed for process $(2)$ can be attributed to the vibrational distribution of $\operatorname{HS}(\mathrm{X})$ formed in process (1) and the favorable oscillator strength for the $\operatorname{HS}(\mathrm{X}) \rightarrow$ $\operatorname{HS}\left({ }^{2} \Sigma^{-}\right)$transition.

Based on the energetic consideration, $\mathrm{HS}(\mathrm{X}, \mathrm{v} \geq 2)$ can be excited by the absorption of a $193 \mathrm{~nm}$ photon to the repulsive $\mathrm{HS}\left({ }^{2} \Sigma^{+}\right)$state, which asymptotically correlates with $S\left({ }^{1} S\right)+H\left({ }^{2} S\right)$. We have searched for $S\left({ }^{1} S\right)$ using the REMPI detection scheme. The $S^{+}$ signal due to $S\left({ }^{1} S\right)$ is not found, within the sensitivity of our experiment, indicating that a negligible intensity of $S\left({ }^{1} S\right)$ atoms is formed by process (2). The excitation from $\mathrm{HS}(\mathrm{X}, \mathrm{v})$ to $\mathrm{HS}(\mathrm{A})$ should be negligible except at $\mathrm{v} \geq 4$.

The fine-structure distribution $S\left({ }^{3} \mathrm{P}_{2}\right): \mathrm{S}\left({ }^{\beta} \mathrm{P}_{1}\right): S\left({ }^{3} \mathrm{P}_{0}\right)=0.68 \pm 0.03: 0.24 \pm 0.03$ 
: $0.08 \pm 0.03$ measured for process (2) is colder than the statistical distribution of 0.56 : $0.33: 0.11$. The experimental distribution may have a finite contribution from process (3). However, since the distribution is measured at a high $\mathrm{F}$ value, at which process (2) dominates, we may conclude that the experimental distribution represents mostly the finestructure distribution for process (2). In a theoretical photodissociation study, Freed and co-workers show that photodissociation may proceed in two limiting cases,$^{30}$ depending on the relative available kinetic energy of the dissociation process. At low recoil energies, the fine-structure distribution is governed by the adiabatic potential surfaces and by the symmetry correlation. At the high energy limit, it is shown that a frame transformation will result in a statistical fine-structure distribution. According to the diagram ${ }^{31,32}$ correlating the projections $\Omega$ of the total electronic angular momentum vectors of the separated atoms along the internuclear axis with the corresponding $\Omega$ values for the electronic states of the molecule, the $\mathrm{HS}\left({ }^{2} \Sigma\right)$ state adiabatically correlates to $\mathrm{S}\left({ }^{3} \mathrm{P}_{1}\right)+$ $\left.\mathrm{H}^{2} \mathrm{~S}\right)$. Since the major product observed is $\mathrm{S}\left({ }^{3} \mathrm{P}_{2}\right)$, we may conclude that the photodissociation process (2) is not a case of the low recoil energy which is governed by the adiabatic correlation.

The available recoil kinetic energy of $22,585 \mathrm{~cm}^{-1}$ for the formation of $\mathrm{S}\left({ }^{3} \mathrm{P}\right)$ from process (2) is much higher than the spin-orbit splitting $\Delta \mathrm{E}_{\mathrm{so}}\left({ }^{3} \mathrm{P}_{2}-{ }^{3} \mathrm{P}_{1}\right)=396.93 \mathrm{~cm}^{-1}{ }^{21,22}$ The translational adiabaticity parameter for spin-orbit transition is given as: $\zeta_{\mathrm{t}}=\alpha \Delta \mathrm{E}_{\mathrm{so}} / \hbar v$, where $\alpha$ is the "range" of interatomic force and $v$ is the recoil velocity. For $\zeta_{1} \leq 1$, the spin-orbit transition becomes efficient. For the recoil velocity corresponding to the available kinetic energy and the typical range parameter ${ }^{31,33} \alpha \approx 1-2 \AA, \zeta_{\mathrm{t}}$ for this system 
is significantly less than one. Therefore, we expect that nonadiabatic transitions between spin-orbit levels of $S\left({ }^{3} \mathrm{P}_{\mathrm{J}}\right)$ are efficient during the dissociation via the $\operatorname{HS}\left({ }^{2} \Sigma\right)$ state. The fine structure distribution for $S\left({ }^{\beta} \mathrm{P}_{\mathrm{J}}\right.$ ) observed for process (2), although not statistical, may be close to the case of the high energy limit.

Process (3) was not observed in the H-atom TOF experiments of van Veen et al. ${ }^{2}$ and Continetti et al. ${ }^{6}$ In order to observe the secondary dissociation process (2), a high photodissociation laser power of $250 \mathrm{~mJ} /$ pulse was used in the experiment of Continetti et al. This, together with the small cross section for process $(3)\left(0.3 \times 10^{-18} \mathrm{~cm}^{2}\right)$ compared to that for process (1) $\left(6.5 \times 10^{-18} \mathrm{~cm}^{2}\right)$, may hinder the observation of process (3).

Due to the uncertainties involved in the calibration of the $\mathrm{S}^{+}$signals from $\mathrm{CS}_{2}$ and $\mathrm{H}_{2} \mathrm{~S}$, the absolute cross section $\sigma_{2}=1.1 \times 10^{-18} \mathrm{~cm}^{2}$ obtained here is considered a rough estimate. 


\section{CONCLUSION}

Using 2+1 REMPI detection schemes for $S\left({ }^{3} P_{2,1,0} ;{ }^{1} D_{2}\right)$, we have examined the $193 \mathrm{~nm}$ photodissociation of $\mathrm{HS}(\mathrm{X}, \mathrm{v})$ prepared by process $(1)$. The branching ratio $\mathrm{S}\left({ }^{3} \mathrm{P}\right)$ : $S\left({ }^{1} D\right)$ measured for process $(2)$ is consistent with the direct photodissociation mechanism for $\operatorname{HS}(\mathrm{X}, \mathrm{v})$ via the excited repulsive $\operatorname{HS}\left({ }^{2} \Sigma\right)$ and $\operatorname{HS}\left({ }^{2} \Delta\right)$ surfaces, as proposed by Continetti et al. ${ }^{5}$ This experiment has identified the formation of $S\left({ }^{3} \mathrm{P}_{\mathrm{J}},{ }^{1} \mathrm{D}_{2}\right)$ by the onephoton process (3). Process (3) is shown to be a minor channel compared to process (1). By calibrating the formation of $S\left({ }^{3} \mathrm{P}_{\mathrm{J}} ;{ }^{1} \mathrm{D}_{2}\right)$ atoms from $\mathrm{H}_{2} \mathrm{~S}$ to those from $\mathrm{CS}_{2}$, we have obtained estimates for the photodissociation cross sections of processes (2) and (3). 


\section{ACKNOWLEDGEMENT}

A Research Opportunity Award from NSF, which provided partial support for P.J.H.T. during his stay in Ames, is gratefully acknowledged. 


\section{REFERENCES}

(1) W. G. Hawkins and P. L. Houston, J. Phys. Chem. 73, 297 (1980).

(2) G. N. A. van Veen, K. A. Mohamed, T. Baller, and A. E. de Vries, Chem. Phys. 74, 261 (1983).

(3) Z. Xu, B. Koplitz, and C. Wittig, J. Chem. Phys. 즈, 1062 (1987).

(4) X. Xie, L. Schnieder, H. Wallmeier, R. Boettner, K. H. Welge, and M. N. R. Ashfold, J. Chem. Phys. 92, 1608 (1990).

(5) R. E. Continetti, B. A. Balko, and Y. T. Lee, Chem. Phys. Lett. 185, 400 (1991).

(6) L. C. Lee, X. Wang, and M. Suto, J. Chem. Phys. $\underline{86}, 4353$ (1987).

(7) M. D. Person, K. Q. Lao, B. J. Eckholm, and L. J. Butler, 91, 812 (1989).

(8) B. R. Weiner, H. B. Levene, J. J. Valentini, and A. P. Baronavski, J. Chem. Phys. 90, 1403 (1989).

(9) R. J. Brudzynski, R. J. Sension, and B. Hudson, Chem. Phys. Lett. 165, 487 (1990).

(10) J. Steadman and T. Baer, J. Chem. Phys. 모, 5507 (1988),

(11) J. Steadman and T. Baer, J. Chem. Phys. 91, 6113 (1989).

(12) K. Kleinermanns, E. Linnebach, and R. Suntz, J. Phys. chem. 91, 5543 (1987).

(13) B. Heumann, R. Duren, and R. Schinke, Chem. Phys. Lett. 180, 583 (1991).

(14) S.-K. Shih, S. D. Peyerimhoff, and R. J. Buenker, Chem. Phys. 17, 391 (1976).

(15) K. C. Kulander, Chem. Phys. Lett. 103, 373 (1984).

(16) K. Weide, V. Staemmler, and R. Schinke, J. Chem. Phys. 93, 861 (1990). 
(17) P. J. Bruna and G. Hirsch, Mol. Phys. 61, 1359 (1987).

(18) R. Roberge and O. R. Salahub, J. Chem. Phys. 70, 1177 (1979).

(19) S. Nourbakhsh, K. Norwood, H.-M. Yin, C.-L. Liao, and C. Y. Ng, J. Chem. Phys. 95, 946 (1991).

(20) J. G. Calvert and J. N. Pitts, Jr., Photochemistry (Wiley, New York, 1966).

(21) P. Brewer, van Veen, and R. Bershon, Chem. Phys. Lett. 91, 126 (1982); G. Black and Jusinski, J. Chem. Phys. $\underline{82}, 789$ (1985).

(22) C.-W. Hsu, C.-L. Liao, Z.-X. Ma, P. J. H. Tjossem, and C. Y. Ng, J. Chem. Phys., submitted.

(23) C.-W. Hsu, C.-L. Liao, and C. Y. Ng, SPIE Conference Proceedings, Optical Methods for Time- and State-Resolved Selective Chemistry, edited by C. Y. Ng, Vol. 1638 (1922), in press.

(24) V. R. McCrary, R. Lu, D. Zakheim, J. A. Russell, J. B. Halpern, and W. M. Jackson, J. Chem. Phys. 83, 3481 (1985); J. W. Rabalais, J. M. McDonald, V. Scherr, and S. P. McGlynn, Chem. Rev. 71, 73 (1971).

(25) I. M. Waller and W. J. Hepburn, J. Chem. Phys. ㅁ7, 3261 (1987).

(26) W.-B. Tzeng, H.-M. Yin, W.-Y. Leung, J.-Y. Luo, S, Nourbakhsh, G. D. Flesch, and C. Y. Ng, J. Chem. Phys. $\underline{88}, 1658$ (1988).

(27) D. J. Bamford, M. J. Dyer, and W. K. Bishel, Phys. Rev. A ㅁ6, 3497 (1987).

(28) A. Yariv, Quantum Electronics (Wiley, New York, 1975).

(29) M. W. Schmidt, K. K. Baldridge, J. A. Boatz, J. H. Jensen, S. Koseki, M. S. Gordon, K. A. Nguyen, T. L. Windus, and S. T. Elbert, QCPE Bulletin, 10, 52 
(1990).

(30) S. J. Singer, K. F. Freed, and Y. B. Band, J. Chem. Phys. $\underline{79}$, 6060 (1983).

(31) Y. L. Huang and R. J. Gordon, J. Chem. Phys. 94, 2640 (1991).

(32) G. Herzberg, Spectra of Diatomic Molecules (van Nostrand Reinhold, New York, 1950).

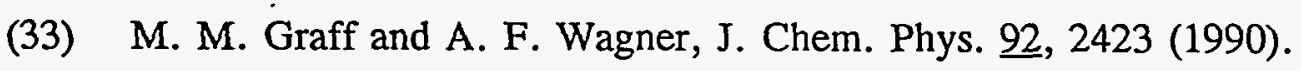


PAPER 3.

A STUDY OF $S\left({ }^{3} P_{2,1,0} ;{ }^{1} D_{2} ;{ }^{1} S_{0}\right)$ PRODUCTION IN THE $193 \mathrm{~nm}$ PHOTODISSOCIATION OF $\mathrm{CH}_{3} \mathrm{SH}$ 


\begin{abstract}
The dynamics of $\mathrm{S}\left({ }^{3} \mathrm{P}_{2,1,0} ;{ }^{1} \mathrm{D}_{2} ;{ }^{1} \mathrm{~S}_{0}\right)$ production from the $193 \mathrm{~nm}$ photodissociation of $\mathrm{CH}_{3} \mathrm{SH}$ has been examined by $2+1$ resonance-enhanced-multiphoton-ionization (REMPI) techniques. Using the rate equation scheme, we have rationalized the intensities of $S\left({ }^{3} \mathrm{P}_{2,1,0} ;{ }^{1} \mathrm{D}_{2} ;{ }^{1} \mathrm{~S}_{0}\right)$ observed according to the sequential two-photon dissociative pathways, (A): $\mathrm{CH}_{3} \mathrm{SH}+\mathrm{h} \nu(193 \mathrm{~nm}) \rightarrow \mathrm{CH}_{3} \mathrm{~S}+\mathrm{h} \nu(193 \mathrm{~nm}) \rightarrow \mathrm{S}$ and $(\mathrm{B}): \mathrm{CH}_{3} \mathrm{SH}+$ $\mathrm{h} \nu(193 \mathrm{~nm}) \rightarrow \mathrm{HS}+\mathrm{h} \nu(193 \mathrm{~nm}) \rightarrow \mathrm{S}$, as the major mechanisms for $\mathrm{S}$ production. We have satisfactorily fitted the photodissociation laser power dependencies for $S\left({ }^{3} \mathrm{P}\right)$ and $\mathrm{S}\left({ }^{1} \mathrm{D}\right)$ produced from $\mathrm{CH}_{3} \mathrm{SH}$ by invoking photodissociation cross sections and branching ratios $\mathrm{S}\left({ }^{3} \mathrm{P}\right) / \mathrm{S}\left({ }^{1} \mathrm{D}\right)$ for $\mathrm{CH}_{3} \mathrm{~S}$ and $\mathrm{HS}$ similar to those determined previously in the $193 \mathrm{~nm}$ photodissociation of $\mathrm{CH}_{3} \mathrm{SCH}_{3}$ and $\mathrm{H}_{2} \mathrm{~S}$. This observation supports that the $193 \mathrm{~nm}$ photodissociation of $\mathrm{CH}_{3} \mathrm{~S}$ and $\mathrm{HS}$ prepared from $\mathrm{CH}_{3} \mathrm{SH}$ yield predominantly $\mathrm{S}\left({ }^{1} \mathrm{D}\right)$ and $\mathrm{S}\left({ }^{3} \mathrm{P}\right)$, similar to the cases for $\mathrm{CH}_{3} \mathrm{~S}$ prepared from $\mathrm{CH}_{3} \mathrm{SCH}_{3}$ and for $\mathrm{HS}$ prepared from $\mathrm{H}_{2} \mathrm{~S}$, respectively. A small amount of $\mathrm{S}\left({ }^{1} \mathrm{~S}_{0}\right)$ observed from the $193 \mathrm{~nm}$ photodissociation of $\mathrm{CH}_{3} \mathrm{SH}$ is attributed to pathway (B).
\end{abstract}




\section{INTRODUCTION}

Knowledge about the formation of radical species from solar ultraviolet (UV) and vacuum ultraviolet (VUV) photolysis of organosulfur compounds, and about the subsequent photochemistry involving these radical species, is relevant to the modeling of atmospheric sulfur chemistry. ${ }^{1}$ The previous experimental and theoretical studies of the UV and VUV photochemistry of $\mathrm{CH}_{3} \mathrm{SH}$ have focussed on the primary photodissociation of $\mathrm{CH}_{3} \mathrm{SH}$ according to the single-photon processes (1) and (2)..$^{2-9}$

$$
\begin{array}{ll}
\mathrm{CH}_{3} \mathrm{SH}+\mathrm{h} \nu & \stackrel{\sigma_{1}}{\rightarrow} \mathrm{CH}_{3} \mathrm{~S}+\mathrm{H} \\
& \stackrel{\sigma_{2}}{\rightarrow} \mathrm{HS}+\mathrm{CH}_{3}
\end{array}
$$

Detailed examination has not been made on the subsequent photodissociation of product $\mathrm{CH}_{3} \mathrm{~S}$ and $\mathrm{HS}$ [processes (3) and (4)] initially formed by processes (1) and (2), respectively.

$$
\begin{aligned}
& \mathrm{CH}_{3} \mathrm{~S}+\mathrm{h} \nu \stackrel{\sigma_{3}}{\rightarrow} \mathrm{CH}_{3}+\mathrm{S} \\
& \mathrm{SH}+\mathrm{h} \nu \stackrel{\sigma_{4}}{\rightarrow} \mathrm{H}+\mathrm{S}
\end{aligned}
$$

The dominance of process (1) over process (2) has been suggested in the UV and VUV flash photolysis of $\mathrm{CH}_{3} \mathrm{SH}$. The relative degree of S-H to C-S bond cleavage in the photodissociation of $\mathrm{CH}_{3} \mathrm{SH}$ has been estimated to be 3:1 at $214 \mathrm{~nm},{ }^{3}$ 0.63:0.37 at 195 
$\mathrm{nm},{ }^{2}$ and $0.79: 0.21$ at $185 \mathrm{~nm}^{4}$. At $193 \mathrm{~nm}$, the exothermicity at $0 \mathrm{~K}$ for processes (1) is $-62 \mathrm{kcal} / \mathrm{mol}$, while that for process (2) is $-75.4 \mathrm{kcal} / \mathrm{mol} .^{9}$ Based on the kinetic energy release measurement in the $193 \mathrm{~nm}$ photodissociation of $\mathrm{CH}_{3} \mathrm{SH},{ }^{7,8}$ the most probable internal energy for photo-fragments of process (2) corresponds to $\approx 30 \%$ of the available energy. According to the time-of-flight (TOF) spectrum of $\mathrm{CH}_{3} \mathrm{~S}$ measured by Kelly et al., ${ }^{8}$ the kinetic energy release for process (1) is peaked at $\approx 56 \mathrm{kcal} / \mathrm{mol}$, indicating that the most probable internal excitation of $\mathrm{CH}_{3} \mathrm{~S}$ is $\approx 6 \mathrm{kcal} / \mathrm{mol}$, about $10 \%$ of the available energy. This observation is consistent with the conclusion that the formation of $\mathrm{CH}_{3} \mathrm{~S}$ and $\mathrm{H}$ by process (1) at $193 \mathrm{~nm}$ involves the direct recoil of fragments on a repulsive energy surface. The recent $a b$ initio calculation of the adiabatic electronic states by Mauflih et al. ${ }^{6}$ has shown that the $\mathrm{CH}_{3} \mathrm{SH}\left(2^{1} \mathrm{~A}^{\prime \prime}\right)$ potential energy surface accessed by a $193 \mathrm{~nm}$ excitation is bound in the S-H coordinate. Nevertheless, the observation of efficient S-H bond cleavage may be attributed to a strong coupling between the bound $\mathrm{CH}_{3} \mathrm{SH}\left(2^{1} \mathrm{~A}\right.$ ") state and the dissociative $\mathrm{CH}_{3} \mathrm{SH}\left(1^{1} \mathrm{~A}^{\prime \prime}\right)$ state. ${ }^{8}$

The kinetic energy distribution observed for $S$ in the $193 \mathrm{~nm}$ photodissociation TOF mass spectrometric study of $\mathrm{CH}_{3} \mathrm{SH}$ by Nourbakhsh et al. ${ }^{7}$ suggests that HS initially formed by process (2) may further dissociate by absorbing a second $193 \mathrm{~nm}$ photon according to process (4). The further photodissociation of HS has also been observed in the $193 \mathrm{~nm}$ photodissociation TOF mass spectrometric studies of $\mathrm{H}_{2} \mathrm{~S}$. The results of these studies suggest that $\mathrm{S}$ atoms produced by process (4) are predominantly in the $\mathrm{S}\left({ }^{3} \mathrm{P}\right)$ ground state. ${ }^{711}$ Similarly, $193 \mathrm{~nm}$ photodissociation studies of $\mathrm{CH}_{3} \mathrm{SCH}_{3}$ (Ref. 12) and 
$\mathrm{CH}_{3} \mathrm{SSCH}_{3}$ (Ref. 13) reveal that the primary $\mathrm{SCH}_{3}$ fragments may dissociate by the absorption of a second photon to produce $S$ predominantly in the excited $S\left({ }^{l} D\right)$ state.

Direct measurements of the nascent electronic state distribution of $S\left({ }^{3} \mathrm{P}_{2,1,0} ;{ }^{1} \mathrm{D}_{2}\right)$ resulting from the $193 \mathrm{~nm}$ photodissociation of $\mathrm{CH}_{3} \mathrm{SCH}_{3}$ and $\mathrm{H}_{2} \mathrm{~S}$ have been made recently in our laboratory using $2+1$ resonance-enhanced-multiphoton-ionization (REMPI) detection techniques. ${ }^{10,14}$ By calibrating the $S^{+}$intensities due to $S\left({ }^{3} \mathrm{P}_{2,1,0} ;{ }^{1} \mathrm{D}_{2}\right)$ formed from $\mathrm{CH}_{3} \mathrm{SCH}_{3}$ and $\mathrm{H}_{2} \mathrm{~S}$ at $193 \mathrm{~nm}$ to those from $\mathrm{CS}_{2}$ [process (5)], we obtain estimates of $\approx 1.0 \times 10^{-18} \mathrm{~cm}^{2}$ and $1.1 \times 10^{-18} \mathrm{~cm}^{2}$ for the absolute photodissociation cross sections for processes (3) and (4) at $193 \mathrm{~nm}$, respectively.

$\mathrm{CS}_{2}+\mathrm{h} \nu(193 \mathrm{~nm}) \rightarrow \mathrm{CS}+\mathrm{S}\left({ }^{3} \mathrm{P}_{2,1,0} ; \mathrm{D}_{2}\right)$

The absolute cross section for process (5) is known; and the branching ratio for $S\left({ }^{3} \mathrm{P}\right) / \mathrm{S}\left({ }^{1} \mathrm{D}\right)(=2.78)$ and the fine structure distribution of $\left.\mathrm{S}^{\beta} \mathrm{P}_{2,1,0}\right)$ formed by process (5) has been measured in detail by VUV laser-induced fluorescence ${ }^{15}$ and TOF mass spectrometric methods. ${ }^{16}$ The branching ratio $S\left({ }^{3} \mathrm{P}\right) / \mathrm{S}\left({ }^{1} \mathrm{D}\right)$ determined for process (3) is $0.15 / 0.85$, while that for process (4) is $0.87 / 0.13$. We note that the detailed photodissociation dynamics of $\mathrm{CH}_{3} \mathrm{~S}$ and $\mathrm{HS}$ depend on their internal excitations and thus these cross sections and branching ratios are characteristic of $\mathrm{CH}_{3} \mathrm{~S}$ and HS prepared in the $193 \mathrm{~nm}$ photodissociation of $\mathrm{CH}_{3} \mathrm{SCH}_{3}$ and $\mathrm{H}_{2} \mathrm{~S}$.

We have extended our investigation of the $S\left({ }^{3} \mathrm{P}_{2,1,0} ;{ }^{1} \mathrm{D}_{2} ;{ }^{1} \mathrm{~S}_{0}\right)$ production from the $193 \mathrm{~nm}$ photodissociation of $\mathrm{CH}_{3} \mathrm{SH}$ using the $2+1$ REMPI detection method. In this 
article, we analyze the production of $\mathrm{S}$ atoms from the photodissociation of $\mathrm{CH}_{3} \mathrm{SH}$ at 193 $\mathrm{nm}$ according to the stepwise two-photon pathways, (A): $\mathrm{CH}_{3} \mathrm{SH}+\mathrm{h} \nu(193 \mathrm{~nm}) \rightarrow \mathrm{CH}_{3} \mathrm{~S}$ $+\mathrm{h} \nu(193 \mathrm{~nm}) \rightarrow \mathrm{S}$ and $(\mathrm{B}): \mathrm{CH}_{3} \mathrm{SH}+\mathrm{h} \nu(193 \mathrm{~nm}) \rightarrow \mathrm{HS}+\mathrm{h} \nu(193 \mathrm{~nm}) \rightarrow \mathrm{S}$, which are comprised of processes (1) and (3) and processes (2) and (4), respectively. Considering that the energetics for the formation of $\mathrm{CH}_{3} \mathrm{~S}$ and $\mathrm{HS}$ from the $193 \mathrm{~nm}$ photodissociation of $\mathrm{CH}_{3} \mathrm{SH}$ are similar to the formation of $\mathrm{CH}_{3} \mathrm{~S}$ from $\mathrm{CH}_{3} \mathrm{SCH}_{3}$ and the formation of $\mathrm{HS}$ from $\mathrm{H}_{2} \mathrm{~S}$, respectively, ${ }^{9,17}$ we expect that the knowledge gained in previous studies about the photodissociation dynamics of $\mathrm{CH}_{3} \mathrm{~S}$ prepared from $\mathrm{CH}_{3} \mathrm{SCH}_{3}$ and of $\mathrm{HS}$ prepared from $\mathrm{H}_{2} \mathrm{~S}$ is useful for the data analysis of the $S\left({ }^{3} \mathrm{P}_{2,1,0} ;{ }^{1} \mathrm{D}_{2}\right)$ production in the photodissociation of $\mathrm{CH}_{3} \mathrm{SH}$.

Based on the measurement of the photodissociation laser power dependence for the $\mathrm{S}\left({ }^{3} \mathrm{P}\right) / \mathrm{S}\left({ }^{1} \mathrm{D}\right)$ branching ratio, we have also considered the single-photon photodissociation process (6) as a possible channel for the $\mathrm{S}$ production from $\mathrm{CH}_{3} \mathrm{SH}$.

$$
\mathrm{CH}_{3} \mathrm{SH}+\mathrm{h} \nu(193 \mathrm{~nm}) \stackrel{\sigma_{5}}{\rightarrow} \mathrm{CH}_{4}+\mathrm{S}
$$




\section{EXPERIMENTAL}

The experimental setup and procedures have been described in detail. ${ }^{10,14}$ A homebuilt TOF spectrometer of the two-stage Wiley-McLaren design is used to detect $\mathrm{S}^{+}$ions. Briefly, a pulsed molecular beam of neat $\mathrm{CH}_{3} \mathrm{SH}$ is produced by supersonic expansion through a pulsed valve (nozzle diameter $=0.5 \mathrm{~mm}$, temperature $\approx 298^{\circ} \mathrm{K}$, stagnation pressure $=120$ torr). The molecular beam is skimmed by a conical skimmer before intersecting with both the photodissociation and ionization lasers $8.3 \mathrm{~cm}$ downstream from the skimmer. The molecular beam source chamber and the photodissociation chamber are differentially pumped by a diffusion pump and a turbomolecular pump, respectively. For the pulse valve operating at a repetition rate of $17 \mathrm{~Hz}$, the beam source chamber and the photodissociation chamber are maintained at pressures of $\approx 1 \times 10^{-4}$ and $2 \times 10^{-6}$ Torr, respectively.

The ArF photodissociation laser (Questek 2460) is operated in a constant pulse energy mode. The laser beam is attenuated by layers of stainless steel wire mesh and is

spatially filtered by two irises before being focused by a fused-silica lens (200 mm f.1.) to a spot of $\approx 2 \times 2 \mathrm{~mm}^{2}$ in the interaction region. The ArF laser energies used are in the range of $100-1000 \mu \mathrm{J} /$ pulse.

The ionization of $S\left({ }^{3} \mathrm{P}_{2,1,0} ;{ }^{1} \mathrm{D}_{2} ;{ }^{1} \mathrm{~S}_{0}\right)$ is accomplished with an excimer laser (Lambda Physik EMG 201 MSC) pumped dye laser (Lambda Physik FL3002) system. The pulse energy, typically $\approx 200 \mu \mathrm{J} /$ pulse, is monitored with a pyroelectric detector (Molectron J3- 
05). The dye laser beam propagates coaxially with the ArF laser beam into the reaction chamber and intersects with the molecular beam at $90^{\circ}$.

The firing of the photodissociation laser is delayed by $640 \mu \mathrm{s}$ with respect to the trigger pulse for opening the pulsed valve. A delay of $50 \mathrm{~ns}$ between the photodissociation and ionization lasers is set throughout all the experiments. The firing sequence of the pulsed valve and the two lasers is controlled by two digital delay units (Stanford Research, DG 535). The ion signal from the microchannel plate detector and the dye laser signal from the pyroelectric detector are fed into two identical boxcar integrators (Stanford Research, SR250), which are interfaced to an IBM AT computer.

The $\mathrm{CS}_{2}$ sample (Aldrich, $99 \%$ purity) is degassed by a series of freeze-pump-thaw cycles. The $\mathrm{CH}_{3} \mathrm{SH}$ (Matheson, $99 \%$ purity) is used without further purification.

\section{A. Detection of $S\left({ }^{3} \mathbf{P}_{2,1,0}\right), S\left({ }^{1} D_{2}\right)$, and $S\left({ }^{1} S_{0}\right)$}

Probing of $S\left(3^{3} \mathrm{P}_{\mathrm{J}}\right), \mathrm{S}\left(3^{1} \mathrm{D}_{2}\right)$ and $\mathrm{S}\left(3^{1} \mathrm{~S}_{0}\right)$ atomic states is accomplished by two-photon absorption $\mathrm{S}\left(3^{3} \mathrm{P}_{\mathrm{J}}\right) \rightarrow \mathrm{S}\left(4^{3} \mathrm{P}_{\mathrm{J}}\right), \mathrm{S}\left(3^{1} \mathrm{D}_{2}\right) \rightarrow \mathrm{S}\left(4^{1} \mathrm{~F}_{3}\right)$, and $\mathrm{S}\left(3^{1} \mathrm{~S}_{0}\right) \rightarrow \mathrm{S}\left(4^{1} \mathrm{D}_{2}\right)$, followed by absorption of a third photon to produce $\mathrm{S}^{+}$ion in the ${ }^{4} \mathrm{~S}^{0},{ }^{2} \mathrm{D}^{0}$, and ${ }^{2} \mathrm{P}^{0}$ states, respectively. ${ }^{10,14,18-21}$ The $S^{+}$peaks corresponding to the ionization of $S\left({ }^{3} \mathrm{P}_{2,1,0}\right), S\left({ }^{1} \mathrm{D}_{2}\right)$, and $S\left({ }^{1} S_{0}\right)$ appear at the respective wavelength regions of $308-311,288.19$, and $299.575 \mathrm{~nm}^{21}$

The fine-structure distribution of $S\left(3^{3} \mathrm{P}_{2,1,0}\right)$ is measured by summation over the peak intensities corresponding to transitions to the upper $\mathrm{S}\left(4^{3} \mathrm{P}_{2,1,0}\right)$ fine-structure levels. ${ }^{22}$ The fine-structure distribution for $\mathrm{S}\left({ }^{3} \mathrm{P}_{2,1,0}\right)$ formed in the $193 \mathrm{~nm}$ photodissociation of $\mathrm{CS}_{2}$ is determined here using $2+1$ REMPI detection schemes and is in excellent agreement with that obtained using the VUV laser-induced fluorescence technique. ${ }^{15}$ 
B. $S\left({ }^{3} \mathrm{P}\right) / \mathrm{S}\left({ }^{1} \mathrm{D}\right)$.branching ratio and absolute cross section for processes (1)-(4) and (6) The rate equations applicable to $\mathrm{CH}_{3} \mathrm{SH}, \mathrm{CH}_{3} \mathrm{~S}, \mathrm{HS}$, and $\mathrm{S}$ according to processes (1)-(4) and (6) are:

$$
\begin{aligned}
& \mathrm{d}\left[\mathrm{CH}_{3} \mathrm{SH}\right] / \mathrm{dt}=-\mathrm{I} \sigma_{\mathrm{t}}\left[\mathrm{CH}_{3} \mathrm{SH}\right], \\
& \mathrm{d}\left[\mathrm{CH}_{3} \mathrm{~S}\right] / \mathrm{dt}=\mathrm{I} \sigma_{1}\left[\mathrm{CH}_{3} \mathrm{SH}\right]-\mathrm{I} \sigma_{3}\left[\mathrm{CH}_{3} \mathrm{~S}\right], \\
& \mathrm{d}[\mathrm{HS}] / \mathrm{dt}=\mathrm{I} \sigma_{2}\left[\mathrm{CH}_{3} \mathrm{SH}\right]-\mathrm{I} \sigma_{4}[\mathrm{HS}], \\
& \mathrm{d}[\mathrm{S}(3)] / \mathrm{dt}=\mathrm{I} \sigma_{3}\left[\mathrm{CH}_{3} \mathrm{~S}\right], \\
& \mathrm{d}[\mathrm{S}(4)] / \mathrm{dt}=\mathrm{I} \sigma_{4}[\mathrm{HS}], \\
& \mathrm{d}[\mathrm{S}(6)] / \mathrm{dt}=\mathrm{I} \sigma_{6}\left[\mathrm{CH}_{3} \mathrm{SH}\right] .
\end{aligned}
$$

Here, I is the ArF laser photon flux [\# of photons $\left./\left(\mathrm{cm}^{2} . \sec \right)\right]$ and $\sigma_{1}, \sigma_{2}, \sigma_{3}, \sigma_{4}, \sigma_{6}$, and $\sigma_{t}$ represent the absolute cross sections for process (1), (2), (3), (4), (6), and the total absorption cross section of $\mathrm{CH}_{3} \mathrm{SH}$, respectively. For each laser pulse the number densities for $\mathrm{CH}_{3} \mathrm{SH}\left(\left[\mathrm{CH}_{3} \mathrm{SH}\right)\right], \mathrm{CH}_{3} \mathrm{~S}\left(\left[\mathrm{CH}_{3} \mathrm{~S}\right]\right)$, $\mathrm{HS}([\mathrm{HS}])$, and $\mathrm{S}([\mathrm{S}(3)]$, [S(4)], and [S(6)] from processes (3), (4), and (6), respectively), are related to $\sigma_{1}, \sigma_{2}, \sigma_{3}, \sigma_{4}, \sigma_{6}, \sigma_{t}$, the laser fluence (F) (\# of photons $/ \mathrm{cm}^{2}$ ) and the initial number density of $\mathrm{CH}_{3} \mathrm{SH}\left(\left[\mathrm{CH}_{3} \mathrm{SH}\right]_{0}\right)$ by the relations:

$$
\begin{aligned}
& {\left[\mathrm{CH}_{3} \mathrm{SH}\right]=\left[\mathrm{CH}_{3} \mathrm{SH}\right]_{0} \exp \left[-\sigma_{\mathrm{t}} \mathrm{F}\right],} \\
& {\left[\mathrm{CH}_{3} \mathrm{~S}\right]=\left[\mathrm{CH}_{3} \mathrm{SH}\right]_{0}\left[\sigma_{1} /\left(\sigma_{\mathrm{t}}-\sigma_{3}\right)\right]\left[\exp \left(-\sigma_{3} \mathrm{~F}\right)-\exp \left(-\sigma_{\mathrm{t}} \mathrm{F}\right)\right],} \\
& {[\mathrm{HS}]=\left[\mathrm{CH}_{3} \mathrm{SH}\right]_{0}\left[\sigma_{2} /\left(\sigma_{\mathrm{t}}-\sigma_{4}\right)\right]\left[\exp \left(-\sigma_{4} \mathrm{~F}\right)-\exp \left(-\sigma_{\mathrm{t}} \mathrm{F}\right)\right],}
\end{aligned}
$$




$$
\begin{aligned}
& {[\mathrm{S}(3)]=\left[\mathrm{CH}_{3} \mathrm{SH}\right]_{0}\left[\sigma_{3} \sigma_{1} /\left(\sigma_{3}-\sigma_{\imath}\right)\right]\left[-\exp \left(-\sigma_{\mathrm{t}} \mathrm{F}\right) / \sigma_{\mathrm{t}}+\exp \left(-\sigma_{3} \mathrm{~F}\right) / \sigma_{3}+1 / \sigma_{\mathrm{t}}-1 / \sigma_{3}\right]} \\
& {[\mathrm{S}(4)]=\left[\mathrm{CH}_{3} \mathrm{SH}\right]_{0}\left[\sigma_{4} \sigma_{2} /\left(\sigma_{4}-\sigma_{\imath}\right)\right]\left[-\exp \left(-\sigma_{\mathrm{t}} \mathrm{F}\right) / \sigma_{\mathrm{t}}+\exp \left(-\sigma_{4} \mathrm{~F}\right) / \sigma_{4}+1 / \sigma_{\mathrm{t}}-1 / \sigma_{4}\right]} \\
& {[\mathrm{S}(6)]=\left[\mathrm{CH}_{3} \mathrm{SH}\right]_{0}\left(\sigma_{6} / \sigma_{\mathfrak{t}}\right)\left[1-\exp \left(-\sigma_{\mathrm{t}} \mathrm{F}\right)\right]}
\end{aligned}
$$

The intensity of $\mathrm{S}^{+}$resulting from the $2+1$ REMPI is directly proportional to the number density of $S$. In order to determine the $S\left({ }^{3} \mathrm{P}\right) / \mathrm{S}\left({ }^{1} \mathrm{D}\right)$ branching ratio for $S\left({ }^{3} \mathrm{P}_{2,1,0}\right)$ formed from $\mathrm{CH}_{3} \mathrm{SH}$, calibrations are made between the $\mathrm{S}^{+}$signals due to the formation of $S\left({ }^{3} \mathrm{P}_{2,1,0} ;{ }^{1} \mathrm{D}_{2}\right)$ from $\mathrm{CH}_{3} \mathrm{SH}$ and those from $\mathrm{CS}_{2}$. Detailed calibration procedures have been described previously. ${ }^{14}$

The absolute total cross section $\sigma_{\mathrm{t}}$ is known to be $5.6 \times 10^{-18} \mathrm{~cm}^{2},{ }^{23}$. Averaging the results of the previous UV photolysis studies, ${ }^{1-3}$ we obtain an estimate of about $3 / 1$ for the ratio $\sigma_{1} / \sigma_{2}$. In the data analysis, we assume that the branching ratios $S\left({ }^{3} \mathrm{P}\right) / \mathrm{S}\left({ }^{1} \mathrm{~S}\right)$ and absolute cross sections for the $193 \mathrm{~nm}$ photodissociation of $\mathrm{HS}$ and $\mathrm{CH}_{3} \mathrm{~S}$ prepared by processes (1) and (2) are similar to those formed from the $193 \mathrm{~nm}$ photodissociation of $\mathrm{H}_{2} \mathrm{~S}$ and $\mathrm{CH}_{3} \mathrm{SCH}_{3}$, respectively. That is, we fit the observed intensities for $\mathrm{S}\left({ }^{3} \mathrm{P}\right)$ and $\mathrm{S}\left({ }^{1} \mathrm{D}\right)$ from, the $193 \mathrm{~nm}$ photodissociation of $\mathrm{CH}_{3} \mathrm{SH}$ by using $\sigma_{3} \approx 1.0 \times 10^{-18} \mathrm{~cm}^{2}, \sigma_{4} \approx$ $1.1 \times 10^{-18} \mathrm{~cm}^{2}, \mathrm{~S}\left({ }^{3} \mathrm{P}\right) / \mathrm{S}\left({ }^{1} \mathrm{D}\right) \approx 0.15 / 0.85$ for process $(3)$, and $\mathrm{S}\left({ }^{3} \mathrm{P}\right) / \mathrm{S}\left({ }^{1} \mathrm{D}\right) \approx 0.87 / 0.13$ for process (4). The values for $\sigma_{1}, \sigma_{2}$, and $\sigma_{6}$ are also varied to fit the photodissociation laser power dependencies of the $S\left({ }^{\beta} \mathrm{P}\right)$ and $S\left({ }^{1} \mathrm{D}\right)$ intensities under the constraints that $\sigma_{\mathrm{t}} \geq$ $\sigma_{1}+\sigma_{2}+\sigma_{6}$ and $\sigma_{1} / \sigma_{3} \approx 1 / 3$ 


\section{RESULTS AND DISCUSSION}

The $S^{+}$intensities observed in the $2+1$ REMPI of $S\left({ }^{\beta} \mathrm{P}\right)$ and $S\left({ }^{1} \mathrm{D}\right)$ are plotted as a function of $193 \mathrm{~nm}$ photodissociation laser photon fluence in Figs. 1(a) and 1(b), respectively. The branching ratio $\mathrm{S}\left({ }^{3} \mathrm{P}\right) / \mathrm{S}\left({ }^{1} \mathrm{D}\right)$ from $\mathrm{CH}_{3} \mathrm{SH}$ is found to change from $0.59 / 0.41$ at $\mathrm{F}=1 \times 10^{16}$ photons $/ \mathrm{cm}^{2}$ to $0.43 / 0.57$ at $\mathrm{F}=8 \times 10^{16}$ photons $/ \mathrm{cm}^{2}$. This observation, together with the relatively slow change for the slope of the $S^{+}$intensity, especially the $S^{+}$intensity due to $S\left({ }^{3} \mathrm{P}\right)$ at low photon fluxes, supports that $S\left({ }^{3} \mathrm{P}\right)$ and $S\left({ }^{1} \mathrm{D}\right)$ atoms may also be produced by the single-photon process (6). For h $\nu=147.9 \mathrm{kcal} / \mathrm{mol}$ $(193 \mathrm{~nm})$, process (6) is highly exothermic $\left(\Delta \mathrm{H}_{\mathrm{fo}}=-95.4 \mathrm{kcal} / \mathrm{mol}\right){ }^{17}$ However, the potential barrier for process (6) may be high.

The determination of the $S\left({ }^{3} \mathrm{P}\right) / \mathrm{S}\left({ }^{1} \mathrm{D}\right)$ branching ratio from the $S\left({ }^{3} \mathrm{P}_{2}\right) / \mathrm{S}\left({ }^{1} \mathrm{D}\right)$ ratio requires knowledge of the fine-structure distribution $S\left({ }^{3} \mathrm{P}_{2}\right): S\left({ }^{\beta} \mathrm{P}_{1}\right): S\left({ }^{3} \mathrm{P}_{0}\right)$. At $\mathrm{F}=$ $8 \times 10^{16}$ photons $/ \mathrm{cm}^{2}$, the fine-structure distribution for $\mathrm{S}\left({ }^{\beta} \mathrm{P}_{\mathrm{J}}\right)$ from $\mathrm{CH}_{3} \mathrm{SH}$ is determined to be ${ }^{3} \mathrm{P}_{2}:{ }^{3} \mathrm{P}_{1}:{ }^{3} \mathrm{P}_{0}=0.66 \pm 0.04: 0.23 \pm 0.04: 0.11 \pm 0.04$, which is slightly colder than that expected from a statistical distribution. This distribution is slightly colder than that observed from $\mathrm{CH}_{3} \mathrm{SCH}_{3}$, but slightly hotter than that from $\mathrm{H}_{2} \mathrm{~S}$. The small $\mathrm{S}^{+}$ signal due to $S\left({ }^{3} \mathrm{P}_{0}\right)$ prevents us from accurately determining the population of $S\left({ }^{3} \mathrm{P}_{0}\right)$ relative to that of $S\left({ }^{3} \mathrm{P}_{2}\right)$ at lower photon fluxes. Here, we assume that the fine-structure distribution measured at $\mathrm{F}=8 \times 10^{16}$ photons $/ \mathrm{cm}^{2}$ remains the same throughout the entire range of photon flux. Because the population of $S\left({ }^{3} \mathrm{P}_{2}\right)$ is dominant in the production of 
Figure 1. Photodissociation laser fluence (\# photons $/ \mathrm{cm}^{2}$ ) dependence of $\mathrm{S}^{+}$signal due to the ionization of (a) $S\left({ }^{1} D\right)$ and (b) $S\left({ }^{3} P\right)$ formed by process (3) ( $\left.\checkmark\right)$, process (4) $(\Delta)$, and process (6) $(\square),(O)$ Experimental data; $(\bullet)$ best fits using Eqs. (16)-(18). The fitting requires that $\sigma_{\mathrm{t}}=5.6 \times 10^{-18} \mathrm{~cm}^{2}, \sigma_{1} / \sigma_{2}=$ $3 / 1, \sigma_{3}=1.0 \times 10^{-18} \mathrm{~cm}^{2}$, and $\sigma_{4}=1.1 \times 10^{-18} \mathrm{~cm}^{2}$. 


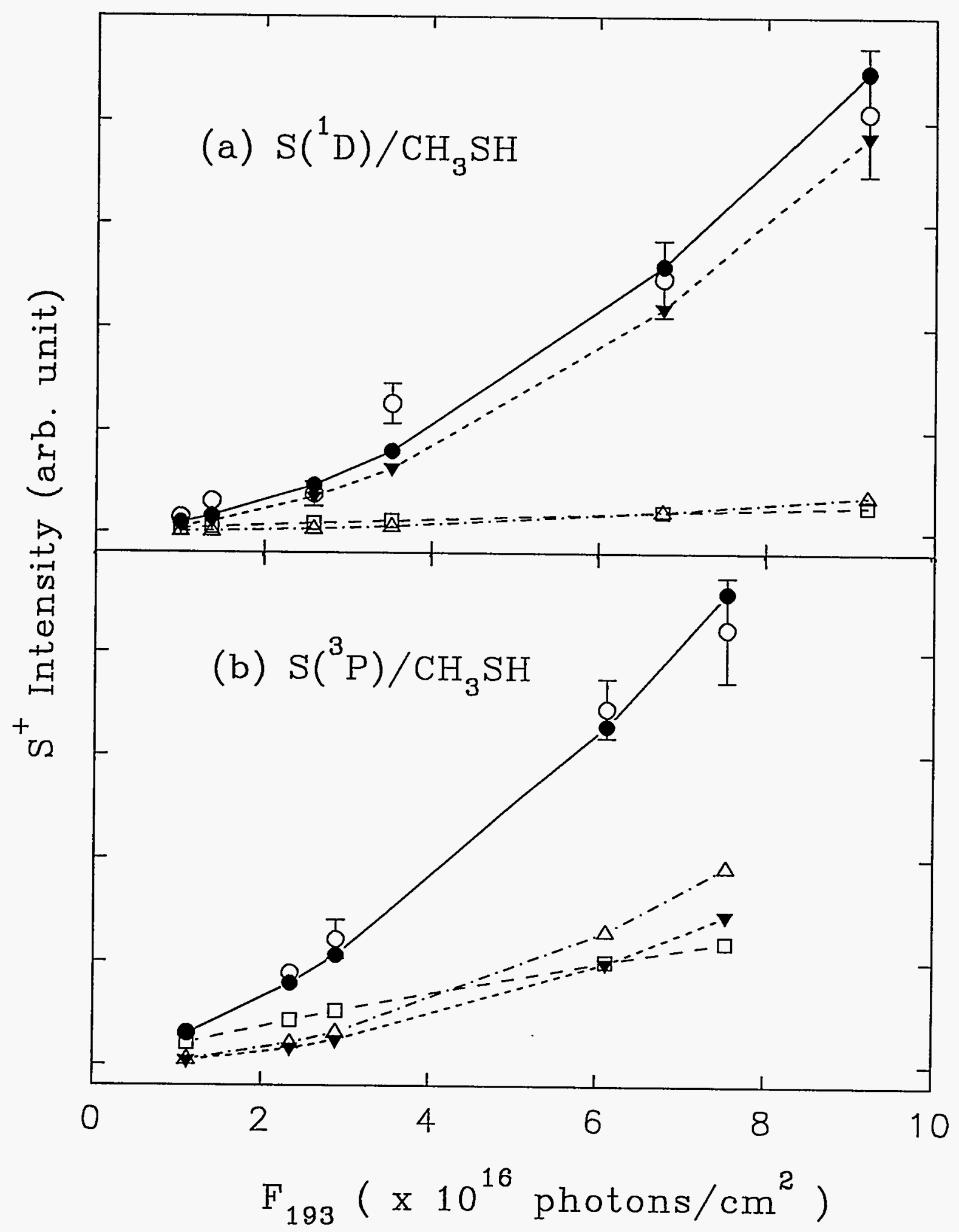


$\mathrm{S}\left({ }^{3} \mathrm{P}\right)$, the fine-structure distribution used should have a minor effect on the values reported for the branching ratios $S\left({ }^{3}\right) / S\left({ }^{1} D\right)$ and for the photodissociation cross sections.

A typical simulation for the $S^{+}$intensity due to the ionization of $S\left({ }^{3} \mathrm{P}\right)$ and $S\left({ }^{1} \mathrm{D}\right)$ formed in processes (1)-(4) and (6) using Eqs.(13)-(18) are also shown in Figs. 1(a) and 1(b) $[\nabla$ for process (3), $\Delta$ for process (4), and $\square$ for process (6)]. The solid circles represent the sum of best fitted values due to processes (3), (4), and (6). In this simulation, we assume that $\sigma_{\mathrm{t}}=5.6 \times 10^{-18} \mathrm{~cm}^{2}, \sigma_{1} / \sigma_{2}=3 / 1, \sigma_{3}=1.0 \times 10^{-18} \mathrm{~cm}^{2}$, and $\sigma_{4}$ $=1.1 \times 10^{-18} \mathrm{~cm}^{2}$. The cross sections corresponding to the best fit are: $\sigma_{1}=3.7 \times 10^{-18}$ $\mathrm{cm}^{2}, \sigma_{2}=1.2 \times 10^{-18} \mathrm{~cm}^{2}$, and $\sigma_{6}=3.5 \times 10^{-20} \mathrm{~cm}^{2}$. The branching ratio $\mathrm{S}\left({ }^{3} \mathrm{P}\right) / \mathrm{S}\left({ }^{1} \mathrm{D}\right)$ due to the secondary processes (3) and (4) are $0.22 / 0.78$ and $0.8 / 0.2$, respectively. As shown in the figures, the overwhelming intensity of $S\left({ }^{1} D\right)$ produced at high photodissociation laser fluxes is attributable to the photodissociation process $\mathrm{CH}_{3} \mathrm{~S}+\mathrm{h} \nu \rightarrow \mathrm{S}\left({ }^{\mathrm{l}} \mathrm{D}\right)+\mathrm{CH}_{3}$, while the dissociation process $\mathrm{HS}+\mathrm{h} \nu \rightarrow \mathrm{H}+\mathrm{S}\left({ }^{3} \mathrm{P}\right)$ accounts for the major intensity of $\mathrm{S}\left({ }^{3} \mathrm{P}\right)$ produced at high photon fluxes. The higher $\sigma_{\mathrm{t}}$ value, compared to $4.94 \times 10^{-18} \mathrm{~cm}^{2}$ for the sum $\sigma_{1}+\sigma_{2}+\sigma_{6}$, may be interpreted that the absorption of a $193 \mathrm{~nm}$ photon also induces other processes, such as rearrangement and/or dissociation, which do not lead to the production of $\mathrm{S}$ atoms.

Since the previous experimental values for $\sigma_{1} / \sigma_{2}$ in the vicinity of $193 \mathrm{~nm}$ fall in the range from $1.7 / 1$ to $4 / 1$, it is desirable to examine the effect of $\sigma_{1} / \sigma_{2}$ by adjusting its value in our fittings. By varying the value for $\sigma_{1} / \sigma_{2}$ in the range from $1.7 / 1$ to $4 / 1$ and by setting $\sigma_{3}=1.0 \times 10^{-18} \mathrm{~cm}^{2}$ and $\sigma_{4}=1.1 \times 10^{-18} \mathrm{~cm}^{2}$, we find that the best fitted value 
for $S\left({ }^{3} \mathrm{P}\right) / \mathrm{S}\left({ }^{1} \mathrm{D}\right)$ of process (3) varies from $0.14 / 0.86$ to $0.25 / 0.75$, while that for process (4) is in the range from $0.72 / 0.28$ to $0.87 / 0.13$.

Attempts have also been made to fit the observed the photodissociation laser power dependencies for $S\left({ }^{3} \mathrm{P}\right)$ and $S\left({ }^{1} \mathrm{D}_{2}\right)$ from $\mathrm{CH}_{3} \mathrm{SH}$ by setting the branching ratios $\mathrm{S}\left({ }^{3} \mathrm{P}\right) / \mathrm{S}\left({ }^{1} \mathrm{D}\right)$ $=0.15 / 0.85$ and $0.87 / 0.13$ for processes (3) and (4) respectively. The best fitted values for $\sigma_{3}$ and $\sigma_{4}$ are found to fall in the respective ranges of $0.9-1.2 \times 10^{-18} \mathrm{~cm}^{2}$ and $0.9-1.6 \times 10^{-}$ ${ }^{18} \mathrm{~cm}^{2}$ when $\sigma_{1} / \sigma_{2}$ is varied in the range from $1.7 / 1$ to $4 / 1$.

According to the fittings described above, we may conclude that the values for $\sigma_{3}$ and $\sigma_{4}$ are most likely in the respective range of $0.9-1.2 \times 10^{-18} \mathrm{~cm}^{2}$ and $0.9-1.6 \times 10^{-18} \mathrm{~cm}^{2}$. The branching ratio $S\left({ }^{3} \mathrm{P}\right) / \mathrm{S}\left({ }^{1} \mathrm{D}\right)$ for process (3) may be in the range from $0.14 / 0.86$ to $0.25 / 0.75$ and that for process (4) from $0.72 / 0.28$ to $0.87 / 0.13$. Because $\sigma_{6}$ is very small compared to other cross sections, its value is not sensitive to the fittings. Process (6) is important only at low photodissociation laser power. Further experiments are required to confirm the involvement of this process.

Based on the $a b$ initio multiconfiguration self-consistence-field (MCSCF) potential energy surfaces for $\mathrm{CH}_{3} \mathrm{~S}$ calculated along the $\mathrm{CH}_{3}$-S distance, Hsu et al. ${ }^{14}$ have pointed out that the formation of $\left.\mathrm{S}^{3} \mathrm{P}_{\mathrm{f}}\right)$ proceeds most likely by predissociation of $\mathrm{CH}_{3} \mathrm{~S}\left(\widetilde{\mathrm{C}^{2}}{ }^{2} \mathrm{~A}_{2}\right)$ via the repulsive $\mathrm{CH}_{3} \mathrm{~S}\left(\widetilde{\mathrm{B}}{ }^{2} \mathrm{~A}_{2}\right)$ state, while the formation of $S\left({ }^{1} \mathrm{D}_{2}\right)$ may result from predissociation of $\mathrm{CH}_{3} \mathrm{~S}\left(\widetilde{\mathrm{C}}{ }^{2} \mathrm{~A}_{2}\right)$ via the $\mathrm{CH}_{3} \mathrm{~S}\left(\widetilde{\mathrm{E}}{ }^{2} \mathrm{E}\right)$ repulsive state. The dominant production of $\left.\mathrm{S}^{1} \mathrm{D}_{2}\right)$ observed from $\mathrm{CH}_{3} \mathrm{~S}$ initially formed in the $193 \mathrm{~nm}$ photodissociation of $\mathrm{CH}_{3} \mathrm{SCH}_{3}$ has been attributed to the more favorable couplings of $\mathrm{CH}_{3} \mathrm{~S}(\widetilde{\mathrm{E}})$ and $\mathrm{CH}_{3} \mathrm{~S}(\widetilde{\mathrm{C}})$ state. The previous $193 \mathrm{~nm}$ photofragmentation study of $\mathrm{CH}_{3} \mathrm{SCH}_{3}{ }^{13}$ indicates 
that about $45 \%$ of the available energy appears as the most probable internal energies for product $\mathrm{CH}_{3} \mathrm{~S}(\widetilde{\mathrm{X}})+\mathrm{CH}_{3}$. The direct excitation to the $\mathrm{CH}_{3} \mathrm{~S}(\widetilde{\mathrm{E}})$ state from rovibrationally excited $\mathrm{CH}_{3} \mathrm{~S}(\widetilde{\mathrm{X}})$ state is possible. The direct formation of $\mathrm{CH}_{3} \mathrm{~S}(\widetilde{\mathrm{E}})$ radicals is expected to favor the $\left.\mathrm{S}^{1} \mathrm{D}_{2}\right)+\mathrm{CH}_{3}\left(\widetilde{\mathrm{X}}^{2} \mathrm{~A}^{\prime \prime}\right)$ dissociation channel. Assuming that the internal energies are equally distributed to all internal degrees of freedom, the most probable internal excitation for $\mathrm{CH}_{3} \mathrm{~S}$ prepared in the $193 \mathrm{~nm}$ photodissociation of $\mathrm{CH}_{3} \mathrm{SCH}_{3}$ is about $18 \mathrm{kcal} / \mathrm{mol}$. This compares to the most probable internal excitation of $\approx 6 \mathrm{kcal} / \mathrm{mol}$ for $\mathrm{CH}_{3} \mathrm{~S}$ formed by process (1) at $193 \mathrm{~nm}$. The extent of excitation to the $\mathrm{CH}_{3} \mathrm{~S}(\widetilde{\mathrm{E}})$ state at $193 \mathrm{~nm}$ for colder $\mathrm{CH}_{3} \mathrm{~S}$ radicals prepared from $\mathrm{CH}_{3} \mathrm{SH}$ is expected to be less, which in turn should lower the relative production of $S\left({ }^{i} \mathrm{D}\right)$ compared to that observed from $\mathrm{CH}_{3} \mathrm{SCH}_{3}$. That is, the branching ratio for $\mathrm{S}\left({ }^{3} \mathrm{P}\right) / \mathrm{S}\left({ }^{1} \mathrm{D}\right)$ of process (3) at $193 \mathrm{~nm}$ is most likely more than $0.15 / 0.85$.

The $a b$ initio potential energy curves calculated by Bruna and Hirsch ${ }^{24}$ show that the $\operatorname{HS}\left({ }^{2} \Sigma\right)$ and $\operatorname{HS}\left({ }^{2} \Delta\right)$ potential surfaces are repulsive and correlate asymptotically with the formation of $S\left({ }^{3} \mathrm{P}\right)+\mathrm{H}\left({ }^{2} \mathrm{~S}\right)$ and $\mathrm{S}\left({ }^{1} \mathrm{D}\right)+\mathrm{H}\left({ }^{2} \mathrm{~S}\right)$, respectively. The direct dissociation mechanism for the $193 \mathrm{~nm}$ photodissociation of $\mathrm{HS}(\mathrm{X}, \mathrm{v})$ has been suggested previously in the H-atom TOF mass spectrometric ${ }^{11}$ and REMPI studies. ${ }^{10}$ The HS(X,v) radicals formed in the $193 \mathrm{~nm}$ photodissociation of $\mathrm{H}_{2} \mathrm{~S}$ are found to be overwhelmingly in the $v=0$ state. The dominant formation of $S\left({ }^{3} \mathrm{P}\right)$ from $\mathrm{HS}(\mathrm{X})$ thus formed may be accounted for by the excitation $\mathrm{HS}(\mathrm{X}, \mathrm{v}=0) \rightarrow \mathrm{HS}\left({ }^{2} \Sigma^{-}\right)$. Energetically, a $193 \mathrm{~nm}$ photon can excite $H S\left(X^{2} \Pi, v \geq 1\right)$ to the $H S\left({ }^{2} \Delta\right)$ state which is expected to lead to the formation of $S\left({ }^{1} D\right)$. The previous kinetic energy release study of $\mathrm{H}_{2} \mathrm{~S}^{11}$ indicates that the most probable internal 
excitation for HS corresponds to $\approx 5 \%$ (about $3 \mathrm{kcal} / \mathrm{mol}$ ) of the available energy. Assuming that internal excitations are distributed equally to all internal degrees of freedom, we estimated that the most probable vibrational energy for $\mathrm{HS}(\mathrm{X})$ from $\mathrm{CH}_{3} \mathrm{SH}$ is $\approx 7.5 \mathrm{kcal} / \mathrm{mol}$. A higher population of $\mathrm{HS}(\mathrm{X}, \mathrm{v} \geq 1)$ formed in the $193 \mathrm{~nm}$ photodissociation of $\mathrm{CH}_{3} \mathrm{SH}$ should lead to a $\mathrm{S}\left({ }^{3} \mathrm{P}\right) / \mathrm{S}\left({ }^{1} \mathrm{D}_{2}\right)$ branching ratio lower than $0.87 / 0.13$ for process (4) at $193 \mathrm{~nm}$.

The formation of $S$ atoms in the ${ }^{1} S_{0}$ state is observed here at high photodissociation laser power. The $\mathrm{S}^{+}$peak due to ionization of $\mathrm{S}\left({ }^{1} \mathrm{~S}\right)$ at $299.575 \mathrm{~nm}$ can only be observed at high photon fluxes and is estimated to be $\approx 12$ times less than that for $S\left({ }^{1} D\right)$ at 288.19 $\mathrm{nm}$. However, the intensity for $S\left({ }^{1} \mathrm{~S}_{0}\right)$ relative to those for $S\left({ }^{3} \mathrm{P}_{\mathrm{J}} ;{ }^{1} \mathrm{D}\right)$ cannot be quantified because $S\left({ }^{1} S\right)$ atoms are not produced in the calibration reaction (5). The formation of $\mathrm{S}\left({ }^{1} \mathrm{~S}\right)$ was not found in the $193 \mathrm{~nm}$ photodissociation of $\mathrm{CH}_{3} \mathrm{SCH}_{3}$ and $\mathrm{H}_{2} \mathrm{~S}$. It is unlikely that $\mathrm{S}\left({ }^{1} \mathrm{~S}\right)$ can be produced from the photodissociation of $\mathrm{CH}_{3} \mathrm{~S}$ radicals because the product internal energy for $\mathrm{CH}_{3} \mathrm{~S}$ prepared from $\mathrm{CH}_{3} \mathrm{SH}$ is expected to be lower than that from $\mathrm{CH}_{3} \mathrm{SCH}_{3}$. According to the ab initio potential energy curves of $\mathrm{HS},{ }^{17}$ the excited $\mathrm{HS}\left({ }^{2} \Sigma^{+}\right)$ state is repulsive and correlate asymptotically with the dissociation channel $S\left({ }^{1} S_{0}\right)+H\left({ }^{2} S\right)$. Since the formation of the $\mathrm{HS}\left({ }^{2} \Sigma^{+}\right)$state due to $193 \mathrm{~nm}$ excitation is energetically feasible for $H S\left(X^{2} \Pi, v \geq 2\right)$, the formation of $S\left({ }^{1} S_{0}\right)$ may be attributed to $H S\left(X^{2} \Pi, v \geq 2\right)$ formed in process (2) at $193 \mathrm{~nm}$. We note that the $193 \mathrm{~nm}$ photoexcitation of $\mathrm{H}_{2} \mathrm{~S}$ can populate $\mathrm{HS}(\mathrm{X}, \mathrm{v})$ states up to $\mathrm{v}=6$. However, the fact that $S\left({ }^{\prime} S\right)$ is not found may result from the very low population of $H S(X, v \geq 2)$ from $\mathrm{H}_{2} S$. The detection of $S\left({ }^{1} S\right)$ is consistent 
with the conclusion that the population of $\operatorname{HS}(X, v \geq 2)$ radicals is increased in the $193 \mathrm{~nm}$ photodissociation of $\mathrm{CH}_{3} \mathrm{SH}$.

State-to-state photodissociation cross sections for molecules are expected to depend on their internal energy distributions. The photodissociation cross sections for $\mathrm{CH}_{3} \mathrm{~S}$ and $\mathrm{HS}$, estimated in the photodissociation studies of $\mathrm{H}_{2} \mathrm{~S}, \mathrm{CH}_{3} \mathrm{SH}$, and $\mathrm{CH}_{3} \mathrm{SCH}_{3}$, represent cross sections averaged over the internal state distributions of $\mathrm{CH}_{3} \mathrm{~S}$ and HS characteristic of the photodissociation processes. We note that the width of the internal energy distributions for $\mathrm{CH}_{3} \mathrm{~S}$ and $\mathrm{HS}$ formed in the photodissociation of $\mathrm{CH}_{3} \mathrm{SCH}_{3}$ and $\mathrm{CH}_{3} \mathrm{SH}$ are quite broad ( $\approx 20 \mathrm{kcal} / \mathrm{mol}$ ). The relatively broad internal energy distributions might suppress the variation of photodissociation cross sections for $\mathrm{CH}_{3} \mathrm{~S}$ and $\mathrm{HS}$ prepared from different precursor molecules. The MCSCF calculation indicates that the $193 \mathrm{~nm}$ excitation of $\mathrm{CH}_{3} \mathrm{~S}(\tilde{\mathrm{X}}, v=0)$ to $\mathrm{CH}_{3} \mathrm{~S}(\tilde{\mathrm{C}})$ has overwhelmingly the highest oscillator strength. If the subsequent predissociation processes from $\mathrm{CH}_{3} \mathrm{~S}(\tilde{\mathrm{C}})$ dictate the relative populations of $S\left({ }^{3} \mathrm{P}\right)$ and $S\left({ }^{1} \mathrm{D}\right)$, the minor excitation from vibrationally excited $\mathrm{CH}_{3} \mathrm{~S}(\tilde{\mathrm{X}})$ to $\mathrm{CH}_{3} \mathrm{~S}(\tilde{\mathrm{E}})$ would only have a minor effect on the $\mathrm{S}\left({ }^{3} \mathrm{P}\right) / \mathrm{S}\left({ }^{1} \mathrm{D}\right)$ branching ratio. In the case of HS, the oscillator strength for the transition $\operatorname{HS}(\mathrm{X}) \rightarrow \mathrm{HS}\left({ }^{2} \Sigma\right)$ is the highest, and thus the formation of $\mathrm{S}\left({ }^{3} \mathrm{P}\right)$ should dominate if the vibrational distributions of HS formed in the photodissociation of $\mathrm{H}_{2} \mathrm{~S}$ and $\mathrm{CH}_{3} \mathrm{SH}$ do not differ significantly. The good fitting obtained for the $193 \mathrm{~nm}$ photon flux dependencies for the formation of $S\left({ }^{3} \mathrm{P}\right)$ and $S\left({ }^{1} \mathrm{D}\right)$ from $\mathrm{CH}_{3} \mathrm{SH}$, using the $\sigma_{3}$ and $\sigma_{4}$ values and the $\mathrm{S}\left({ }^{3} \mathrm{P}\right) / \mathrm{S}\left({ }^{1} \mathrm{D}\right)$ branching ratios determined from $\mathrm{H}_{2} \mathrm{~S}$ and $\mathrm{CH}_{3} \mathrm{SCH}_{3}$, can be taken as support of the conclusion that the internal energy distributions of $\mathrm{CH}_{3} \mathrm{~S}$ and $\mathrm{HS}$ prepared from $\mathrm{CH}_{3} \mathrm{SH}$ are not significantly different from 
those from $\mathrm{CH}_{3} \mathrm{SCH}_{3}$ and $\mathrm{H}_{2} \mathrm{~S}$. The similar fine-structure distributions for $\mathrm{S}\left({ }^{3} \mathrm{P}_{2,1,0}\right)$ observed from $\mathrm{H}_{2} \mathrm{~S}, \mathrm{CH}_{3} \mathrm{SH}$, and $\mathrm{CH}_{3} \mathrm{SCH}_{3}$ support that the photodissociation dynamics of $\mathrm{HS}$ and $\mathrm{CH}_{3} \mathrm{~S}$ are mostly governed by repulsive excited states.

In order to further examine the dependencies of the branching ratios $\mathrm{S}\left({ }^{\beta} \mathrm{P}\right) / \mathrm{S}\left({ }^{1} \mathrm{D}\right)$ and the photodissociation cross sections on the internal energy distributions of $\mathrm{CH}_{3} \mathrm{~S}$ and $\mathrm{HS}$, it would be interesting to compare the cross sections and branching ratios $\mathrm{S}\left({ }^{3} \mathrm{P}\right) / \mathrm{S}\left({ }^{1} \mathrm{D}\right)$ for processes (3) and (4) measured using supersonically cooled $\mathrm{CH}_{3} \mathrm{~S}$ and HS beams. 


\section{CONCLUSION}

Using $2+1$ REMPI detection schemes for $\mathrm{S}\left({ }^{3} \mathrm{P}_{2,1,0} ;{ }^{1} \mathrm{D}_{2} ;{ }^{1} \mathrm{~S}_{0}\right)$, we have examined the $193 \mathrm{~nm}$ photodissociations of $\mathrm{CH}_{3} \mathrm{~S}(\widetilde{\mathrm{X}})$ and $\mathrm{HS}(\mathrm{X}, \mathrm{v})$ prepared by processes (1) and (2), respectively. Although the cross sections for processes (1)-(4) and (6) and the $\mathrm{S}\left({ }^{\mathrm{P}} \mathrm{P}\right) / \mathrm{S}\left({ }^{1} \mathrm{D}\right)$ branching ratios for processes (3) and (4) at $193 \mathrm{~nm}$ cannot be uniquely determined in this experiment, we find that good fits for the photodissociation laser power dependencies for $\mathrm{S}\left({ }^{3} \mathrm{P}\right)$ and $\mathrm{S}\left({ }^{1} \mathrm{D}\right)$ can be obtained by using similar values of $\sigma_{3}$ and $\sigma_{4}$ and the $S\left({ }^{3} \mathrm{P}\right) / \mathrm{S}\left({ }^{1} \mathrm{D}\right)$ branching ratios determined in the previous $193 \mathrm{~nm}$ photodissociation experiments of $\mathrm{CH}_{3} \mathrm{SCH}_{3}$ and $\mathrm{H}_{2} \mathrm{~S}$. This observation can be taken as evidence that the cross sections, as well as the relative intensities, for $S\left({ }^{3} \mathrm{P}_{\mathrm{J}} ;{ }^{1} \mathrm{D}_{2}\right)$ formed in the photodissociation of $\mathrm{CH}_{3} \mathrm{~S}$ and $\mathrm{HS}$ prepared in the photodissociation of $\mathrm{CH}_{3} \mathrm{SCH}_{3}$ and $\mathrm{H}_{2} \mathrm{~S}$ at $193 \mathrm{~nm}$, respectively, are similar to those from $\mathrm{CH}_{3} \mathrm{SH}$. The $\mathrm{S}\left({ }^{1} \mathrm{~S}\right)$ observed in this experiment is attributed to the higher population of $H S(X, v \geq 2)$ resulting from the photodissociation of $\mathrm{CH}_{3} \mathrm{SH}$ compared to that from $\mathrm{H}_{2} \mathrm{~S}$. The one-photon process (6) for the formation of $S\left({ }^{3} \mathrm{P}_{\mathrm{J}},{ }^{1} \mathrm{D}\right)$ is also suggested in this experiment as a minor channel in the $193 \mathrm{~nm}$ photodissociation of $\mathrm{CH}_{3} \mathrm{SH}$. 


\section{REFERENCES}

(1) B. J. Finlayson-Pitts and J. N. Pitts, Jr., "Atmospheric Chemistry" (Wiley, New York, 1986).

(2) A. B. Callear and D. R. Dickson, Trans. Faraday Soc. 661987 (1970).

(3) L. Bridges and J. M. White, J. Phys. Chem. 77, 295 (1973).

(4) D. Kamra and J. M. White, J. Photochem. 4, 361 (1975).

(5) I. Tokue, A. Hiraya and K. Shobatake, Chem. Phys. 116, 449 (1987).

(6) B. Mouflih, C. Larrieu and M. Chaillet, Chem. Phys. 119, 221 (1988).

(7) S. Nourbakhsh, K. Norwood, H.-M. Yin, C.-L. Liao and C. Y. Ng, J. Chem. Phys. 95, 946 (1991).

(8) J. S. Keller, P. W. Kash, E. Jensen and L. J. Butler, J. Chem. Phys. 96, 4324 (1992).

(9) S.-W. Chiu, W.-K. Li, W.-B. Tzeng, and C. Y. Ng, J. Chem. Phys. 97, 6557 (1992).

(10) C.-W. Hsu, C.-L. Liao, Z.-X. Ma, P. J. H. Tjossem, and C. Y. Ng, Chem. Phys. Lett. 199, 78 (1992).

(11) R. E. Continetti, B. A. Balko and Y. T. Lee, Chem. Phys. Lett., 185, 400 (1991).

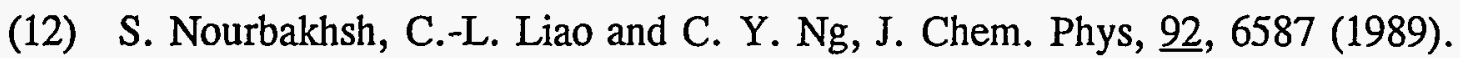

(13) S. Nourbakhsh, K. Norwood, H.-M. Yin, C.-L. Liao and C. Y. Ng, J. Chem. Phys. 95, 5014 (1991). 
(14) C.-W. Hsu, C.-L. Liao, Z.-X. Ma, P. J. H. Tjossem and C. Y. Ng, J. Chem. Phys., 97, 6283 (1992).

(15) I. M. Waller and W. J. Hepburn, J. Chem. Phys., 87, 3261 (1987).

(16) W.-B. Tzeng, H.-M. Yin, W.-Y. Leung, J.-Y. Luo, S. Nourbakhsh, G. J. Flesch, and C. Y. Ng, J. Chem. Phys. $\underline{88}, 1658$ (1988).

(17) S. G. Lias, J. E. Bartmess, J. F. Liebman, J. L. Holmes, R. D. Levin, and W. G. Mallard, J. Phys. Chem. Ref. Data 17, Suppl. No. 1 (1988).

(18) P. Brewer, N. van Veen, and R. Bershon, Chem. Phys. Lett. 91, 126 (1982).

(19) G. Black and L. E. Jusinski, J. Chem. Phys. $\underline{82}$, 789 (1985)

(20) G. Black and L. E. Jusinski, J. Chem. Soc. Faraday Trans. 2 82, 2143 (1986).

(21) T. V. Venkitachalam and A. S. Rao, Appl. Phys. B 2, 102 (1991).

(22) D. J. Bamford, M. J. Dyer and W. K. Bishel, Phys. Rev. A 36, 3497 (1987).

(23) J. G. Calvert and J. N. Pitts., Photochemistry (Wiley, New York, 1966).

(24) P. J. Bruna and G. Hirsch, Mol. Phys., 61, 1359 (1987). 
PAPER 4

ROTATIONALLY RESOLVED NONRESONANT TWO-PHOTON IONIZATION OF SH 


\begin{abstract}
The threshold photoelectron (PE) spectrum for nascent $\mathrm{SH}$ formed in the ultraviolet photodissociation of $\mathrm{H}_{2} \mathrm{~S}$ has been measured using the nonresonant two-photon pulsed field ionization (N2P-PFI) technique. The rotationally-resolved N2P-PFI-PE spectrum of SH indicates that photoionization dynamics favors the rotational angular momentum change $\Delta N \leq 0$ with the $\Delta N$ values up to -3 , an observation similar to that found in the PFI-PE spectra of $\mathrm{OH}(\mathrm{OD})$ and NO. The ionization energy for $\mathrm{SH}\left(X^{2} \Pi_{3 / 2}\right)$ is determined to be $84,057.5 \pm 3 \mathrm{~cm}^{-1}(10.4219 \pm 0.0004 \mathrm{eV})$. The spin-orbit splitting for $\operatorname{SH}\left(X^{2} \Pi_{3 / 2,1 / 2}\right)$ is $377 \pm 2 \mathrm{~cm}^{-1}$, in agreement with the literature value. This study illustrates that the PFI-PE detection method can be a sensitive probe for the nascent internal energy distribution of photoproducts.
\end{abstract}




\section{INTRODUCTION}

The study of molecular photoionization by high resolution photoelectron (PE) spectroscopy has been most valuable for the understanding of detailed photoionization dynamics and for obtaining accurate spectroscopic and energetic information about neutral and ionic species. ${ }^{1}$ However, the typical energy resolution of 5-25 meV attained by conventional PE spectroscopic techniques is generally insufficient for obtaining rovibronically-resolved PE spectra of polyatomic species. With the recent development of the laser pulsed field ionization (PFI) ${ }^{2}$ method, a version of the zero-kinetic-energy (ZEKE) PE technique, ${ }^{3,4}$ the energy resolution for PE spectroscopy has improved to subwavenumbers, approaching that achieved in optical spectroscopy. Rotationally and vibrationally resolved PFI-PE spectra have been reported for many diatomic molecules ${ }^{5-15}$ and for polyatomic species. ${ }^{16-29}$ Due to the simplicity and the high resolution achieved by the PFI method, its application is expected to expand rapidly, covering many more molecular species in the near future.

Most of previous PFI-PE studies applied the resonance-enhanced ${ }^{23,25,28}$ two-color laser excitation, or the single vacuum ultraviolet (VUV) ${ }^{5-9,14-19,21}$ laser excitation schemes. Recently, Bondybey and co-workers have demonstrated that PFI-PE spectra for NO (Ref. 13), $\mathrm{H}_{2} \mathrm{~S}$ (Ref. 20), $\mathrm{CH}_{3} \mathrm{I}$ (Ref. 24), $\mathrm{CS}_{2}$ (Ref. 22), and (NO) ${ }_{2}$ (Ref. 29) can be obtained with good sensitivity by using the one-color nonresonant two-photon (N2P) excitation. In many cases, the N2P-PFI-PE spectra are found to be surprisingly similar to those acquired by the single VUV photon ionization scheme. 
Since the single VUV photon and two-photon excitation schemes are governed by different selection rules, we expect differences in the resulting PFI-PE spectra. When molecular species under investigation are excited directly from their molecular ground states in the N2P scheme, and the excitation process is mediated by an intermediate repulsive state, the PFI-PE spectra are free from modulated structures observed in a resonant experiment. The recent N2P-PFI study on $\mathrm{CH}_{3} \mathrm{I}$ indicates that the involvement of a dissociative intermediate state along the C-I dissociation coordinate allows the observation of a longer $\mathrm{C}-\mathrm{I}$ stretching vibrational progression of $\mathrm{CH}_{3} \mathrm{I}^{+}$compared to that found in a HeI PE spectroscopic study ${ }^{24}$ The N2P-PFI scheme is very attractive because of its high sensitivity and the availability of commercial pulsed dye lasers with an output range of $200-400 \mathrm{~nm}$, as required for the ionization of most polyatomic species at their thresholds.

An exciting development of PFI-PE spectroscopy is that it allows high resolution PE studies for not only stable molecules, but also transient radicals. Elegant PFI-PE experiments on radicals such as $\mathrm{OH}(\mathrm{OD})$ (Ref. 14) and $\mathrm{CH}_{3}$ (Ref. 21) and $\mathrm{C}_{6} \mathrm{H}_{5} \mathrm{CH}_{2}$ (benzyl radical) $)^{28}$ have been made recently by the groups of White and Weisshaar, respectively. The PE studies of transient molecules and radicals is traditionally a difficult field, partly because of the difficulties involved in the preparation of specific transient species of interest. Transient species prepared by pyrolysis, discharge, and fast chemical reactions are often internally excited. This, coupled with the relatively poor energy resolution used in conventional PE spectroscopic studies, makes the assignment of the PE features and ionization threshold difficult. 
It has been well-demonstrated that many rotationally and vibrationally cold radicals can be prepared with high purity and intensity using a pulsed laser photodissociation radicals source. ${ }^{30,31}$ The ideal combination of the PFI-PE detection and pulsed radical beam source provides the sensitivity needed for high resolution PE studies of radicals. The application of high resolution PFI-PE spectroscopy to the study of transient species has just begun, and its impact on the energetic and spectroscopic measurements of transient radicals is expected to continue for many years to come.

As part of the effort in our laboratory to characterize the structure and energetics of combustion-related polyatomic molecules and radicals by photoionization and photodissociation methods, ${ }^{30-37}$ we have undertaken N2P-PFI studies of selected organosulfur species. Here, we present the N2P-PFI-PE spectrum of SH and its assignment. In this experiment, a one-color three-photon process is involved. That is, the SH radicals are first prepared by the single-photon dissociation process,

$$
\mathrm{H}_{2} \mathrm{~S}+\mathrm{h} \nu \rightarrow \mathrm{SH}\left(X^{2} \Pi_{3 / 2,1 / 2}\right)+\mathrm{H}
$$

The subsequent ionization of $\mathrm{SH}$ is accomplished by N2P excitations of SH to high-n Rydberg states $\left[\mathrm{SH}^{*}(\mathrm{n})\right]$ followed by PFI of $\mathrm{SH}^{*}(\mathrm{n})$.

$$
\mathrm{SH}\left(X^{2} \Pi_{3 / 2, I / 2}\right)+2 \mathrm{~h} \nu \rightarrow \mathrm{SH}^{*}(\mathrm{n}) \rightarrow \mathrm{SH}^{+}\left(X^{3} \Sigma^{-}\right)+\mathrm{e}^{-}
$$


The two additional photons absorbed by SH in process (2) are furnished by the same laser pulse which induced the dissociation of $\mathrm{H}_{2} \mathrm{~S}$ in process (1). 


\section{EXPERIMENTAL}

A schematic diagram of the experimental apparatus is shown in Fig. 1. The experimental apparatus is modified from the laser ionization time-of-flight (TOF) mass spectrometer used in previous photodissociation studies. ${ }^{38,39}$ A two-stage microchannel plate detector and a set of simple aperture lenses have been added for PE detection below the photoionization region and opposite to the ion TOF tube.

For this experiment, $\mathrm{H}_{2} \mathrm{~S}$ (Union Carbide, $99 \%$ purity) is used without further purification. The $\mathrm{H}_{2} \mathrm{~S}$ sample (7\%) seeded in Ar carrier gas (total stagnation pressure $\approx$ $2.5 \mathrm{bar}$ ) is introduced into the photoionization region by supersonic expansion through a pulsed valve with a nozzle diameter of $0.5 \mathrm{~mm}$. The molecular beam is skimmed by a conical skimmer ( $1 \mathrm{~mm}$ in diameter, $3.8 \mathrm{~cm}$ from the nozzle) before intersecting with a tunable laser beam $\left(90^{\circ}, 8.3 \mathrm{~cm}\right.$ downstream from the skimmer). Both the pulsed valve and the dye laser are operated at a repetition rate of $13 \mathrm{~Hz}$.

The molecular beam source chamber is pumped by a freon-trapped, 6 in. diffusion pump (pumping speed $\approx 2,000 \ell / \mathrm{s}$ ), while the photoionization chamber and the ion-TOF tube are evacuated by two $50 \mathrm{l} / \mathrm{s}$ turbomolecular pumps. During the experiment, the beam source chamber and the photoionization chamber are maintained at pressures of about $1 \times 10^{-4}$ and $2 \times 10^{-6}$ Torr, respectively.

The second harmonic output of an excimer (Lambda Physik EMG 201 MSC) pumped-dye laser (Lambda Physik FL 3002) is focused into the photoionization region by a $200 \mathrm{~mm}$ focal length fused-silica lens. Coumarin 102 dye is used to produce the 
Figure 1. Cross sectional view of the ion-TOF and PFI-PE apparatus: (1)photodissociation and photoionization chamber; (2) photodissociation and photoionization region; (3) beam source chamber; (4) pulsed valve; (5) skimmer; (6) ion TOF tube; (7) ion microchannel plate detector; and (8)electron microchannel plate detector. 


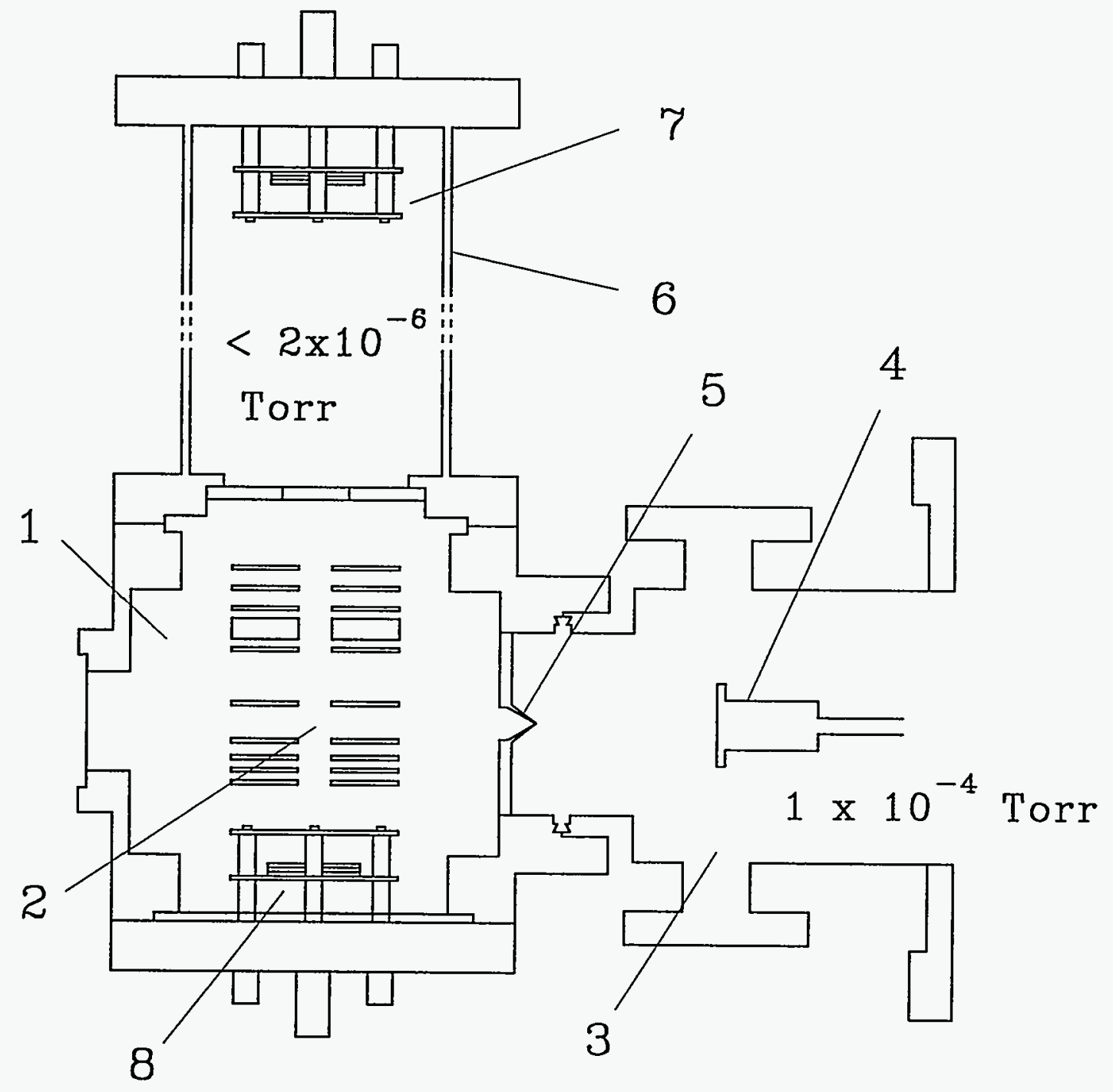


fundamental output in the $468-481 \mathrm{~nm}$ region. Typical laser pulse energies used in the second harmonic output range of $234-240 \mathrm{~nm}$ are $1.2 \mathrm{~mJ}$, as monitored with a pyroelectric detector. The wavelength calibration is made using the known ZEKE spectrum of atomic sulfur, ${ }^{40}$ which is produced by the multiphoton laser photodissociation of $\mathrm{H}_{2} \mathrm{~S}$.

Ion detection using the ion TOF mass spectrometer has been described in detail previously. ${ }^{38,39}$ Here, a constant electric field of $280 \mathrm{~V} / \mathrm{cm}$ is used to extract the ions formed in the photoionization region. Since the N2P ionization processes compete with many multiphoton ionization and fragmentation channels, it is necessary to optimize the $\mathrm{SH}^{+}$ion signal by varying the dye laser power. As indicated above, the $\mathrm{SH}^{+}$formation is expected to be the result of a three-photon process. This expectation is confirmed by the observed laser power dependence of the $\mathrm{SH}^{+}$signal.

The ZEKE/PFI detection scheme relies on delayed PFI of long-lived high-n Rydberg states populated by laser excitation at a few wavenumbers below the ionization threshold. In this experiment, the firing of the photodissociation and excitation laser is delayed by $650 \mu$ s with respect to the triggering pulse for opening the pulsed valve. A pulsed field of $1.1 \mathrm{~V} / \mathrm{cm}$ with a width of $1 \mu \mathrm{s}$ is applied to the repeller plate $4.5 \mu \mathrm{s}$ after firing the dye laser. The pulsed field serves to field-ionize the molecular species in high-n Rydberg states as well as to extract the electrons thus formed to the microchannel plate electron detector. The firing sequence of the pulsed valve, dye laser, and pulsed electric field is controlled by two digital delay units (Stanford Research DG535). The electron signal from the electron detector and the laser energy signal from the pyroelectric detector are fed into two identical boxcar integrators (Stanford Research SR250), which are 
interfaced to an IBM/AT computer. The electron and laser energy signals are averaged for 30 shots at each laser wavelength.

The bandwidth of the dye laser is $0.2 \mathrm{~cm}^{-1}$ for the fundamental and $\approx 0.4 \mathrm{~cm}^{-1}$ for the second harmonic outputs. For a two-photon ionization process, the resolution due to the ionization laser is expected to be $\approx 0.8 \mathrm{~cm}^{-1}$. In order to examine the PE energy resolution of this experiment, we have reproduced the N2P-PFI-PE spectrum for $\mathrm{H}_{2} \mathrm{~S}$ reported previously. ${ }^{20}$ Figure 2 shows a section of the N2P-PFI-PE spectrum for $\mathrm{H}_{2} \mathrm{~S}$, together with the assignment, in the region of $84,388-84,496 \mathrm{~cm}^{-1}\left(2 \times 42,194-2 \times 42,248 \mathrm{~cm}^{-}\right.$ 1) obtained using a pulsed field of $0.55 \mathrm{~V} / \mathrm{cm}$. In this experiment, the excitation laser is delayed by $450 \mu \mathrm{s}^{41}$ with respect to the triggering pulse for opening the pulsed valve. Since the spectrum of Fig. 2 is similar to that obtained by Bondybey and co-workers, ${ }^{20}$ we conclude that the PE energy resolution achieved in this experiment is similar to that used in the previous experiment. 
Figure 2. N2P-PFI-PE spectrum for $\mathrm{H}_{2} \mathrm{~S}$ in the region of $42,194-42,248 \mathrm{~cm}^{-1}$, together with the rotational assignment (see Ref. 20), obtained using a pulsed field of $0.55 \mathrm{~V} / \mathrm{cm}$. The PE signals $\left[\mathrm{I}\left(\mathrm{e}^{-}\right)\right]$have not been normalized with the photoionization laser pulse energy. 


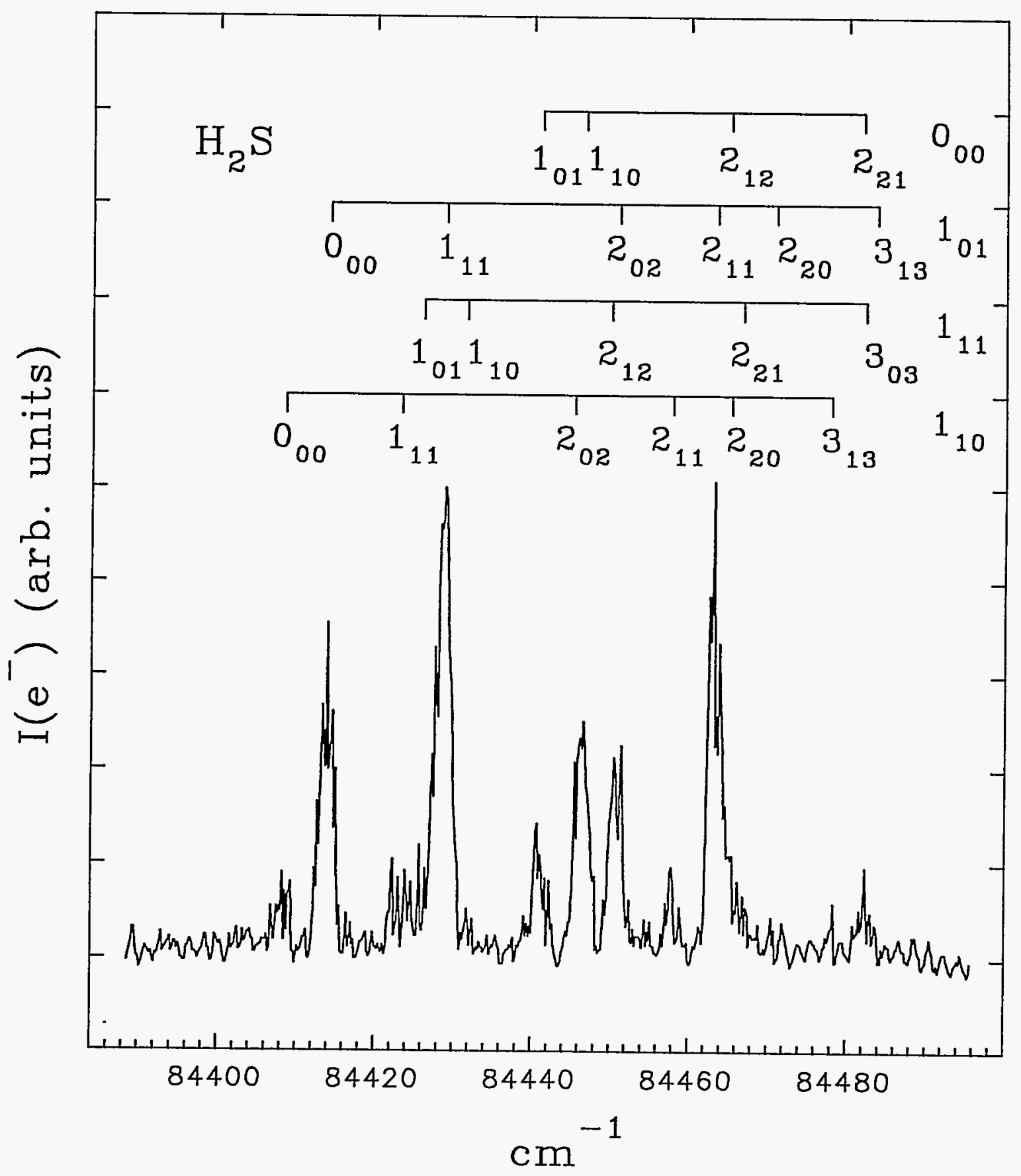




\section{RESULTS AND DISCUSSION}

The photoionization efficiency (PIE) spectrum for $\mathrm{SH}^{+}$observed in the region $83,000-85,080 \mathrm{~cm}^{-1}\left(2 \times 41,500-2 \times 42,540 \mathrm{~cm}^{-1}\right)$ is depicted in Fig. 3. Here, we note that $\mathrm{SH}^{+}$ions are formed by N2P ionization instead of PFI. Since $\mathrm{SH}^{+}$is produced by a threephoton process, the $\mathrm{SH}^{+}$signals have been normalized by the cubic power of the laser energy. The N2P-PIE spectrum is roughly similar to the PIE spectrum for $\mathrm{SH}^{+}$measured in a VUV PIE experiment. ${ }^{42}$

The ionization energy (IE) for $\mathrm{H}_{2} \mathrm{~S}$ is $10.4683 \pm 0.0002 \mathrm{Ev}\left(84,432 \pm 2 \mathrm{~cm}^{-1}\right)^{20}$, which is higher than that for $\mathrm{SH}(10.43 \pm 0.03 \mathrm{Ev})^{43}$. As shown in Fig. 3, the PIE for $\mathrm{SH}^{+}$rises above the background level at $\approx 83,320 \mathrm{~cm}^{-1}\left(2 \times 41,660 \mathrm{~cm}^{-1}\right)$, an energy lower than the IE of SH. The gradual increase in the PIE for $\mathrm{SH}^{+}$is consistent with the interpretation that some of the SH radicals formed by process (1) in the energy range of $41,500-42,540 \mathrm{~cm}^{-1}$ are internally excited. The previous photodissociation study of $\mathrm{H}_{2} \mathrm{~S}$ by Weiner et al. ${ }^{44}$ indicates that the excited $\mathrm{SH}\left({ }^{2} \Pi_{I / 2}\right)$ spin-orbit state, which lies 376.96 $\mathrm{cm}^{-1}$ (Ref. 45) above the ground $\mathrm{SH}\left(X^{2} \Pi_{3 / 2}\right)$ state, is significantly populated. The population ratios $\mathrm{SH}\left(X^{2} \Pi_{3 / 2}\right) / \mathrm{SH}\left({ }^{2} \Pi_{1 / 2}\right)$ are measured to be 1.48 and 1.18 at the photolysis wavelengths of 222 and $248 \mathrm{~nm}$, respectively. The same study also found that the rotational state distributions of SH formed by process (1) at 193, 222, and $248 \mathrm{~nm}$ are nearly identical and can be characterized by a rotational temperature of $\approx 300 \mathrm{~K}^{.4}$ Although vibrationally excited $\mathrm{SH}$ radicals are also produced, it is well known from previous photodissociation experiments that $\mathrm{SH}\left(X^{2} \Pi\right)$ radicals of process (1) at these 
Figure 3. N2P-PIE spectrum for $\mathrm{SH}^{+}$in the region of $41,500-42,540 \mathrm{~cm}^{-1}$. The $\mathrm{SH}^{+}$ ion signals $\left[\mathrm{I}\left(\mathrm{SH}^{+}\right)\right]$have been normalized by the cubic power of the laser pulse energy. 


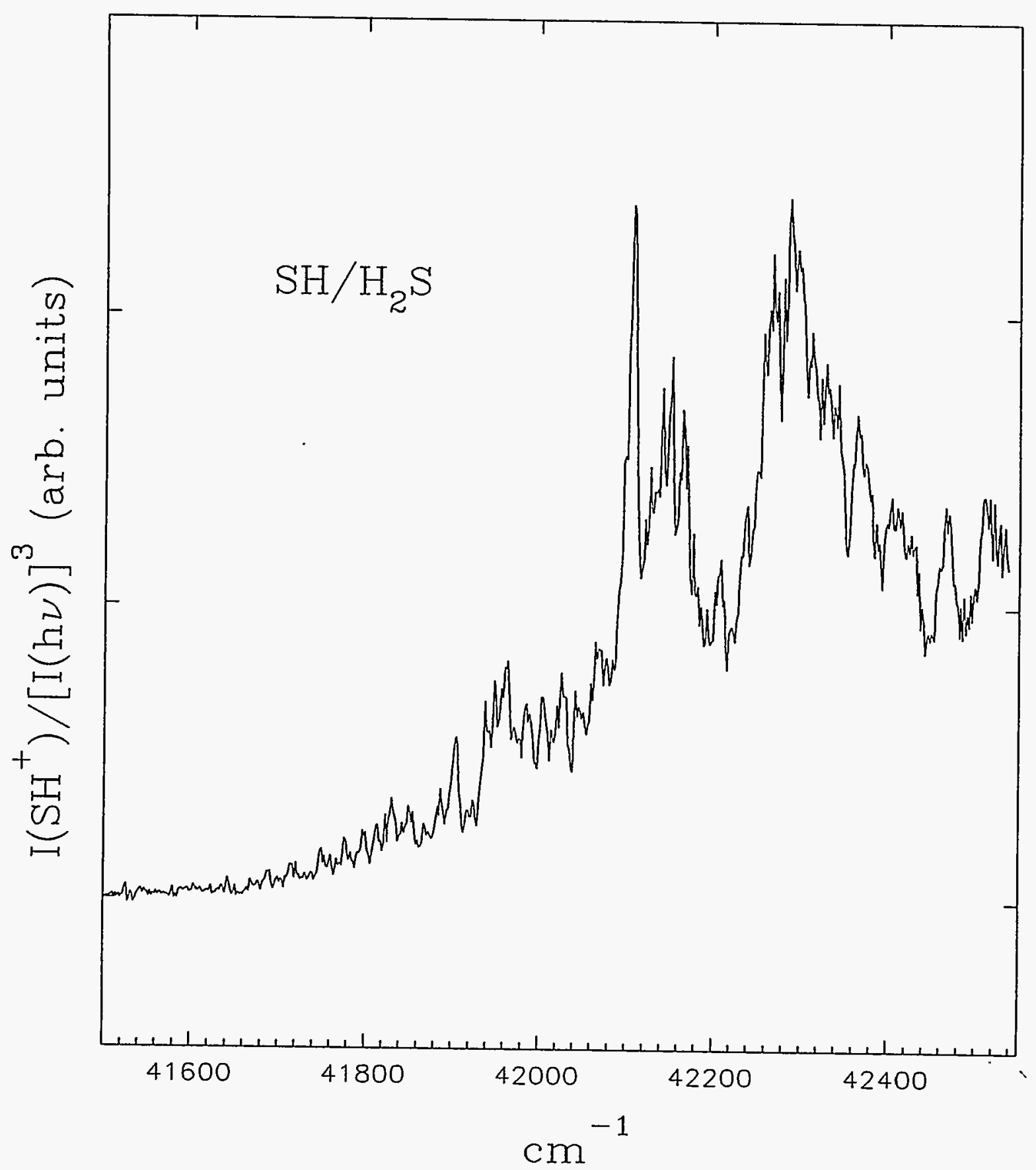


photolysis wavelengths are predominantly in the $\nu=0$ vibrational ground state. ${ }^{46}$

Figures 4(a) and 5(a) show the N2P-PFI-PE spectra for SH observed in the regions $83,100-83,800$ and $83,800-84,500 \mathrm{~cm}^{-1}$, respectively. The pulsed field of $1.1 \mathrm{~V} / \mathrm{cm}$ used here corresponds to a Stark shift ${ }^{47}$ of $\approx 3.1 \mathrm{~cm}^{-1}$ for a PFI-PE peak center. This shift has not been corrected for in the figures. The PE signals plotted in the figures have been normalized to the cubic power of the laser energy. We expect that the structures at energies below $84,432 \mathrm{~cm}^{-1}$, the IE for $\mathrm{H}_{2} \mathrm{~S}$, result predominantly from the N2P-PFI of SH formed in process (1). Two strong PE peaks at $41,579.7 \mathrm{~cm}^{-1}$ and $41,778.1 \mathrm{~cm}^{-1}$ [marked ( $\nabla$ ) in Fig. 4(a)] are identified as the PFI-PE peaks for sulfur atom, corresponding to the ionization transitions $\mathrm{S}^{+}\left({ }^{4} S^{\circ}{ }_{3 / 2}\right) \leftarrow \mathrm{S}\left(3 p^{4}{ }^{3} P_{1}\right)$ and $\mathrm{S}^{+}\left({ }^{4} S^{\circ}{ }_{3 / 2}\right) \leftarrow \mathrm{S}\left(3 p^{4}{ }^{3} P_{2}\right)$, respectively. ${ }^{40}$ The latter peak is found to overlap with PE peaks of SH.

Some features observed close to the IE of $\mathrm{H}_{2} \mathrm{~S}$ may be due to the hot band ionization of $\mathrm{H}_{2} \mathrm{~S}$. Since $\mathrm{H}_{2} \mathrm{~S}^{+}$and $\mathrm{SH}^{+}$are formed by two-photon and three-photon processes, respectively, it is possible to examine the influence of $\mathrm{H}_{2} \mathrm{~S}$ ionization on the PFI-PE spectrum of SH by measuring the spectrum at different laser pulse energies. Figures $6(\mathrm{a})$ and $6(\mathrm{~b})$ show the spectra taken at laser pulse energies of 1.2 and $0.7 \mathrm{~mJ}$, respectively. As shown in these figures, the relative intensities for the PE peaks observed in the region of $41,600-42,100 \mathrm{~cm}^{-1}$ remain essentially unchanged, whereas the intensities for most of the PE features in the region greater than $42,100 \mathrm{~cm}^{-1}$ increase significantly with respect to those for PE peaks in the $41,600-42,100 \mathrm{~cm}^{-1}$ region as the laser energy is decreased. At the lower laser energy of $0.7 \mathrm{~mJ}$, the PE band in the region greater than $42,100 \mathrm{~cm}^{-1}$ becomes dominant compared to those at lower energies. This observation 
Figure 4. (a) N2P-PFI-PE spectrum for $\mathrm{SH}\left(X^{2} \Pi_{3 / 2,1 / 2}\right)$ in the region of $41,550-41,900$ $\mathrm{cm}^{-1}$. The PE signals $\left[\mathrm{I}\left(\mathrm{e}^{-}\right)\right]$have been normalized by the cubic power of the laser pulse energy. The two peaks marked by triangles at $41,579.7 \mathrm{~cm}^{-1}$ and $41,778.1 \mathrm{~cm}^{-1}$ are identified as the PFI-PE peaks for sulfur atom, corresponding to the ionization transitions $\mathrm{S}^{+}\left({ }^{4} S^{\circ}{ }_{3 / 2}\right) \leftarrow S\left(3 p^{4}{ }^{3} P_{1}\right)$ and $\mathrm{S}^{+}\left({ }^{4} S^{\circ}{ }_{3 / 2}\right) \leftarrow \mathrm{S}\left(3 p^{4}{ }^{3} P_{2}\right)$, respectively.

(b) Simulated PE spectrum for $\mathrm{SH}\left(\mathrm{X}^{2} \Pi_{3 / 2,1 / 2}\right)$ in the region of $41,550-41,900$ $\mathrm{cm}^{-1}$. The positions of the $\mathrm{S}_{\mathrm{i} 2}$ and $\mathrm{T}_{\mathrm{i} 2}\left(\mathrm{i}=\mathrm{F}_{1}{ }^{+}, \mathrm{F}_{2}{ }^{+}\right.$, and $\left.\mathrm{F}_{3}{ }^{+}\right)$rotational branches (dashed lines) are not included in the simulation. 


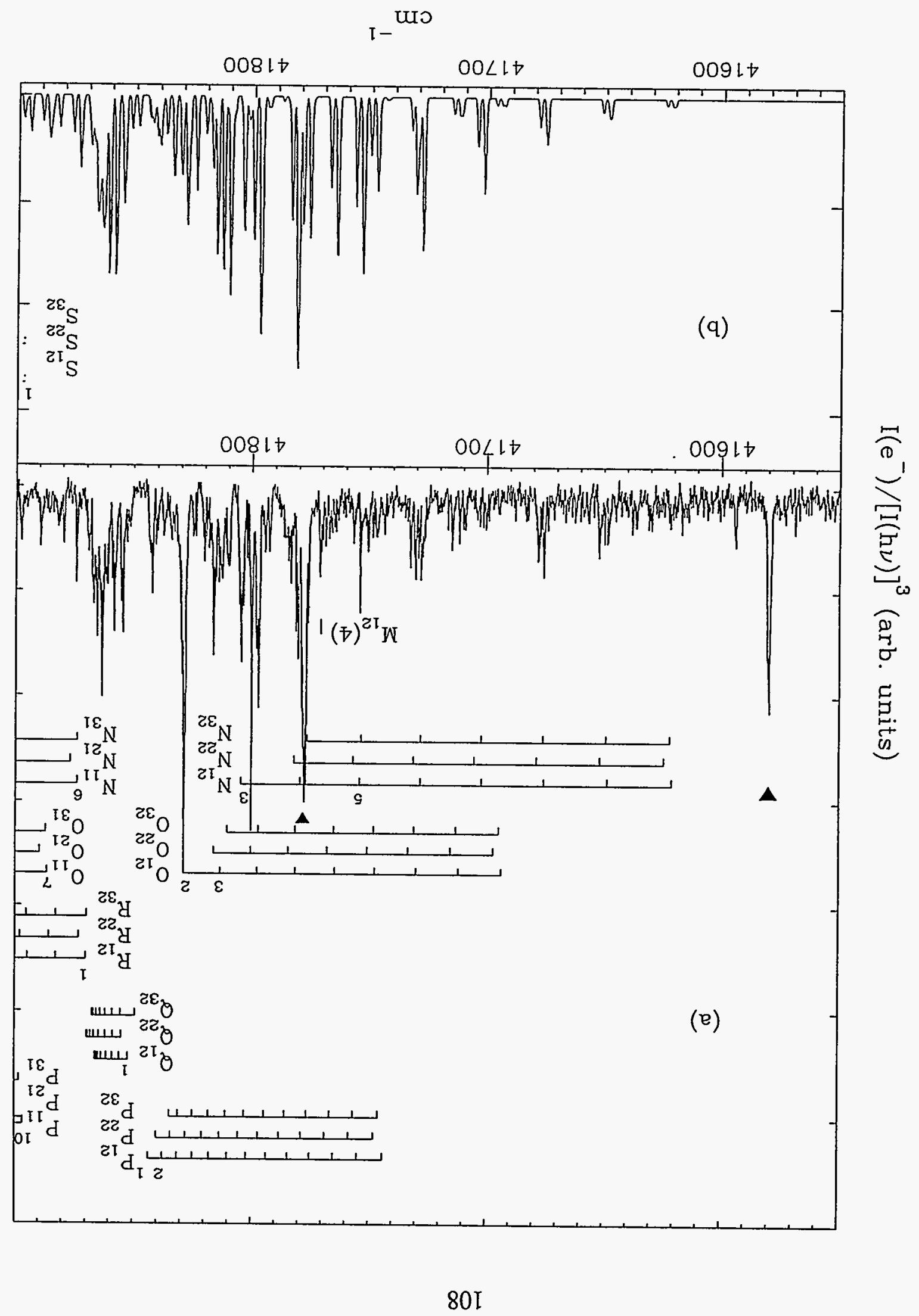


Figure 5. (a) N2P-PFI-PE spectrum for $\mathrm{SH}\left(X^{2} \Pi_{3 / 2,1 / 2}\right)$ in the region of $41,900-42,250$ $\mathrm{cm}^{-1}$. The PE signals $[\mathrm{I}(\mathrm{e})]$ have been normalized by the cubic power of the laser pulse energy. The PE peaks marked by asterisks are attributable to hot band ionization of $\mathrm{H}_{2} \mathrm{~S}$.

(b) Simulated PE spectra for $\mathrm{SH}\left(X^{2} \Pi_{3 / 2,1 / 2}\right)$ in the region of $41,900-42,250$ $\mathrm{cm}^{-1}$. The position for the $\mathrm{S}_{\mathrm{i} 1}, \mathrm{~T}_{\mathrm{i} 1}, \mathrm{~S}_{\mathrm{i} 2}$, and $\mathrm{T}_{\mathrm{i} 2}\left[\mathrm{i}=1\left(\mathrm{~F}_{1}{ }^{+}\right), 2\left(\mathrm{~F}_{2}{ }^{+}\right)\right.$, and 3 $\left(\mathrm{F}_{3}{ }^{+}\right)$] rotational branches are shown by dashed lines. These branches are not included in the simulation. 


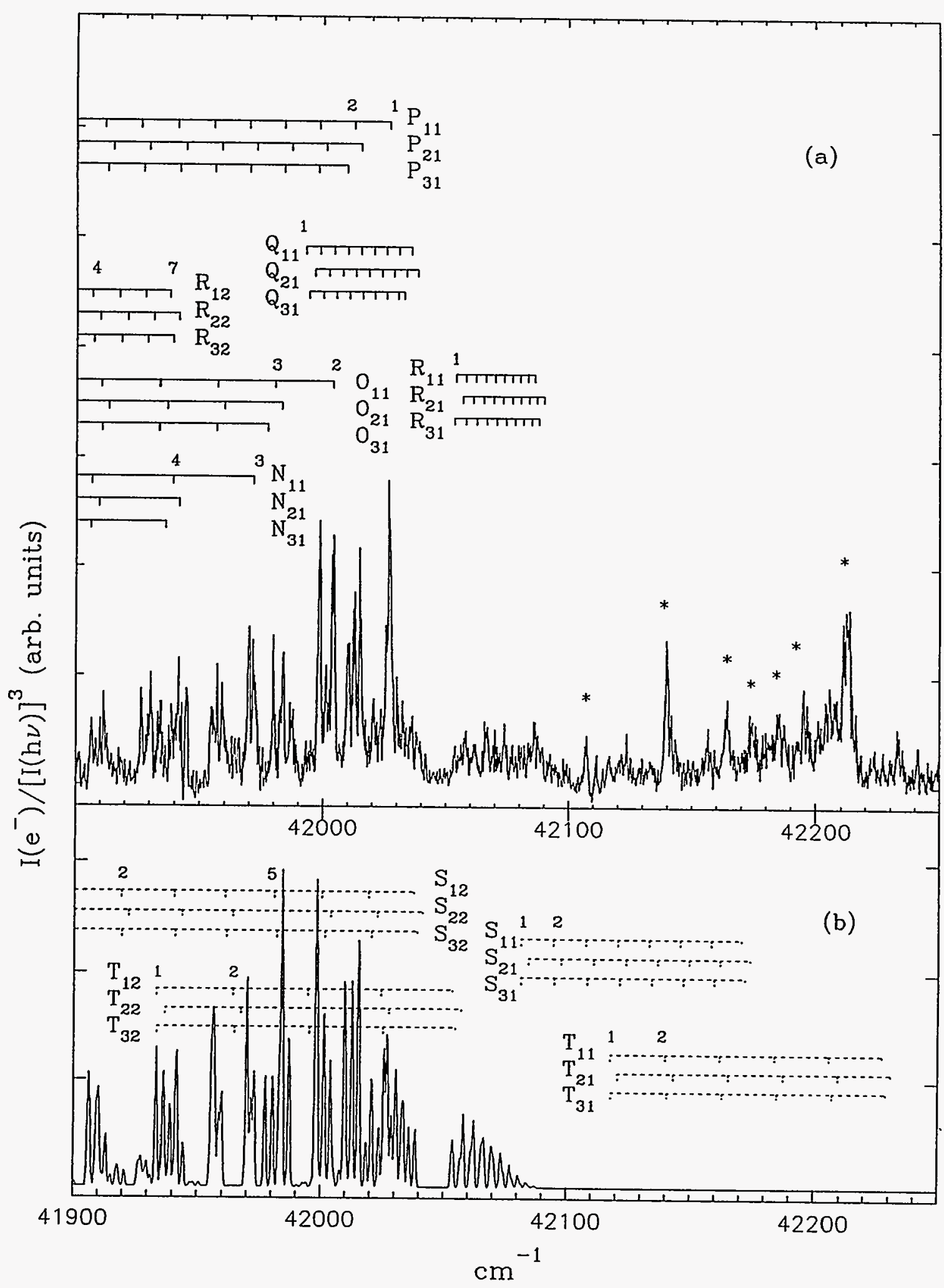


Figure 6. PFI-PE spectra in the region of $41,520-42,300 \mathrm{~cm}^{-1}$ obtained at a laser pulse energy (a) $1.2 \mathrm{~mJ}$ and (b) $0.7 \mathrm{~mJ}$. The PE signals [I(e)] have not been normalized by the laser pulse energy. 


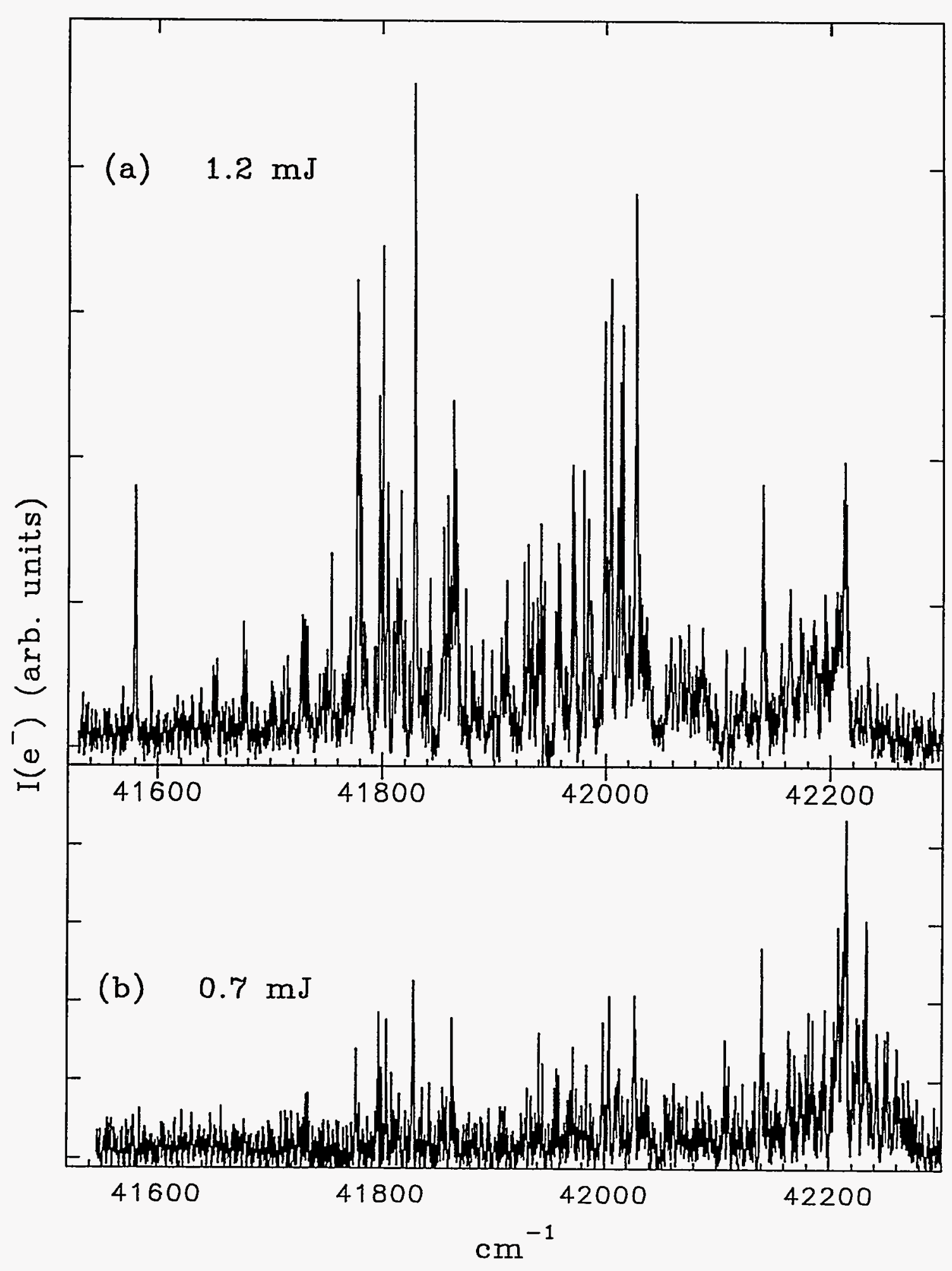


indicates that the prominent features in the region greater than $\approx 42,100 \mathrm{~cm}^{-1}$ are attributable to hot band ionization of $\mathrm{H}_{2} \mathrm{~S}$.

The neutral $\mathrm{SH}\left(X^{2} \Pi\right)$ ground state can be characterized by the Hund's case (a) coupling scheme. ${ }^{45}$ This is justified because of the large spin-orbit splitting and the relatively low rotational state population (with the maximum rotational level $N^{n} \approx 10$ ) for $\mathrm{SH}\left(X^{2} \mathrm{I}\right)$ formed in this experiment. The $\mathrm{F}_{1}\left(J^{\prime \prime}=N^{\prime \prime}+1 / 2\right)$ and $\mathrm{F}_{2}\left(J^{\prime \prime}=N^{\prime \prime}-1 / 2\right)$ levels refer to the ${ }^{2} \Pi_{3 / 2}$ and ${ }^{2} \Pi_{1 / 2}$ spin-orbit states of $S H$, respectively. The energy expression for the Hund's case (b) coupling is used to describe the $\mathrm{SH}^{+}\left(\mathrm{X}^{3} \Sigma^{-}\right)$ionic ground state. The ionic rotational level labelled by $N^{+}$represents the core angular momentum excluding electron spin. When the interaction with electron spin is taking into account, each rotational level splits into three spin-rotation fine structure components with the total angular momentum $J^{+}=N^{+}+1\left(\mathrm{~F}_{1}^{+}\right.$level $), J^{+}=N^{+}\left(\mathrm{F}_{2}{ }^{+}\right.$level $)$, and $J^{+}=N^{+}-1\left(\mathrm{~F}_{3}{ }^{+}\right.$ level).

The $\pi$-valence molecular orbitals in the $\mathrm{SH}\left(X^{2} \Pi_{i}\right)$ state are pure $3 p_{u}$ atomic-like species. ${ }^{48}$ The simultaneous absorption of two photons should favor the ejection of a $p$ or an $f$ electron within the sudden approximation. The electron angular momentum $\ell$ for an odd partial wave ( $p$ or $f$ ) has negative parity. Most of the peaks observed are assigned to the transitions with the angular momentum transfer $|\Delta J| \leq 7 / 2$ (see discussion below). Therefore, it is likely that the ionization process involves the emission of a $p$ partial wave photoelectron. Nevertheless, this cannot exclude the possibility for the emission of an $f$ partial wave photoelectron. McKoy and co-workers ${ }^{49,50}$ have shown that the rescattering 
of the photoelectron within the ion core is very important and can lead to a significant change in angular momentum of the final continuum channel. The rescattering could alter the primary odd $\ell$ electron into a partial wave channel of even $\ell$.

Figure 7 shows a transition diagram for the $\mathrm{N}, \mathrm{O}, \mathrm{P}, \mathrm{Q}, \mathrm{R}$, and $\mathrm{S}$ rotational branches from $\left(N^{\prime \prime}, J^{\prime \prime}\right)$ levels of $\operatorname{SH}\left(X^{2} \Pi_{3 / 2}\right)$. Each rotational level for $\operatorname{SH}\left(X^{2} \Pi_{3 / 2}\right)$ is split into the positive parity $\left(\Pi^{+}\right)$and negative parity $\left(\Pi^{-}\right)$components. The average ratio $\Pi^{+} / \Pi^{-}$was found to be about one for SH formed at 193, 222, and $248 \mathrm{~nm} .{ }^{44}$ Based on this result, we estimated that the $\Pi^{+}$and $\Pi^{-}$components of $S H$ are produced with equal intensities by process (1) at $234-240 \mathrm{~nm}$ in this experiment. The small $\Lambda$-doubling cannot be resolved using our experimental energy resolution. The angular momentum selection rules for two-photon ionization of a diatomic molecule limit the allowed transitions to $\Delta J$ $=J^{+}-J^{\prime \prime}=\ell+5 / 2, \ldots,-\ell-5 / 2$, where $\ell$ is the angular momentum for the photoelectron. If we assume that photoionization predominantly involves the ejection of an odd ( $p$ or $f$ ) $\ell$ partial wave photoelectron, we could associate the transition ending on $N^{+}=0,2 \ldots$ (even) states from the $\Pi^{+}$state of $\mathrm{SH}$ and $N^{+}=1,3 \ldots$ (odd) from the $\Pi^{-}$ state of SH.

The rotational branches $(\mathrm{N}, \mathrm{O}, \mathrm{P}, \mathrm{Q}, \mathrm{R}, \mathrm{S}$, and $\mathrm{T})$ designate the changes in the core angular momentum apart from spin, $\Delta N\left(=N^{+}-N^{\prime \prime}\right)=-3,-2,-1,0,+1,+2$, and +3 , respectively. The first and second subscripts attached to the rotational branches [see Figs. 4(a) and 5(a)] denote the $\mathrm{F}^{+}\left(\mathrm{F}_{1}{ }^{+}, \mathrm{F}_{2}{ }^{+}\right.$, or $\left.\mathrm{F}_{3}{ }^{+}\right)$levels for $\mathrm{SH}^{+}\left(\mathrm{X}^{3} \Sigma\right)$ and the $\mathrm{F}\left(\mathrm{F}_{1}\right.$ or $\left.\mathrm{F}_{2}\right)$ levels for $\mathrm{SH}\left(\mathrm{X}^{2} \Pi_{i}\right)$, respectively. For example, the $\mathrm{P}_{21}(2)$ line represents the transition originating from the $N^{\prime \prime}=2$ and $J^{\prime \prime}=5 / 2\left(\mathrm{~F}_{1}\right.$ level) of the $\operatorname{SH}\left(X^{2} \Pi_{3 / 2}\right)$ state and 
Figure 7. Schematic diagram for the energy levels and symmetry labels for two-photon ionization transitions from the $\mathrm{F}_{1}$ $\left(X^{2} \Pi_{3 / 2}\right)$ manifold of $\mathrm{SH}$ to the $\mathrm{F}_{1}{ }^{+}, \mathrm{F}_{2}{ }^{+}$, and $\mathrm{F}_{3}{ }^{+}$levels of $\mathrm{SH}^{+}\left(X^{3} \Sigma^{-}\right)$. Typical transitions for the $\mathrm{N}, \mathrm{O}, \mathrm{P}, \mathrm{Q}, \mathrm{R}$, and $\mathrm{S}$ branches are shown. The subscript $\mathrm{i}=1\left(\mathrm{~F}_{1}^{+}\right), 2\left(\mathrm{~F}_{2}^{+}\right)$, and $3\left(\mathrm{~F}_{3}^{+}\right)$. 

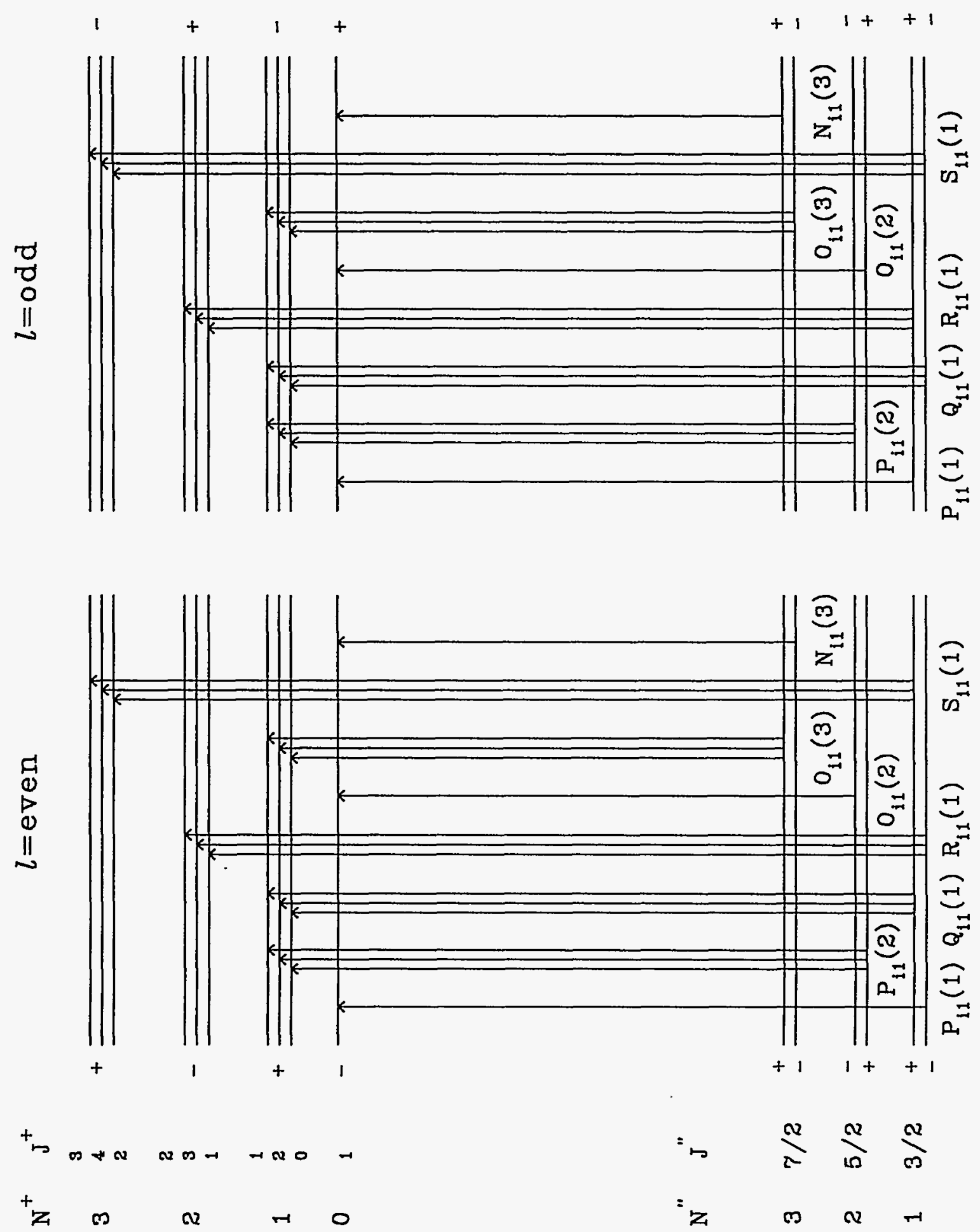
ending on the $N^{+}=1$ and $J^{+}=1\left(\mathrm{~F}_{2}^{+}\right.$level $)$of the $\mathrm{SH}^{+}\left(X^{3} \Sigma^{-}\right)$state.

In order to understand the photoionization dynamics of $\mathrm{SH}$, it is necessary to simulate the relative intensities for PE peaks observed in the spectra of Figs. 4(a) and 5(a). Xie and Zare ${ }^{51}$ have derived electric-dipole-allowed photoionization selection rules for the interpretation of rotationally resolved PE spectra for diatomic molecules. However, the theoretical treatment for photoionization out of a valence ${ }^{2} \Pi$ state [Hund's case (a)] has not yet been worked out in detail. We have attempted to simulate the experimental PE spectrum of SH semi-empirically by adjusting the relative intensities $\left[\mathrm{I}_{\mathrm{B}}\right]$ for the rotational branches $(B=N, O, P, Q, R, S$, or $T)$. For a given spin-orbit $\left({ }^{2} \Pi_{3 / 2}\right.$ or $\left.{ }^{2} \Pi_{1 / 2}\right)$ manifold, the relative PE peak intensities $\left[I_{\mathrm{PE}}\left(\mathrm{B}, J^{\prime \prime}\right)\right]$ are calculated as,

$$
\mathrm{I}_{\mathrm{PE}}\left(\mathrm{B}, J^{\prime \prime}\right)=\mathrm{r}_{\mathrm{B}}\left[\left(2 J^{\prime \prime}+1\right) / \mathrm{Q}_{\mathrm{rot}}\right] \exp \left(-\Delta \mathrm{E}_{\mathrm{rot}} / \mathrm{kT}_{\mathrm{r}}\right),
$$

where $\Delta \mathrm{E}_{\text {rot }}$ is the rotational energy measured with respect to the energy for the lowest $J^{\prime \prime}$ level of the spin-orbit states $\left[-170 \mathrm{~cm}^{-1}\right.$ for $\mathrm{SH}\left(X^{2} \Pi_{3 / 2}\right)$ and $+198 \mathrm{~cm}^{-1}$ for $\left.S H\left({ }^{2} \Pi_{1 / 2}\right)\right]$ and $\mathrm{Q}_{\mathrm{rot}}$ is the rotational partition function. We assume that the probabilities are identical for the ionization transitions from a specific $\Pi^{+}$or $\Pi^{-}$state of $\mathrm{SH}$ to the $\mathrm{F}^{+}\left(\mathrm{F}_{1}{ }^{+}, \mathrm{F}_{2}{ }^{+}, \mathrm{F}_{3}{ }^{+}\right)$ levels of a given $N^{+}$ionic state. The probabilities for transitions from different $J^{\prime \prime}$ levels within a rotational branch are also assumed to be uniform. Based on the previous photodissociation study of Weiner et al. ${ }^{44}$ we have assumed that the rotational distribution for SH formed here by process (1) is characterized by a temperature of $300 \mathrm{~K}$ for both of the spin-orbit states. The calculated intensities are combined with a Gaussian line shape 
with a full-width-at-half-maximum of $1 \mathrm{~cm}^{-1}$. The rotational, fine structure, and centrifugal constants for $\mathrm{SH}^{+}$are taken from Horani et al. ${ }^{52}$ (Ref. 53), and the rotational and centrifugal constants for SH are obtained from Ramsey ${ }^{54}$ (Ref. 55). The transition frequencies calculated based on these constants agree with the experimental PE peak positions to within $2 \mathrm{~cm}^{-1}$. Although the energy resolution is not sufficient to resolve the small $\Lambda$-doubling, many of the spin-rotation components for $\mathrm{SH}^{+}\left(X^{3} \Sigma^{-}\right)$are resolved in the spectra shown in Figs. 4(a) and 5(a). In the simulation, we found that the intensities for the $\mathrm{S}$ and $\mathrm{T}$ branches are small compared to the $\mathrm{N}, \mathrm{O}, \mathrm{P}, \mathrm{Q}$, and $\mathrm{R}$ branches. The simulated spectra shown in Figs. 4(b) and 5(b) are obtained using the relative rotational branch intensities, $r_{N}: r_{O}: r_{P}: r_{Q}: r_{R}=0.19: 0.23: 0.37: 0.14: 0.07$ and $0.32: 0.36$ : $0.11: 0.16: 0.05$ for ionization from the $\mathrm{SH}\left(X^{2} \Pi_{3 / 2}\right)$ and $\mathrm{SH}\left({ }^{2} \Pi_{1 / 2}\right)$ states, respectively. The simulated spectra reproduce roughly the general profile of relative experimental peak intensities. The differences in detail between the simulated and experimental spectra can be attributed partly to local autoionization mechanisms. For example, the relative intensities of the two peaks observed at $84,057.5 \mathrm{~cm}^{-1}\left[\mathrm{P}_{1}(1)\right]$ and $83,660.3 \mathrm{~cm}^{-1}\left[\mathrm{O}_{12}(2)\right]$ are significantly stronger than those predicted by the simulated spectra. The strong intensities observed for the $P_{1}(1)$ and $\mathrm{O}_{12}(2)$ lines may be due to near resonance autoionization processes. Furthermore, the characterization of the rotational distribution of $\mathrm{SH}$ produced by process (1) using an equilibrium rotational temperature is an crude assumption. The deviation of the actual rotational distribution of SH from the assumed equilibrium distribution will also limit the ability of Eq. (3) to reproduce the experimental PE spectrum of SH. We note that a PE peak at $41,770.6 \mathrm{~cm}^{-1}$ [Fig. 4(a)] coincides with 
the expected $\mathrm{M}_{12}(4)$ transition. Since no other structures can definitely be correlated with the $\mathrm{M}$ branch transitions, the existence of the $\mathrm{M}$ branch must be considered as uncertain.

Although the contributions for the $S_{i 2}$ and $T_{i 2}(i=1-3)$ rotational branches are neglected in the simulation of the spectrum in the energy region lower than $42,100 \mathrm{~cm}^{-1}$, we have marked (dashed lines) the positions of the these branches in Figs. 4(b) and 5(b) to illustrate the lack of correlations of the predicted and experimental PE peaks. The predicted positions of the $S_{i 1}$ and $T_{i 1}(i=1-3)$ branches fall in the region greater than $42,080 \mathrm{~cm}^{-1}$ and are also marked (dashed lines) in Figs. 5(b). As pointed out above, the intensities of the major features [marked in asterisks in Fig. 5(a)], observed in this region increases significantly relative to PE peaks at lower energies as the laser pulsed energy is decreased, supporting the conclusion that these features are attributable to hot band ionization of $\mathrm{H}_{2} \mathrm{~S}$. Due to the interference of these prominent PE features of $\mathrm{H}_{2} \mathrm{~S}$, the analysis of the remaining minor PE features are difficult. It is possible that some of these weak PE structures are attributable to the $S_{i 1}$ and $T_{i 1}(i=1-3)$ rotational branches. However, by comparing the intensities of PE peaks in this region and those in lower energies, we conclude that the $S_{i 1}$ and $T_{i 1}(i=1-3)$ branches are weak with intensities lower than that of the $R_{i 1}(i=1-3)$ branch. For this reason, we have not included the $S_{i 1}$ and $T_{i 1}(i=1-3)$ branches in the simulation.

Based on the simulation shown in Figs. 4(b) and 5(b), we conclude that the intensities for the rotational branches with $\Delta N \leq 0$ are significantly stronger than those with $\Delta N>0$. The rotational angular momentum transfer $\Delta N$ up to -3 is observed. Similar observations of enhanced intensities for $\Delta N \leq 0$ rotational branches have been 
reported in the studies of NO (Refs. 11-13), $\mathrm{OH}$ (OD) (Ref. 14), $\mathrm{N}_{2} \mathrm{O}$ (Ref. 16), and $\mathrm{HCl}$ (Refs. 15, 56). This phenomenon is rationalized by electric-field-induced rotational autoionization processes. ${ }^{14}$ This propensity can be accounted for by the interaction of the high-n-Rydberg $(n>150)$ states close to a rotational ionization limit of the ion with the lower-n-Rydberg $(20<\mathrm{n}<80)$ states converging to a higher rotational ionization limit. ${ }^{14}$ It is plausible that the application of the pulsed electric field ionizes the high-n-Rydberg molecules and simultaneously allows the isoenergetic low-n-Rydberg states to autoionize. Since the rotational spacing is smaller for lower $\mathrm{N}^{+}$levels than for higher $\mathrm{N}^{+}$levels, the density of available isoenergetic lower-n Rydberg states is greater for field-induced autoionization into lower $\mathrm{N}^{+}$levels. Furthermore, the optical excitation to lower- $\mathrm{n}$ Rydberg states converging to higher $\mathrm{N}^{+}$levels is limited by the relatively cold rotational distribution of SH. Because of the greater number of optically accessible lower-n Rydberg state converging to lower $\mathrm{N}^{+}$levels, field-induced rotational autoionization favors the $\Delta N$ $\leq 0$ rotational branches.

Another possible mechanism involves a heterogeneous perturbation of the Rydberg state. ${ }^{57}$ It is generally found that in heterogeneous interaction, the $\mathrm{P}$ branches for transitions to high-n-Rydberg states are enhanced and the corresponding $R$ branches are weakened, while the opposite holds for transitions to the lower-n-Rydberg states. Since electrons are excited to the high-n-Rydberg states before the application of field ionization, the perturbation by the Rydberg state may favor the transition amplitude for the branches with $\Delta N \leq 0$ relative to those with $\Delta N>0$.

After taking into account the Stark shift correction, the ionization energy IE for 
$\mathrm{SH}\left(X^{2} \Pi_{3 / 2}\right)$ is $84,057.5 \pm 3 \mathrm{~cm}^{-1}(10.4219 \pm 0.0004 \mathrm{eV})$, as determined by the lowest possible ionization transition, i.e., the $\mathrm{P}_{1}(1)$ line. This value favorably compares to a value of $10.43 \pm 0.03 \mathrm{eV}$ obtained from the extrapolation of a short Rydberg series. ${ }^{43}$

Since the sampling of SH by PFI takes place in a collision free environment, knowing the photoionization oscillator strengths would have allowed the estimation of the nascent SH product state distribution. Although the oscillator strengths for photoionization transitions of interest to the present experiment are unknown, preventing a detailed simulation of the PE spectrum for SH, we may conclude from the semi-empirical analysis that SH radicals are produced in both the $X^{2} \Pi_{3 / 2}$ and ${ }^{2} \Pi_{1 / 2}$ states by process (1), and that the rotational distributions of $\mathrm{SH}$ in these two spin-orbit states can be characterized by a rotational temperature of $\approx 300 \mathrm{~K}$, in accordance with previous observations. 


\section{CONCLUSION}

Using the N2P-PFI scheme, we have obtained the threshold PE spectra for SH at high resolution. The assignment of the rotationally-resolved N2P-PFI-PE spectrum allows highly accurate determination of the IE for SH. A propensity favoring the rotational branches with $\Delta N \leq 0$ is observed for SH. Pulsed field ionization PE detection can be a sensitive and quantitative means for probing the nascent state distribution of photoproducts when the oscillator strengths for photoionization are known. We hope that this study will stimulate a detailed theoretical interpretation of the observed PE spectrum for SH. 


\section{REFERENCES}

(1) J. W. Rabalais, "Principles of Ultraviolet Photoelectron Spectroscopy" (Wiley, New York, 1977).

(2) G Reiser, W. Habenicht, K. Müller-Dethlefs, and E. W. Schlag, Chem. Phys. Lett. 152, 119 (1988).

(3) K. Müller-Dethlefs, M. Sander, and E. W. Schlag, Z. Naturforsch. A 모, 1089 (1984).

(4) K. Müller-Dethlefs and E. W. Schlag, Annu. Rev, Phys. Chem. 42, 109 (1991).

(5) R. G. Tonkyn, J. W. Winniczek, and M. G. White, Chem. Phys. Lett. 164, 137 (1989).

(6) M. Braunstein, V. McKoy, S. N. Dixit, R. G. Tonkyn, and M. G. White, $J$. Chem. Phys. 93, 5345 (1990).

(7) W. Kong, D. Rogers, and J. W. Hepburn, Chem. Phys. Lett. 203, 497 (1993).

(8) W. Kong, D. Rogers, J. W. Hepburn, K. Wang, and V. McKoy, J. Chem. Phys. 99, 3159 (1993).

(9) R. T. Wiedmann, M. G. White, K. Wang, and V. Mckoy, J. Chem. Phys. $\underline{98}$, 7673 (1993).

(10) K. Müller-Dethefs, M. Sander, and E. W. Schlag, Chem Phys. Lett. 112, 291 (1984).

(11) G. Reiser and K. Müller-Dethelefs, J. Phys. Chem. 6, 9 (1992).

(12) M. Sander, L. A. Chewter, K. Müller-Dethefs, and E. W. Schlag, Phys. Rev. A 
$\underline{36}, 4543$ (1987).

(13) A. Stribel, I. Fischer, J. Staecker, G. Niedner-Schatteburg, K. Müller-Dethlefs and C. E. Bondybey, J. Chem. Phys. 97, 2332 (1992).

(14) R. T. Wiedmann, R. G. Tonkyn, M. G. White, K. Wang, and V. McKoy, J. Chem. Phys. 97, 768 (1992).

(15) R. G. Tonkyn, R. T. Wiedmann, and M. G. White, J. Chem. Phys. 96, 3696 (1992).

(16) R. T. Wiedmann,E. R. Grant, R. G. Tonkyn, and M. G. White, J. Chem. Phys. 95, 746 (1991).

(17) R. G. Tonkyn, R. Wiedemann, E. R. Grant, and M. G. White, J. Chem. Phys. 95, 7033 (1991).

(18) M.-T. Lee, K. Wang, V. McKoy, R. G. Tonykn, R. T. Wiedmann, E. R. Grant, and M. G. White, J. Chem. Phys. 96, 7848 (1992).

(19) R. T. Wiedmann and M. G. White, "Optical Methods for Time- and StateResolved Chemistry", C. Y. Ng, Ed., SPIE Proc. 1638 (1992), p. 273.

(20) I. Fischer, A. Lochschmidt, A. Strobel, G. Niedner-Schatteburg, K. MüllerDethlefs, and V. E. Bondybey, J. Chem. Phys. 98, 3592 (1993).

(21) J. A. Blush, P. Chen, R. T. Wiedman, and M. G. White, J. Chem. Phys. 98 , 3557 (1993).

(22) I. Fischer, A. Lochschmidt, A. Strobel, G. Niedner-Schatteburg, K. MüllerDethelef, and V. E. Bondybey, Chem. Phys. Lett. 202, 542 (1993).

(23) S. T. Pratt, P. M. Dehmer, and J. L. Dehmer, J. Chem. Phys. 99, 6233 (1933). 
(24) A, Strobel, A. Lochschmidt, I. Fisher, G. Niedner-Schatteburg, and V. E. Bondybey, J. Chem. Phys. ⒐ 733 (1993).

(25) W. Habenicht, G. Reiser, and K. Müller-Dethlefs, J. Chem. Phys. 95, 4809 (1991).

(26) G. Reiser, W. Habenicht, and K. Müller-Dethlefs, J. Chem. Phys. 98 , 8462 (1993).

(27) L. A. Chewter, M. Sander, K. Müller-Dethefs, and E. W. Schlag, J. Chem. Phys. $\underline{86}, 4737$ (1987).

(28) G. C. Eiden, F. Weinhold, and J. C. Weisshaar, J. Chem. Phys. 95, 8665 (1991).

(29) I. Fischer, A. Strobel, J. Staecher, G. Niedner-Schatteburg, K. Müller-Dethlefs, and V. E. Bondybey, J. Chem. Phys. 96, 7171 (1992).

(30) K. Norwood, S Nourbakhsh, G.-Z. He, and C. Y. Ng, Chem. Phys. Lett. 184, 147 (1991).

(31) S. Nourbakhsh, K. Norwood, G.-Z. He, and C. Y. Ng, J. Am. Chem. Phys. 113 , $6311(1991)$.

(32) S. Nourbakhsh, K. Norwood, H-M. Yin, C.-L. Liao, and C. Y. Ng, J. Chem. Phys. 95, 946 (1991).

(33) S. Nourbakhsh, C.-L. Liao, and C. Y. Ng, J. Chem. Phys. 92, 6587-93 (1990).

(34) S. Nourbakhsh, K. Norwood, H.-M. Yin, C.-L. Liao, and C. Y. Ng, J. Chem. Phys. 95, 5014-5023 (1991).

(35) Z.-X. Ma, C.-L. Liao, H.-M. Yin, C. Y. Ng, S.-W. Chiu, I. Ma, and W.-K. Li, , Chem. Phys. Lett. 213, 250 (1993). 
(36) W.-K. Li, S.-W. Chiu, and C. Y. Ng, J. Chem. Phys. 99, 8440 (1993).

(37) N. L. Ma, W.-K. Li, and C. Y. Ng, J. Chem. Phys. 99 , 6470 (1993).

(38) C.-W. Hsu, C.-L. Liao, Z.-X, Ma, P. J. H. Tjossem, and C. Y. Ng, Chem. Phys. Lett. 199, 78 (1992).

(39) C. W. Hsu, C.-L. Liao, Z.-X. Ma, P.J. H. Tjossem, and C. Y. Ng, J. Chem. Phys. 97, 6283 (1992).

(40) C. E. Moore, "Atomic Energy Levels", Natl. Bur. Stand. (U.S.) Circ. No. 467 (U.S. GPO, Washington, D.C. 1949), Vol. I.

(41) The N2P-PFI-PE signal for SH is found to be maximized at a delayed time of 650 $\mu \mathrm{s}$. We found that the N2P-PFI-PE spectrum for $\mathrm{H}_{2} \mathrm{~S}$ obtained at a delay of 450 $\mu \mathrm{s}$ has the highest resolution and corresponds to the lowest $\mathrm{H}_{2} \mathrm{~S}$ rotational temperature.

(42) J. Berkowitz, private communication.

(43) B. A. Morrow, J. Phys. 44, 2447 (1966).

(44) B. R. Weiner, H. B. Levene, J. J. Valentini, and A. P. Baronavski, J. Chem. Phys. 90, 1403 (1989).

(45) G. Herzberg, "Molecular Spectra and Molecular Structure, Vol.1: Spectra of Diatomic Molecules" (van Nostrand Reinhold, New York, 1950).

(46) R. E. Continetti, B. A. Balko, and Y. T. Lee, Chem. Phys. Lett. 182, 400 (1991); and references therein.

(47) W. A. Chupka, J. Chem. Phys. $\underline{98}, 4520$ (1993).

(48) P. J. Bruna and G. Hirsch, Mol. Phys. $\underline{61}, 1359$ (1987). 
(49) H. Rudolph, V. McKoy, and S. N. Dixit, J. Chem. Phys. 90, 2570 (1989).

(50) K. Wang and V. McKoy, J. Chem. Phys. 95, 8718 (1991).

(51) J.-C. Xie and R. N. Zare, J. Chem. Phys. 93, 3033 (1990).

(52) M. Horani, S. Leach, and J. Rostas, J. Mol. Spect. 23 115 (1967).

(53) The rotational constant $B=9.134 \mathrm{~cm}^{-1}$, the spin splitting constants $\lambda=5.71 \mathrm{~cm}^{-1}$ and $\gamma=-0.165 \mathrm{~cm}^{-1}$, and the centrifugal constant $\mathrm{D}=0.000489 \mathrm{~cm}^{-1}$. The energies for the $\mathrm{F}^{+}$levels are: $\mathrm{F}_{1}{ }^{+}\left(N^{+}\right)=\mathrm{B} N^{+}\left(N^{+}+1\right)+\left(2 N^{+}+3\right) \mathrm{B}-\lambda-$ $\left[\left(2 N^{+}+3\right)^{2} \mathrm{~B}^{2}+\lambda^{2}-2 \lambda \mathrm{B}\right]^{1 / 2}+\gamma\left(N^{+}+1\right)-\mathrm{D}\left[N^{+}\left(N^{+}+1\right)\right]^{2} ; \mathrm{F}_{2}{ }^{+}\left(N^{+}\right)=$ $\mathrm{B} N^{+}\left(N^{+}+1\right)-\mathrm{D}\left[N^{+}\left(N^{+}+1\right)\right]^{2} ;$ and $\mathrm{F}_{3}{ }^{+}\left(N^{+}\right)=\mathrm{B} N^{+}\left(N^{+}+1\right)-\left(2 N^{+}-1\right) \mathrm{B}-\lambda$ $+\left[\left(2 N^{+}-1\right)^{2} \mathrm{~B}^{2}+\lambda^{2}-2 \lambda \mathrm{B}\right]^{1 / 2}-\gamma N^{+}-\mathrm{D}\left[N^{+}\left(N^{+}+1\right)\right]^{2}$. See Ref. 45 .

(54) D. A. Ramsey, J. Chem. Phys. 20, 1920 (1952).

(55) The rotational constant $\mathrm{B}=9.461 \mathrm{~cm}^{-1}$ and the centrifugal constant $\mathrm{D}=0.00048$ $\mathrm{cm}^{-1}$. The energies for $F\left(F_{1}\right.$ and $\left.F_{2}\right)$ levels are: $F_{1}\left(J^{\prime \prime}\right)=B\left\{\left(J^{\prime \prime}+1 / 2\right)^{2}-\Lambda^{2}\right.$ $\left.(1 / 2)\left[4\left(J^{\prime \prime}+1 / 2\right)^{2}+\mathrm{Y}(\mathrm{Y}-4) \Lambda^{2}\right]^{1 / 2}\right\}-\mathrm{D} J^{\prime \prime 4}$ and $\mathrm{F}_{2}\left(J^{\prime \prime}\right)=\mathrm{B}\left\{\left(J^{\prime \prime}+1 / 2\right)^{2}-\Lambda^{2}+\right.$ $\left.(1 / 2)\left[4\left(J^{\prime \prime}+1 / 2\right)^{2}+Y(Y-4) \Lambda^{2}\right]^{1 / 2}\right\}-D\left(J^{\prime \prime}+1\right)^{4}$. Here, $\Lambda=1$ for a $\Pi$ state and $\mathrm{Y}=\mathrm{A}_{\mathrm{o}} / \mathrm{B}$, where $\mathrm{A}_{\mathrm{o}}\left(-376.96 \mathrm{~cm}^{-1}\right)$ is the spin-orbit splitting. See Ref. 45 .

(56) K. S. Haber, Y. Jiang, G. P. Bryant, E. R. Grant, and H, Lefebvre-Brion, Phys. Rev. A 44, 5331 (1991).

(57) C. Jungen, J. Chem. Phys. $\underline{53}, 4168$ (1970). 
PAPER 5.

NONRESONANT TWO-PHOTON PULSED FIELD IONIZATION OF $\mathrm{CH}_{3} \mathrm{~S}$ FORMED IN PHOTODISSOCIATION OF $\mathrm{CH}_{3} \mathrm{SH}$ AND $\mathrm{CH}_{3} \mathrm{SSCH}_{3}$ 


\begin{abstract}
Threshold photoelectron (PE) spectra for $\mathrm{CH}_{3} \mathrm{~S}$ formed in the photodissociation of $\mathrm{CH}_{3} \mathrm{SH}$ and $\mathrm{CH}_{3} \mathrm{SSCH}_{3}$ in the photon energy range of $36,850-38,150 \mathrm{~cm}^{-1}$ have been measured using the nonresonant two-photon pulsed field ionization (N2P-PFI) technique. Both spin-orbit states $\mathrm{CH}_{3} \mathrm{~S}\left(\tilde{X}^{2} E_{3 / 2}\right)$ and $\mathrm{CH}_{3} \mathrm{~S}\left({ }^{2} E_{1 / 2}\right)$ are observed from $\mathrm{CH}_{3} \mathrm{SH}$ and $\mathrm{CH}_{3} \mathrm{SSCH}_{3}$ in this photodissociation energy range. However, negligible intensities of vibrationally excited $\mathrm{CH}_{3} \mathrm{~S}$ radicals are produced from $\mathrm{CH}_{3} \mathrm{SH}$. In the case of $\mathrm{CH}_{3} \mathrm{~S}$ from $\mathrm{CH}_{3} \mathrm{SSCH}_{3}$, the population ratio $\mathrm{CH}_{3} \mathrm{~S}\left(\nu_{3}=1\right) / \mathrm{CH}_{3} \mathrm{~S}\left(\nu_{3}=0\right)$ is estimated to be $\approx 0.18$. The simulation of the N2P-PFI-PE spectra reveals that the rotational temperature for $\mathrm{CH}_{3} \mathrm{~S}\left(\tilde{\mathrm{X}}^{2} E_{3 / 2,1 / 2}\right)$ formed by photodissociation of $\mathrm{CH}_{3} \mathrm{SH}$ is $\approx 200-250 \mathrm{~K}$ and the branching ratio $\mathrm{CH}_{3} \mathrm{~S}\left({ }^{2} E_{1 / 2}\right) / \mathrm{CH}_{3} \mathrm{~S}\left(\tilde{X}^{2} E_{3 / 2}\right)$ is $0.5 \pm 0.1$. For $\mathrm{CH}_{3} \mathrm{~S}\left(\tilde{X}^{2} E_{3 / 2,1 / 2}\right)$ produced from $\mathrm{CH}_{3} \mathrm{SSCH}_{3}$, the rotational temperature for $\mathrm{CH}_{3} \mathrm{~S}\left(\tilde{\mathrm{X}}^{2} E_{3 / 2,1 / 2}\right)$ is $\approx 800-900 \mathrm{~K}$ and the branching ratio $\left.\mathrm{CH}_{3} \mathrm{~S}^{2} E_{1 / 2}\right) / \mathrm{CH}_{3} \mathrm{~S}\left(\tilde{X}^{2} E_{3 / 2}\right)$ is $1.1 \pm 0.2$. This experiment demonstrates that the PFI-PE spectroscopic method can be a sensitive probe for nascent rovibronic state distributions of photoproducts. Furthermore, the simulation also shows that the photoionization dynamics of $\mathrm{CH}_{3} \mathrm{~S}$ may involve rotational angular momentum changes up to \pm 4. The ionization energy and C-S stretching frequency for $\mathrm{CH}_{3} \mathrm{~S}^{+}\left(\tilde{X}^{3} A_{2}\right)$ are determined to be $74,726 \pm 8 \mathrm{~cm}^{-1}(9.2649 \pm 0.0010 \mathrm{eV})$ and $733 \pm 5 \mathrm{~cm}^{-1}$, respectively. The spin-orbit splitting for $\mathrm{CH}_{3} \mathrm{~S}\left(\tilde{X}^{2} E_{3 / 2,1 / 2}\right)$ is $257 \pm 5 \mathrm{~cm}^{-1}$, in agreement with the literature values.
\end{abstract}




\section{INTRODUCTION}

Photoelectron (PE) spectroscopy performed at a sufficiently high resolution provides quantitative information of the rovibronic populations of the molecular species under investigation. With the recent development of the pulsed field ionization (PFI) technique, ${ }^{1}$ a version of the zero-kinetic-energy (ZEKE) PE technique, ${ }^{2,3}$ the attainable resolution of PE spectroscopy has approached that of optical spectroscopy. The possibility of PFI-PE as an alternative for the laser-induced fluorescence (LIF) technique to probe nascent product rovibronic state distributions has become a reality. ${ }^{4}$

In a series of recent investigations, ${ }^{5-9}$ Bondybey and co-workers have demonstrated that PFI-PE spectra for molecular species can be obtained with good sensitivity by using the one-color nonresonant two-photon (N2P) excitation. In many cases, the N2P-PFI-PE spectra are surprisingly similar to those acquired by the single vacuum ultraviolet (VUV) photon ionization scheme. ${ }^{6}$ The N2P-PFI scheme is very attractive because of its high sensitivity and the availability of commercial pulsed dye lasers with an output range of $200-400 \mathrm{~nm}$, as required for the ionization of most polyatomic species at their thresholds.

We have recently succeeded in employing the N2P-PFI-PE technique for studying SH radicals produced in the photodissociation of $\mathrm{H}_{2} \mathrm{~S} .{ }^{4}$ The rotationally-resolved N2P-PFI$\mathrm{PE}$ spectrum for $\mathrm{SH}$ provides estimates for the nascent rotational population of $\mathrm{SH}$ and the branching ratio for $\mathrm{SH}\left(\mathrm{X}^{2} \Pi_{3 / 2}\right) / \mathrm{SH}\left({ }^{2} \Pi_{1 / 2}\right)$. Highly accurate ionization energies (IE) for $\mathrm{SH}\left(\mathrm{X}^{2} \Pi_{3 / 2,1 / 2}\right)$ have been determined by simulation of the N2P-PFI-PE spectrum of SH. We have extended the one-color N2P-PFI-PE technique to include the investigation of 
polyatomic radicals. ${ }^{10}$

Here we present the results and analysis of the N2P-PFI-PE spectra of $\mathrm{CH}_{3} \mathrm{~S}$ formed in the photodissociation of $\mathrm{CH}_{3} \mathrm{SH}$ [process (1)] and $\mathrm{CH}_{3} \mathrm{SSCH}_{3}$ [process (2)]. In this experiment, a one-color three-photon process is involved. That is, the $\mathrm{CH}_{3} \mathrm{~S}$ radicals are first prepared by the single-photon dissociation process in the wavelength range of 262$271 \mathrm{~nm}$.

$$
\begin{aligned}
& \mathrm{CH}_{3} \mathrm{SH}+\mathrm{h} \nu \rightarrow \mathrm{CH}_{3} \mathrm{~S}\left(\tilde{X}^{2} E_{3 / 2,1 / 2}\right)+\mathrm{H} \\
& \mathrm{CH}_{3} \mathrm{SSCH}_{3}+\mathrm{h} \nu \rightarrow 2 \mathrm{CH}_{3} \mathrm{~S}\left(\tilde{X}^{2} E_{3 / 2,1 / 2}\right)
\end{aligned}
$$

The subsequent ionization of $\mathrm{CH}_{3} \mathrm{~S}$ is accomplished by $\mathrm{N} 2 \mathrm{P}$ excitations of $\mathrm{CH}_{3} \mathrm{~S}$ to high-n Rydberg states $\left[\mathrm{CH}_{3} \mathrm{~S}^{*}(\mathrm{n})\right]$, followed by PFI of $\mathrm{CH}_{3} \mathrm{~S}^{*}(\mathrm{n})$.

$$
\mathrm{CH}_{3} \mathrm{~S}\left(\tilde{X}^{2} E_{3 / 2,1 / 2}\right)+2 \mathrm{~h} \nu \rightarrow \mathrm{CH}_{3} \mathrm{~S}^{*}(\mathrm{n}) \rightarrow \mathrm{CH}_{3} \mathrm{~S}^{+}\left(\tilde{X}^{3} A_{2}\right)+\mathrm{e}^{-}
$$

The two additional photons absorbed by $\mathrm{CH}_{3} \mathrm{~S}$ in process (3) are furnished by the same laser pulse which induced the dissociation of $\mathrm{CH}_{3} \mathrm{SH}$ in process (1) or $\mathrm{CH}_{3} \mathrm{SSCH}_{3}$ in process (2). In addition to providing information on the spin-orbit and rovibronic state distributions of processes (1) and (2), the simulation of the observed N2P-PFI-PE spectra of $\mathrm{CH}_{3} \mathrm{~S}\left(\tilde{X}^{2} E_{3 / 2,1 / 2}\right)$ obtained in this experiment also yields a highly accurate value for the IE of $\mathrm{CH}_{3} \mathrm{~S}\left(\tilde{X}^{2} E_{3 / 2}\right)$ and the rotational constants for $\mathrm{CH}_{3} \mathrm{~S}^{+}\left(\tilde{X}^{3} A_{2}\right)$. 
The photodissociation of $\mathrm{CH}_{3} \mathrm{SH}$ and $\mathrm{CH}_{3} \mathrm{SSCH}_{3}$ at higher photon energies (193 and $248 \mathrm{~nm}$ ) have been the subject of several recent experimental ${ }^{11-15}$ and theoretical ${ }^{16-20}$ investigations. For $\mathrm{CH}_{3} \mathrm{SH}$, the experiments indicate that process (1) is favored at lower photon energies, whereas the cleavage of the $\mathrm{H}_{3} \mathrm{C}$-SH bond becomes more important at shorter wavelengths. The role of conical intersections in the photodissociation of $\mathrm{CH}_{3} \mathrm{SH}$ has been the subject of a recent theoretical study by Yarkony. ${ }^{20}$ The studies of $\mathrm{CH}_{3} \mathrm{SSCH}_{3}$ indicate that $\mathrm{CH}_{3} \mathrm{~S}$ is the predominant product at $248 \mathrm{~nm},{ }^{15}$ whereas both $\mathrm{CH}_{3} \mathrm{SS}$ and $\mathrm{CH}_{3} \mathrm{~S}$ are produced at $193 \mathrm{~nm}$, with $\mathrm{CH}_{3} \mathrm{SS}$ being the predominant photoproduct. ${ }^{12,15}$ Since the photodissociation wavelength range of interest here is $262-271 \mathrm{~nm}$, processes (1) and (2) are expected to be the predominant channels for the respective photodissociations of $\mathrm{CH}_{3} \mathrm{SH}$ and $\mathrm{CH}_{3} \mathrm{SSCH}_{3}$.

Two recent VUV photoionization mass spectrometric studies of $\mathrm{CH}_{3} \mathrm{~S}$ have been reported. ${ }^{21,22}$ The IE values for $\mathrm{CH}_{3} \mathrm{~S}\left(\tilde{X}^{2} E_{3 / 2,2 / 2}\right)$ determined in this study are significantly more accurate than those obtained in the previous VUV photoionization mass spectrometric experiments. The present N2P-PFI-PE study also provides an accurate measure for the C-S stretching $\left(\nu_{3}{ }^{+}\right)$vibrational frequency for $\mathrm{CH}_{3} \mathrm{~S}^{+}\left(\tilde{X}^{3} A_{2}\right)$. 


\section{EXPERIMENTAL}

The experimental apparatus used in this study has been described in detail. ${ }^{4}$ Briefly, it is modified from the laser ionization time-of-flight (TOF) mass spectrometer used in previous photodissociation studies. ${ }^{23,24}$ A two-stage microchannel plate detector and a set of simple aperture lenses have been added for PE detection below the photoionization region and opposite to the ion TOF tube.

For this experiment, $\mathrm{CH}_{3} \mathrm{SH}$ ( $99.5 \%$ pure) and $\mathrm{CH}_{3} \mathrm{SSCH}_{3}$ ( $99 \%$ pure) are obtained from Aldrich and are used without further purification. The $\mathrm{CH}_{3} \mathrm{SH}(8 \%)$ or $\mathrm{CH}_{3} \mathrm{SSCH}_{3}$ (vapor pressure $\approx 40$ Torr at $298 \mathrm{~K}$ ) sample is seeded in Ar carrier gas to a total stagnation pressure of $\approx 2.5$ bar or $\approx 1.3$ bar, respectively. The gas mixture is introduced into the photoionization region by supersonic expansion through a pulsed valve with a nozzle diameter of $0.5 \mathrm{~mm}$. The molecular beam is skimmed by a conical skimmer ( $1 \mathrm{~mm}$ in diameter, $3.8 \mathrm{~cm}$ from the nozzle) before intersecting with a tunable laser beam $\left(90^{\circ}, 8.3 \mathrm{~cm}\right.$ down stream from the skimmer). Both the pulsed valve and the dye laser are operated at a repetition rate of $13 \mathrm{~Hz}$.

The molecular beam source chamber is pumped by a freon-trapped, 6 in. diffusion pump (pumping speed $\approx 2,000 \mathrm{l} / \mathrm{s}$ ), while the photoionization chamber and the ion-TOF tube are evacuated by two $50 \mathrm{l} / \mathrm{s}$ turbomolecular pumps. During the experiment, the beam source chamber and the photoionization chamber are maintained at pressures of about $1 \times 10^{-4}$ and $2 \times 10^{-6}$ Torr, respectively.

The second harmonic output of an excimer (Lambda Physik EMG 201 MSC) 
pumped-dye laser (Lambda Physik FL 3002) is focused into the photoionization region by a $200 \mathrm{~mm}$ focal length fused-silica lens. Coumarin 153 dye is used to produce the fundamental output in the 524-542 nm region. Typical laser pulse energies used in the second harmonic output range of $262-271 \mathrm{~nm}$ are $1.2 \mathrm{~mJ}$, as monitored with a pyroelectric detector. The wavelength calibration uses the known resonance-enhanced multiphoton ionization spectrum of atomic sulfur, ${ }^{25}$ which is produced by the multiphoton laser photodissociation of $\mathrm{CH}_{3} \mathrm{SH}$ and $\mathrm{CH}_{3} \mathrm{SSCH}_{3}$.

Ion detection using the ion TOF mass spectrometer has been described in detail previously. ${ }^{23,24}$ Here, a constant electric field of $280 \mathrm{~V} / \mathrm{cm}$ is used to extract the ions formed in the photoionization region. Since the N2P ionization processes compete with many multiphoton ionization and fragmentation channels, it is necessary to optimize the $\mathrm{CH}_{3} \mathrm{~S}^{+}$ion signal by varying the dye laser power.

The ZEKE/PFI detection scheme relies on delayed PFI of long-lived high-n Rydberg states populated by laser excitation at a few wavenumbers below the ionization threshold. In this experiment, the firing of the photodissociation and excitation laser is delayed by $750 \mu \mathrm{s}$ with respect to the triggering pulse for opening the pulsed valve. A 1 $\mu \mathrm{s}$ pulsed field of $3.1 \mathrm{~V} / \mathrm{cm}$ is applied to the repeller plate $3 \mu \mathrm{s}$ after firing the dye laser. The pulsed field field-ionizes the molecular species in high-n Rydberg states as well as extracts the electrons thus formed to the microchannel plate electron detector. The firing sequence of the pulsed valve, dye laser, and pulsed electric field is controlled by two digital delay units (Stanford Research DG535). The electron signal from the electron detector and the laser energy signal from the pyroelectric detector are fed into two 
identical boxcar integrators (Stanford Research SR250), which are interfaced to an IBM/AT computer. The electron and laser energy signals are averaged for 30 shots at each laser wavelength.

The bandwidth of the dye laser is $0.2 \mathrm{~cm}^{-1}$ for the fundamental and $\approx 0.4 \mathrm{~cm}^{-1}$ for the second harmonic outputs. For a two-photon ionization process, the resolution due to the ionization laser is expected to be $\approx 0.8 \mathrm{~cm}^{-1}$. We have reproduced the N2P-PFI-PE spectrum for $\mathrm{H}_{2} \mathrm{~S}$ reported previously. ${ }^{4,6}$ This spectrum suggests that the PE energy resolution achieved in this experiment is similar to that obtained by Bondybey and coworkers ${ }^{6}$ using the same value of ionization pulsed field. 


\section{RESULTS}

\section{A. $\mathrm{CH}_{3} \mathrm{~S}$ from $\mathrm{CH}_{3} \mathrm{SH}$}

Figure 1(a) shows the N2P-PFI-PE spectrum in the region of $36,850-38,060 \mathrm{~cm}^{-1}$ for nascent $\mathrm{CH}_{3} \mathrm{~S}\left(\tilde{X}^{2} E_{3 / 2,1 / 2}\right)$ radicals formed by process (1). This spectrum is the average of four independent and reproducible scans. The pulsed field of $3.1 \mathrm{~V} / \mathrm{cm}$ used in this measurement corresponds to a Stark shift of $5.3 \mathrm{~cm}^{-1}$. We note that PE signals at photon energies $>37,810 \mathrm{~cm}^{-1}$ are mostly due to the ionization of $\mathrm{CH}_{3} \mathrm{SH}$, the IE of which is $76,302 \mathrm{~cm}^{-1}\left(2 \times 38,151 \mathrm{~cm}^{-1}\right){ }^{10}$ The $\mathrm{N} 2 \mathrm{P}$ ion spectrum for $\mathrm{CH}_{3} \mathrm{~S}$ measured in the region of $36,900-37,460 \mathrm{~cm}^{-1}$ is depicted in Fig. 1(b) for comparison with the PFI-PE spectrum. Since the ionization of $\mathrm{CH}_{3} \mathrm{~S}$ from $\mathrm{CH}_{3} \mathrm{SH}$ is the result of a three photon process, the PE and $\mathrm{CH}_{3} \mathrm{~S}^{+}$ion signals of Figs. 1(a) and 1(b) have been normalized by the cube of the laser pulse energy.

\section{B. $\mathrm{CH}_{3} \mathrm{~S}$ from $\mathrm{CH}_{3} \mathrm{SSCH}_{3}$}

The N2P-PFI-PE spectrum in the region of $36,850-38,150 \mathrm{~cm}^{-1}$ for $\mathrm{CH}_{3} \mathrm{~S}$ formed by the photodissociation of $\mathrm{CH}_{3} \mathrm{SSCH}_{3}$ [process (2)] is shown in Fig 2(a). This PFI-PE spectrum of $\mathrm{CH}_{3} \mathrm{~S}$ is the average of three independent and reproducible scans. The corresponding N2P ion spectrum in the region of $36,900-37,520 \mathrm{~cm}^{-1}$ for $\mathrm{CH}_{3} \mathrm{~S}$ is depicted in Fig. 2(b). Similar to the spectra shown in Figs. 1(a) and 1(b), the $\mathrm{PE}$ and $\mathrm{CH}_{3} \mathrm{~S}^{+}$ion signals of Figs. 2(a) and 2(b) have been normalized by the cube of the laser pulse energy. 
Figure 1 (a) The N2P-PFI-PE spectrum in the region of $36,850-38,150 \mathrm{~cm}^{-1}$ for nascent $\mathrm{CH}_{3} \mathrm{~S}\left(\tilde{X}^{2} E_{3 / 2,1 / 2}\right)$ radicals formed by process (1). This spectrum is the average of four independent scans. A pulsed field of $3.1 \mathrm{~V} / \mathrm{cm}$ was used in this measurement. The PE signals $[I(e)]$ have been normalized with the cube of the laser pulse energy. Note that the PFI-PE signals at photon energies $>37,810 \mathrm{~cm}^{-1}$ are due to ionization of $\mathrm{CH}_{3} \mathrm{SH}$. The dip marked by $\boldsymbol{\nabla}$ is caused by the resonance-enhanced multiphoton ionization of $\mathrm{S}$ atoms. See the text.

(b) The $\mathrm{N} 2 \mathrm{P}$ ion spectrum for $\mathrm{CH}_{3} \mathrm{~S}^{+}$from $\mathrm{CH}_{3} \mathrm{SH}$ in the region of 36,900$37,460 \mathrm{~cm}^{-1}$. The $\mathrm{CH}_{3} \mathrm{~S}^{+}$ion signals have been normalized with the cube of the laser pulse energy. 


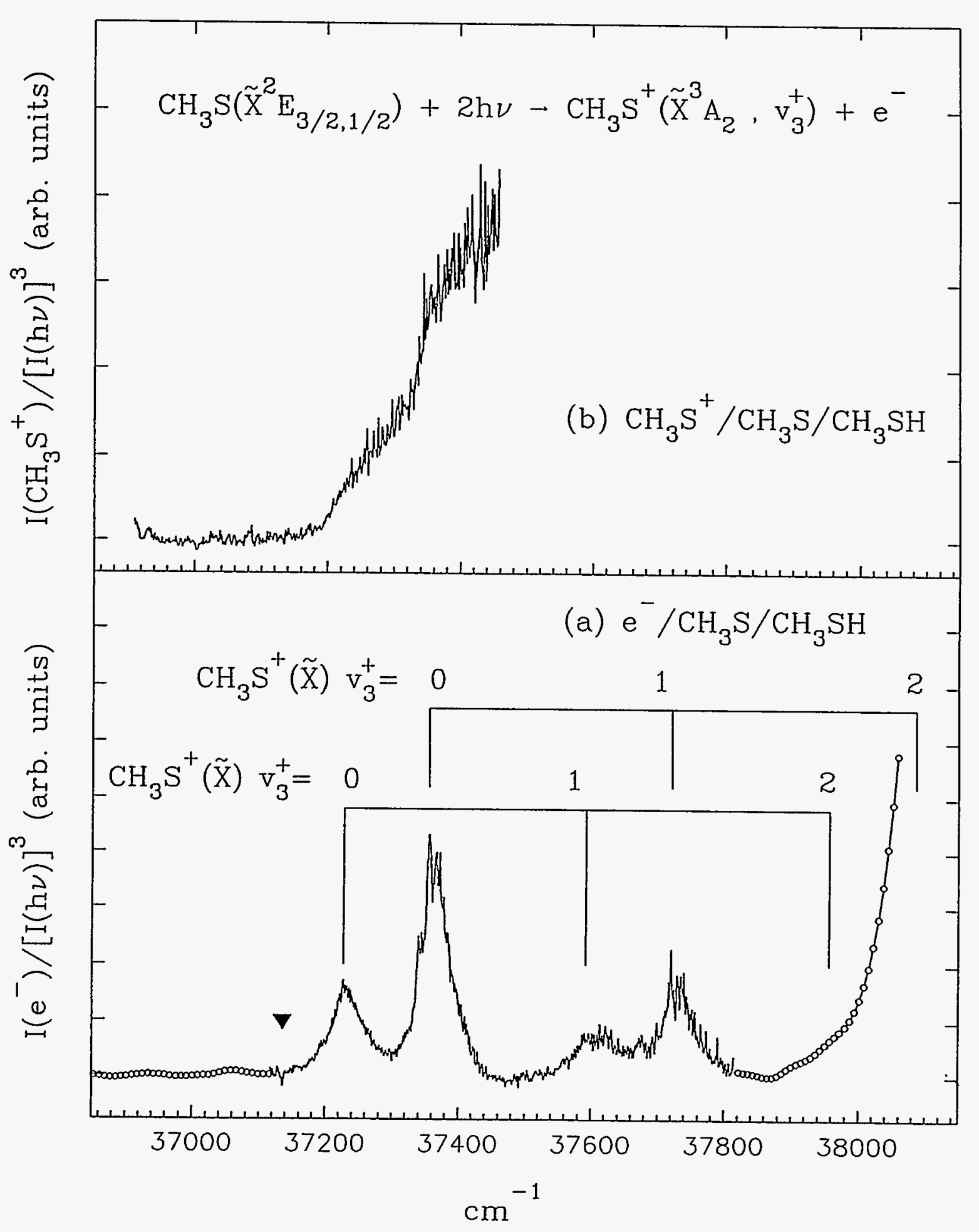


Figure 2 (a) The N2P-PFI-PE spectrum in the region of $36,850-38,150 \mathrm{~cm}^{-1}$ for nascent $\mathrm{CH}_{3} \mathrm{~S}\left(\tilde{X}^{2} E_{3 / 2,1 / 2}\right)$ radicals formed by process (2). This spectrum is the average of three independent scans. A pulsed field of $3.1 \mathrm{~V} / \mathrm{cm}$ was used in the measurement. The PE signals $\left[\mathrm{I}\left(\mathrm{e}^{-}\right)\right]$have been normalized with the cube of the laser pulse energy. The hot PE band attributable to the ionization of $\mathrm{CH}_{3} \mathrm{~S}\left(\tilde{\mathrm{X}}, \nu_{3}=1\right)$ is marked by an arrow.

(b) The N2P ion spectrum for $\mathrm{CH}_{3} \mathrm{~S}^{+}$from $\mathrm{CH}_{3} \mathrm{SSCH}_{3}$ in the region of $36,900-37,520 \mathrm{~cm}^{-1}$. The $\mathrm{CH}_{3} \mathrm{~S}^{+}$ion signals have been normalized with the cube of the laser pulse energy. The dips marked by $\checkmark$ in Figs. 2(a) and 2(b) are caused by the resonance-enhanced multiphoton ionization of $S$ atoms. 


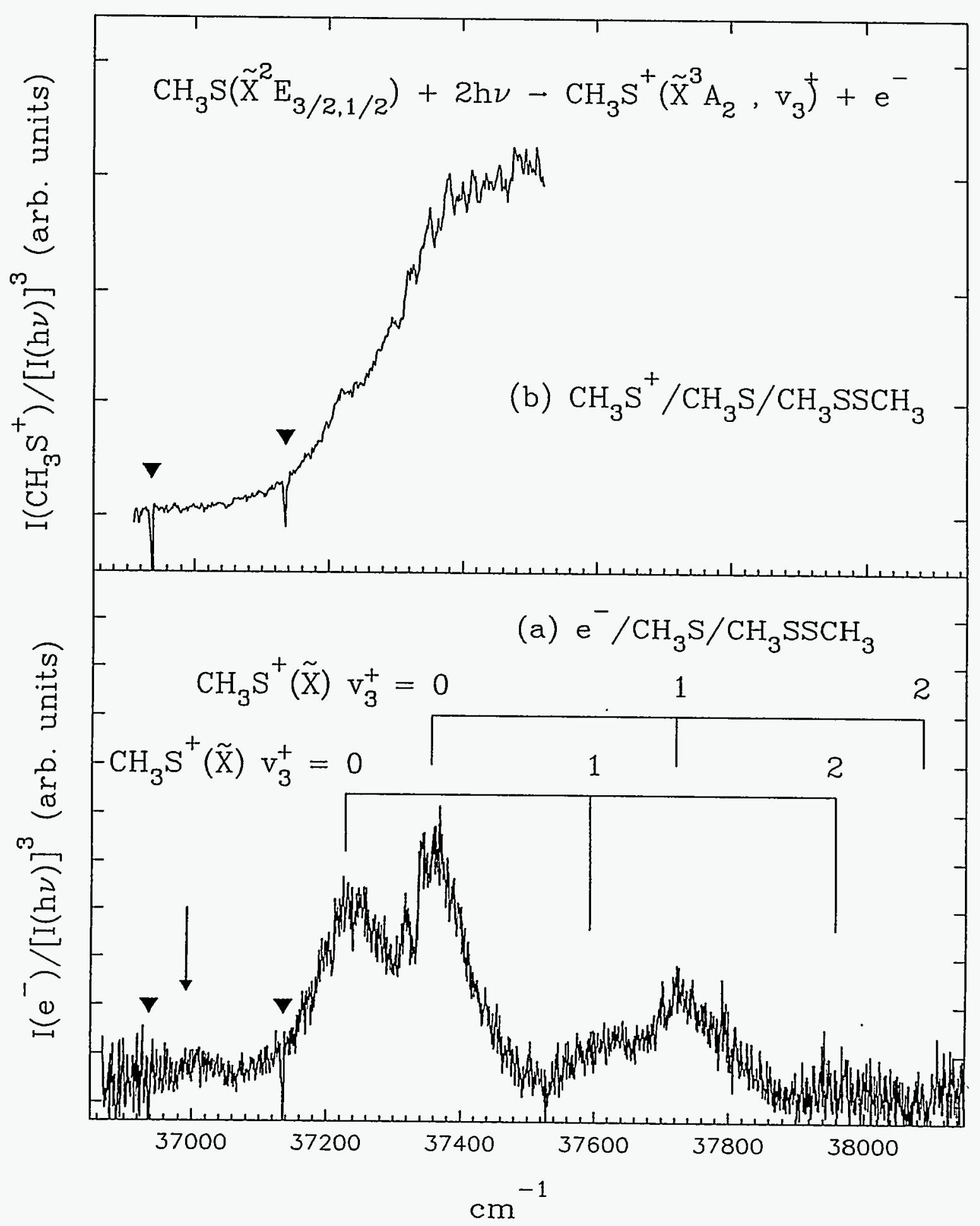




\section{DISCUSSION}

Two resolved peaks centered at 74,459 and $74,716 \mathrm{~cm}^{-1}(2 \times 37,229.5$ and $2 \times 37,358$ $\mathrm{cm}^{-1}$ ) are observed in the PFI-PE spectrum of Fig. 1(a). These structures correlate well with the two step-like features observed in the $\mathrm{N}_{2} \mathrm{P} \mathrm{CH}_{3} \mathrm{~S}^{+}$ion spectrum shown in Fig. 1(b). The spacing between these two peaks is $257 \pm 5 \mathrm{~cm}^{-1}$, which is in excellent agreement with the spin-orbit splitting of 255.5 and $259.1 \mathrm{~cm}^{-1}$ determined in previous laser induced fluorescence studies. ${ }^{26,27}$ Based on this observation, we assign the peaks centered at 74,459 and $74,716 \mathrm{~cm}^{-1}$ to ionization transitions, $\left.\mathrm{CH}_{3} \mathrm{~S}^{2} E_{1 / 2}\right) \rightarrow \mathrm{CH}_{3} \mathrm{~S}^{+}\left(\tilde{X}^{3} A_{2}\right.$, $\left.\nu_{3}{ }^{+}=0\right)$ and $\mathrm{CH}_{3} \mathrm{~S}\left(\tilde{X}^{2} E_{3 / 2}\right) \rightarrow \mathrm{CH}_{3} \mathrm{~S}^{+}\left(\tilde{X}^{3} A_{2}, \nu_{3}{ }^{+}=0\right)$, respectively. The widths for these PE bands are similar and have a value of $\approx 50 \mathrm{~cm}^{-1}$ for the full-width-at-half-maximum (FWHM). The profiles of these PE bands are mostly determined by the rotational populations of $\mathrm{CH}_{3} \mathrm{~S}\left(\tilde{X}^{2} E_{3 / 2,1 / 2}\right)$. The rotational populations of the precursor $\mathrm{CH}_{3} \mathrm{SH}$ molecules may also have a finite contribution to the observed widths of these PE bands.

Two weaker PE bands observed at 75,189 and 75,446 $\mathrm{cm}^{-1}(2 \times 37,594.5$ and $\left.2 \times 37,723 \mathrm{~cm}^{-1}\right)$, have structures and relative intensities similar to the two strong PE bands at 74,459 and $74,716 \mathrm{~cm}^{-1}$. The $a b$ initio calculations ${ }^{16}$ indicate that the equilibrium geometries for $\mathrm{CH}_{3} \mathrm{~S}$ and $\mathrm{CH}_{3} \mathrm{~S}^{+}$are similar. A noticeable difference is that the $\mathrm{C}$-S bond distance in $\mathrm{CH}_{3} \mathrm{~S}^{+}$is shorter than that in $\mathrm{CH}_{3} \mathrm{~S}$ by $0.04 \AA$, suggesting that the $\nu_{3}{ }^{+}$mode of $\mathrm{CH}_{3} \mathrm{~S}^{+}$may be excited in the ionization transition. For this reason, we assign the PE bands at 75,189 and $75,446 \mathrm{~cm}^{-1}$ to ionization transitions, $\mathrm{CH}_{3} \mathrm{~S}\left({ }^{2} E_{1 / 2}\right) \rightarrow \mathrm{CH}_{3} \mathrm{~S}^{+}\left(\tilde{X}^{3} A_{2}\right.$, $\left.\nu_{3}{ }^{+}=1\right)$ and $\mathrm{CH}_{3} \mathrm{~S}\left(\tilde{X}^{2} E_{3 / 2}\right) \rightarrow \mathrm{CH}_{3} \mathrm{~S}^{+}\left(\tilde{X}^{3} A_{2}, \nu_{3}{ }^{+}=1\right)$, respectively. 
The bond dissociation energy for $\mathrm{CH}_{3} \mathrm{~S}-\mathrm{H}$ is in the range of $86-90 \mathrm{kcal} / \mathrm{mol}^{-1}{ }^{12,14,22}$ Thus, for a photodissociation energy of $37,300 \mathrm{~cm}^{-1}(107 \mathrm{kcal} / \mathrm{mol})$, the available energy $\left(\mathrm{E}_{\mathrm{av}}\right)$ for process $(1)$ is $\approx 19 \mathrm{kcal} / \mathrm{mol}$. Energetically, it is possible that the formation of $\mathrm{CH}_{3} \mathrm{~S}$ from $\mathrm{CH}_{3} \mathrm{SH}$ results in the excited $\nu_{3}$ mode of $\mathrm{CH}_{3} \mathrm{~S}$, the vibrational quantum of which is $727 \pm 3 \mathrm{~cm}^{-1} .{ }^{27}$ As shown in the PFI-PE and N2P ion spectra of Figs. 1(a) and 1(b), negligible signals are found below $37,160 \mathrm{~cm}^{-1}$, indicating that the formation of vibrationally excited $\mathrm{CH}_{3} \mathrm{~S}$ radicals is not important in this energy range. At higher photodissociation energies, previous experiments show that the formation of $\mathrm{CH}_{3} \mathrm{~S}$ in excited vibrational states by process (1) is possible. ${ }^{12-14}$ The photodissociation study of $\mathrm{CH}_{3} \mathrm{SH}$ at $248 \mathrm{~nm}\left(40,323 \mathrm{~cm}^{-1}\right)$ indicates that $\mathrm{CH}_{3} \mathrm{~S}$ radicals may be produced in vibrationally excited states with a C-S stretching vibrational progression that extends to $\nu_{3}$ $=2$, while $\nu_{3}$ levels up to 17 are observed at $193 \mathrm{~nm}\left(51,813 \mathrm{~cm}^{-1}\right) .{ }^{14}$

Four PFI-PE bands in positions similar to those resolved in Fig. 1(a) are observed in the N2P-PFI-PE spectrum for $\mathrm{CH}_{3} \mathrm{~S}$ from $\mathrm{CH}_{3} \mathrm{SSCH}_{3}$ [Fig. 2(a)]. It is thus logical to conclude that $\mathrm{CH}_{3} \mathrm{~S}\left(\tilde{X}^{2} E_{3 / 2,1 / 2}\right)$ radicals are also produced by process (2), and that their ionization produces $\mathrm{CH}_{3} \mathrm{~S}^{+}\left(\tilde{X}^{3} A_{2}, \nu_{3}{ }^{+}=0,1\right)$. The broader $\mathrm{PE}$ bands observed for $\mathrm{CH}_{3} \mathrm{~S}\left(\tilde{X}^{2} E_{3 / 2,1 / 2}\right)$ from $\mathrm{CH}_{3} \mathrm{SSCH}_{3}$ are consistent with the conclusion that $\mathrm{CH}_{3} \mathrm{~S}\left(\tilde{X}^{2} E_{3 / 2,1 / 2}\right)$ radicals formed in process (2) are rotationally hotter than those produced in process (1). The $\mathrm{CH}_{3} \mathrm{~S}$ radicals produced from $\mathrm{CH}_{3} \mathrm{SSCH}_{3}$ are expected to be internally hotter than those produced from $\mathrm{CH}_{3} \mathrm{SH}$, partly because of the weaker $\mathrm{S}-\mathrm{S}$ bond energy. That is, at the same photodissociation energy, process (2) is more exothermic than process (1). As described below, the simple impulsive dissociation model predicts that the $\mathrm{CH}_{3} \mathrm{~S}$ fragments 
from $\mathrm{CH}_{3} \mathrm{SSCH}_{3}$ are rotationally excited to a greater extent than those from $\mathrm{CH}_{3} \mathrm{SH}$.

A careful examination of the PFI-PE spectrum of $\mathrm{CH}_{3} \mathrm{~S}$ from $\mathrm{CH}_{3} \mathrm{SSCH}_{3}$ reveals a small PE band at 73,987 $\mathrm{cm}^{-1}$ [marked by an arrow in Fig. 2(a)], which is about $729 \mathrm{~cm}^{-}$ ${ }^{1}$ below the main $\mathrm{PE}$ bands observed at $74,716 \mathrm{~cm}^{-1}$. Since the spacing between these bands is comparable to the literature value ${ }^{27}$ of $727 \pm 3 \mathrm{~cm}^{-1}$ for the $\nu_{3}$ mode of $\mathrm{CH}_{3} \mathrm{~S}\left(\tilde{X}^{2} E_{3 / 2}\right)$, we assign the small peak at 73,987 to be a hot PE band due to ionization of $\mathrm{CH}_{3} \mathrm{~S}\left(\tilde{X}^{2} E_{3 / 2}, \nu_{3}=1\right)$. Comparing the intensities of these bands, we estimate that the population ratio $\mathrm{CH}_{3} \mathrm{~S}\left(\tilde{X}^{2} E_{3 / 2}, \nu_{3}=1\right) / \mathrm{CH}_{3} \mathrm{~S}\left(\tilde{X}^{2} E_{3 / 2}, \nu_{3}=0\right)$ is about 0.18 .

The more gradual rise at the ionization threshold of the $\mathrm{CH}_{3} \mathrm{~S}^{+}$ion spectrum of Fig. 2(b) compared to that depicted in Fig. 1(b) is also consistent with the higher rotational temperature $\left(\mathrm{T}_{\mathrm{r}}\right)^{28}$ for $\mathrm{CH}_{3} \mathrm{~S}$ and the formation of $\mathrm{CH}_{3} \mathrm{~S}\left(\overline{\mathrm{X}}, \nu_{3}=1\right)$ from process (2). Because of the higher $\mathrm{T}_{\mathrm{r}}$ for $\mathrm{CH}_{3} \mathrm{~S}$ from $\mathrm{CH}_{3} \mathrm{SSCH}_{3}$, the step-like feature corresponding to the onset for the ionization transition $\mathrm{CH}_{3} \mathrm{~S}\left({ }^{2} E_{1 / 2}\right) \rightarrow \mathrm{CH}_{3} \mathrm{~S}^{+}\left(\tilde{X}^{3} A_{2}\right)$, which is resolved in the spectrum of Fig. 1(b), is not discernible in Fig. 2(b).

In order to gain insight into the photoionization dynamics, and to determine the IE and spectroscopic constants for $\mathrm{CH}_{3} \mathrm{~S}^{+}\left(\tilde{X}^{3} A_{2}\right)$, it is necessary to simulate the observed N2PPFI-PE spectra for $\mathrm{CH}_{3} \mathrm{~S}\left(\tilde{X}^{2} E_{3 / 2, I / 2}\right)$. Since the equilibrium geometry for $\mathrm{CH}_{3} \mathrm{~S}$ in its ground state is predicted to be distorted only slightly from the $\mathrm{C}_{3 \mathrm{v}}$ symmetry by the JahnTeller effect, ${ }^{16}$ we assume $\mathrm{C}_{3 \mathrm{v}}$ structures for both $\mathrm{CH}_{3} \mathrm{~S}\left(\tilde{X}^{2} E_{3 / 2,1 / 2}\right)$ and $\mathrm{CH}_{3} \mathrm{~S}^{+}\left(\tilde{X}^{3} A_{2}\right)$. That is, the rotational spectrum for $\mathrm{CH}_{3} \mathrm{~S}$ is treated as a symmetric top case in the simulation. The nuclear spin statistical weights for the $a$ and $e$ rovibronic levels of $\mathrm{CH}_{3} \mathrm{~S}\left(\tilde{X}^{2} E_{3 / 2,1 / 2}\right)$ are 2 and 1 , respectively. ${ }^{29}$ Rotational branches labelled as $B=M, N, O, P, Q, R, S, T$, and 
$U$ corresponding to rotational angular momentum changes of $\Delta N=N^{+}-N^{\prime \prime}=-4,-3,-2$, $-1,0,1,2,3$, and 4 , respectively, for $\Delta K= \pm 1$; and $P, Q$, and $R$ corresponding to $\Delta N$ $=-1,0$, and 1 , respectively, for $\Delta K= \pm 2$, are assumed to be the probable ionization transitions. The transition probabilities for all these branches are assumed to be equal. The probabilities for transitions from different $J^{\prime \prime}$ levels within each branch are also assumed to be identical. For a given spin-orbit manifold $\left({ }^{2} E_{3 / 2}\right.$ or $\left.{ }^{2} E_{1 / 2}\right)$, we assume that the relative PE peak intensities $\left[I\left(B, J^{\prime \prime}\right)\right]$ are calculated as

$$
\mathrm{I}\left(B, J^{\prime \prime}\right)=\left[\left(2 J^{\prime \prime}+1\right) / \mathrm{Q}_{\mathrm{rol}}\right] \exp \left(-\Delta \mathrm{E}_{\mathrm{rot}} / \mathrm{kT}_{\mathrm{r}}\right),
$$

where $\Delta \mathrm{E}_{\text {rot }}$ is the rotational energy measured with respect to the lowest $J^{\prime \prime}$ level of the spin-orbit states $\left[-127.15 \mathrm{~cm}^{-1}\right.$ for $\mathrm{CH}_{3} \mathrm{~S}\left(\tilde{X}^{2} E_{3 / 2}\right)$ and $+127.86 \mathrm{~cm}^{-1}$ for $\left.\mathrm{CH}_{3} \mathrm{~S}\left({ }^{2} E_{1 / 2}\right)\right]$ and $\mathrm{Q}_{\text {rot }}$ is the rotational partition function.

The energy expressions used are from Endo et $a .^{30}$ and ignore the Jahn-Teller effect. Taking into account the laser line width and the PFI effect on the width, the calculated line intensities are combined using a Gaussian lineshape with a FWHM of $4 \mathrm{~cm}^{-}$ 1. Pertinent parameters used in the simulation of the spectra of Figs. 1(a) and 2(a) are summarized in Table I. The uncertainties for these parameters are determined by careful comparisons of the experimental and simulated PE spectra. When a given parameter used is within the range of the indicated uncertainties, the resulting simulated spectrum is indistinguishable from the best fit to the experimental spectrum.

The rotational constants, $\mathrm{A}=5.68 \mathrm{~cm}^{-1}$ and $\mathrm{B}=0.45 \mathrm{~cm}^{-1}$, for $\mathrm{CH}_{3} \mathrm{~S}$ in its ground 
Table I Parameters for $\mathrm{CH}_{3} \mathrm{~S}$ and $\mathrm{CH}_{3} \mathrm{~S}^{+}$used in the simulation of the N2P-PFI-PE spectra of $\mathrm{CH}_{3} \mathrm{~S}\left(\tilde{X}^{2} E_{3 / 2,1 / 2}\right)$ formed in the photodissociation of $\mathrm{CH}_{3} \mathrm{SH}$ and $\mathrm{CH}_{3} \mathrm{SSCH}_{3}{ }^{a}$

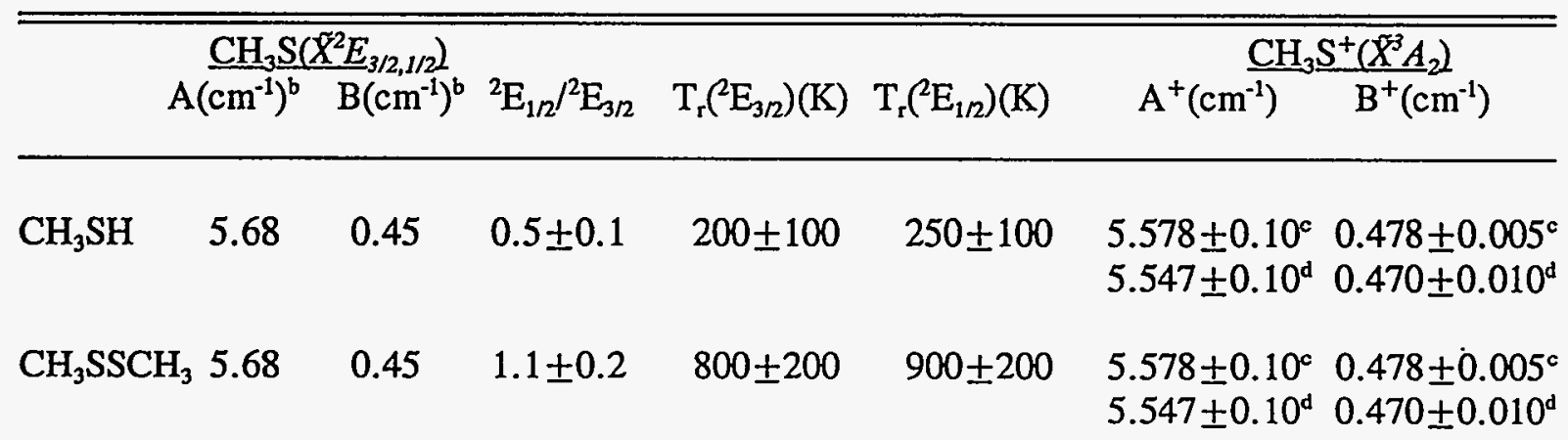

a) Other parameters used include IE $\left[\mathrm{CH}_{3} \mathrm{~S}\left(\tilde{\mathrm{X}}^{2} \mathrm{E}_{32}\right)\right]=74,726 \pm 8 \mathrm{~cm}^{-1}(9.2649 \pm 0.0010 \mathrm{eV})$, the spin-orbit splitting for $\mathrm{CH}_{3} \mathrm{~S}\left(\tilde{X}^{2} E_{3 / 2,1 / 2}\right)=255.5 \mathrm{~cm}^{-1}$ (Ref. 26), and the relative FranckCondon factors for ionization transitions, $\mathrm{CH}_{3} \mathrm{~S}\left(\tilde{X}, \nu_{3}=0\right) \rightarrow \mathrm{CH}_{3} \mathrm{~S}^{+}\left(\tilde{X}, \nu_{3}{ }^{+}=0\right): \mathrm{CH}_{3} \mathrm{~S}\left(\tilde{X}, \nu_{3}=0\right)$ $\rightarrow \mathrm{CH}_{3} \mathrm{~S}^{+}\left(\chi^{\prime}, \nu_{3}{ }^{+}=1\right)=1.00: 0.46$.

b) Values determined in a LIF study (Ref. 26).

c) Values for $\mathrm{CH}_{3} \mathrm{~S}^{+}\left(\tilde{\mathrm{X}}^{3} \mathrm{~A}_{2}, \nu_{3}{ }^{+}=0\right)$.

d) Values for $\mathrm{CH}_{3} \mathrm{~S}^{+}\left(\tilde{\mathrm{X}}^{3} \mathrm{~A}_{2}, \nu_{3}{ }^{+}=1\right)$. 
state are obtained from Miller and co-workers. ${ }^{26}$ The rotational constants $\mathrm{A}^{+}$and $\mathrm{B}^{+}$for $\mathrm{CH}_{3} \mathrm{~S}^{+}\left(\tilde{X}^{3} A_{2}\right)$ are unknown. Based on the ab initio geometries for $\mathrm{CH}_{3} \mathrm{~S}(\tilde{X})$ and $\mathrm{CH}_{3} \mathrm{~S}^{+}(\tilde{X})$ obtained by the second order Møller Plesset (MP2) perturbation calculations using the 6$31 \mathrm{G}(\mathrm{d})$ basis set, ${ }^{16}$ values for the rotational constants of $\mathrm{CH}_{3} \mathrm{~S}(\tilde{X})$ and $\mathrm{CH}_{3} \mathrm{~S}^{+}(\tilde{X})$ are found to be $\left(\mathrm{A}=5.305 \mathrm{~cm}^{-1}, \mathrm{~B}=0.445 \mathrm{~cm}^{-1}\right)$ and $\left(\mathrm{A}^{+}=5.181 \mathrm{~cm}^{-1}, \mathrm{~B}^{+}=0.466 \mathrm{~cm}^{-1}\right)$, respectively. Since the experimental and theoretical values for the rotational constants A and $\mathrm{B}$ are very close, we assume that the theoretical predictions for $\mathrm{A}^{+}$and $\mathrm{B}^{+}$have uncertainties similar to those observed experimentally. We find that the best fit for the PE bands centered at 74,459 and $74,716 \mathrm{~cm}^{-1}$ is observed for rotational constants $\mathrm{A}^{+}=$ $5.55 \pm 0.20 \mathrm{~cm}^{-1}$ and $\mathrm{B}^{+}=0.478 \pm 0.005 \mathrm{~cm}^{-1}$ for $\mathrm{CH}_{3} \mathrm{~S}^{+}\left(\tilde{X}^{3} A_{2}, \nu_{3}{ }^{+}=0\right)$, which are obtained essentially by scaling the theoretical $\mathrm{A}^{+}$and $\mathrm{B}^{+}$values by factors of 1.071 and 1.026 , respectively. Note that the latter factors are comparable to the ratios of 1.071 and 1.011 observed for the experimental to theoretical values of A and B, respectively. For $\mathrm{CH}_{3} \mathrm{~S}^{+}\left(\tilde{\mathrm{X}}^{3} A_{2}, \nu_{3}{ }^{+}=1\right)$, the rotational constants used are $\mathrm{A}^{+}=5.55 \pm 0.20 \mathrm{~cm}^{-1}$ and $\mathrm{B}^{+}$ $=0.470 \pm 0.010 \mathrm{~cm}^{-1}$. The widths of the $\mathrm{CH}_{3} \mathrm{~S}\left(\tilde{X}^{2} E_{3 / 2}\right)$ and $\mathrm{CH}_{3}\left({ }^{2} E_{1 / 2}\right) \mathrm{PE}$ bands resolved in Fig. 1(a) are found to be well-characterized by $T_{r}=200 \pm 100$ and $250 \pm 100 \mathrm{~K}$, respectively.

A population ratio of $0.5 \pm 0.1$ for $\mathrm{CH}_{3} \mathrm{~S}\left({ }^{2} E_{1 / 2}\right) / \mathrm{CH}_{3} \mathrm{~S}\left(\tilde{X}^{2} E_{3 / 2}\right)$ yields the best fit for the PFI-PE spectrum of Fig. 1(a). The absorption cross section for $\mathrm{CH}_{3} \mathrm{SH}$ at around 265 $\mathrm{nm}$ (i.e., the photon energies of interest here) is unstructured and nearly constant. As pointed out above, the formation of $\mathrm{CH}_{3} \mathrm{~S}+\mathrm{H}$ from the photodissociation of $\mathrm{CH}_{3} \mathrm{SH}$ in this photon energy region is the dominant product channel. ${ }^{31}$ Assuming that the PFI 
detection efficiencies are the same for $\mathrm{CH}_{3} \mathrm{~S}\left(\tilde{X}^{2} E_{3 / 2}\right)$ and $\mathrm{CH}_{3} \mathrm{~S}\left({ }^{2} E_{1 / 2}\right)$, we conclude that for process (1) the relative populations are $\mathrm{CH}_{3} \mathrm{~S}\left({ }^{2} E_{1 / 2}\right): \mathrm{CH}_{3} \mathrm{~S}\left(\tilde{X}^{2} E_{3 / 2}\right)=0.5: 1.0$.

The energy of $74,726 \mathrm{~cm}^{-1}$ used in the simulation for the lowest possible transition, $\mathrm{CH}_{3} \mathrm{~S}\left(\tilde{X}^{2} E_{3 / 2}\right) \rightarrow \mathrm{CH}_{3} \mathrm{~S}^{+}\left(\tilde{X}^{3} A_{2}\right)$, is taken to be the IE of $\mathrm{CH}_{3} \mathrm{~S}\left(\tilde{X}^{2} E_{3 / 2}\right)$. After taking into account the resolution of the ionization laser, the Stark shift effect, and the effects on the IE due to the uncertainties of $\mathrm{A}^{+}\left( \pm 0.2 \mathrm{~cm}^{-1}\right), \mathrm{B}^{+}\left( \pm 0.005 \mathrm{~cm}^{-1}\right)$, and $T_{r}( \pm 100 \mathrm{~K})$, we assign an uncertainty of $\pm 8 \mathrm{~cm}^{-1}$ for the $1 E$ 's of $\mathrm{CH}_{3} \mathrm{~S}$. Using the spin-orbit splitting of $255.5 \mathrm{~cm}^{-1}$, we obtain IE[CH $\left.\mathrm{CH}_{3}\left(\tilde{X}^{2} E_{3 / 2}\right)\right]=74,726 \pm 8 \mathrm{~cm}^{-1}(9.2649 \pm 0.0010 \mathrm{eV})$ and $\mathrm{IE}\left[\mathrm{CH}_{3} \mathrm{~S}\left({ }^{2} E_{1 / 2}\right)\right]=74,471 \pm 8 \mathrm{~cm}^{-1}(9.2333 \pm 0.0010 \mathrm{eV})$. The $\operatorname{IE}\left[\mathrm{CH}_{3} \mathrm{~S}\left(\tilde{X}^{2} E_{3 / 2}\right)\right]$ value is in excellent agreement with the value of $9.262 \pm 0.005 \mathrm{eV}$ obtained in a gas cell VUV photoionization mass spectrometric experiment in which the $\mathrm{CH}_{3} \mathrm{~S}$ radicals were prepared by the reaction of $\mathrm{F}$ with $\mathrm{CH}_{3} \mathrm{SH}$. The value of $9.225 \pm 0.014 \mathrm{eV}$ determined in the experiment of Nourbakhsh et al. ${ }^{21}$, which used a laser photodissociation supersonic radical source, agrees with the value for $\operatorname{IE}\left[\mathrm{CH}_{3} \mathrm{~S}\left({ }^{2} E_{1 / 2}\right)\right]$. In the latter experiment, $\mathrm{CH}_{3} \mathrm{~S}$ radicals were prepared by $193 \mathrm{~nm}$ photodissociation of $\mathrm{CH}_{3} \mathrm{SCH}_{3}$ in the high pressure region of a free jet. The agreement of the IE value obtained by Nourbakhsh et al. with the $\mathrm{IE}\left[\mathrm{CH}_{3} \mathrm{~S}\left({ }^{2} E_{1 / 2}\right)\right]$ determined here indicates that spin-orbit excited $\mathrm{CH}_{3} \mathrm{~S}\left({ }^{2} E_{1 / 2}\right)$ radicals are formed by $193 \mathrm{~nm}$ photodissociation of $\mathrm{CH}_{3} \mathrm{SCH}_{3}$, and that the relaxation of spin-orbit excited $\mathrm{CH}_{3} \mathrm{~S}\left({ }^{2} E_{1 / 2}\right)$ radicals is inefficient in a supersonic expansion. This conclusion is in accord with the observation of the previous LIF studies of $\mathrm{CH}_{3} \mathrm{~S}^{26,27}$

The relative Franck-Condon factors for ionization transitions, $\mathrm{CH}_{3} \mathrm{~S}\left(\tilde{X}, \nu_{3}=0\right) \rightarrow$ $\mathrm{CH}_{3} \mathrm{~S}^{+}\left(\tilde{X}, \nu_{3}{ }^{+}=0\right): \mathrm{CH}_{3} \mathrm{~S}\left(\tilde{X}, \nu_{3}=0\right) \rightarrow \mathrm{CH}_{3} \mathrm{~S}^{+}\left(\tilde{X}, \nu_{3}{ }^{+}=1\right)$ is determined to be $1.00: 0.46$. 
Using the IEs for the transitions from $\mathrm{CH}_{3} \mathrm{~S}\left(\tilde{X}^{2} E_{3 / 2}\right)$ to the $\nu_{3}{ }^{+}=0,1$ states of $\mathrm{CH}_{3} \mathrm{~S}^{+}\left(\tilde{X}^{3} A_{2}\right)$, we obtain a value of $733 \pm 5 \mathrm{~cm}^{-1}$ for the $\nu_{3}{ }^{+}$vibrational spacing of $\mathrm{CH}_{3} \mathrm{~S}^{+}\left(\tilde{X}^{3} A_{2}\right)$. The latter value is higher than the ab initio prediction of $698 \mathrm{~cm}^{-1}{ }^{16}$

The simulated PE spectrum for $\mathrm{CH}_{3} \mathrm{~S}\left(\tilde{X}^{2} E_{3 / 2,1 / 2}\right)$ from $\mathrm{CH}_{3} \mathrm{SH}$ is shown in Fig. 3(b). The experimental PE bands [Fig. 3(a)] for the ionization transitions $\mathrm{CH}_{3} \mathrm{~S}\left(\tilde{X}^{2} E_{3 / 2,1 / 2}\right) \rightarrow$ $\mathrm{CH}_{3} \mathrm{~S}^{+}\left(\tilde{X}^{3} A_{2}, \nu_{3}{ }^{+}=0\right)$ are well reproduced by the theoretical fit. The experimental PE bands for the ionization transition $\mathrm{CH}_{3} \mathrm{~S}\left(\tilde{X}^{2} E_{3 / 2,1 / 2}\right) \rightarrow \mathrm{CH}_{3} \mathrm{~S}^{+}\left(X^{3} A_{2}, \nu_{3}{ }^{+}=1\right)$ are also in good agreement with the theoretical fit, except for some minor details. Minor disagreements between the experimental and simulated spectra can be attributed to local perturbations of autoionization processes. The good fit observed between the experimental and simulated spectra suggests that the characterization of the rotational populations of nascent $\mathrm{CH}_{3} \mathrm{~S}\left(\tilde{X}^{2} E_{3 / 2,1 / 2}\right)$ radicals formed by process (1) by equilibrium $\mathrm{T}_{\mathrm{r}}$ 's is a good approximation and that the autoionization dynamics for $\mathrm{CH}_{3} \mathrm{~S}$ are not particularly sensitive to the rotational levels of $\mathrm{CH}_{3} \mathrm{~S}$.

In order to shed light on the photoionization dynamics of $\mathrm{CH}_{3} \mathrm{~S}\left(\tilde{X}^{2} E_{3 / 2,1 / 2}\right)$, the simulated spectrum is decomposed into the five components shown as five curves in Fig. 3(b). Four components are due to $\Delta K= \pm 1$ with $|\Delta N| \leq 1,|\Delta N|=2,|\Delta N|=3$, and $|\Delta N|=4$, respectively, and one component results from $\Delta K= \pm 2$ and $|\Delta N| \leq 1$. The PE band for $\mathrm{CH}_{3} \mathrm{~S}\left(\tilde{X}^{2} E_{3 / 2}\right)$ exhibits more structure than that for $\mathrm{CH}_{3} \mathrm{~S}\left({ }^{2} E_{1 / 2}\right)$, as confirmed by the simulated spectrum. The simulation suggests that the two strong peaks at 37,355 and $37,367 \mathrm{~cm}^{-1}$ in the $\mathrm{CH}_{3} \mathrm{~S}\left(\tilde{X}^{2} E_{3 / 2}\right) \mathrm{PE}$ band are attributable to $\Delta N=-1$ and $\Delta N=0,1$, respectively, for $\Delta K= \pm 1$. The shoulders at 37,$325 ; 37,334 ; 37,345$; and 
Figure 3 (a) Enlarged view of the N2P-PFI-PE spectrum in the region of 37,100$37,800 \mathrm{~cm}^{-1}$ for nascent $\mathrm{CH}_{3} \mathrm{~S}\left(\tilde{X}^{2} E_{3 / 2,1 / 2}\right)$ radicals formed by the photodissociation of $\mathrm{CH}_{3} \mathrm{SH}$.

(b) The best simulated spectrum for Fig. 3(a). The parameters used in the simulation are summarized in Table I. The simulated spectrum is decomposed into five components as shown. Four components are due to $\Delta K= \pm 1$ with $|\Delta N| \leq 1[(1)],|\Delta N|=2[(2)],|\Delta N|=3[(3)]$, and $|\Delta N|=4[(4)]$, respectively, and one component is from $\Delta K= \pm 2$ and $|\Delta N| \leq 1[(5)]$. 


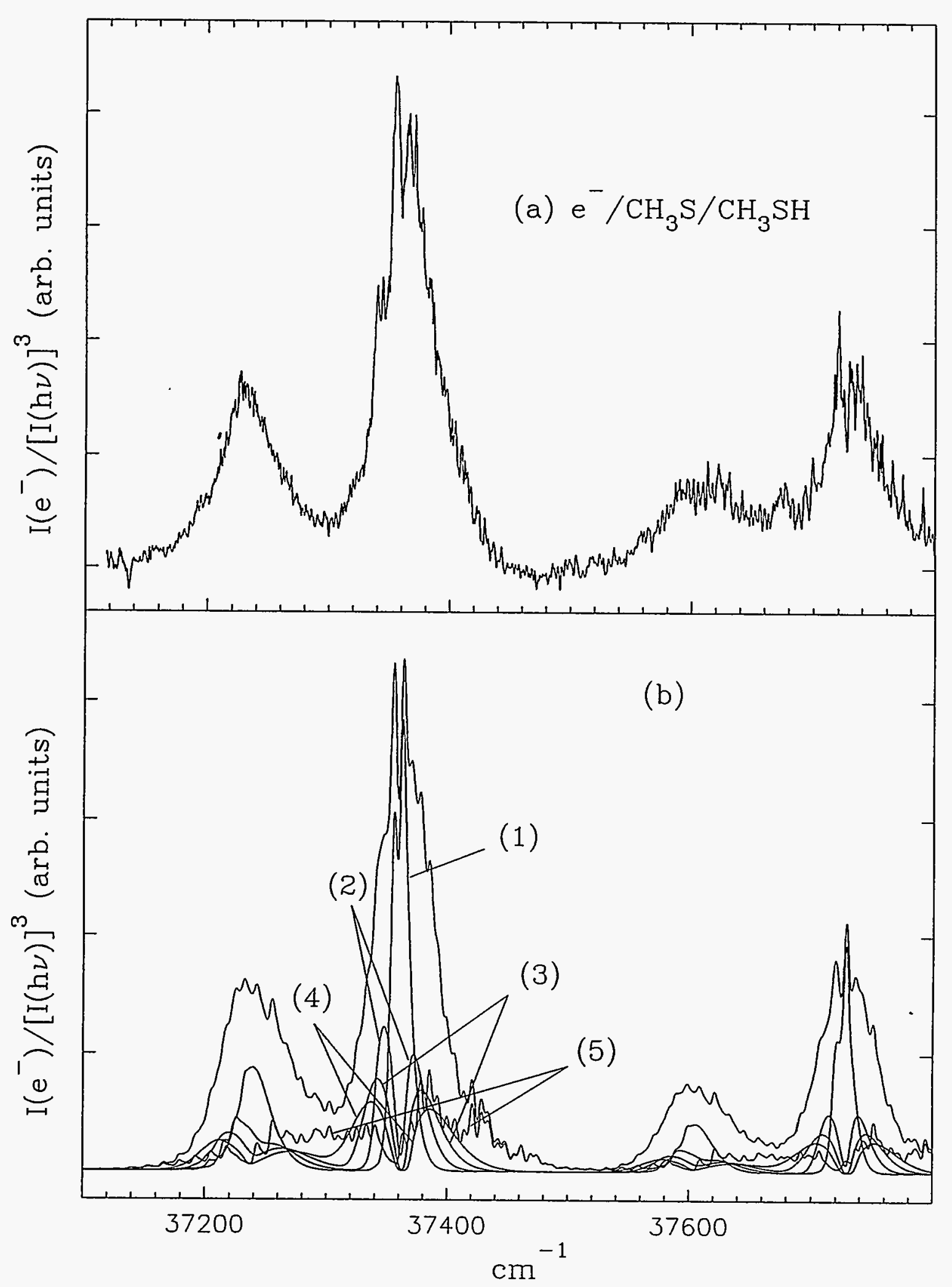


$37,372 \mathrm{~cm}^{-1}$ may be assigned to the respective transition of $\Delta N=-4,-3,-2$, and +2 , with $\Delta K= \pm 1$. The shoulders at 37,378 and $37,384 \mathrm{~cm}^{-1}$ resolved in the experimental band are also reproduced in the simulated spectrum, which suggests that these features may be due to the transitions $\Delta N=3,4$ for $\Delta K= \pm 1$. In addition, note that two of the peaks from $|\Delta N| \leq 1$ with $\Delta K= \pm 2$ are predicted to appear at the same position and thus may also contribute to these observed features. The rotational branches $|\Delta N|>1$ with $\Delta K$ $= \pm 2$ contribute nearly constant intensities throughout the spectrum. For this reason, they are not included in the simulation.

The simulation is also performed for the N2P-PFI-PE spectrum of $\mathrm{CH}_{3} \mathrm{~S}$ produced from photodissociation of $\mathrm{CH}_{3} \mathrm{SSCH}_{3}$. The parameters used are the same as those for simulating the spectrum of Fig. 1(a), except for the $T_{r}$ values and relative populations for the spin-orbit states $\mathrm{CH}_{3} \mathrm{~S}\left(\tilde{X}^{2} E_{3 / 2}\right)$ and $\mathrm{CH}_{3} \mathrm{~S}\left({ }^{2} E_{1 / 2}\right)$. We find that the widths of the $\mathrm{CH}_{3} \mathrm{~S}\left(\tilde{X}^{2} E_{3 / 2}\right)$ and $\mathrm{CH}_{3} \mathrm{~S}\left({ }^{2} E_{1 / 2}\right)$ PE bands observed in Fig. 1(a) correspond $\mathrm{T}_{\mathrm{r}}=800 \pm 200$ and $900 \pm 200 \mathrm{~K}$, respectively, while the relative intensities for the $\mathrm{CH}_{3} \mathrm{~S}\left(\tilde{X}^{2} E_{3 / 2}\right)$ and $\mathrm{CH}_{3} \mathrm{~S}\left({ }^{2} E_{1 / 2}\right) \mathrm{PE}$ bands are consistent with a value of $1.1 \pm 0.2$ for the population ratio $\mathrm{CH}_{3} \mathrm{~S}\left({ }^{2} E_{1 / 2}\right) / \mathrm{CH}_{3} \mathrm{~S}\left(\tilde{X}^{2} E_{3 / 2}\right)$.

The simulated spectrum for $\mathrm{CH}_{3} \mathrm{~S}\left(\tilde{X}^{2} E_{3 / 2,1 / 2}\right)$ from $\mathrm{CH}_{3} \mathrm{SSCH}_{3}$ is shown in Fig. 4(b). The general profile of the experimental spectrum [Fig. 4(a)] is roughly reproduced by the simulated spectrum. Similar to the analysis of the N2P-PFI-PE spectrum for $\mathrm{CH}_{3} \mathrm{~S}$ from $\mathrm{CH}_{3} \mathrm{SH}$, the contributions to the simulated spectrum for $\mathrm{CH}_{3} \mathrm{~S}$ from $\mathrm{CH}_{3} \mathrm{SSCH}_{3}$ are also decomposed into the five components shown in Fig. 4(b). A noticeable peak at 37,316 $\mathrm{cm}^{-1}$ may be attributed to the rotational branch $\Delta N=-3$ for $\Delta K= \pm 1$. This feature is 
Figure 4 (a) Enlarged view of the N2P-PFI-PE spectrum in the region of 37,100$37,800 \mathrm{~cm}^{-1}$ for nascent $\mathrm{CH}_{3} \mathrm{~S}\left(\tilde{X}^{2} E_{3 / 2,1 / 2}\right)$ radicals formed by the photodissociation of $\mathrm{CH}_{3} \mathrm{SSCH}_{3}$.

(b) The best simulated spectrum for Fig. 4(a). The parameters used in the simulation are summarized in Table $I$. The simulated spectrum is decomposed into five components as shown. Four components are due to $\Delta K= \pm 1$ with $|\Delta N| \leq 1[(1)],|\Delta N|=2[(2)],|\Delta N|=3[(3)]$, and $|\Delta N|=4[(4)]$, respectively, and one component is from $\Delta K= \pm 2$ and $|\Delta N| \leq 1[(5)]$. 


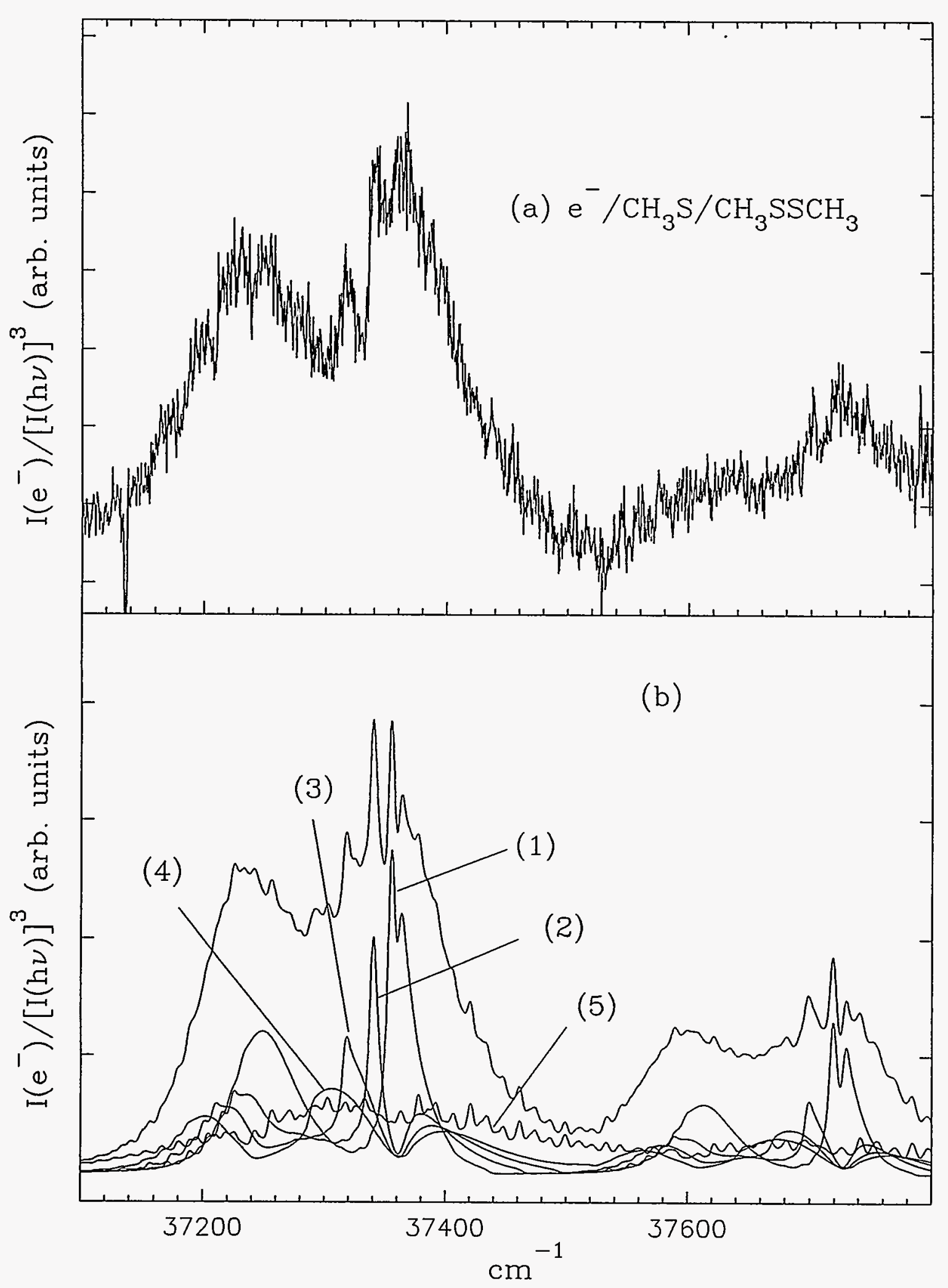


very sensitive to variations in $\mathrm{A}^{+}$and $\mathrm{B}^{+}$. Contrary to the simulated spectrum which shows three resolved peaks in the region $37,340-37,380 \mathrm{~cm}^{-1}$, the experimental spectrum exhibits only two partially resolved broad peaks. We find a similar observation when comparing the simulated and experimental PE band in the region of $37,710-37,750 \mathrm{~cm}^{-1}$. The conclusion that the autoionization processes for $\mathrm{CH}_{3} \mathrm{~S}$ are relatively insensitive to the rotational levels obtained in the simulation of the $\mathrm{PE}$ spectrum of $\mathrm{CH}_{3} \mathrm{~S}$ from $\mathrm{CH}_{3} \mathrm{SH}$ should also apply here. If this conclusion is valid, the difference between the experimental and simulated spectra is most likely due to the non-equilibrium rotational distributions for $\mathrm{CH}_{3} \mathrm{~S}\left(\tilde{X}^{2} E_{3 / 2,1 / 2}\right)$ from $\mathrm{CH}_{3} \mathrm{SSCH}_{3}$.

One of the conclusions obtained from the simulation of the N2P-PFI-PE spectra of $\mathrm{CH}_{3} \mathrm{~S}$ from processes (1) and (2) is that $\mathrm{T}_{\mathrm{r}}$ for nascent $\mathrm{CH}_{3} \mathrm{~S}\left(\tilde{X}^{2} E_{3 / 2,1 / 2}\right)$ radicals formed from $\mathrm{CH}_{3} \mathrm{SH}$ is significantly lower than for those formed from $\mathrm{CH}_{3} \mathrm{SSCH}_{3}$. The can be qualitatively explained using the impulsive model ${ }^{32,33}$ of molecular dissociation. This model assumes that the molecule breaks apart due to vibrational motion without general equilibration of internal energies. For a triatomic molecule $\alpha \beta \gamma$ that dissociates into $\alpha+$ $\beta \gamma$, this model implies that the atoms of dissociating bond $\alpha-\beta$ recoil sharply before atom $\gamma$ has time to respond. Thus, $\mathrm{E}_{\mathrm{av}}$ is partitioned between the recoiling atoms $\alpha$ and $\beta$ according to the conservation of linear momentum. The energy acquired by $\beta$ manifests as translation ( $E_{v}$ ), rotation ( $E_{r}$ ), and vibration ( $\left.E_{v}\right)$ of the $\beta \gamma$ fragment through the inelastic collision of $\beta$ and $\gamma^{34}$

This model has been generalized to include dissociation of polyatomic molecules $\mathrm{AB}$ into fragments $\mathrm{A}$ and $\mathrm{B}$, which may also be polyatomic species. ${ }^{33}$ Assuming that $\mathrm{AB}$ 
is bonded through atom $\alpha$ (in A) and atom $\beta$ (in B), it can be shown that the energy partitioned into $B\left[E_{B}\right] i^{35}$

$$
\mathrm{E}_{\mathrm{B}}=\left(\mu / \mathrm{m}_{\beta}\right) \mathrm{E}_{\mathrm{av}},
$$

where $\mu$ is the reduced mass of $\alpha$ and $\beta$ and $\mathrm{m}_{\beta}$ is the mass of $\beta$. $\mathrm{E}_{\mathrm{B}}$ is further partitioned into $E_{\imath}, E_{r}$, and $E_{v}$ of $B$ according to the equations: ${ }^{35}$

$$
\begin{aligned}
& \mathrm{E}_{\mathrm{l}}(\mathrm{B})=\left(\mathrm{m}_{\beta} / \mathrm{m}_{\mathrm{B}}\right) \mathrm{E}_{\mathrm{B}} \\
& \mathrm{E}_{\mathrm{r}}(\mathrm{B})+\mathrm{E}_{\mathrm{v}}(\mathrm{B})=\left(1-\mathrm{m}_{\beta} / \mathrm{m}_{\mathrm{B}}\right) \mathrm{E}_{\mathrm{B}}
\end{aligned}
$$

Considering further that $\mathrm{B}$ is a diatom $\beta-\gamma$, the internal energy can be separated into the rotational and vibrational components, as in the case of a triatomic molecule.

$$
\begin{aligned}
& \mathrm{E}_{\mathrm{r}}(\mathrm{B})=\left(1-\mathrm{m}_{\beta} / \mathrm{m}_{\mathrm{B}}\right) \mathrm{E}_{\mathrm{B}} \sin ^{2} \phi, \\
& \mathrm{E}_{\mathrm{v}}(\mathrm{B})=\left(1-\mathrm{m}_{\beta} / \mathrm{m}_{\mathrm{B}}\right) \mathrm{E}_{\mathrm{B}} \cos ^{2} \phi,
\end{aligned}
$$

where $\phi$ is the $\mathrm{A}(\alpha)-\beta-\gamma$ bond angle.

If we consider that the $\mathrm{CH}_{3}$ group is a pseudo-atom of mass $=15$ a.m.u., the rotational energies acquired by nascent $\mathrm{CH}_{3} \mathrm{~S}$ from $\mathrm{CH}_{3} \mathrm{SH}$ and $\mathrm{CH}_{3} \mathrm{SSCH}_{3}$ can be 
calculated using equation (8), provided that the geometries for the dissociating molecules are known. For the purpose of estimating the $\mathrm{E}_{\mathrm{r}}$ value for $\mathrm{CH}_{3} \mathrm{~S}$, we assume that the geometries for the dissociating $\mathrm{CH}_{3} \mathrm{SH}$ and $\mathrm{CH}_{3} \mathrm{SSCH}_{3}$ are the same as those for their ground states. The ground state geometries for $\mathrm{CH}_{3} \mathrm{SH}$ and $\mathrm{CH}_{3} \mathrm{SSCH}_{3}$ are obtained from $a b$ initio calculations at the MP2/6-31G(d) level of theory. ${ }^{20,36}$ In the case of $\mathrm{CH}_{3} \mathrm{SH}$, the theoretical and experimental structures are in good agreement. ${ }^{37}$ Using the S-H bond energy of $86-90 \mathrm{kcal} / \mathrm{mol}^{12,14,38}$ in $\mathrm{CH}_{3} \mathrm{SH}$, together with the $a b$ initio geometry for $\mathrm{CH}_{3} \mathrm{SH}\left(\tilde{X}^{1} A^{\prime}\right)$, we obtain a value of $\approx 63 \mathrm{~cm}^{-1}$ for $\mathrm{E}_{\mathrm{r}}$ of the $\mathrm{CH}_{3} \mathrm{~S}$ fragment at a photodissociation energy of $37,300 \mathrm{~cm}^{-1}$. This $E_{\mathrm{r}}$ value of $63 \mathrm{~cm}^{-1}$ corresponds to $T_{\mathrm{r}} \approx 63$ $\mathrm{K}$, which is lower than the experimental $\mathrm{T}_{\mathrm{r}}$ values of $200-250 \mathrm{~K}$ for $\mathrm{CH}_{3} \mathrm{~S}\left(\tilde{X}^{2} E_{3 / 2,1 / 2}\right)$ from $\mathrm{CH}_{3} \mathrm{SH}$. The cleavage of the $\mathrm{S}-\mathrm{S}$ bond in $\mathrm{CH}_{3} \mathrm{SSCH}_{3}$ requires $74.8 \mathrm{kcal} / \mathrm{mol}{ }^{11}$ Equation (7) predicts a value of $\approx 1709 \mathrm{~cm}^{-1}$ for $\mathrm{E}_{\mathrm{r}}$ of $\mathrm{CH}_{3} \mathrm{~S}$ from $\mathrm{CH}_{3} \mathrm{SSCH}_{3}$, which translates into a $T_{r} \approx 1660 \mathrm{~K}$, significantly greater than the experimental $T_{r}$ of $800-900 \mathrm{~K}$ for $\mathrm{CH}_{3} \mathrm{~S}\left(\tilde{X}^{2} E_{3 / 2,1 / 2}\right)$. The difference between experimental and predicted $\mathrm{E}_{\mathrm{r}}$ 's may be partly attributed to unrealistic assumption that the dissociation geometries for $\mathrm{CH}_{3} \mathrm{SH}$ and $\mathrm{CH}_{3} \mathrm{SSCH}_{3}$ are the same as their equilibrium ground state structures. While the impulsive dissociation model gives predictions in qualitative agreement with experimental results, the model is not expected to yield accurate internal energy partitions because product electronic excitations have not been taken into account.

In IE measurements of polyatomic radicals, it is advantageous to prepare a cold radical beam. This experiment confirms the theoretical expectation that relatively cold polyatomic radicals can be prepared by photodissociation of molecular precursors when 
the photodissociation involves the ejection of a light fragment, such as the hydrogen atom in process (1). 


\section{CONCLUSION}

The N2P-PFI-PE spectra for $\mathrm{CH}_{3} \mathrm{~S}$ formed in the photodissociation of $\mathrm{CH}_{3} \mathrm{SH}$ and $\mathrm{CH}_{3} \mathrm{SSCH}_{3}$ have been obtained near the ionization threshold of $\mathrm{CH}_{3} \mathrm{~S}$. Both the $\mathrm{CH}_{3} \mathrm{~S}\left(\tilde{\mathrm{X}}^{2} E_{3 / 2}\right)$ and $\mathrm{CH}_{3} \mathrm{~S}\left({ }^{2} E_{1 / 2}\right)$ spin-orbit states are formed in processes (1) and (2) with values of $0.5 \pm 0.1$ and $1.1 \pm 0.2$, respectively, for the ratio $\mathrm{CH}_{3} \mathrm{~S}\left({ }^{2} E_{1 / 2}\right) / \mathrm{CH}_{3} \mathrm{~S}\left(\tilde{X}^{2} E_{3 / 2}\right)$. From the simulation of the PFI-PE spectra for $\mathrm{CH}_{3} \mathrm{~S}\left(\tilde{X}^{2} E_{3 / 2,1 / 2}\right)$, we obtain estimates for the rovibronic state distributions of nascent $\mathrm{CH}_{3} \mathrm{~S}\left(\tilde{X}^{2} E_{3 / 2,1 / 2}\right)$ formed in the photodissociation wavelength range of $262-271 \mathrm{~nm}$. As a good approximation, the rotational populations of $\mathrm{CH}_{3} \mathrm{~S}$ from $\mathrm{CH}_{3} \mathrm{SH}$ and $\mathrm{CH}_{3} \mathrm{SSCH}_{3}$ can be characterized by $\mathrm{T}_{\mathrm{r}}=200-250$ and $800-900 \mathrm{~K}$, respectively. This experiment, together with the N2P-PFI-PE experiment of $\mathrm{SH}$ from $\mathrm{H}_{2} \mathrm{~S}$, demonstrates that the PFI-PE technique can be used to probe the rovibronic state distribution of nascent photofragments.

The simulation also shows that the pulsed electric field induced autoionization processes for $\mathrm{CH}_{3} \mathrm{~S}$ are not very sensitive to the rotational level of $\mathrm{CH}_{3} \mathrm{~S}\left(\tilde{X}^{2} E_{3 / 2,1 / 2}\right)$. The IEs for $\mathrm{CH}_{3} \mathrm{~S}\left(\tilde{X}^{2} E_{3 / 2}\right)\left(74,726 \pm 8 \mathrm{~cm}^{-1}\right.$ or $\left.9.2649 \pm 0.0010 \mathrm{eV}\right)$ and $\mathrm{CH}_{3} \mathrm{~S}\left({ }^{2} E_{1 / 2}\right)(74,471$ $\pm 8 \mathrm{~cm}^{-1}$ or $\left.9.2333 \pm 0.0010 \mathrm{eV}\right)$ and the C-S stretching frequency $\left(733 \pm 5 \mathrm{~cm}^{-1}\right)$ are determined with high accuracy. 


\section{ACKNOWLEDGEMENT}

CYN acknowledge the Donors of the Petroleum Research Fund, administered by the American Chemical Society, for the partial support of this research. The authors are grateful to helpful discussions with Prof. T. A. Miller and Dr. M. G. White. 


\section{REFERENCES}

(1) G. Reiser, W. Habenicht, K. Müller-Dethlefs, and E. W. Schlag, Chem. Phys. Lett. $\underline{152}, 119$ (1988).

(2) K. Müller-Dethefs, M. Sander, and E. W. Schlag, Z. Naturforsch. A 모, 1089 (1984); K. Müller-Dethefs and E. W. Schlag, Annu. Rev, Phys. Chem. 42, 109 (1991).

(3) I. Powis, T. Baer, and C. Y. Ng, Eds., "High Resolution Laser Photoionization and Photoelectron Studies" (Wiley, Chichester, 1994), in press.

(4) C.-W. Hsu, D. P. Baldwin, C.-L. Liao, and C. Y. Ng, J. Chem. Phys. 100, xxxx (1994).

(5) A. Stribel, I. Fischer, J. Staecker, G. Niedner-Schatteburg, K. Müller-Dethlefs and C. E. Bondybey, J. Chem. Phys. 97, 2332 (1992).

(6) I. Fischer, A. Lochschmidt, A. Strobel, G. Niedner-Schatteburg, K. Müller-Dethlefs, and V. E. Bondybey, J. Chem. Phys. 98, 3592 (1993).

(7) I. Fischer, A. Lochschmidt, A. Strobel, G. Niedner-Schatteburg, K. Müller-Dethelef, and V. E. Bondybey, Chem. Phys. Lett. 202, 542 (1993).

(8) A. Strobel, A. Lochschmidt, I. Fisher, G. Niedner-Schatteburg, and V. E. Bondybey, J. Chem. Phys. 99, 733 (1993).

(9) I. Fischer, A. Strobel, J. Staecher, G. Niedner-Schatteburg, K. Müller-Dethlefs, and V. E. Bondybey, J. Chem. Phys. 므, 7171 (1992).

(10) C.-W. Hsu, D. P. Baldwin, C.-L. Liao, and C. Y. Ng, "Laser Techniques for State- 
Selected and State-to-State Chemistry II", J. W. Hepburn, ed., SPIE Proc. 2124 (1994), in press.

(11) S. Nourbakhsh, C.-L. Liao, and C. Y. Ng, J. Chem. Phys. 92, 6587 (1990).

(12) S. Nourbakhsh, K. Norwood, H.-M. Yin, C.-L. Liao, and C.Y. Ng, J. Chem. Phys. 95, 946 (1991).

(13) J. S. Keller, P. W. Kash, E. Jensen, and L. J. Butler, J. Chem. Phys. 96, 4324 (1992).

(14) J. Segall, Y. Wen, R. singer, M. Dulligan, and C. Wittig, J. Chem. Phys. 99, 6600 (1993).

(15) Y. R. Lee, C. L. Chiu, and S. M. Lin, J. Chem. Phys., in press.

(16) S.-W. Chiu, W.-K. Li, W.-B. Tzeng, and C. Y. Ng, J. Chem. Phys. 97, 6557-6568 (1992).

(17) D. P. Chong and C. Y. Ng, J. Chem. Phys. 98, 759-760 (1993).

(18) L. A. Curtiss, R. H. Nobes, J. A. Pople, and L. Radom, J. Chem. Phys. 97, 6766 (1992).

(19) R. H. Nobes and L. Radom, Chem. Phys. Lett. 189, 554 (1992).

(20) D. R. Yarkony, J. Chem. Phys. 100, 3639 (1994) and references therein.

(21) S. Nourbakhsh, K. Norwood, G.-Z. He, and C. Y. Ng, J. Am. Chem. Phys. 113, 6311 (1991).

(22) B. Ruscic and J. Berkowitz, J. Chem. Phys. 97, 1818 (1992).

(23) C.-W. Hsu, C.-L. Liao, Z.-X, Ma, P. J. H. Tjossem, and C. Y. Ng, Chem. Phys. 
Lett. 199, 78 (1992).

(24) C. W. Hsu, C.-L. Liao, Z.-X. Ma, P.J. H. Tjossem, and C. Y. Ng, J. Chem. Phys. 97, 6283 (1992).

(25) C. E. Moore, "Atomic Energy Levels", Natl. Bur. Stand. (U.S.) Circ. No. 467 (U.S. GPO, Washington, D.C. 1949), Vol. I.

(26) Y.-C. Hsu, X. Liu, and T. A. Miller, J. Chem. Phys. 90, 6852 (1989).

(27) S.-Y. Chiang and Y.-P. Lee, J. Chem. Phys. 95, 66 (1991).

(28) Using a rotational temperature $\left(\mathrm{T}_{\mathrm{r}}\right)$ to characterize the rotational population of nascent $\mathrm{CH}_{3} \mathrm{~S}$ radicals is an approximation, in which equilibrium among the rotational levels is assumed.

(29) X.-M. Liu, C. P. Damo, T.-Y. Lin. S. C. Foster, P. Misra, L. Yu, and T. A. Miller, J. Phys. Chem. 93, 2266 (1989).

(30) Y. Endo, S. Saito, and E. Hirota, J. Chem. Phys. $\underline{81,} 122$ (1984).

(31) J. G. Calvert and J. N. Pitts, Jr., "Photochemistry" (Wiley, New York, 1966).

(32) G. E. Busch and K. R. Wilson, J. Chem. Phys. 56, 3626 (1972).

(33) K. A. Trentelman, S. H. Kable, D. B. Moss, and P. L. Houston, J. Chem. Phys. 91, 7498 (1989).

(34) Reference 32. The values for $\mathrm{E}_{\mathrm{t}}, \mathrm{E}_{\mathrm{r}}$, and $\mathrm{E}_{\mathrm{v}}$ of fragment $\beta \gamma$ are calculated as: $\mathrm{E}_{\mathrm{q}}=$ $\left(\mu_{\alpha \beta} / \mathrm{m}_{\beta \gamma}\right) \mathrm{E}_{\mathrm{av}}, \mathrm{E}_{\mathrm{r}}=\left(1-\mu_{\alpha \beta} / \mu_{\mathrm{f}}\right) \mathrm{E}_{\mathrm{av}} \sin ^{2} \phi$, and $\mathrm{E}_{\mathrm{v}}=\left(1-\mu_{\alpha \beta} / \mu_{\mathrm{f}}\right) \mathrm{E}_{\mathrm{av}} \cos ^{2} \phi$, where $\mu_{\alpha \beta}$ and $\mu_{\mathrm{f}}$ are the reduced mass of atoms $\alpha$ and $\beta$ and atom $\alpha$ and fragment $\beta \gamma$, respectively, and $\phi$ is the bond angle of $\alpha-\beta-\gamma$.

(35) The expressions for the energies partitioned to $A\left[E_{A}, E_{l}(A), E_{r}(A)\right.$, and $\left.E_{v}(A)\right]$ are 
similar to equations (5), (6) and (7).

(36) W.-K. Li, S.-W. Chiu, and Z.-X. Ma, and C. Y. Ng, J. Chem. Phys. 99, 8440 (1993).

(37) G. Herzberg, "Electronic Spectra and Electronic Structures of Polyatomic Molecules" (Van Nostrand Reinhold, New York, 1966).

(38) J. M. Nicovich, K. D. Kruetter, C. A. van Dijk, and P. H. Wine, J. Phys. Chem. 96, 2518 (1992). 


\section{GENERAL CONCLUSION}

Using the $2+1$ REMPI detection scheme for $S\left({ }^{3} \mathrm{P}_{2,1,0},{ }^{1} \mathrm{D}_{2}\right)$, we have examined the $193 \mathrm{~nm}$ photodissociation of $\mathrm{CH}_{3} \mathrm{~S}(\widetilde{\mathrm{X}})$ and $\mathrm{SH}(\mathrm{X}, \mathrm{v})$ prepared from processes (1) and (3), respectively.

$\mathrm{CH}_{3} \mathrm{SCH}_{3}+\mathrm{h} \nu(193 \mathrm{~nm}) \rightarrow \mathrm{CH}_{3} \mathrm{~S}(\widetilde{\mathrm{X}})+\mathrm{CH}_{3}$,

$\mathrm{CH}_{3} \mathrm{~S}(\widetilde{\mathrm{X}})+\mathrm{h} \nu(193 \mathrm{~nm}) \rightarrow \mathrm{CH}_{3}+\mathrm{S}\left({ }^{3} \mathrm{P}_{2,1,0},{ }^{1} \mathrm{D}_{2}\right)$,

$\mathrm{H}_{2} \mathrm{~S}+\mathrm{h} \nu(193 \mathrm{~nm}) \rightarrow \mathrm{SH}(\mathrm{X}, v)+\mathrm{H}$,

$\mathrm{SH}(\mathrm{X}, v)+\mathrm{h} \nu(193 \mathrm{~nm}) \rightarrow \mathrm{H}\left({ }^{2} \mathrm{~S}\right)+\mathrm{S}\left({ }^{3} \mathrm{P}_{2,1,0} ;{ }^{1} \mathrm{D}_{2}\right)$.

The absolute photodissociation cross sections for $\mathrm{CH}_{3} \mathrm{~S}$ and $\mathrm{SH}$ at $193 \mathrm{~nm}$ are estimated to be $1 \times 10^{-18}$ and $1.1 \times 10^{-18} \mathrm{~cm}^{2}$, respectively. The branching ratio $\mathrm{S}\left({ }^{3} \mathrm{P}\right): \mathrm{S}\left({ }^{1} \mathrm{D}\right)$ measured for process (2) is rationalized based on the potential energy curves along the $\mathrm{CH}_{3} \mathrm{~S}$ dissociation coordinate using the MCSCF and FOCI methods. The branching ratio $\mathrm{S}\left({ }^{3} \mathrm{P}\right): \mathrm{S}\left({ }^{\mathrm{I}} \mathrm{D}\right)$ measured for process (4) is consistent with the direct photodissociation mechanism for $\mathrm{SH}(\mathrm{X}, v)$ via the excited repulsive $\mathrm{SH}\left({ }^{2} \Sigma\right)$ and $\left.\mathrm{SH}^{(}{ }^{2} \Delta\right)$ surfaces, as proposed by Continetti et $a 1^{16}$. The fine structure distributions $S\left({ }^{3} \mathrm{P}_{2}\right): \mathrm{S}\left({ }^{\beta} \mathrm{P}_{1}\right): \mathrm{S}\left({ }^{3} \mathrm{P}_{0}\right)$ have been measured for processes (2) and (4) and are found to be $0.59: 0.32: 0.09$ and $0.68: 0.24$ : 0.08 , respectively.

The $193 \mathrm{~nm}$ photodissociation of $\mathrm{CH}_{3} \mathrm{~S}(\widetilde{\mathrm{X}})$ and $\mathrm{SH}(\mathrm{X}, \mathrm{v})$ prepared from $\mathrm{CH}_{3} \mathrm{SH}$ (processes (5) and (6)) have also been examined.

$$
\begin{aligned}
& \mathrm{CH}_{3} \mathrm{SH}+\mathrm{h} \nu(193 \mathrm{~nm}) \rightarrow \mathrm{CH}_{3} \mathrm{~S}(\widetilde{\mathrm{X}})+\mathrm{H}, \\
& \mathrm{CH}_{3} \mathrm{SH}+\mathrm{h} \nu(193 \mathrm{~nm}) \rightarrow \mathrm{SH}(\mathrm{X}, v)+\mathrm{CH}_{3}
\end{aligned}
$$


The small difference in the branching ratios observed for $\mathrm{CH}_{3} \mathrm{~S}$ and $\mathrm{SH}$, prepared from different parents, suggests the dependency of the branching ratios on the internal energy distributions of the intermediate radicals.

Using the N2P-PFI scheme, we have obtained the threshold PE spectra for SH and $\mathrm{CH}_{3} \mathrm{~S}$ at high resolution. The absorption cross section for the first-photon excitation for $\mathrm{H}_{2} \mathrm{~S}$ is continuous around $235 \mathrm{~nm}^{17}$. Therefore, the spectrum obtained by scanning the UV energy over this region reflects the cross section for the two-photon threshold photoionization of SH. Similarly, the spectrum obtained by scanning the UV energy over $267 \mathrm{~nm}$ for $\mathrm{CH}_{3} \mathrm{SH}$ (Ref. 17) reflects the cross section for the two-photon threshold photoionization of $\mathrm{CH}_{3} \mathrm{~S}$. The assignment of the rotationally resolved N2P-PFI-PE spectrum allows a highly accurate determination of the IE for SH. The improved value for the IE for $\mathrm{CH}_{3} \mathrm{~S}$ is also obtained from the simulation spectrum. To our knowledge, this is the first application of N2P threshold photoionization to the study of free radical species. 


\section{REFERENCES}

(1) A. Levy, E. L. Merryman, and W. T. Reid, Environ. Sci. Technol. 4 4 , 653 (1970).

(2) W. B. Tzeng, H.-M. Yin, W.-Y. Leung, J.-Y. Luo, S. Nourbakhsh, G. D. Flesch, and C. Y. Ng, J. Chem. Phys. $\underline{88}, 1658$ (1986).

(3) S. Nourbakhsh, C.-L. Liao, and C. Y. Ng, J. Chem. Phys. 92, 6587(1989).

(4) S. Nourbakhsh, K. Norwood, H.-M. Yin, C.-L. Liao, and C. Y. Ng, J. Chem. Phys. 95, 5014 (1991).

(5) S. Nourbakhsh, K. Norwood, H.-M. Yin, C.-L. Liao, and C. Y. Ng, J. Chem. Phys. 95, 946 (1991).

(6) S. Nourbakhsh, H.-M. Yin, C.-L. Liao, and C. Y. Ng, Chem. Phys. Lett. $\underline{183}$, 348 (1991).

(7) C.-L. Liao, C.-W. Hsu, and C. Y. Ng, Optical Methods for Time- and StateResolved Selective Chemistry, C. Y. Ng, Editor, Proc.SPIE 1638, p. 245-253 (1992).

(8) C.-W. Hsu, C.-L. Liao, Z.-X. Ma, P. J. H. Tjossem, and C. Y. Ng, J. Chem. Phys. 97, 6283 (1992).

(9) C.-W. Hsu, C.-L. Liao, Z.-X. Ma, P. J. H. Tjossem, and C. Y. Ng, Chem. Phys. Lett. 199, 78 (1992).

(10) G. Resiser, W. Habenicht, K. Müller-Dethlefs, and E. W. Schlag, Chem. Phys. Lett. $\underline{152}, 119$ (1988).

(11) K, Müller-Dethlefs, M. Sander, and E. W. Schlag, Z. Naturforsch. Teil A $\underline{39}$, 
1089 (1984).

(12) K, Müller-Dethlefs and E. W. Schlag, Annu. Rev. Phys. Chem. 42, 109 (1991).

(13) C.-W. Hsu, D. P. Baldwin, C.-L. Liao, and C. Y. Ng, Optical Methods for Timeand State-Resolved Selective Chemistry, C. Y. Ng, Editor, Proc.SPIE, in press.

(14) C.-W. Hsu, D. P. Baldwin, C.-L. Liao, and C. Y. Ng, J. Chem. Phys., in press.

(15) C.-W. Hsu and C. Y. Ng, J. Chem. Phys., to be submitted.

(16) R. E. Continetti, B. A. Balko, and Y. T. Lee, Chem. Phys. Lett. 185, 400 (1991).

(17) J. G. Calvert and J. N. Pitts, Jr., "Photochemistry" (Wiley, New York, 1966). 
APPENDIX.

COMPUTER PROGRAMS 
This program is designed to analyze the rotationally resolved photoionization spectrum of HS. Rotational constants for neutral (HS) are obtained from Ramsey. Rotational constants for ion (HS+)

c are taken from Horani et al.

c

Program HSrot3

Real*4 HSn1(15,2),HSn2(15,2),HSi1(15,1),HSi2(15,1),HSi3(15,1)

Real*4 TP1(15,2),TP2(15,2),TP3(15,2)

Real*4 A0,Bvn,Dvn,Lambda,Beta,Bvi,Dvi,gamma,Lamb,Q1,Q2,IP,kB

Integer*2 $\mathrm{K}, \mathrm{i}, \mathrm{jj}$, NPoints

Parameter $($ Lambda $=1 ., B v n=9.461, \mathrm{Dvn}=0.00048)$

Parameter (Bvi $=9.134, \mathrm{Dvi}=.000489)$

Parameter $(\mathrm{IP}=83888.7, \mathrm{NPoints}=2101, \mathrm{kB}=0.69503)$

Real*4 width,J,step,temp1,temp2,cc,nrgmin,spect(NPoints)

Character Fname*10,Tfname*10,Filename*8

common/BL1/step,nrgmin

common/BL2/spect, Filename

common/BL3/TP1,TP2,TP3,cc, width,K

c

c

c

c

c

c

c

c

c

c

c

c

c

c

c

c

c

c currentnrg : current wavenumber (cm-1)

c width : Gaussian FWHM (cm-1)

c NPoints : number of points in a scan 
c temp1,temp2 : neutral rotational temperature (K) $(\mathrm{Pi} 3 / 2 \& 1 / 2)$

c $\mathrm{kB}:$ Boltzmann constant $(\mathrm{cm}-1)$

c Q1, Q2 : Rotational partition functions

c deltaw : the energy difference between currentnrg and peak position

c spect(j): spectrum for each branch

c P11..R23 : 18 sub branches delta $K=0,-1,+1$

c $011 . . S 23: 12$ sub branches delta $K=-2,+2$

c N11..T23: 12 sub branches delta $K=-3,+3$

c M11..M23 : 6 sub branches delta $\mathrm{K}=-4$

c There are 16 rotational branches in the simulation ( 3 sub branches for

c each branch) shown as follows:

c P1..R2 : 6 branches

c O1..S2: 4 branches

c N1..T2: 4 branches

c M1..M2 : 2 branches

Fname $=$ 'hszar1.eng'

Tfname $=$ 'hstran.eng',

step $=.002$

nrgmin $=41550$.

width $=1.0$

gamma $=-.165$

$\mathrm{Lamb}=5.71$

$\mathrm{A} 0=-376.96$

$\mathrm{cc}=-0.693147 /$ (width*width)

write(*,'(e9.3)')nrgmin

write $(*, *)$ ' enter the temperature for $\mathrm{Pi}(3 / 2)$ and $\mathrm{Pi}(1 / 2)$ :'

$\operatorname{read}\left({ }^{*},{ }^{\prime}(2 \mathrm{f} 10.3)^{\prime}\right)$ temp1,temp2

c Calculate $\mathrm{Pi}(3 / 2)$ state energy

$\mathrm{Q} 1=0$.

write (*,*)' J $\mathrm{K}$ rotational Boltzmann'

do $211 \mathrm{~K}=1,15$

$\mathrm{J}=\mathrm{K}+.5$

$\mathrm{Y}=\mathrm{A} 0 / \mathrm{Bvn}$

Beta $=0.5 * \operatorname{sqrt}(4 *(\mathrm{~J}+0.5) *(\mathrm{~J}+0.5)+\mathrm{Y} *(\mathrm{Y}-4) *$ lambda*lambda $)$

$\mathrm{HSn} 1(\mathrm{~K}, 0)=\mathrm{Bvn} *((\mathrm{~J}+.5) *(\mathrm{~J}+.5)$-lambda*lambda-Beta $)$

$* \quad-\mathrm{Dvn} * \mathrm{~J} * \mathrm{~J} * \mathrm{~J} * \mathrm{~J}$

$\mathrm{HSn} 1(\mathrm{~K}, 1)=(2 * \mathrm{~J}+1) * \exp ((-\mathrm{HSn} 1(\mathrm{~K}, 0)+\mathrm{HSn} 1(1,0)) /(\mathrm{kB} * \operatorname{temp} 1))$

$\mathrm{Q} 1=\mathrm{Q} 1+\mathrm{HSn} 1(\mathrm{~K}, 1)$

211 continue

write $(* *)$ 
c Calculate $\mathrm{Pi}(1 / 2)$ state energy

$$
\begin{aligned}
& \mathrm{Q} 2=0 . \\
& \text { do } 212 \mathrm{~K}=1,15 \\
& \mathrm{~J}=\mathrm{K}-.5 \\
& \mathrm{Y}=\mathrm{A} 0 / \mathrm{Bvn}
\end{aligned}
$$

Beta $=0.5 * \operatorname{sqrt}(4 *(\mathrm{~J}+0.5) *(\mathrm{~J}+0.5)+\mathrm{Y} *(\mathrm{Y}-4) * 1 \mathrm{ambda} *$ lambda $)$

$\mathrm{HSn} 2(\mathrm{~K}, 0)=\mathrm{Bvn} *((\mathrm{~J}+.5) *(\mathrm{~J}+.5)$-lambda*lambda + Beta $)$

$*$ $-\mathrm{Dvn} *(\mathrm{~J}+1) *(\mathrm{~J}+1) *(\mathrm{~J}+1) *(\mathrm{~J}+1)$

$\mathrm{HSn} 2(\mathrm{~K}, 1)=(2 * \mathrm{~J}+1) * \exp \left((-\mathrm{HSn} 2(\mathrm{~K}, 0)+\mathrm{HSn} 2(1,0)) /\left(\mathrm{kB}^{*}\right.\right.$ temp2) $)$

$\mathrm{Q} 2=\mathrm{Q} 2+\mathrm{HSn} 2(\mathrm{~K}, 1)$

212 continue

do $231 \mathrm{~K}=1,15$

$\mathrm{HSn} 1(\mathrm{~K}, 1)=\mathrm{HSn} 1(\mathrm{~K}, 1) / \mathrm{Q} 1$

write $(*, 220) J, K, H S n 1(K, 0), H S n 1(K, 1)$

220 format(f6.1,i4,2e12.5)

231 continue

do $232 \mathrm{~K}=1,15$

$\mathrm{HSn} 2(\mathrm{~K}, 1)=\mathrm{HSn} 2(\mathrm{~K}, 1) / \mathrm{Q} 2$

write $(*, 220) \mathrm{J}, \mathrm{K}, \mathrm{HSn} 2(\mathrm{~K}, 0), \mathrm{HSn} 2(\mathrm{~K}, 1)$

232 continue

write $(*, *)$

c Calculate Sigmma(F1,F2,F3) state energy

write(**,*)' J K rotational,

do $213 \mathrm{~K}=0,15$

$$
\mathrm{J}=\mathrm{K}+1
$$

$\operatorname{HSil}(\mathrm{K}, 0)=\mathrm{Bvi}^{*} \mathrm{~K} *(\mathrm{~K}+1)+\mathrm{Bvi}^{*}(2 * \mathrm{~K}+3)-\operatorname{lamb}-\operatorname{sqrt}((2 * \mathrm{~K}+3) *$

* $\quad(2 * \mathrm{~K}+3) *$ Bvi $*$ Bvi +lamb*lamb- $2 *$ lamb*Bvi $)+$ gamma $*(\mathrm{~K}+1)$

* $\quad-\mathrm{Dvi}^{*} \mathrm{~K} * \mathrm{~K} *(\mathrm{~K}+1) *(\mathrm{~K}+1)+\mathrm{IP}$ write(*,221)J, $\mathrm{K}, \mathrm{HSi1}(\mathrm{K}, 0)$

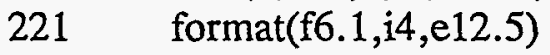

213 continue

write $(*, *)$

do $214 \mathrm{~K}=1,15$

$\mathrm{J}=\mathrm{K}$

$\operatorname{HSi} 2(\mathrm{~K}, 0)=$ Bvi $^{*} \mathrm{~K} *(\mathrm{~K}+1)-\mathrm{Dvi} * \mathrm{~K} * \mathrm{~K} *(\mathrm{~K}+1) *(\mathrm{~K}+1)+\mathrm{IP}$ write $(*, 221) \mathrm{J}, \mathrm{K}, \mathrm{HSi} 2(\mathrm{~K}, 0)$

214 continue

do $215 \mathrm{~K}=1,15$

$\mathrm{J}=\mathrm{K}-1$

$\operatorname{HSi} 3(\mathrm{~K}, 0)=\mathrm{Bvi} * \mathrm{~K} *(\mathrm{~K}+1)-\mathrm{Bvi} *(2 * \mathrm{~K}-1)-\mathrm{lamb}+\operatorname{sqrt}((2 * \mathrm{~K}-1) *$ 


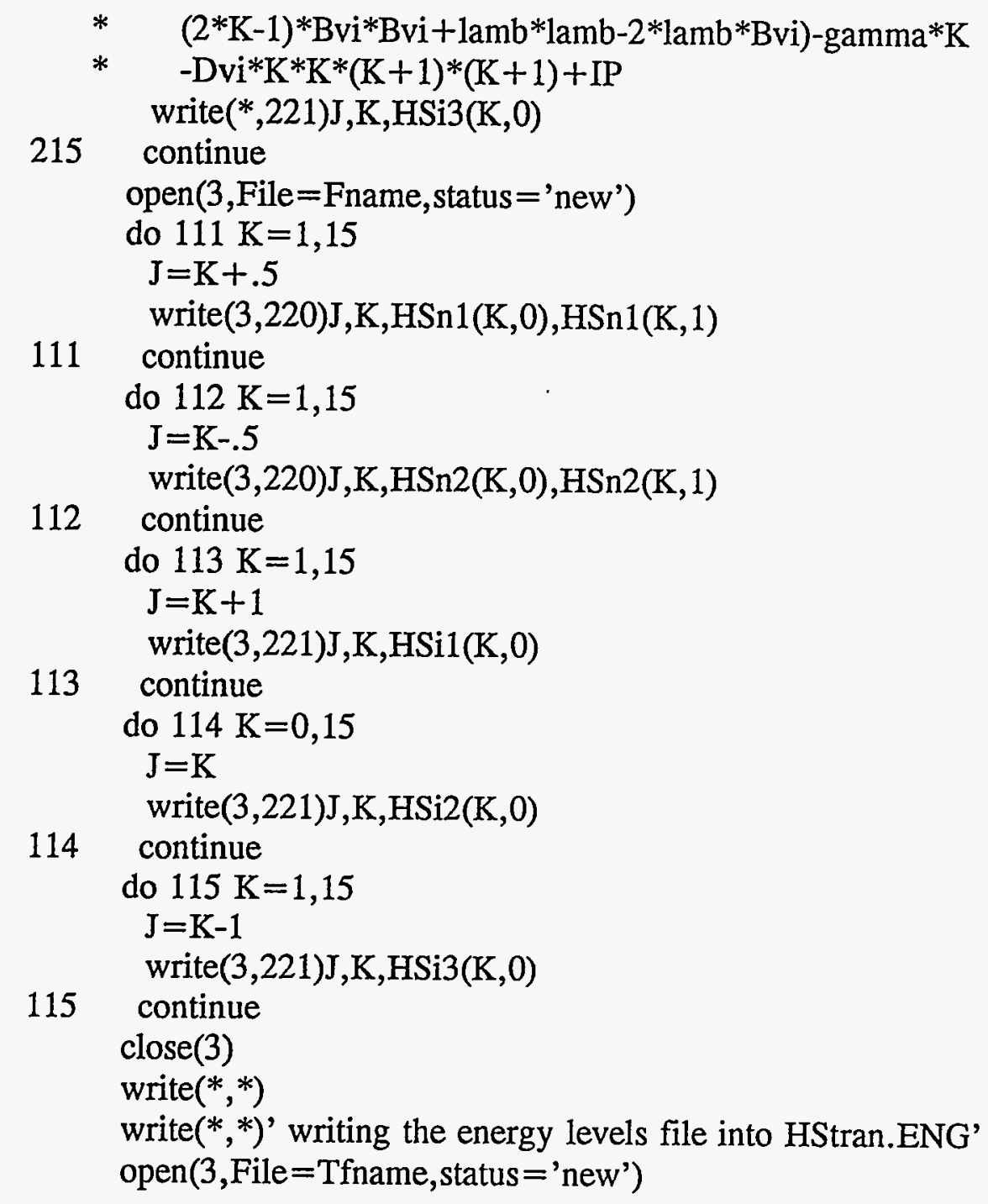

c now calculate the P1 branch:

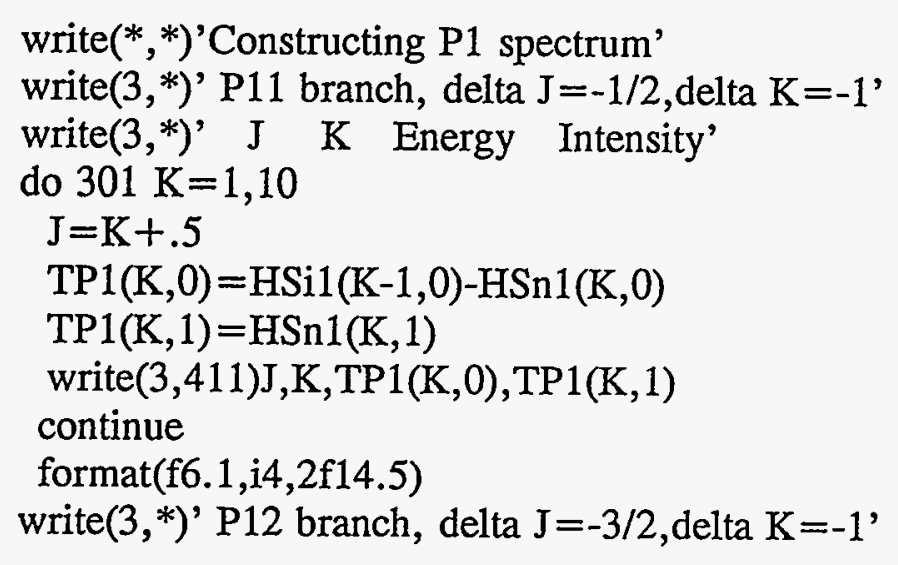


do $302 \mathrm{~K}=2,10$

$$
\mathrm{J}=\mathrm{K}+.5
$$

$\mathrm{TP} 2(\mathrm{~K}, 0)=\mathrm{HSi} 2(\mathrm{~K}-1,0)-\mathrm{HSn} 1(\mathrm{~K}, 0)$

$\mathrm{TP} 2(\mathrm{~K}, 1)=\mathrm{HSn} 1(\mathrm{~K}, 1)$

302 continue

write $(3,411) \mathrm{J}, \mathrm{K}, \mathrm{TP} 2(\mathrm{~K}, 0), \mathrm{TP} 2(\mathrm{~K}, 1)$

write $\left(3,{ }^{*}\right)^{\prime} \mathrm{P} 13$ branch, delta $\mathrm{J}=-5 / 2$, delta $\mathrm{K}=-1$ '

do $303 \mathrm{~K}=2,10$

$$
\mathrm{J}=\mathrm{K}+.5
$$

$\mathrm{TP} 3(\mathrm{~K}, 0)=\mathrm{HSi} 3(\mathrm{~K}-1,0)-\mathrm{HSn} 1(\mathrm{~K}, 0)$

$\mathrm{TP} 3(\mathrm{~K}, 1)=\mathrm{HSn} 1(\mathrm{~K}, 1)$

303 continue

$$
\text { write }(3,411) \mathrm{J}, \mathrm{K}, \mathrm{TP} 3(\mathrm{~K}, 0), \mathrm{TP} 3(\mathrm{~K}, 1)
$$

call HS

Filename $=$ 'HSO1.wei'

call WriteFile

call zero

c now calculate the Q1 branch:

write $(*, *)$ 'Constructing Q1 spectrum'

write $\left(3,{ }^{*}\right)$ ' Q11 branch, delta $\mathrm{J}=1 / 2$, delta $\mathrm{K}=0$ '

do $304 \mathrm{~K}=1,10$

$$
\begin{aligned}
& \mathrm{J}=\mathrm{K}+.5 \\
& \mathrm{TP} 1(\mathrm{~K}, 0)=\mathrm{HSi} 1(\mathrm{~K}, 0)-\mathrm{HSn} 1(\mathrm{~K}, 0)
\end{aligned}
$$$$
\mathrm{TP} 1(\mathrm{~K}, 1)=\mathrm{HSn} 1(\mathrm{~K}, 1)
$$

$$
\text { write }(3,411) \mathrm{J}, \mathrm{K}, \mathrm{TP} 1(\mathrm{~K}, 0), \mathrm{TP} 1(\mathrm{~K}, 1)
$$

304 continue

write $\left(3,{ }^{*}\right)^{\prime} \mathrm{Q} 12$ branch, delta $\mathrm{J}=-1 / 2$, delta $\mathrm{K}=0$ ' do $305 \mathrm{~K}=1,10$

$$
\mathrm{J}=\mathrm{K}+.5
$$

$\mathrm{TP} 2(\mathrm{~K}, 0)=\mathrm{HSi} 2(\mathrm{~K}, 0)-\mathrm{HSn} 1(\mathrm{~K}, 0)$

$\mathrm{TP} 2(\mathrm{~K}, 1)=\mathrm{HSn} 1(\mathrm{~K}, 1)$

write $(3,411) \mathrm{J}, \mathrm{K}, \mathrm{TP} 2(\mathrm{~K}, 0), \mathrm{TP} 2(\mathrm{~K}, 1)$

305 continue

write $\left(3,{ }^{*}\right)^{\prime} \mathrm{Q} 13$ branch, delta $\mathrm{J}=-3 / 2$, delta $\mathrm{K}=0$ '

do $306 \mathrm{~K}=1,10$

$$
\begin{aligned}
& \mathrm{J}=\mathrm{K}+.5 \\
& \mathrm{TP} 3(\mathrm{~K}, 0)=\mathrm{HSi} 3(\mathrm{~K}, 0)-\mathrm{HSn} 1(\mathrm{~K}, 0)
\end{aligned}
$$$$
\mathrm{TP} 3(\mathrm{~K}, 1)=\mathrm{HSn} 1(\mathrm{~K}, 1)
$$

$$
\text { write }(3,411) J, K, T P 3(K, 0), T P 3(K, 1)
$$

306 continue

call HS 
Filename $=$ 'HS02. wei'

call WriteFile

call zero

c now calculate the R1 branch:

write(*,*)'Constructing R1 spectrum'

write $\left(3,{ }^{*}\right)$ ' $\mathrm{R} 11$ branch, delta $\mathrm{J}=3 / 2$, delta $\mathrm{K}=+1$ '

do $307 \mathrm{~K}=1,10$

$$
\mathrm{J}=\mathrm{K}+.5
$$

$\mathrm{TP} 1(\mathrm{~K}, 0)=\mathrm{HSi} 1(\mathrm{~K}+1,0)-\mathrm{HSn} 1(\mathrm{~K}, 0)$

$\operatorname{TP} 1(\mathrm{~K}, 1)=\mathrm{HSn} 1(\mathrm{~K}, 1)$

307

$$
\text { write }(3,411) \mathrm{J}, \mathrm{K}, \mathrm{TP} 1(\mathrm{~K}, 0), \mathrm{TP} 1(\mathrm{~K}, 1)
$$

continue

write $\left(3,{ }^{*}\right)$ ' $R 12$ branch, delta $\mathrm{J}=1 / 2$, delta $\mathrm{K}=+1$ '

do $308 \mathrm{~K}=1,10$

$$
\mathrm{J}=\mathrm{K}+.5
$$$$
\mathrm{TP} 2(\mathrm{~K}, 0)=\mathrm{HSi} 2(\mathrm{~K}+1,0)-\mathrm{HSn} 1(\mathrm{~K}, 0)
$$$$
\mathrm{TP} 2(\mathrm{~K}, 1)=\mathrm{HSn} 1(\mathrm{~K}, 1)
$$

308

$$
\begin{aligned}
& \text { write }(3,411) \mathrm{J}, \mathrm{K}, \mathrm{TP} 2(\mathrm{~K}, 0), \mathrm{TP} 2(\mathrm{~K}, 1) \\
& \text { continue }
\end{aligned}
$$

write $\left(3,{ }^{*}\right)$ ' $\mathrm{R} 13$ branch, delta $\mathrm{J}=-1 / 2$, delta $\mathrm{K}=+1$ ' do $309 \mathrm{~K}=1,10$

$$
\mathrm{J}=\mathrm{K}+.5
$$$$
\mathrm{TP} 3(\mathrm{~K}, 0)=\mathrm{HSi} 3(\mathrm{~K}+1,0)-\mathrm{HSn} 1(\mathrm{~K}, 0)
$$

$$
\begin{aligned}
& \text { TP3(K, 1) =HSn1(K, 1) } \\
& \text { write }(3,411) \mathrm{J}, \mathrm{K}, \mathrm{TP} 3(\mathrm{~K}, 0), \mathrm{TP} 3(\mathrm{~K}, 1)
\end{aligned}
$$

309

$$
\text { continue }
$$

call HS

Filename $=$ 'HS03.wei'

call WriteFile

call zero

c now calculate the $\mathrm{P} 2$ branch:

write $(*, *)$ 'Constructing P2 spectrum'

write $(3, *)$ ' $\mathrm{P} 21$ branch, delta $\mathrm{J}=1 / 2$, delta $\mathrm{K}=-1$ '

do $310 \mathrm{~K}=1,13$

$$
\mathrm{J}=\mathrm{K}-.5
$$$$
\operatorname{TP} 1(\mathrm{~K}, 0)=\mathrm{HSi} 1(\mathrm{~K}-1,0)-\mathrm{HSn} 2(\mathrm{~K}, 0)
$$

$\operatorname{TP} 1(\mathrm{~K}, 1)=\mathrm{HSn} 2(\mathrm{~K}, 1)$

$$
\text { write }(3,411) \mathrm{J}, \mathrm{K}, \mathrm{TP} 1(\mathrm{~K}, 0), \mathrm{TP} 1(\mathrm{~K}, 1)
$$


write $\left(3,{ }^{*}\right)^{\prime} \mathrm{P} 22$ branch, delta $\mathrm{J}=-1 / 2$, delta $\mathrm{K}=-1$ ' do $311 \mathrm{~K}=2,13$

$\mathrm{J}=\mathrm{K}-.5$

$\mathrm{TP} 2(\mathrm{~K}, 0)=\mathrm{HSi} 2(\mathrm{~K}-1,0)-\mathrm{HSn} 2(\mathrm{~K}, 0)$

$\mathrm{TP} 2(\mathrm{~K}, 1)=\mathrm{HSn} 2(\mathrm{~K}, 1)$

write $(3,411) \mathrm{J}, \mathrm{K}, \mathrm{TP} 2(\mathrm{~K}, 0), \mathrm{TP} 2(\mathrm{~K}, 1)$

311 continue

write $(3, *)$ ' $\mathrm{P} 23$ branch, delta $\mathrm{J}=-3 / 2$, delta $\mathrm{K}=-1$ '

do $312 \mathrm{~K}=2,13$

$\mathrm{J}=\mathrm{K}-.5$

$\mathrm{TP} 3(\mathrm{~K}, 0)=\mathrm{HSi} 3(\mathrm{~K}-1,0)-\mathrm{HSn} 2(\mathrm{~K}, 0)$

$\mathrm{TP} 3(\mathrm{~K}, 1)=\mathrm{HSn} 2(\mathrm{~K}, 1)$

write $(3,411) \mathrm{J}, \mathrm{K}, \mathrm{TP} 3(\mathrm{~K}, 0), \mathrm{TP} 3(\mathrm{~K}, 1)$

312 continue

call HS

Filename $=$ 'HSO4.wei'

call WriteFile

call zero

c now calculate the $\mathrm{Q} 2$ branch:

write(*,*)'Constructing Q2 spectrum'

write $\left(3,{ }^{*}\right)$ ' Q21 branch, delta $\mathrm{J}=3 / 2$, delta $\mathrm{K}=0$ '

do $313 \mathrm{~K}=1,10$

$\mathrm{J}=\mathrm{K}-.5$

$\mathrm{TP} 1(\mathrm{~K}, 0)=\mathrm{HSi} 1(\mathrm{~K}, 0)-\mathrm{HSn} 2(\mathrm{~K}, 0)$

$\operatorname{TP} 1(\mathrm{~K}, 1)=\mathrm{HSn} 2(\mathrm{~K}, 1)$

write $(3,411) \mathrm{J}, \mathrm{K}, \mathrm{TP} 1(\mathrm{~K}, 0), \mathrm{TP} 1(\mathrm{~K}, 1)$

313 continue

write( $3, *)^{\prime}$ Q22 branch, delta $\mathrm{J}=1 / 2$, delta $\mathrm{K}=0$ '

do $314 \mathrm{~K}=1,10$

$\mathrm{J}=\mathrm{K}-.5$

$\mathrm{TP} 2(\mathrm{~K}, 0)=\mathrm{HSi} 2(\mathrm{~K}, 0)-\mathrm{HSn} 2(\mathrm{~K}, 0)$

$\mathrm{TP} 2(\mathrm{~K}, 1)=\mathrm{HSn} 2(\mathrm{~K}, 1)$

write( 3,411$) \mathrm{J}, \mathrm{K}, \mathrm{TP} 2(\mathrm{~K}, 0), \mathrm{TP} 2(\mathrm{~K}, 1)$

314 continue

write $(3, *)$ ' Q23 branch, delta $J=-1 / 2$, delta $K=0$ '

do $315 \mathrm{~K}=1,10$

$\mathrm{J}=\mathrm{K}-.5$

$\mathrm{TP} 3(\mathrm{~K}, 0)=\mathrm{HSi} 3(\mathrm{~K}, 0)-\mathrm{HSn} 2(\mathrm{~K}, 0)$

$\mathrm{TP} 3(\mathrm{~K}, 1)=\mathrm{HSn} 2(\mathrm{~K}, 1)$

write $(3,411) \mathrm{J}, \mathrm{K}, \mathrm{TP} 3(\mathrm{~K}, 0), \mathrm{TP} 3(\mathrm{~K}, 1)$

315 continue 
call HS

Filename $=$ 'HS05. wei'

call WriteFile

call zero

c now calculate the $\mathrm{R} 2$ branch:

write $(*, *)$ 'Constructing R2 spectrum'

write $\left(3,{ }^{*}\right)$ ' $\mathrm{R} 21$ branch, delta $\mathrm{J}=5 / 2$, delta $\mathrm{K}=+1$ '

do $316 \mathrm{~K}=1,10$

$$
\mathrm{J}=\mathrm{K}-.5
$$

$\mathrm{TP} 1(\mathrm{~K}, 0)=\mathrm{HSi} 1(\mathrm{~K}+1,0)-\mathrm{HSn} 2(\mathrm{~K}, 0)$

$\mathrm{TP} 1(\mathrm{~K}, 1)=\mathrm{HSn} 2(\mathrm{~K}, 1)$

write $(3,411) \mathrm{J}, \mathrm{K}, \mathrm{TP} 1(\mathrm{~K}, 0), \mathrm{TP} 1(\mathrm{~K}, 1)$

316 continue

write $(3, *)$ ' $R 22$ branch, delta $J=3 / 2$, delta $K=+1$ '

do $317 \mathrm{~K}=1,10$

$$
\begin{aligned}
& \mathrm{J}=\mathrm{K}-.5 \\
& \mathrm{TP} 2(\mathrm{~K}, 0)=\mathrm{HSi} 2(\mathrm{~K}+1,0)-\mathrm{HSn} 2(\mathrm{~K}, 0)
\end{aligned}
$$$$
\mathrm{TP} 2(\mathrm{~K}, 1)=\mathrm{HSn} 2(\mathrm{~K}, 1)
$$$$
\text { write }(3,411) \mathrm{J}, \mathrm{K}, \mathrm{TP} 2(\mathrm{~K}, 0), \mathrm{TP} 2(\mathrm{~K}, 1)
$$

317 continue

write $\left(3,{ }^{*}\right.$ ') $\mathrm{R} 23$ branch, delta $\mathrm{J}=1 / 2$, delta $\mathrm{K}=+1$ '

do $318 \mathrm{~K}=1,10$

$$
\mathrm{J}=\mathrm{K}-.5
$$$$
\mathrm{TP} 3(\mathrm{~K}, 0)=\mathrm{HSi} 3(\mathrm{~K}+1,0)-\mathrm{HSn} 2(\mathrm{~K}, 0)
$$

$\mathrm{TP} 3(\mathrm{~K}, 1)=\mathrm{HSn} 2(\mathrm{~K}, 1)$

write $(3,411) \mathrm{J}, \mathrm{K}, \mathrm{TP} 3(\mathrm{~K}, 0), \mathrm{TP} 3(\mathrm{~K}, 1)$

318 continue

call HS

Filename $=$ 'HSO6. wei'

call WriteFile

call zero

c now calculate the $\mathrm{O} 1$ branch:

write $(*, *)^{\prime}$ Constructing 01 spectrum'

write $\left(3,{ }^{*}\right)$ ' 011 branch, delta $\mathrm{J}=-3 / 2$, delta $\mathrm{K}=-2$ '

do $319 \mathrm{~K}=2,10$

$\mathrm{J}=\mathrm{K}+.5$

$\mathrm{TP} 1(\mathrm{~K}, 0)=\mathrm{HSi} 1(\mathrm{~K}-2,0)-\mathrm{HSn} 1(\mathrm{~K}, 0)$

$\mathrm{TP} 1(\mathrm{~K}, 1)=\mathrm{HSn} 1(\mathrm{~K}, 1)$

write $(3,411) \mathrm{J}, \mathrm{K}, \mathrm{TP} 1(\mathrm{~K}, 0), \mathrm{TP} 1(\mathrm{~K}, 1)$ 
319 continue

write $\left(3,{ }^{*}\right)$ ' 012 branch, delta $\mathrm{J}=-5 / 2$, delta $\mathrm{K}=-2$ '

do $320 \mathrm{~K}=3,10$

$\mathrm{J}=\mathrm{K}+.5$

$\mathrm{TP} 2(\mathrm{~K}, 0)=\mathrm{HSi} 2(\mathrm{~K}-2,0)-\mathrm{HSn} 1(\mathrm{~K}, 0)$

$\mathrm{TP} 2(\mathrm{~K}, 1)=\mathrm{HSn} 1(\mathrm{~K}, 1)$

write(3,411)J,K,TP2(K,0),TP2(K,1)

320 continue

write( $3, *$ ') $\mathrm{O} 13$ branch, delta $\mathrm{J}=-7 / 2$, delta $\mathrm{K}=-2$ '

do $321 \mathrm{~K}=3,10$

$\mathrm{J}=\mathrm{K}+.5$

$\mathrm{TP} 3(\mathrm{~K}, 0)=\mathrm{HSi} 3(\mathrm{~K}-2,0)-\mathrm{HSn} 1(\mathrm{~K}, 0)$

$\mathrm{TP} 3(\mathrm{~K}, 1)=\mathrm{HSn} 1(\mathrm{~K}, 1)$

write( 3,411$) \mathrm{J}, \mathrm{K}, \mathrm{TP} 3(\mathrm{~K}, 0), \mathrm{TP} 3(\mathrm{~K}, 1)$

321 continue

call HS

Filename $=$ 'HS07. wei'

call WriteFile

call zero

c now calculate the $\mathrm{S} 1$ branch:

write $(*, *)$ 'Constructing S1 spectrum'

write $(3, *)$ ' $S 11$ branch, delta $\mathrm{J}=5 / 2$, delta $\mathrm{K}=+2$ '

do $322 \mathrm{~K}=1,10$

$\mathrm{J}=\mathrm{K}+.5$

$\mathrm{TP} 1(\mathrm{~K}, 0)=\mathrm{HSi} 1(\mathrm{~K}+2,0)-\mathrm{HSn} 1(\mathrm{~K}, 0)$

$\operatorname{TP} 1(\mathrm{~K}, 1)=\mathrm{HSn} 1(\mathrm{~K}, 1)$

write $(3,411) \mathrm{J}, \mathrm{K}, \mathrm{TP} 1(\mathrm{~K}, 0), \mathrm{TP} 1(\mathrm{~K}, 1)$

322 continue

write $(3, *)$ ' $S 12$ branch, delta $\mathrm{J}=3 / 2$, delta $\mathrm{K}=+2$ ' do $323 \mathrm{~K}=1,10$

$\mathrm{J}=\mathrm{K}+.5$

$\mathrm{TP} 2(\mathrm{~K}, 0)=\mathrm{HSi} 2(\mathrm{~K}+2,0)-\mathrm{HSn} 1(\mathrm{~K}, 0)$

$\mathrm{TP} 2(\mathrm{~K}, 1)=\mathrm{HSn} 1(\mathrm{~K}, 1)$

write $(3,411) \mathrm{J}, \mathrm{K}, \mathrm{TP} 2(\mathrm{~K}, 0), \mathrm{TP} 2(\mathrm{~K}, 1)$

323 continue

write $(3, *)$ ' $S 13$ branch, delta $\mathrm{J}=1 / 2$, delta $\mathrm{K}=+2$ '

do $324 \mathrm{~K}=1,10$

$\mathrm{J}=\mathrm{K}+.5$

$\mathrm{TP} 3(\mathrm{~K}, 0)=\mathrm{HSi} 3(\mathrm{~K}+2,0)-\mathrm{HSn} 1(\mathrm{~K}, 0)$

TP3(K, 1) = HSn1 $(\mathrm{K}, 1)$

write $(3,411) \mathrm{J}, \mathrm{K}, \mathrm{TP} 3(\mathrm{~K}, 0), \mathrm{TP} 3(\mathrm{~K}, 1)$ 
324 continue

call HS

Filename $=$ 'HSO8. wei'

call WriteFile

call zero

c now calculate the $\mathrm{O} 2$ branch:

write $(*, *)$ 'Constructing O2 spectrum'

write $(3, *)$ ' $\mathrm{O} 21$ branch, delta $\mathrm{J}=-1 / 2$, delta $\mathrm{K}=-2$ '

do $325 \mathrm{~K}=2,10$

$\mathrm{J}=\mathrm{K}-.5$

$\mathrm{TP} 1(\mathrm{~K}, 0)=\mathrm{HSi} 1(\mathrm{~K}-2,0)-\mathrm{HSn} 2(\mathrm{~K}, 0)$

$\mathrm{TP} 1(\mathrm{~K}, 1)=\mathrm{HSn} 2(\mathrm{~K}, 1)$

write( 3,411$) \mathrm{J}, \mathrm{K}, \mathrm{TP} 1(\mathrm{~K}, 0), \mathrm{TP} 1(\mathrm{~K}, 1)$

325 continue

write $\left(3,{ }^{*}\right)$ ' $\mathrm{O} 22$ branch, delta $\mathrm{J}=-3 / 2$, delta $\mathrm{K}=-2$ '

do $326 \mathrm{~K}=3,10$

$\mathrm{J}=\mathrm{K}-.5$

$\mathrm{TP} 2(\mathrm{~K}, 0)=\mathrm{HSi} 2(\mathrm{~K}-2,0)-\mathrm{HSn} 2(\mathrm{~K}, 0)$

$\mathrm{TP} 2(\mathrm{~K}, 1)=\mathrm{HSn} 2(\mathrm{~K}, 1)$

write(3,411)J,K,TP2(K,0),TP2(K,1)

326 continue

write $\left(3,{ }^{*}\right)$ ' $\mathrm{O} 23$ branch, delta $\mathrm{J}=-5 / 2$, delta $\mathrm{K}=-2$ '

do $327 \mathrm{~K}=3,10$

$$
\begin{aligned}
& \mathrm{J}=\mathrm{K}-.5 \\
& \mathrm{TP} 3(\mathrm{~K}, 0)=\mathrm{HSi} 3(\mathrm{~K}-2,0)-\mathrm{HSn} 2(\mathrm{~K}, 0)
\end{aligned}
$$

$\mathrm{TP} 3(\mathrm{~K}, 1)=\mathrm{HSn} 2(\mathrm{~K}, 1)$

write(3,411)J,K,TP3(K,0),TP3(K,1)

327 continue

call HS

Filename $=$ 'HS09. wei'

call WriteFile

call zero

c now calculate the $\mathrm{S} 2$ branch:

write $(*, *)$ 'Constructing S2 spectrum'

write $(3, *)^{\prime}$ ' 21 branch, delta $\mathrm{J}=7 / 2$, delta $\mathrm{K}=+2$ '

do $328 \mathrm{~K}=1,10$

$\mathrm{J}=\mathrm{K}-.5$

$\mathrm{TP} 1(\mathrm{~K}, 0)=\mathrm{HSi} 1(\mathrm{~K}+2,0)-\mathrm{HSn} 2(\mathrm{~K}, 0)$

$\mathrm{TP} 1(\mathrm{~K}, 1)=\mathrm{HSn} 2(\mathrm{~K}, 1)$ 
328

$$
\text { write }(3,411) \mathrm{J}, \mathrm{K}, \mathrm{TP} 1(\mathrm{~K}, 0), \mathrm{TP} 1(\mathrm{~K}, 1)
$$

\section{continue}

write $(3, *)$ ' $S 22$ branch, delta $\mathrm{J}=5 / 2$, delta $\mathrm{K}=+2$ '

do $329 \mathrm{~K}=1,10$

$$
\begin{aligned}
& \mathrm{J}=\mathrm{K}-.5 \\
& \mathrm{TP} 2(\mathrm{~K}, 0)=\mathrm{HSi} 2(\mathrm{~K}+2,0)-\mathrm{HSn} 2(\mathrm{~K}, 0)
\end{aligned}
$$$$
\mathrm{TP} 2(\mathrm{~K}, 1)=\mathrm{HSn} 2(\mathrm{~K}, 1)
$$$$
\text { write }(3,411) \mathrm{J}, \mathrm{K}, \mathrm{TP} 2(\mathrm{~K}, 0), \mathrm{TP} 2(\mathrm{~K}, 1)
$$

329 continue

write $(3, *)$ ' $S 23$ branch, delta $\mathrm{J}=3 / 2$, delta $\mathrm{K}=+2$ ' do $330 \mathrm{~K}=1,10$

$$
\begin{aligned}
& \mathrm{J}=\mathrm{K}-.5 \\
& \mathrm{TP} 3(\mathrm{~K}, 0)=\mathrm{HSi} 3(\mathrm{~K}+2,0)-\mathrm{HSn} 2(\mathrm{~K}, 0)
\end{aligned}
$$$$
\mathrm{TP} 3(\mathrm{~K}, 1)=\mathrm{HSn} 2(\mathrm{~K}, 1)
$$

330 continue

$$
\text { write }(3,411) J, K, T P 3(K, 0), T P 3(K, 1)
$$

call HS

Filename $=$ 'HS10. wei'

call WriteFile

call zero

c now calculate the N1 branch:

write $(*, *)$ 'Constructing N1 spectrum'

write $(3, *)$ ' $N 11$ branch, delta $\mathrm{J}=-5 / 2$, delta $\mathrm{K}=-3$ ' do $331 \mathrm{~K}=3,10$

$$
\begin{aligned}
& \mathrm{J}=\mathrm{K}+.5 \\
& \mathrm{TP} 1(\mathrm{~K}, 0)=\mathrm{HSi} 1(\mathrm{~K}-3,0)-\mathrm{HSn} 1(\mathrm{~K}, 0)
\end{aligned}
$$$$
\operatorname{TP} 1(\mathrm{~K}, 1)=\mathrm{HSn} 1(\mathrm{~K}, 1)
$$

331

$$
\text { write( } 3,411) J, K, T P 1(K, 0), T P 1(K, 1)
$$

$$
\text { continue }
$$

write $(3, *)^{\prime} \mathrm{N} 12$ branch, delta $\mathrm{J}=-7 / 2$, delta $\mathrm{K}=-3^{\prime}$ ' do $332 \mathrm{~K}=4,10$

$$
\begin{aligned}
& \mathrm{J}=\mathrm{K}+.5 \\
& \mathrm{TP} 2(\mathrm{~K}, 0)=\mathrm{HSi} 2(\mathrm{~K}-3,0)-\mathrm{HSn} 1(\mathrm{~K}, 0)
\end{aligned}
$$$$
\operatorname{TP} 2(\mathrm{~K}, 1)=\operatorname{HSn} 1(\mathrm{~K}, 1)
$$

$$
\begin{aligned}
& \text { write }(3,411) \mathrm{J}, \mathrm{K}, \mathrm{TP} 2(\mathrm{~K}, 0), \mathrm{TP} 2(\mathrm{~K}, 1) \\
& \text { continue }
\end{aligned}
$$

write $\left(3,{ }^{*}\right)^{\prime} \mathrm{N} 13$ branch, delta $\mathrm{J}=-9 / 2$, delta $\mathrm{K}=-3$ '

do $333 \mathrm{~K}=4,10$

$$
\mathrm{J}=\mathrm{K}+.5
$$

$\mathrm{TP} 3(\mathrm{~K}, 0)=\mathrm{HSi} 3(\mathrm{~K}-3,0)-\mathrm{HSn} 1(\mathrm{~K}, 0)$

$$
\mathrm{TP} 3(\mathrm{~K}, 1)=\mathrm{HSn} 1(\mathrm{~K}, 1)
$$


333

write $(3,411) \mathrm{J}, \mathrm{K}, \mathrm{TP} 3(\mathrm{~K}, 0), \mathrm{TP} 3(\mathrm{~K}, 1)$

continue

call HS

Filename $=$ 'HS11. wei'

call WriteFile

call zero

c now calculate the $\mathrm{T} 1$ branch:

write $(*, *)$ 'Constructing T1 spectrum'

write $(3, *)$ ' T11 branch, delta $\mathrm{J}=7 / 2$, delta $\mathrm{K}=+3$ '

do $334 \mathrm{~K}=1,10$

$\mathrm{J}=\mathrm{K}+.5$

$\mathrm{TP} 1(\mathrm{~K}, 0)=\mathrm{HSi} 1(\mathrm{~K}+3,0)-\mathrm{HSn} 1(\mathrm{~K}, 0)$

$\operatorname{TP} 1(\mathrm{~K}, 1)=\mathrm{HSn} 1(\mathrm{~K}, 1)$

write $(3,411) \mathrm{J}, \mathrm{K}, \mathrm{TP} 1(\mathrm{~K}, 0), \mathrm{TP} 1(\mathrm{~K}, 1)$

334 continue

write $(3, *)$ ' T12 branch, delta $\mathrm{J}=5 / 2$, delta $\mathrm{K}=+3$ '

do $335 \mathrm{~K}=1,10$

$$
\mathrm{J}=\mathrm{K}+.5
$$

$\mathrm{TP} 2(\mathrm{~K}, 0)=\mathrm{HSi} 2(\mathrm{~K}+3,0)-\mathrm{HSn} 1(\mathrm{~K}, 0)$

$\mathrm{TP} 2(\mathrm{~K}, 1)=\mathrm{HSn} 1(\mathrm{~K}, 1)$

335 continue

write $(3,411) \mathrm{J}, \mathrm{K}, \mathrm{TP} 2(\mathrm{~K}, 0), \mathrm{TP} 2(\mathrm{~K}, 1)$

write $(3, *)$ ' $\mathrm{T} 13$ branch, delta $\mathrm{J}=3 / 2$, delta $\mathrm{K}=+3$ '

do $336 \mathrm{~K}=1,10$

$$
\begin{aligned}
& \mathrm{J}=\mathrm{K}+.5 \\
& \mathrm{TP} 3(\mathrm{~K}, 0)=\mathrm{HSi} 3(\mathrm{~K}+3,0)-\mathrm{HSn} 1(\mathrm{~K}, 0)
\end{aligned}
$$

TP3(K, 1) = HSn1(K,1)

336 continue

write $(3,411) \mathrm{J}, \mathrm{K}, \mathrm{TP} 3(\mathrm{~K}, 0), \mathrm{TP} 3(\mathrm{~K}, 1)$

call HS

Filename $=$ 'HS12. wei'

call WriteFile

call zero

c now calculate the N2 branch:

write $(*, *)$ 'Constructing N2 spectrum'

write $\left(3,{ }^{*}\right)$ ' $\mathrm{N} 21$ branch, delta $\mathrm{J}=-3 / 2$, delta $\mathrm{K}=-3^{\prime}$

do $337 \mathrm{~K}=3,10$

$\mathrm{J}=\mathrm{K}-.5$

$\mathrm{TP} 1(\mathrm{~K}, 0)=\mathrm{HSi} 1(\mathrm{~K}-3,0)-\mathrm{HSn} 2(\mathrm{~K}, 0)$ 
$\mathrm{TP} 1(\mathrm{~K}, 1)=\mathrm{HSn} 2(\mathrm{~K}, 1)$

337 write $(3,411) \mathrm{J}, \mathrm{K}, \mathrm{TP} 1(\mathrm{~K}, 0), \mathrm{TP} 1(\mathrm{~K}, 1)$

continue

write $\left(3,{ }^{*}\right)$ ' $\mathrm{N} 22$ branch, delta $\mathrm{J}=-5 / 2$, delta $\mathrm{K}=-3$ '

do $338 \mathrm{~K}=4,10$

$\mathrm{J}=\mathrm{K}-.5$

$\mathrm{TP} 2(\mathrm{~K}, 0)=\mathrm{HSi} 2(\mathrm{~K}-3,0)-\mathrm{HSn} 2(\mathrm{~K}, 0)$

$\mathrm{TP} 2(\mathrm{~K}, 1)=\mathrm{HSn} 2(\mathrm{~K}, 1)$

write(3,411)J,K,TP2(K,0),TP2(K, 1$)$

338 continue

write $\left(3,{ }^{*}\right)$ ' $\mathrm{N} 23$ branch, delta $\mathrm{J}=-7 / 2$, delta $\mathrm{K}=-3$ '

do $339 \mathrm{~K}=4,10$

$\mathrm{J}=\mathrm{K}-.5$

$\mathrm{TP} 3(\mathrm{~K}, 0)=\mathrm{HSi} 3(\mathrm{~K}-3,0)-\mathrm{HSn} 2(\mathrm{~K}, 0)$

$\mathrm{TP} 3(\mathrm{~K}, 1)=\mathrm{HSn} 2(\mathrm{~K}, 1)$

write $(3,411) \mathrm{J}, \mathrm{K}, \mathrm{TP} 3(\mathrm{~K}, 0), \mathrm{TP} 3(\mathrm{~K}, 1)$

339 continue

call HS

Filename $=$ 'HS13. wei'

call WriteFile

call zero

c now calculate the $\mathrm{T} 2$ branch:

write $(*, *)$ 'Constructing T2 spectrum'

write $(3, *)$ ' T21 branch, delta $\mathrm{J}=9 / 2$, delta $\mathrm{K}=+3$ '

do $340 \mathrm{~K}=1,10$

$\mathrm{J}=\mathrm{K}-.5$

$\mathrm{TP} 1(\mathrm{~K}, 0)=\mathrm{HSi} 1(\mathrm{~K}+3,0)-\mathrm{HSn} 2(\mathrm{~K}, 0)$

$\mathrm{TP} 1(\mathrm{~K}, 1)=\mathrm{HSn} 2(\mathrm{~K}, 1)$

write $(3,411) \mathrm{J}, \mathrm{K}, \mathrm{TP} 1(\mathrm{~K}, 0), \mathrm{TP} 1(\mathrm{~K}, 1)$

340 continue

write $\left(3,{ }^{*}\right)$ ' T22 branch, delta $\mathrm{J}=7 / 2$, delta $\mathrm{K}=+3$ '

do $341 \mathrm{~K}=1,10$

$\mathrm{J}=\mathrm{K}-.5$

$\mathrm{TP} 2(\mathrm{~K}, 0)=\mathrm{HSi} 2(\mathrm{~K}+3,0)-\mathrm{HSn} 2(\mathrm{~K}, 0)$

$\mathrm{TP} 2(\mathrm{~K}, 1)=\mathrm{HSn} 2(\mathrm{~K}, 1)$

write $(3,411) \mathrm{J}, \mathrm{K}, \mathrm{TP} 2(\mathrm{~K}, 0), \mathrm{TP} 2(\mathrm{~K}, 1)$

341 continue

write $\left(3,{ }^{*}\right)$ ' T2 3 branch, delta $\mathrm{J}=5 / 2$, delta $\mathrm{K}=+3$ '

do $342 \mathrm{~K}=1,10$

$\mathrm{J}=\mathrm{K}-.5$

$\mathrm{TP} 3(\mathrm{~K}, 0)=\mathrm{HSi} 3(\mathrm{~K}+3,0)-\mathrm{HSn} 2(\mathrm{~K}, 0)$ 


$$
\mathrm{TP} 3(\mathrm{~K}, 1)=\mathrm{HSn} 2(\mathrm{~K}, 1)
$$

342

$$
\text { write }(3,411) \mathrm{J}, \mathrm{K}, \mathrm{TP} 3(\mathrm{~K}, 0), \mathrm{TP} 3(\mathrm{~K}, 1)
$$

continue

call HS

Filename $=$ 'HS14.wei'

call WriteFile

call zero

c now calculate the M1 branch:

write $(*, *)$ 'Constructing M1 spectrum'

write $(3, *)$ ' M11 branch, delta $\mathrm{J}=-7 / 2$, delta $\mathrm{K}=-4$ '

do $343 \mathrm{~K}=4,10$

$$
\begin{aligned}
& \mathrm{J}=\mathrm{K}+.5 \\
& \mathrm{TP} 1(\mathrm{~K}, 0)=\mathrm{HSi1}(\mathrm{K}-4,0)-\mathrm{HSn} 1(\mathrm{~K}, 0)
\end{aligned}
$$$$
\mathrm{TP} 1(\mathrm{~K}, 1)=\mathrm{HSn} 1(\mathrm{~K}, 1)
$$$$
\text { write(3,411)J,K,TP1(K,0),TP1(K,1) }
$$

343 continue

write $(3, *)$ ' M12 branch, delta $\mathrm{J}=-9 / 2$, delta $\mathrm{K}=-4$ '

do $344 \mathrm{~K}=5,10$

$$
\begin{aligned}
& \mathrm{J}=\mathrm{K}+.5 \\
& \mathrm{TP} 2(\mathrm{~K}, 0)=\mathrm{HSi} 2(\mathrm{~K}-4,0)-\mathrm{HSn} 1(\mathrm{~K}, 0)
\end{aligned}
$$$$
\mathrm{TP} 2(\mathrm{~K}, 1)=\mathrm{HSn} 1(\mathrm{~K}, 1)
$$

344 continue

$$
\text { write }(3,411) \mathrm{J}, \mathrm{K}, \mathrm{TP} 2(\mathrm{~K}, 0), \mathrm{TP} 2(\mathrm{~K}, 1)
$$

write $\left(3,{ }^{*}\right)$ ' $\mathrm{M} 13$ branch, delta $\mathrm{J}=-11 / 2$, delta $\mathrm{K}=-4$ '

do $345 \mathrm{~K}=5,10$

$$
\begin{aligned}
& \mathrm{J}=\mathrm{K}+.5 \\
& \mathrm{TP} 3(\mathrm{~K}, 0)=\mathrm{HSi} 3(\mathrm{~K}-4,0)-\mathrm{HSn} 1(\mathrm{~K}, 0)
\end{aligned}
$$$$
\text { TP3 }(\mathrm{K}, 1)=\mathrm{HSn} 1(\mathrm{~K}, 1)
$$

345

$$
\begin{aligned}
& \text { write( } 3,411) \mathrm{J}, \mathrm{K}, \mathrm{TP} 3(\mathrm{~K}, 0), \mathrm{TP} 3(\mathrm{~K}, 1) \\
& \text { continue }
\end{aligned}
$$

call HS

Filename $=$ 'HS15. wei'

call WriteFile

call zero

c now calculate the M2 branch:

write(*,*)'Constructing M2 spectrum'

write $(3, *)$ ' M21 branch, delta $\mathrm{J}=-5 / 2$, delta $\mathrm{K}=-4$ '

do $346 \mathrm{~K}=4,10$

$\mathrm{J}=\mathrm{K}-.5$ 


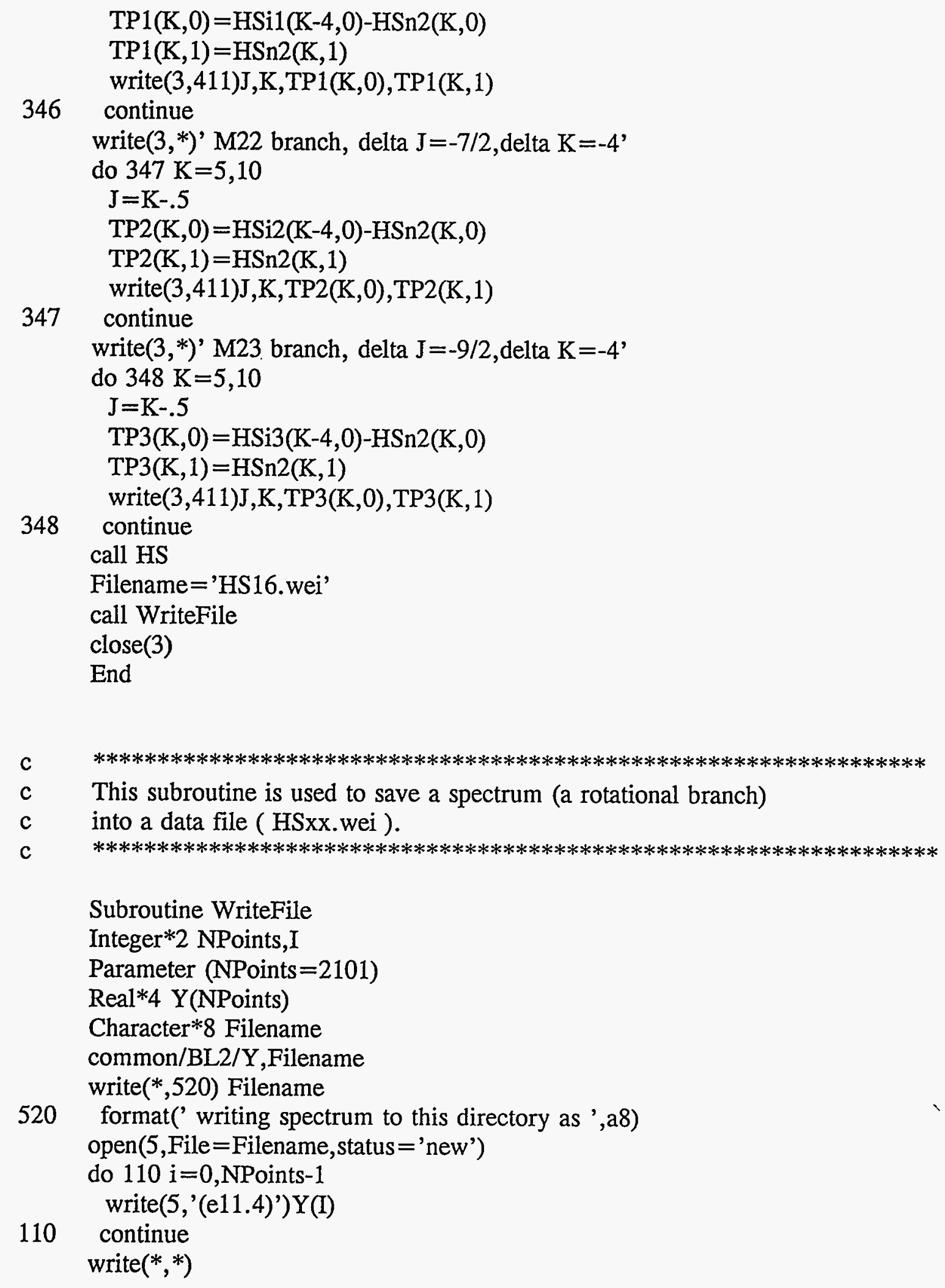


close(5)

return

end

c

c

C

$* * * * * * * * * * * * * * * * * * * * * * * * * * * * * * * * * * * * * * * * * * * * * * * * * * * * * * * * * * * * * * * * * * * * * * * * * * * * *$

This subroutine is used to calculate a spectrum (a rotational branch)

for a transition HS $+<-$ HS.

$* * * * * * * * * * * * * * * * * * * * * * * * * * * * * * * * * * * * * * * * * * * * * * * * * * * * * * * * * * * * * * * * * * * * * * * * * * * * * * * * * *$

Subroutine HS

Integer*2 $\mathrm{K}, \mathrm{i}, \mathrm{jj}, \mathrm{NP}$ oints

parameter (NPoints $=2101)$

Real*4 TP1(15,2), TP2(15,2),TP3(15,2), spect(NPoints)

Real*4 cc,nrgmin,currentnrg,Deltaw, sum1,sum2,sum3, width,J,step

character Filename*8

common/BL1/step,nrgmin

common/BL2/spect, Filename

common/BL3/TP1,TP2,TP3,cc,width,K

do $515 \mathrm{i}=0$,NPoints- 1

sum $1=0.0$

sum $2=0.0$

$\operatorname{sum} 3=0.0$

currentnrg $=1.0 \mathrm{e} 7 /\left(-\right.$ step $\left.^{*} \mathrm{i}+1.0 \mathrm{e} 7 / \mathrm{nrgmin}\right){ }_{2}$

do $516 \mathrm{jj}=1, \mathrm{~K}$

Deltaw = currentnrg-TP1 $(\mathrm{jj}, 0)$

If (abs(Deltaw).1t.(5.0*width)) then

sum $1=\operatorname{sum} 1+10.0 * T P 1(\mathrm{jj}, 1) * \exp \left(\mathrm{cc}^{*}\right.$ Deltaw $*$ Deltaw $)$

endif

Deltaw $=$ currentnrg-TP2 $(\mathrm{jj}, 0)$

If (abs(Deltaw).1t. (5.0*width)) then sum $2=\operatorname{sum} 2+10.0 * \mathrm{TP} 2(\mathrm{jj}, 1) * \exp (\mathrm{cc} *$ Deltaw $*$ Deltaw $)$

endif

Deltaw $=$ currentnrg-TP3 $(\mathrm{jj}, 0)$

If (abs(Deltaw).1t. (5.0*width)) then sum3 $=\operatorname{sum} 3+10.0 * T P 3(j \mathrm{j}, 1) * \exp \left(\mathrm{cc}^{*}\right.$ Deltaw $*$ Deltaw $)$ endif

516 continue

$$
\operatorname{spect}(i)=\operatorname{sum} 1+\operatorname{sum} 2+\operatorname{sum} 3
$$

515 continue

return

end 
c

c This subroutine is used to reset the transition energies and transition

c probabilities of all rotational branches to zero.

c

Subroutine zero

Real*4 TP1(15,2),TP2(15,2),TP3(15,2),cc, width

Integer*2 K

common/BL3/TP1,TP2,TP3,cc, width,K

do $1 \mathrm{i}=1,5$

$\operatorname{TP} 1(\mathrm{i}, 0)=0$.

$\operatorname{TP} 1(\mathrm{i}, 1)=0$.

$\mathrm{TP} 2(\mathrm{i}, 0)=0$.

$\mathrm{TP} 2(\mathrm{i}, 1)=0$.

$\mathrm{TP} 3(\mathrm{i}, 0)=0$.

$\mathrm{TP} 3(\mathrm{i}, 1)=0$.

1 continue

return

end 
c This program is designed to analyze the photoionization spectrum

c of SCH3. Rotational contants for neutral (E state) are obtained

c from T.A. Miller et.al. Rotatioal contants for ion (A state) are

c deduced from simulation.

c $\quad * * * * * * * * * * * * * * * * * * * * * * * * * * * * * * * * * * * * * * * * * * * * * * * * * * * * * * * * * * * * * * * * * * *$

c Please read the file 'Readme.txt' listed on page 196 in order to

c understand the structure of the program

Program SCH3rot1

\$include:'sch31.txt'

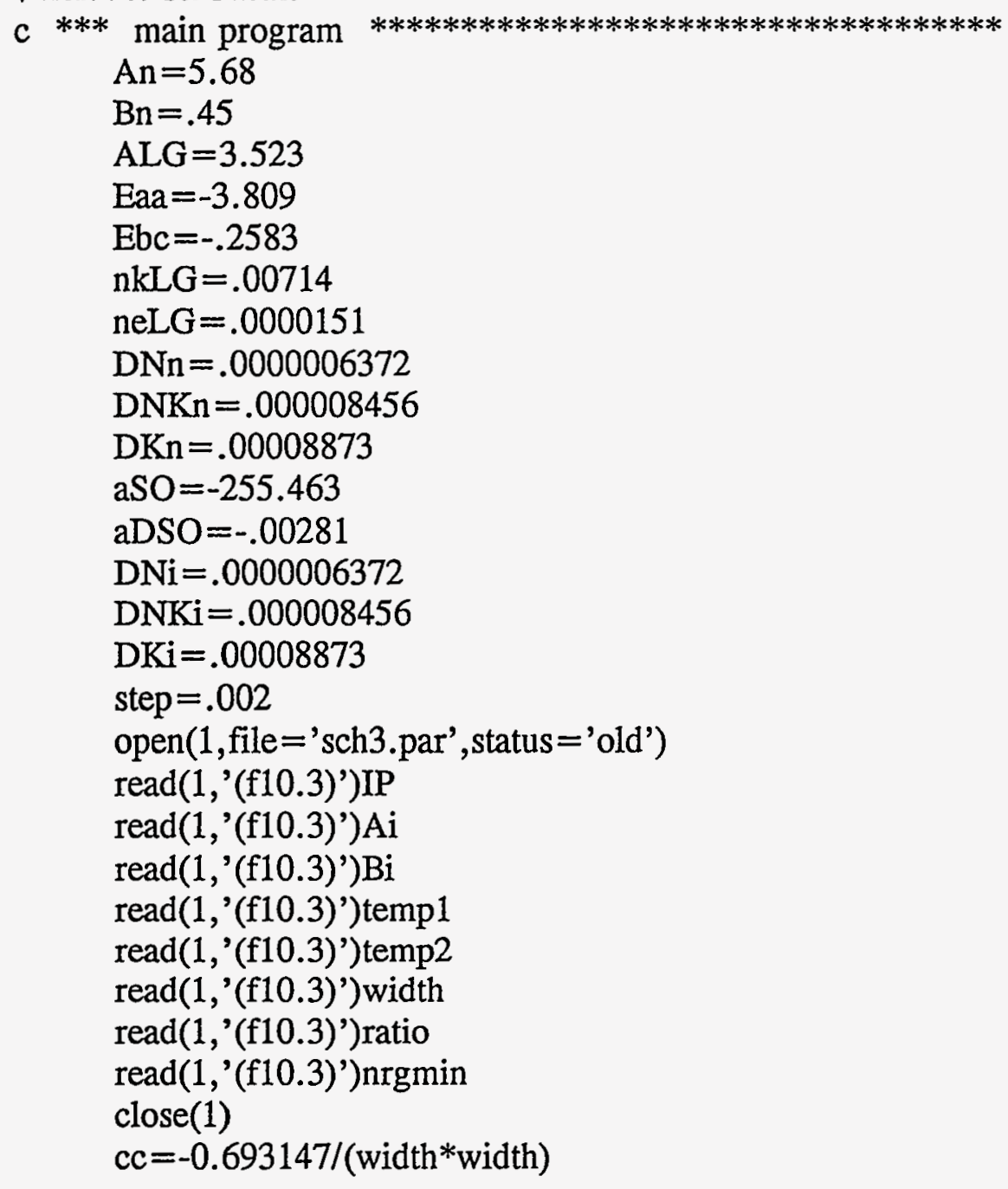

c Calculate A state energy 


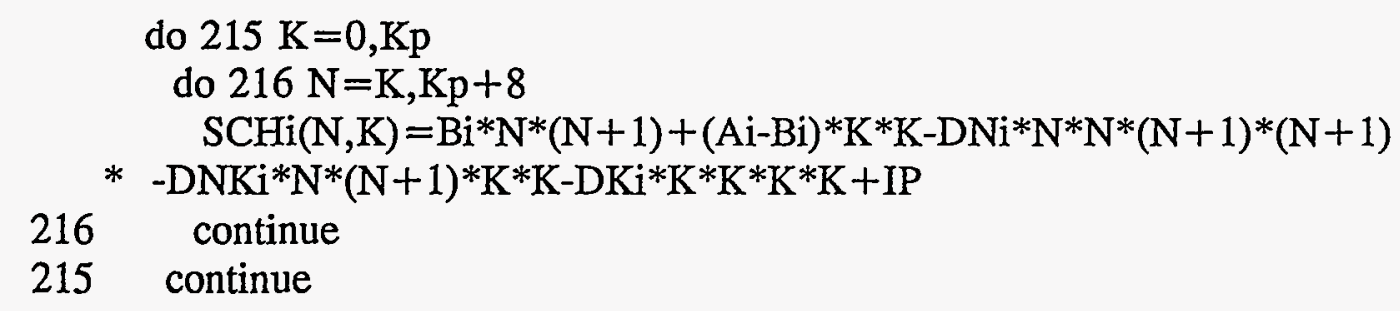

c Calculate $\mathrm{E}(3 / 2)$ state energy

$\mathrm{Q} 1=0$.

sigma $=.5$

$\mathrm{P}=.5$

$\mathrm{J}=.5$

$\mathrm{K}=0$

$\operatorname{SCHn} 0(0,0)=\mathrm{aSO} * \operatorname{sigma}+\mathrm{aDSO} * \mathrm{~K} * \mathrm{~K} *$ sigma $-2 * \mathrm{ALG} * \mathrm{~K}+$ neLG*K$*(\mathrm{~J} *(\mathrm{~J}+1)-$

$* 2 * \mathrm{P} * \operatorname{sigma}+.75)+\mathrm{nkLG} * \mathrm{~K} * \mathrm{~K} * \mathrm{~K}+\mathrm{An}^{*} \mathrm{~K} * \mathrm{~K}+\mathrm{Bn} *(\mathrm{~J} *(\mathrm{~J}+1)-\mathrm{P} * \mathrm{P}+.5)-\mathrm{DNn} *(\mathrm{~J}+.5)$

$* *(\mathrm{~J}+.5) *((\mathrm{~J}+.5) *(\mathrm{~J}+.5)-4 * \mathrm{P} *$ sigma +2$)-\mathrm{DNKn} * \mathrm{~K} * \mathrm{~K} *(\mathrm{~J} *(\mathrm{~J}+1)-2 * \mathrm{P} *$ sigma

$*+.75)-\mathrm{DKn} * \mathrm{~K} * \mathrm{~K} * \mathrm{~K} * \mathrm{~K}+$ Eaa $* \mathrm{~K} *$ sigma-Ebc $* .5$

do $211 \mathrm{~K}=-\mathrm{Kp}, \mathrm{Kp}$

$\mathrm{P}=\mathrm{K}+$ sigma

$\mathrm{i}=\mathrm{abs}(\mathrm{K})$

do $212 \mathrm{~N}=\mathrm{i}, \mathrm{Kp}+8$

$\mathrm{J}=\mathrm{N}+.5$

$\mathrm{SCHn} 0(\mathrm{~N}, \mathrm{~K})=\mathrm{aSO} * \operatorname{sigma}+\mathrm{aDSO} * \mathrm{~K} * \mathrm{~K} * \operatorname{sigma}-2 * \mathrm{ALG}^{*} \mathrm{~K}+$ neLG $^{*} \mathrm{~K} *(\mathrm{~J} *(\mathrm{~J}+1)-$

$* 2 * \mathrm{P} * \operatorname{sigma}+.75)+\mathrm{nkLG} * \mathrm{~K} * \mathrm{~K} * \mathrm{~K}+\mathrm{An}^{*} \mathrm{~K} * \mathrm{~K}+\mathrm{Bn} *(\mathrm{~J} *(\mathrm{~J}+1)-\mathrm{P} * \mathrm{P}+.5)-\mathrm{DNn} *(\mathrm{~J}+.5)$

$* *(\mathrm{~J}+.5) *((\mathrm{~J}+.5) *(\mathrm{~J}+.5)-4 * \mathrm{P} * \operatorname{sigma}+2)-\mathrm{DNKn} * \mathrm{~K} * \mathrm{~K} *(\mathrm{~J} *(\mathrm{~J}+1)-2 * \mathrm{P} *$ sigma

$*+.75)-\mathrm{DKn} * \mathrm{~K} * \mathrm{~K} * \mathrm{~K} * \mathrm{~K}+\mathrm{Eaa}^{*} \mathrm{~K} *$ sigma-Ebc*.5

$\operatorname{SCHn} 1(\mathrm{~N}, \mathrm{~K})=(2 * \mathrm{~J}+1) * \exp ((-\mathrm{SCHn} 0(\mathrm{~N}, \mathrm{~K})+\mathrm{SCHn} 0(0,0)) /(\mathrm{kB} *$ temp 1$))$

if $(\bmod (\mathrm{K}, 3)$.eq.1) $\operatorname{SCHn} 1(\mathrm{~N}, \mathrm{~K})=2 * \operatorname{SCHn} 1(\mathrm{~N}, \mathrm{~K})$

$\mathrm{Q} 1=\mathrm{Q} 1+\mathrm{SCHn} 1(\mathrm{~N}, \mathrm{~K})$

212 continue

211 continue

do $111 \mathrm{~K}=-\mathrm{Kp}, \mathrm{Kp}$

$\mathrm{i}=\mathrm{abs}(\mathrm{K})$

do $121 \mathrm{~N}=\mathrm{i}, \mathrm{Kp}+8$

$\mathrm{SCHn} 1(\mathrm{~N}, \mathrm{~K})=\operatorname{SCHn} 1(\mathrm{~N}, \mathrm{~K}) / \mathrm{Q} 1$

121 continue

111 continue

$\mathrm{m}=1$

call $\mathrm{SCH} 311$

Filename $=$ 'SCH301. CWH'

call WriteFile

call SCH312 
Filename $=$ 'SCH302. CWH'

call WriteFile

c Calculate $\mathrm{E}(1 / 2)$ state energy

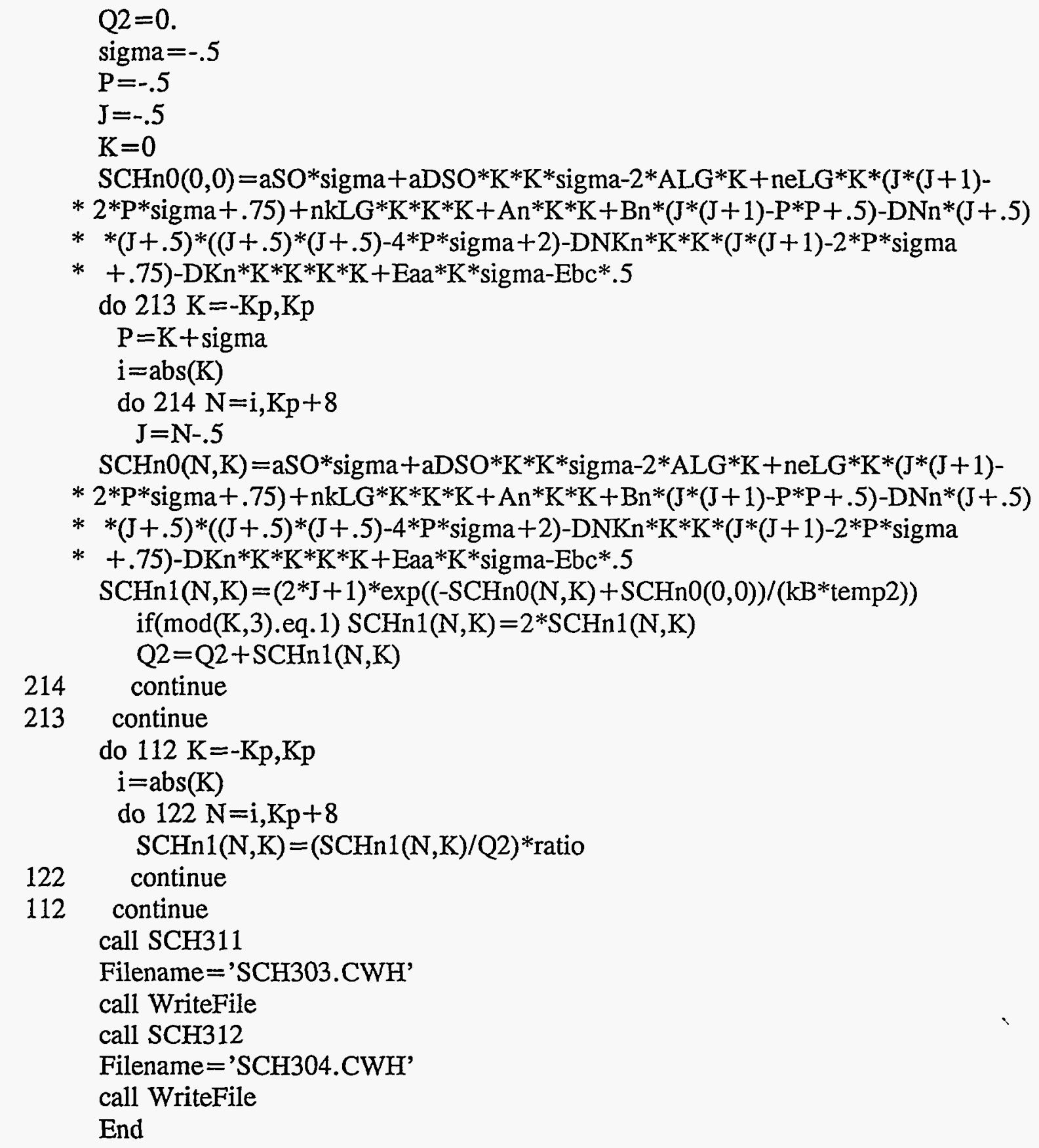


Subroutine WriteFile

\$include:'sch32.txt'

write $(*, 521)$ Filename

521 format(' writing spectrum to this directory as ',a10)

open $(1$, File $=$ Filename, status $=$ 'new')

do $110 \mathrm{i}=0$,NPoints- 1

write $\left(1,{ }^{\prime}(\mathrm{e} 12.5)^{\prime}\right) \mathrm{Y}(\mathrm{I})$

110 continue

write $(*, *)$

close (1)

return

end

Subroutine SCH311

\$include:'sch33.txt'

If(m.eq. 1) then

Tfname $=$ 'SCHtran1.eng'

write $(*, *)$ 'Constructing $\mathrm{p} 1(\mathrm{PQR})$ (delta $|\mathrm{K}|=-1$ ) spectrum'

open (3,File $=$ Tfname, status $=$ 'new')

else

Tfname $=$ 'SCHtran3.eng'

write $(*, *)$ 'Constructing $\mathrm{p} 2(\mathrm{PQR})$ (delta $|\mathrm{K}|=-1$ ) spectrum'

open $(3$, File $=$ Tfname, status $=$ 'new')

endif

c now calculate the $\mathrm{pP}$ branch:

do $301 \mathrm{~K}=1, \mathrm{Kp}-1$

$\mathrm{i}=\mathrm{abs}(\mathrm{K})$

do $1 \mathrm{~N}=\mathrm{i}, \mathrm{Kp}-1+8$

$\mathrm{TPO}(\mathrm{N}, \mathrm{K})=\mathrm{SCHi}(\mathrm{N}-1, \mathrm{~K}-1)-\mathrm{SCHn} 0(\mathrm{~N}, \mathrm{~K})$

$\operatorname{TP} 1(\mathrm{~N}, \mathrm{~K})=\operatorname{SCHn} 1(\mathrm{~N}, \mathrm{~K})$

1 continue

301 continue

411 format $(2 \mathrm{i} 5,2 \mathrm{e} 12.5)$

do $501 \mathrm{i}=0$, NPoints- 1

sum $=0.0$

currentnrg $=1.0 \mathrm{e} 7 /(-$ step $* \mathrm{i}+1.0 \mathrm{e} 7 / \mathrm{nrgmin}) * 2$

do $601 \mathrm{iii}=1, \mathrm{Kp}-1$

$\mathrm{ii}=\mathrm{abs}$ (iii)

do $701 \mathrm{jj}=\mathrm{ii}, \mathrm{N}$

Deltaw $=$ currentnrg-TP0(jj,iii)

If (abs(Deltaw).lt.(5.0*width)) then sum $=$ sum $+100.0 * T P 1\left(\mathrm{jj}\right.$, iii) $* \exp \left(\mathrm{cc}^{*}\right.$ Deltaw $*$ Deltaw $)$ 


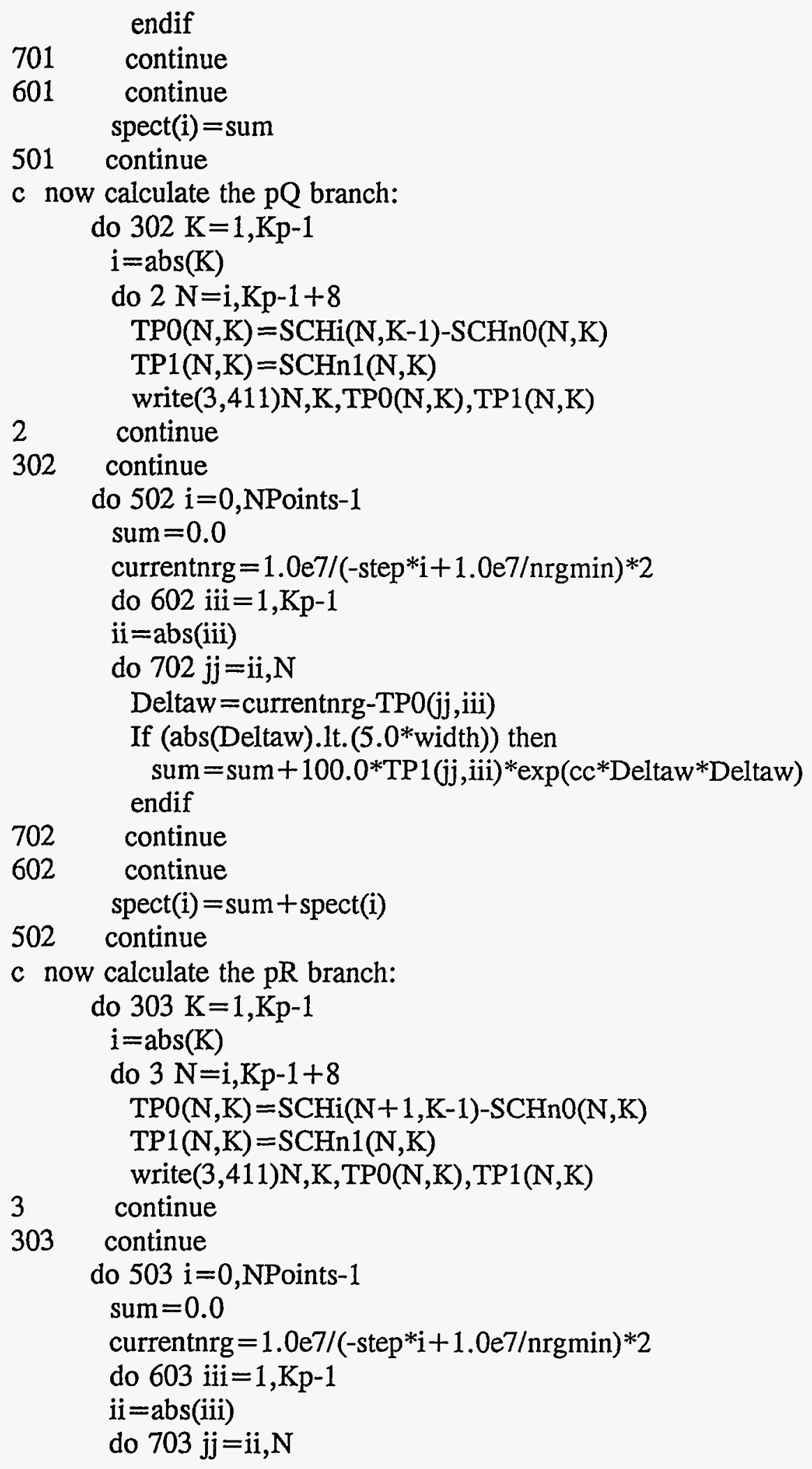


Deltaw $=$ currentnrg-TP0 $(\mathrm{jj}, \mathrm{iii})$

If (abs(Deltaw).1t.(5.0* width)) then sum $=$ sum $+100.0 * T P 1(j j$, iii) $* \exp (c c *$ Deltaw*Deltaw $)$

endif

703 continue

603 continue

503

$\operatorname{spect}(i)=\operatorname{sum}+\operatorname{spect}(i)$

continue

close(3)

$\mathrm{m}=\mathrm{m}+1$

return

end

Subroutine SCH312

\$include:'sch33.txt'

If(m.eq.2) then

Tfname $=$ 'SCHtran2.eng'

write $(*, *)$ 'Constructing $\mathrm{r} 1(\mathrm{PQR})$ (delta $|\mathrm{K}|=+1$ ) spectrum'

open $(3$, File $=$ Tfname, status $=$ 'new')

else

Tfname $=$ 'SCHtran4.eng'

write $(*, *)$ 'Constructing $\mathrm{r} 2(\mathrm{PQR})$ (delta $|\mathrm{K}|=+1$ ) spectrum'

open $(3$, File $=$ Tfname, status $=$ 'new')

endif

c now calculate the $\mathrm{rP}$ branch:

do $304 \mathrm{~K}=-\mathrm{Kp}+3,0$

$\mathrm{i}=\mathrm{abs}(\mathrm{K})$

do $4 \mathrm{~N}=\mathrm{i}+2, \mathrm{Kp}-1+8$

$\mathrm{TPO}(\mathrm{N}, \mathrm{K})=\mathrm{SCHi}(\mathrm{N}-1, \mathrm{i}+1)-\mathrm{SCHn} 0(\mathrm{~N}, \mathrm{~K})$

$\mathrm{TP} 1(\mathrm{~N}, \mathrm{~K})=\operatorname{SCHn} 1(\mathrm{~N}, \mathrm{~K})$

write $(3,411) \mathrm{N}, \mathrm{K}, \mathrm{TP} 0(\mathrm{~N}, \mathrm{~K}), \mathrm{TP} 1(\mathrm{~N}, \mathrm{~K})$

4 continue

304 continue

411 format(2i5,2e12.5)

do $504 \mathrm{i}=0$, NPoints- 1

sum $=0.0$

currentnrg $=1.0 \mathrm{e} 7 /\left(-\right.$ step $^{*} \mathrm{i}+1.0 \mathrm{e} 7 /$ nrgmin $) * 2$

do $604 \mathrm{iii}=-\mathrm{Kp}+3,0$

$\mathrm{ii}=\mathrm{abs}(\mathrm{iii})$

do $704 \mathrm{jj}=\mathrm{ii}+2, \mathrm{~N}$

Deltaw $=$ currentnrg-TP0(jj,iii)

If (abs(Deltaw).lt. $(5.0 *$ width)) then

sum $=$ sum $+100.0 * \mathrm{TP} 1(\mathrm{jj}$, iii) $* \exp (\mathrm{cc} *$ Deltaw*Deltaw $)$ 


$\begin{array}{ll}704 & \text { endif } \\ \text { continue } \\ 604 & \text { continue } \\ \text { spect(i) }=\text { sum } \\ 504 & \text { continue }\end{array}$

c now calculate the rQ branch:

$$
\begin{aligned}
& \text { do } 305 \mathrm{~K}=-\mathrm{Kp}+3,0 \\
& \mathrm{i}=\mathrm{abs}(\mathrm{K}) \\
& \text { do } 5 \mathrm{~N}=\mathrm{i}+1, \mathrm{Kp}-1+8 \\
& \operatorname{TPO}(\mathrm{N}, \mathrm{K})=\mathrm{SCH}(\mathrm{N}, \mathrm{i}+1)-\mathrm{SCHn} 0(\mathrm{~N}, \mathrm{~K}) \\
& \operatorname{TP} 1(\mathrm{~N}, \mathrm{~K})=\mathrm{SCHn} 1(\mathrm{~N}, \mathrm{~K})
\end{aligned}
$$

5 continue

305 continue

do $505 \mathrm{i}=0$,NPoints- 1

$$
\begin{aligned}
& \text { sum }=0.0 \\
& \text { currentnrg }=1.0 \mathrm{e} 7 /\left(- \text { step }^{*} \mathrm{i}+1.0 \mathrm{e} 7 / \mathrm{nrgmin}\right)
\end{aligned}
$$$$
\text { do } 605 \mathrm{iii}=-\mathrm{Kp}+3,0
$$$$
\mathrm{ii}=\mathrm{abs}(\mathrm{iii})
$$$$
\text { do } 705 \mathrm{jj}=\mathrm{ii}+1, \mathrm{~N}
$$$$
\text { Deltaw }=\text { currentnrg-TP0(jj,iii) }
$$

If (abs(Deltaw).1t.(5.0*width)) then

$$
\text { sum }=\text { sum }+100.0 * \mathrm{TP} 1(\mathrm{jj}, \text { iii) } * \exp (\mathrm{cc} * \text { Deltaw } * \text { Deltaw })
$$
endif

705 continue

605 continue

505 continue

c now calculate the $\mathrm{rR}$ branch:

$$
\begin{gathered}
\text { do } 306 \mathrm{~K}=-\mathrm{Kp}+3,0 \\
\mathrm{i}=\mathrm{abs}(\mathrm{K})
\end{gathered}
$$

do $6 \mathrm{~N}=\mathrm{i}, \mathrm{Kp}-1+8$

$$
\begin{aligned}
& \mathrm{TPO}(\mathrm{N}, \mathrm{K})=\operatorname{SCHi}(\mathrm{N}+1, \mathrm{i}+1)-\mathrm{SCHn} 0(\mathrm{~N}, \mathrm{~K}) \\
& \mathrm{TP} 1(\mathrm{~N}, \mathrm{~K})=\operatorname{SCHn} 1(\mathrm{~N}, \mathrm{~K})
\end{aligned}
$$$$
\text { write }(3,411) \mathrm{N}, \mathrm{K}, \mathrm{TP} 0(\mathrm{~N}, \mathrm{~K}), \mathrm{TP} 1(\mathrm{~N}, \mathrm{~K})
$$

6 continue

306 continue

$$
\begin{aligned}
& \text { do } 506 \mathrm{i}=0, \mathrm{NPoints}-1 \\
& \text { sum }=0.0 \\
& \text { currentnrg }=1.0 \mathrm{e} 7 /\left(- \text { step }^{*} \mathrm{i}+1.0 \mathrm{e} 7 / \mathrm{nrgmin}\right) * 2 \\
& \text { do } 606 \mathrm{iii}=-\mathrm{Kp}+3,0 \\
& \mathrm{ii}=\mathrm{abs}(\mathrm{iii}) \\
& \text { do } 706 \mathrm{jj}=\mathrm{ii}, \mathrm{N}
\end{aligned}
$$




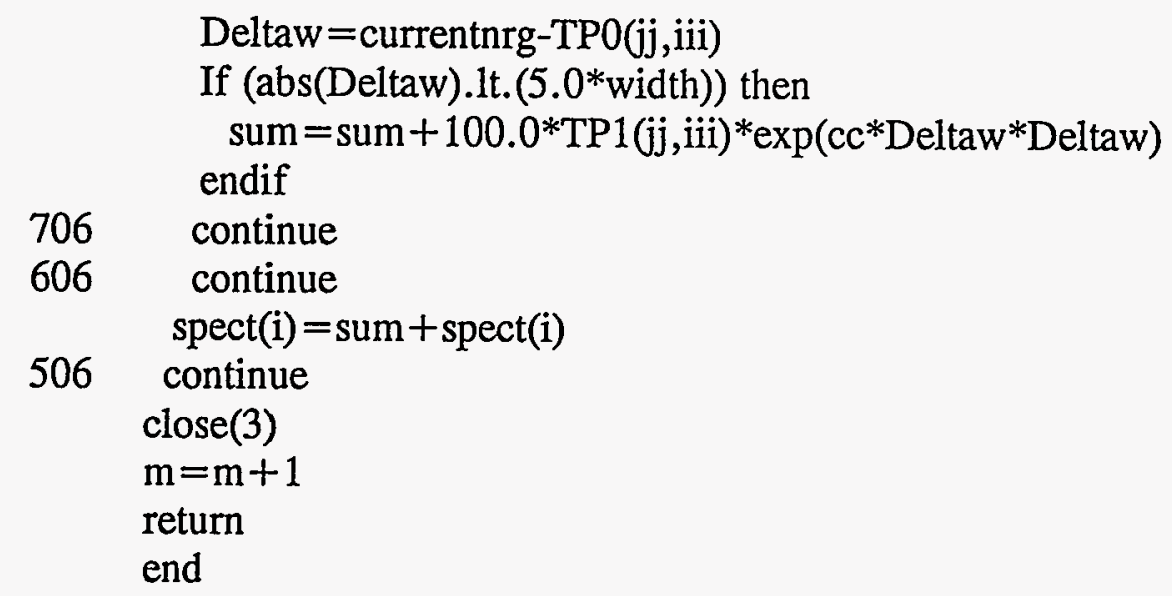


Readme.txt

c $\mathrm{SCHnO}(\mathrm{N}, \mathrm{K})$ : $\mathrm{F} 1$ levels (E 3/2 states) of neutral (SCH3) , $\mathrm{J}=\mathrm{N}+1 / 2$

c

c

or $\mathrm{F} 2$ levels (E $1 / 2$ states) of neutral (SCH3), $\mathrm{J}=\mathrm{N}-1 / 2$

$\mathrm{SCHn} 0->$ energy

SCHn1 $->$ intensity

$\mathrm{SCHi}(\mathrm{N}, \mathrm{K})$ : A state of ion( $\mathrm{SCH} 3+)$, ignoring spin-rotation splitting

TPO $(N, K)$ : Transition energy from neutral to ion

$\mathrm{TP} 1(\mathrm{~N}, \mathrm{~K})$ : Transition probability for TP0 $(\mathrm{N}, \mathrm{K})$, It is determined by

$\mathrm{c}$

c

Boltzmann distribution for nascent $\mathrm{SCH} 3$ and nuclear statistics

Neutral rotational constants : An,Bn,ALG,Eaa,Ebc,nkLG,neLG,DNn, DNKn,DKn, aSO,aDSO

Ion rotational constants : $\mathrm{Ai}, \mathrm{Bi}, \mathrm{DNi}, \mathrm{DNKi}, \mathrm{DKi}$

c IP : ionization potential

c ratio : $(\mathrm{E} 3 / 2) /(\mathrm{E} 1 / 2)$

c step : step size $(\mathrm{nm})$ in the simulation

c nrgmin : minimun wavenumber $(\mathrm{cm}-1)$

c currentnrg : current wavenumber (cm-1)

c width : Gaussian FWHM (cm-1)

c NPoints : number of points in a scan

c temp1,temp2 : neutral rotational temperature (K) (E 3/2 \& 1/2)

c $\mathrm{kB}:$ Boltzmann constant $(\mathrm{cm}-1)$

c Q1, Q2 : Rotational partition functions

c deltaw : the energy difference between currentnrg and peak position

c spect(j): spectrum for each branch

c The rotational branches are designated as follows:

c $\quad \mathrm{p}$ (small p) $\rightarrow$ delta $\mathrm{K}=-1$

c $\quad$ R(big R) $\quad \rightarrow$ delta $\mathrm{N}=+1$

c i.e. $p R$ represents the branch : delta $K=-1$ and delta $N=+1$.

C

C

C

c

c This program only calculates the branches $\mathrm{pP}, \mathrm{pQ}, \mathrm{pR}, \mathrm{rP}, \mathrm{rQ}$, and $\mathrm{rR}$. The calculation for the other branches can be easily modified by changing the delta $\mathrm{N}$ or delta $\mathrm{K}$. 
sch31.txt

Real*4 An,Bn,ALG,Eaa,Ebc, nkLG, neLG,DNn,DNKn,DKn,aSO,aDSO

Real*4 Ai,Bi,DNi,DNKi,DKi,IP, sigma, width, ratio, temp1,temp2

Real*4 cc,nrgmin, currentnrg,Deltaw,J,step, $\mathrm{P}, \mathrm{kB}$

Integer*2 $\mathrm{K}, \mathrm{i}, \mathrm{jj}, \mathrm{ii}, \mathrm{iii}, \mathrm{N}, \mathrm{m}$

parameter $(\mathrm{kB}=0.69503)$

parameter $(\mathrm{Ni}=65, \mathrm{Ki}=113, \mathrm{Kp}=56, \mathrm{NPoints}=2001)$

Real*4 SCHnO(Ni,Ki),SCHn1(Ni,Ki),SCHi(Ni,Ki)

Real*4 TP0(Ni,Ki),TP1(Ni,Ki), spect(NPoints)

Character Filename*10,Tfname*12

common/BL1/spect, Filename

common/BL2/SCHn0,SCHn1,SCHi,TP0,TP1

common/BL3/cc,currentnrg, Deltaw, $m$,step,nrgmin, width

sch32.txt

Parameter (NPoints $=2001)$

Real*4 Y(NPoints)

Character*10 Filename

common/BL1/Y,Filename

sch33.txt

parameter $(\mathrm{Ni}=65, \mathrm{Ki}=113, \mathrm{Kp}=56, \mathrm{NPoints}=2001)$

Real*4 SCHnO(Ni,Ki),SCHn1(Ni,Ki),SCHi(Ni,Ki)

Real*4 TP0(Ni,Ki), TP1(Ni,Ki), spect(NPoints)

Real*4 cc,width,currentnrg,Deltaw, step,sum,nrgmin

integer*2 $\mathrm{m}, \mathrm{i}, \mathrm{ii}, \mathrm{iii}, \mathrm{jj}$

character Tfname*12,Filename*10

common/BL1/spect, Filename

common/BL2/SCHn0,SCHn1,SCHi,TP0,TP1

common/BL3/cc,currentnrg,Deltaw, $m$,step,nrgmin, width

c Typical parameter file 'sch3.par' for simulating PE spectrum of c $\mathrm{CH} 3 \mathrm{~S}$ from $\mathrm{CH} 3 \mathrm{SH}$ is shown as follows:

74594.

5.547

.478

200.

250.

4.

0.5

37060 . 